
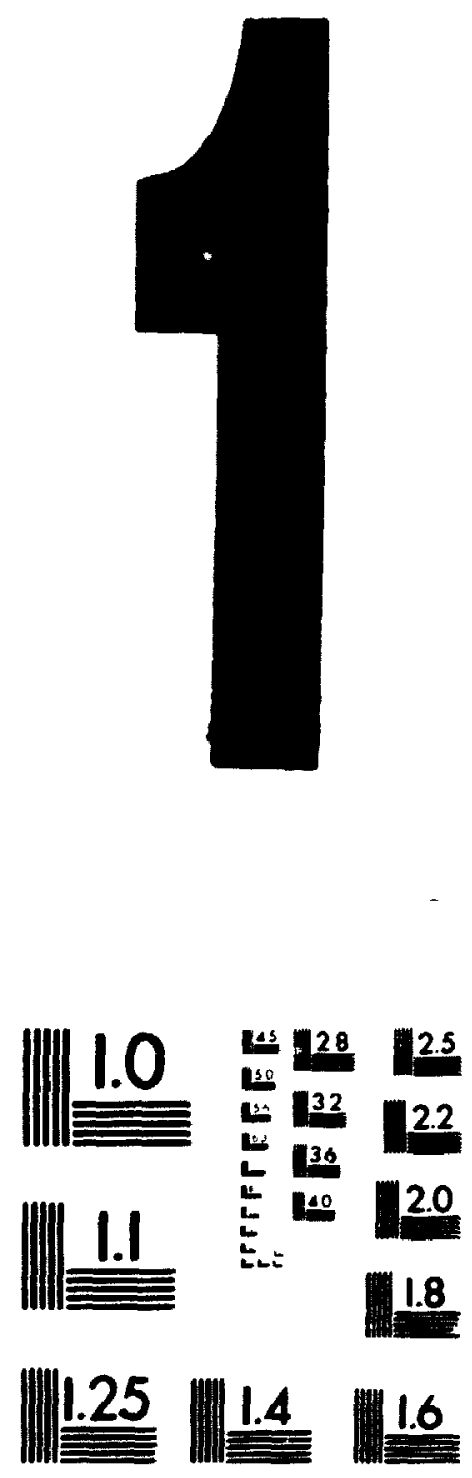

MICROCOPY RESOLUTION TEST CHART NATIONAL BUREAU OF STANDARDS STANDARO REFERENCE MATEFIAL 1010a (ANSI and ISO TEST CHART No 2) 
National Librany

of Canada

Acquisitions and

Bibliographic Services Branch

395 Wellington Street

Ottawa. Ontaro

K1A ON4
Bibliotheque nationale

du Canada

Direction des acquisitions et

des services bibliographiques

395. ne Weltinglon

Ottawa (Ontario)

KIAON4

\section{NOTICE}

The quality of this microform is heavily dependent upon the quality of the original thesis submitted for microfilming. Every effort has been made to ensure the highest quality of reproduction possible.

If pages are missing, contact the university which granted the degree.

Some pages may have indistinct print especially if the original pages were typed with a poor typewriter ribbon or if the university sent us an inferior photocopy.
La qualité de celte microforme dépend grandement de la qualité cie la thèse soumise au microfilmage. Nous avons tout fait pour assurer une qualité supérieure de reproduction.

S'il manque des pages, veuillez communiquer avec l'université qui a conféré le grade.

La qualité d'impression de certaines pages peut laisser à désirer, surtout si les pages originales ont été dactylographiées à l'aide d'un ruban usé ou si l'université nous a fait parvenir une photocopie de qualité inférieure.

Reproduction in full or in part of this microform is governed by the Canadian Copyright Act, R.S.C. 1970, c. C-30, and subsequent amendments.
La reproduction, même partielle, de cette microforme est soumise à la Loi canadienne sur le droit d'auteur, SRC 1970, c. C-30, ot ses amendements subséquents. 


\title{
Determination of Loads Acting on Surfaces of Structural Steel Buildings in Canada
}

\author{
by \\ Jan Chmelicek

\begin{abstract}
A thesis submitted to
the Faculty of Graduate Studies and Research
\end{abstract} \\ in partial fulfilment of the requirements \\ for the degree of \\ Master of Engineering*
}
Department of Civil and Environmental Engineering
Carleton University
Ottawa, Canada

c Jan Chmelicek, September, 1993

* The Civil Engineering Program is a joint program with University of Ottawa, administered by the Ottawa-Carleton Institude for Civil Engineering 
National Library

of Canada

Acquisitions and

Bibliographic Services Branch

395 Wellington Street

Ottawa. Ontario

KIA ON
Bibliotheque nationale

du Canada

Direction des acquisitions et

des senvices bibliographiques

395, ne Wellington

Ottawa (Ontario)

KIA ONA
The author has granted an irrevocable non-exclusive licence allowing the National Library of Canada to reproduce, loan, distribute or sell copies of his/her thesis by any means and in any form or format, making this thesis available to interested persons.
L'auteur a accordé une licence irrévocable et non exclusivé permettant a la Bibliothèque nationale du Canada de reproduire, prêter, distribuer ou vendre des copies de sa thèse de quelque manière et sous quelque forme que ce soit pour mettre des exemplaires de cette these à la disposition des personnes intéressées.
The author retains ownership of the copyright in his/her thesis. Neither the thesis nor substantial extracts from it may be printed or otherwise reproduced without his/her permission.
L'auteur conserve la propriété du droit d'auteur qui protège sa these. Ni la thèse ni des extraits substantiels de celle-ci ne doivent être imprimés ou autrement reproduits sans son autorisation.

ISBN $\quad 0-315-89831-3$ 
Nome JAN CHMELICEK

Dissertation Abstrocts intermational is arronged by broad, general subject categories. Please select the one subject which most nearty describes the content of your dissertation. Enter the corresponding four-digit code in the spaces provided.

C:|v|', $[\sqrt{5} \sqrt{4 \sqrt[3]{3}}$ U.M.I SUAECT COOE

\section{Subject Cologories}

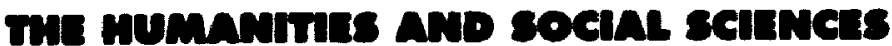

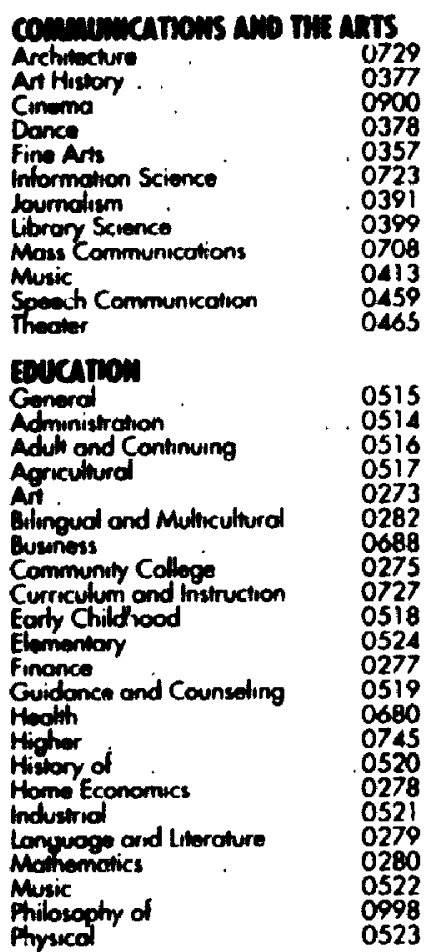

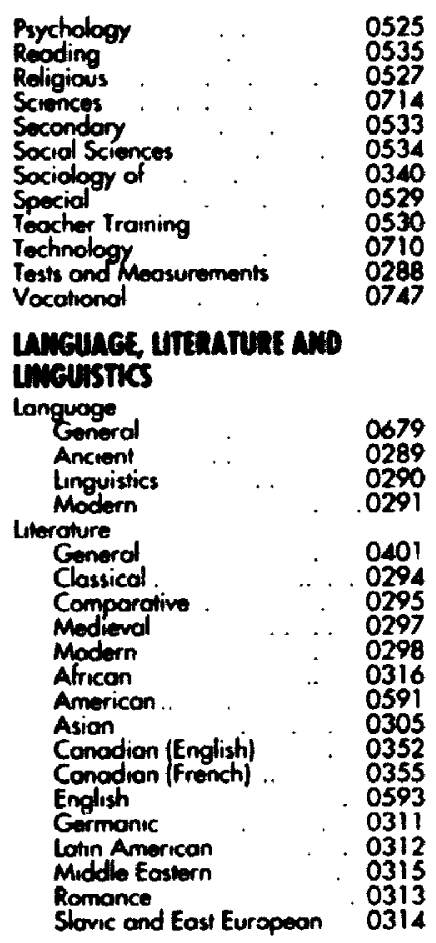

PHLOSOFH, RELEion Amo

nueclogr

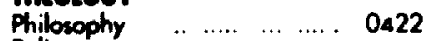

Religuon

Generd ..... , . .0318

$\cdots .0321$

Hitron of $\quad \cdot \quad \cdots 0320$

$\begin{array}{ll}\text { Pistory of } & . \\ \text { Philosophy of . } & 0322 \\ \text { cology. } & 0469\end{array}$

sean saings

Anthropotogy

$\begin{array}{ll}\text { Archoodogy } & 0324 \\ \text { Cuthral } & 0326\end{array}$

$\begin{array}{ll}\text { Cultural } & 0326 \\ \text { Physical .. } & 0327\end{array}$

Business Administration

Generd

Accounting

Bonking

Monagement

Marketing

Conodion Shudies

Economics

Generol

Agriculturd 0503

Commerce-Business ...... 0505

Histony. ". 0509

Hislory. . . OSIO
Lobor

Theory

Folklore

Geography

History

General

0511
0358

0358
0366

0351

0578
American Studies . 0323

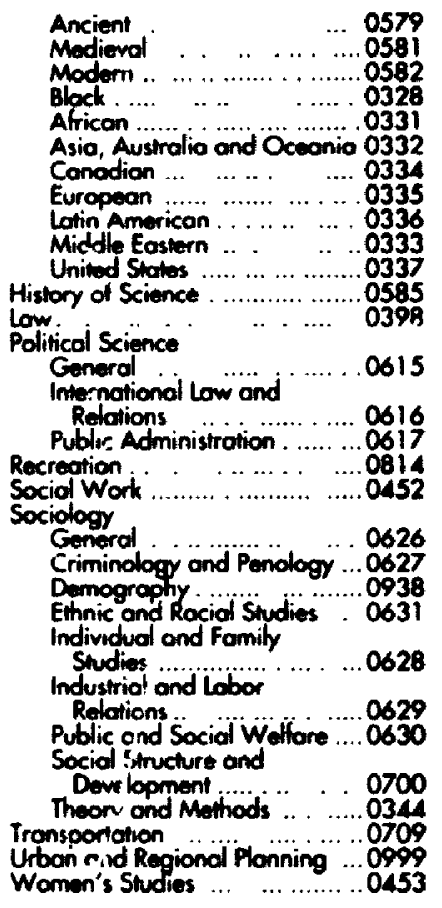

Urbon ridd Regional Plonning ... 0999
Women's Studies ... ............ 0453

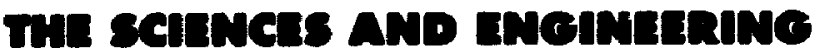

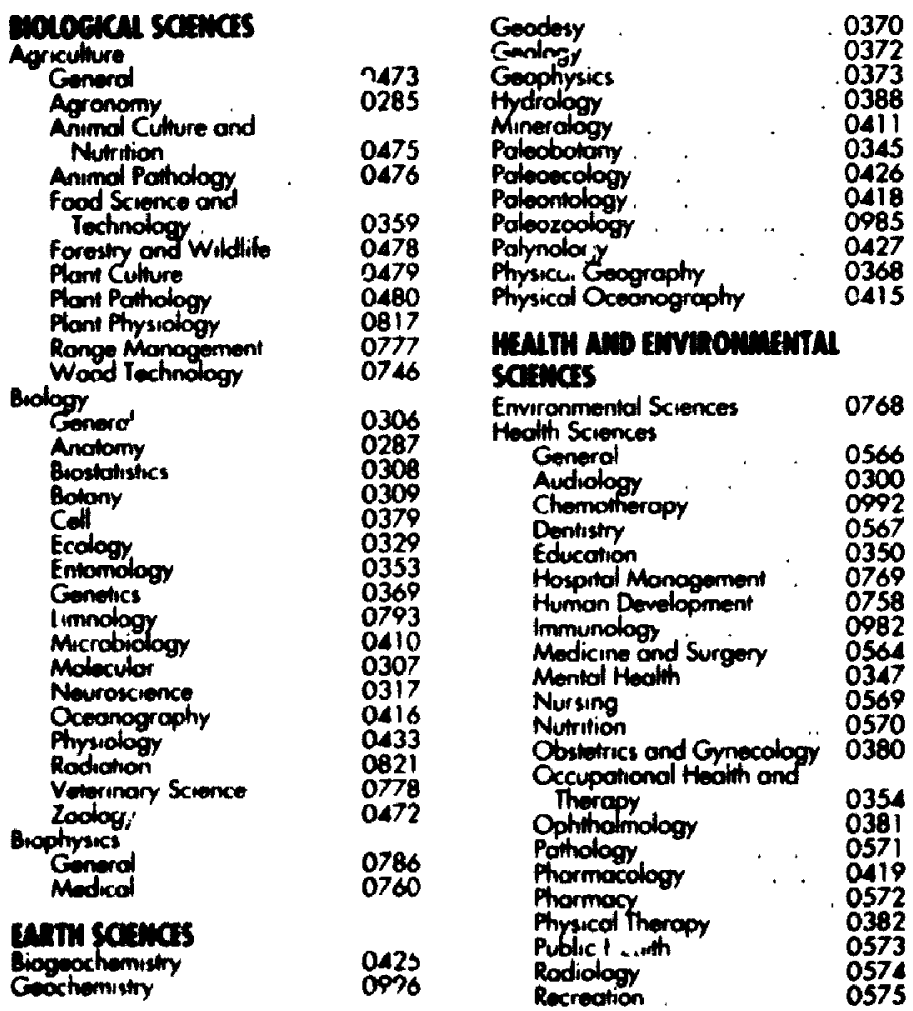

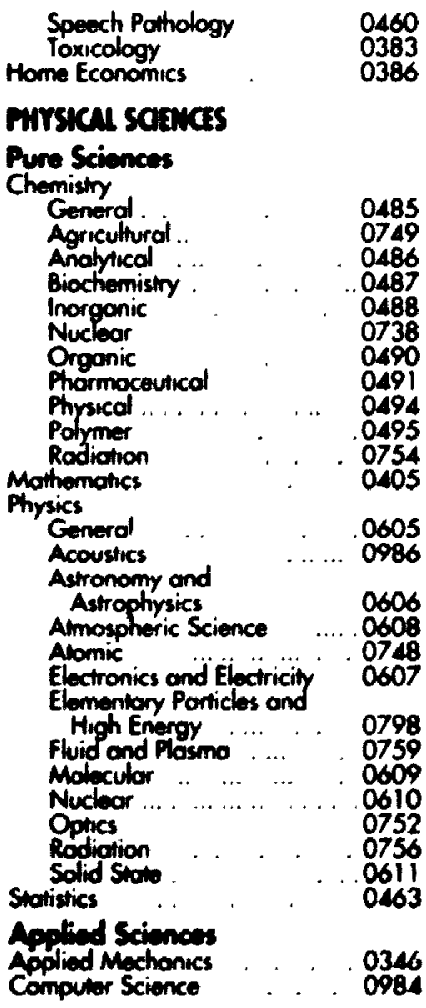

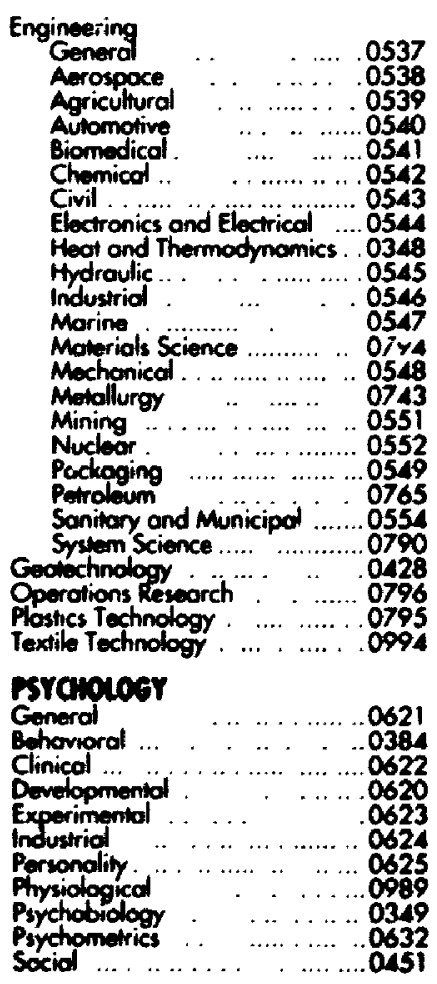


Department of Civil and Environmental Engineering

The Undersigned recommend to the Faculty of Graduate Studies and Research acceptance of the thesis

"Determination of Loads Acting on Surfaces of Structural Steel Buildings in Canada"

\section{Submitted by Jan Chmelicek}

in partial fulfilment of the requirements for the degree of Maiter of Engineering

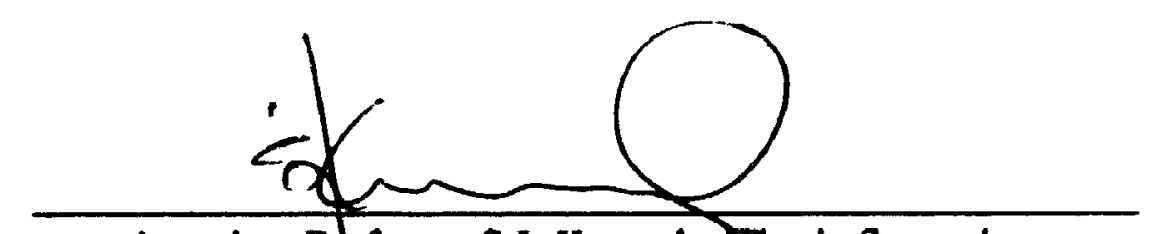

Associate Professor S.J. Kennedy, Thesis Supervisur

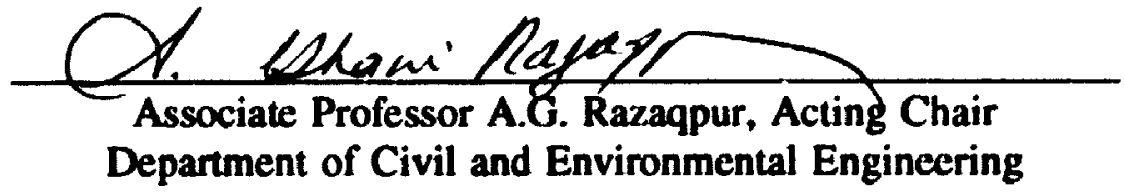

Carleton University

September 14, 1993 


\begin{abstract}
Ar interactive graphics based computer program has been developed to determine the dead loads and live loads due to use and occupancy, snow, and wind loads, acting on roof, wall and floor surfaces of steal buildings. The loads are computed in accordance with Part 4-Structural Design of the National Building Code of Canada 1990, NRC (1990). Interactive graphics, 3 dimensional display of structural systems, building geometry and load distributions, provide a simple, versatile program that emulates the design process, is simple to use (does not require a manual), instructive and informative (visual confirmation of geometry and loads). All the required data bases (climatic design data, dead tables, use and occupancy tables); library functions for snow and wind load calculations; modules for geometric modelling of surfaces; and subroutines for creating files that contain load information have been developed. This work is the first step of the module for determining loads and load mbinations acting on the primary structural members of a steel building.
\end{abstract}




\section{Acknowledgements}

I would like to take this opportunity to thank the people who through their support made this work possible.

To my supervisor Dr. Stephen J. Kennedy for his guidance, advice encouragement and suggestions. To professor Neal M. Holtz for his advice and help to solve the software and computer related hardware problems.

I would also like to express my gratitude to my supervisor and to The Faculty of Graduate Studies and Research at Carleton University for the financial support through the research and teaching assistant positions that made my graduate studies possible.

Finally I would like to, thank to my wife Vlasta for her understanding. encouragement and patience throughout the period which was devoted to this work. 


\section{Table of Contents}

Abstract $\ldots \ldots \ldots \ldots \ldots \ldots \ldots \ldots \ldots \ldots \ldots \ldots \ldots \ldots \ldots \ldots \ldots$

Acknowledgement $\ldots \ldots \ldots \ldots \ldots \ldots \ldots \ldots \ldots \ldots \ldots \ldots \ldots \ldots \ldots \ldots \ldots$ ii

Table of Contents $\ldots \ldots \ldots \ldots \ldots \ldots \ldots \ldots \ldots \ldots \ldots \ldots \ldots$ iii

List of Figures $\ldots \ldots \ldots \ldots \ldots \ldots \ldots \ldots \ldots \ldots \ldots \ldots \ldots \ldots \ldots \ldots$ vi

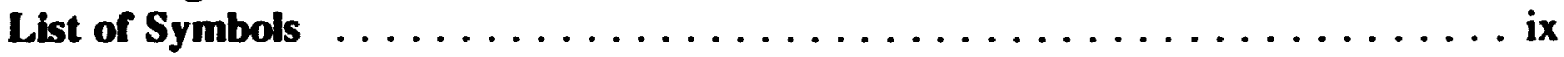

1. Introduction $\ldots \ldots \ldots \ldots \ldots \ldots \ldots \ldots \ldots \ldots \ldots \ldots$ I

1.1 Building Design Fabrication and Construction Process . . . . . . 1

1.2 Required Attributes for Determining Loads ............ 3

1.3 Components/Modules Descripticn .............. 4

1.3.1 Geometric Modelling and Surface Definition ........... 4

1.3.2 Determination of Loads Acting on Surfaces ........... 5

1.3.3 Determination of Tributary Areas . . . . . . . . . . . . 6

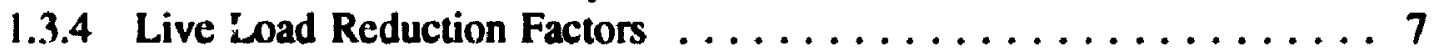

1.3.5 Attributing Loads to Members ............... 7

1.3.6 Detcrmination of Load Combinations . . . . . . . . . . . . 7

1.4 Objectives and Scope . . . . . . . . . . . . . . 8

1.5 Anticipated Technological and Socio-Economic Impact ....... 9

2. Determination of Load Intensities and Mesh Generation $\ldots \ldots \ldots \ldots \ldots 11$

$2.1 \quad$ Limit States Design . . . . . . . . . . . . . . . . 11

2.2 Dead Load ....................... 13

2.3 Live Load Due to Use and Occupancy .............. 14

2.4 Live Load Due to Snow, Ice and Rain .............. 14

2.5 Live Load Due to Wind .................. 22

2.5.1 Definition of Static Design Pressures ............. 23

2.5.2 Reference Velocity Pressure ............... 24

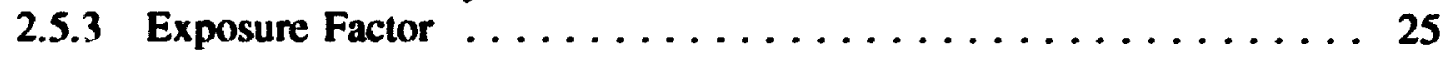

2.5.4 Dynamic Response and Gust Effect Factor ........... 27

2.5.5 Extemal Pressure Coefficient .................. 32

2.5.6 Internal Pressure Coefficient ................. 32

2.6 Attributing Loads and Mesh Generation Within any Given Surface . 34

2.6.1 Mesh Generation ..................... 35

2.6.2 Identification Code for Points defining the Mesh ......... 41

3. Program Description $\ldots \ldots \ldots \ldots \ldots \ldots \ldots \ldots \ldots \ldots \ldots \ldots$

3.1 General Description of the Main Menu and Screen Configuration . . 44

3.2 GEOMETRIC MODELLER - Display, Edit or Create Surfaces . . 49

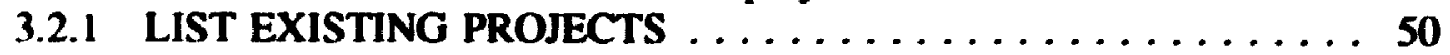

3.2.1.1 DELETE PROJECT $\ldots \ldots \ldots \ldots \ldots \ldots \ldots \ldots \ldots \ldots$

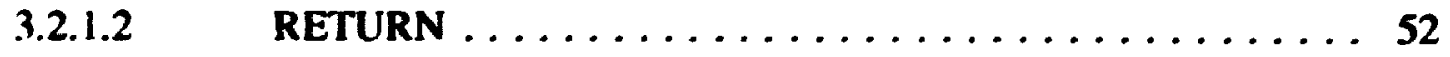

3.2 .2 INFO ACTIVE PROJECT $\ldots \ldots \ldots \ldots \ldots \ldots \ldots \ldots \ldots \ldots 2$ 
3.2.3 CREATE NEW PROJECT $\ldots \ldots \ldots \ldots \ldots \ldots \ldots \ldots \ldots \ldots$.

3.2.3.1 CREATE FLOOR $\ldots \ldots \ldots \ldots \ldots \ldots \ldots \ldots \ldots \ldots$

3.2.3.1.1 NEW SURFACE BY NODES $\ldots \ldots \ldots \ldots \ldots \ldots \ldots$ s5

3.2.3.1.1.1 BY COORDINATES $\ldots \ldots \ldots \ldots \ldots \ldots \ldots \ldots \ldots 5$

3.2.3.1.1.2 BY NODE ID $\ldots \ldots \ldots \ldots \ldots \ldots \ldots \ldots \ldots \ldots$

3.2.3.1.2 DUPLICATE LAST FLOOR $\ldots \ldots \ldots \ldots \ldots \ldots \ldots$ 59

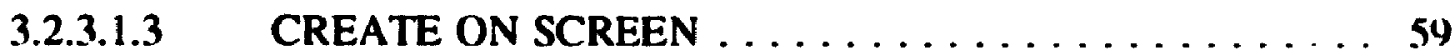

3.2.3.2 CREATE ROOF $\ldots \ldots \ldots \ldots \ldots \ldots \ldots \ldots \ldots \ldots \ldots \ldots$

3.2.3.3 CREATE WALL ................. 61

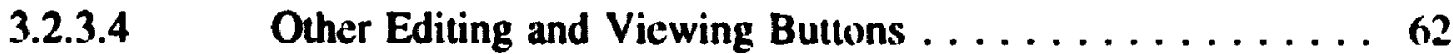

3.2 .4 EDIT ACTIVE PROJECT $\ldots \ldots \ldots \ldots \ldots \ldots \ldots \ldots \ldots \ldots$

3.2.5 STRUCTURE DISPLAY $\ldots \ldots \ldots \ldots \ldots \ldots \ldots \ldots \ldots \ldots$

3.2 .6 LOADS TO SURFACES $\ldots \ldots \ldots \ldots \ldots \ldots \ldots \ldots \ldots \ldots$

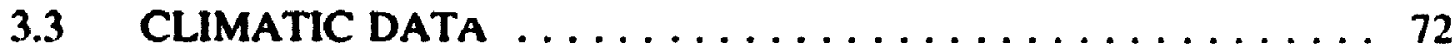

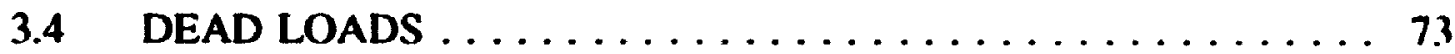

3.5 LIVE LOADS DUE TO USE AND OCCUPANCY . . . . . 78

3.6 Attributing the Loads within Geometric Modeller ......... 81

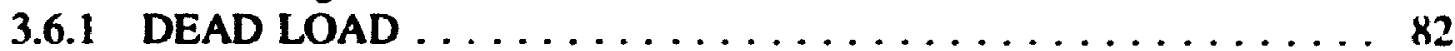

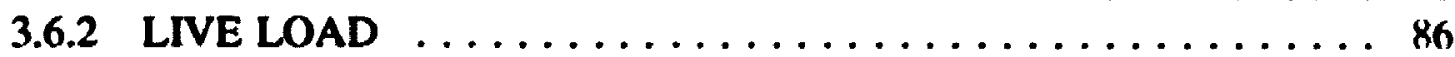

3.6.3 Snow Loads-Roof Geometry and Snow Load Distributions . . . . . 86

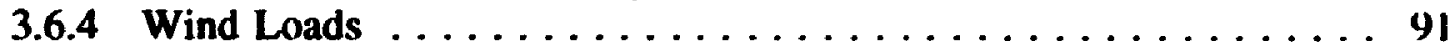

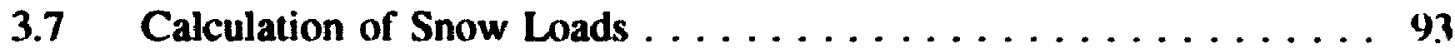

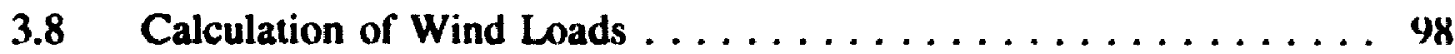

4. Examples $\ldots \ldots \ldots \ldots \ldots \ldots \ldots \ldots \ldots \ldots \ldots \ldots \ldots \ldots$ 1(1)

4.1 High-Rise Building $\ldots \ldots \ldots \ldots \ldots \ldots \ldots \ldots \ldots \ldots$

$4.2 \quad$ Low-Rise Building $\ldots \ldots \ldots \ldots \ldots \ldots \ldots \ldots \ldots \ldots \ldots \ldots \ldots$

5. Conclusions, Recommendations, and Future Work $\ldots \ldots \ldots \ldots \ldots$ 126

5.1 Conclusions .................... 126

5.2 Recommendations and Future Work $\ldots \ldots \ldots \ldots \ldots \ldots$

References $\ldots \ldots \ldots \ldots \ldots \ldots \ldots \ldots \ldots \ldots \ldots \ldots \ldots \ldots \ldots \ldots$ 130

APPENDIX A - Programming Languages and Graphic Tools $\ldots \ldots \ldots \ldots 132$

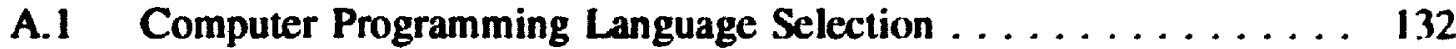

A.1.1 Fortran Programming Language $\ldots \ldots \ldots \ldots \ldots \ldots \ldots \ldots, 132$

A.1.2 " $\mathrm{C}$ " Programming Language $\ldots \ldots \ldots \ldots \ldots \ldots \ldots \ldots \ldots$

A.2 Hardware and Operating System Requirements . . . . . . . 134

A.3 Hoops Graphic Systems .................... 134

A.3.1 Set Up of HOOPS Environment Variables . . . . . . . . 134

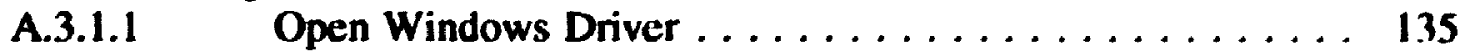

A.3.1.2 SunView Driver $\ldots \ldots \ldots \ldots \ldots \ldots \ldots \ldots \ldots \ldots \ldots$

A.3.2 PostScript Driver .................... 136 
APPENDIX B - File Architecture . . . . . . . . . . . . . . 137

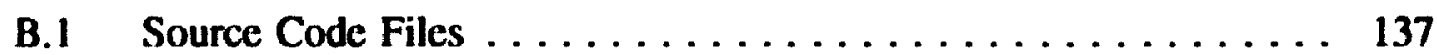

B.I.1 File LDFSSBC.c $\ldots \ldots \ldots \ldots \ldots \ldots \ldots \ldots \ldots \ldots \ldots \ldots \ldots$

B.1.2 File SELECT_LOCATION.c $\ldots \ldots \ldots \ldots \ldots \ldots \ldots \ldots \ldots$

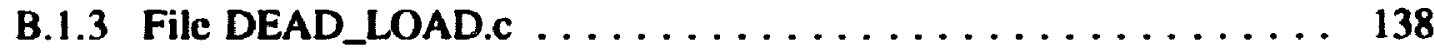

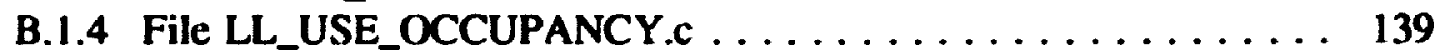

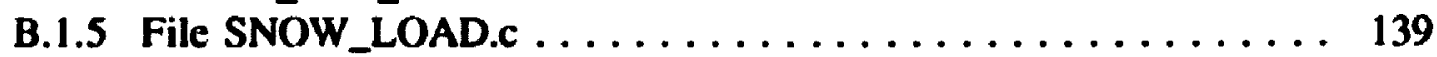

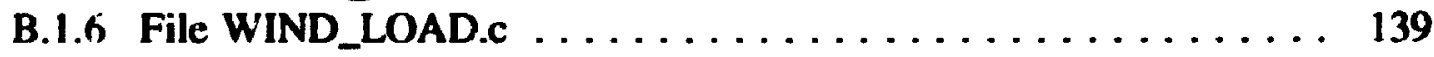

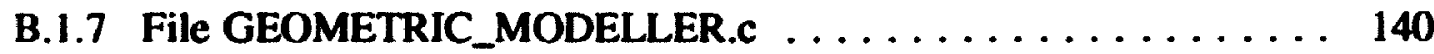

B.2 The Executable File "LDFSSBC" and the Corresponding Defaults 140

B.3 Output Files $\ldots \ldots \ldots \ldots \ldots \ldots \ldots \ldots \ldots \ldots \ldots \ldots$

APPENDIX C - Program Installation and Maintenance ......... 151

C.1 Installing the Software $\ldots \ldots \ldots \ldots \ldots \ldots \ldots \ldots \ldots \ldots \ldots$

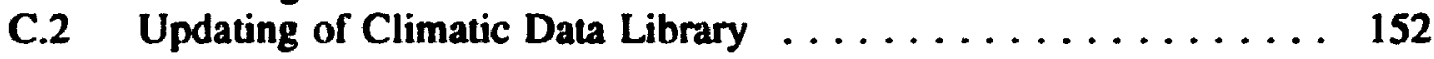

C.3 Updating Dead Load Libraries and Tools ............ 153

C.4 Updating Live Loads Due to Use and Occupancy Libraries . . . . 154

C.5 Updating Live Loads Due to Snow, Ice, and Rain Defaults . . . . . 154

C.6 Updating Live Loads Due to Wind Defaults .... . . . . . . 154 


\section{List of Figures}

Fig. 2.1

Fig. 2.2

Fig. 2.3

Fig. 2.4

Fig. 2.5

Fig. 2.6

Fig. 2.7

Fig. 3.1

Fig. 3.2

Fig. 3.3

Fig. 3.4

Fig. 3.5

Fig. 3.6

Fig. 3.7

Fig. 3.8

Fig. 3.9

Fig. 3.10

Fig. 3.11

Fig. 3.12

Fig. 3.13

Fig. 3.14

Fig. 3.15

Fig. 3.16

Fig. 3.17

Fig. 3.18

Fig. 3.19

Fig. 3.20

Fig. 3.21

Fig. 3.22

Fig. 3.23

Fig. 3.24

Fig. 3.25

Fig. 3.26

Fig. 3.27

Fig. 3.28

Fig. 3.29

Fig. 3.30

Fig. 3.31

Fig. 3.32

Fig. 3.33

Fig. 3.34

Fig. 3.35

Example Calculations; Figure $\mathbf{H}-\mathbf{1} \ldots \ldots \ldots \ldots \ldots \ldots \ldots$ 18

Example Calculations; Figure $\mathbf{H}-3 \ldots \ldots \ldots \ldots \ldots \ldots$

Example Calculations; Figure $\mathbf{H}-4 \ldots \ldots \ldots \ldots \ldots \ldots$ 20

Example Calculations; Figure $\mathbf{H}-5 \ldots \ldots \ldots \ldots \ldots \ldots \ldots \ldots \ldots \ldots$

Speed-Up over Hills and Escarpments . . . . . . . . . . 28

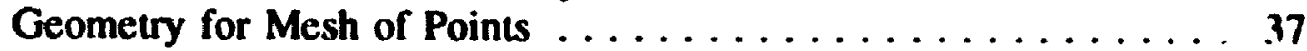

Identification Code for Points of Mesh $\ldots \ldots \ldots \ldots \ldots \ldots \ldots$

Title Screen and Main Menu $\ldots \ldots \ldots \ldots \ldots \ldots \ldots \ldots$

Screen Configuration . . . . . . . . . . . . . . 49

Geometric Modeller - Main Window . . . . . . . . . . . . . 51)

Geometric Modeller-Activate Existing or Delete Project ...... . 5I

Create New Project . . . . . . . . . . . . . . . . 52

Drawing Coordinates Set Up $\ldots \ldots \ldots \ldots \ldots \ldots \ldots \ldots \ldots . \ldots \ldots$

Create New Surfaces Button Menu . . . . . . . . . . 54

New Surface Definition .................. 54

Create New Surface By Nodes ................ 55

Surface Definition By Coordinates $\ldots \ldots \ldots \ldots \ldots \ldots \ldots$ 56

Finished Surface Display $\ldots \ldots \ldots \ldots \ldots \ldots \ldots \ldots \ldots \ldots$

Input Node ID ...................... 57

Select Node ID From Screen $\ldots \ldots \ldots \ldots \ldots \ldots \ldots \ldots \ldots$

Select Node ID From List of Nodes $\ldots \ldots \ldots \ldots \ldots \ldots \ldots$. . . . 59

Create Surface by Duplicating the Last Floor . . . . . . . . (6)

Create Surface by Mouse Selection on Screen . . . . . . . . (6)

Delete Surface From List of Surfaces . . . . . . . . . . 62

Surface ID Information $\ldots \ldots \ldots \ldots \ldots \ldots \ldots \ldots \ldots \ldots$

Node ID Information . . . . . . . . . . . . . . . 64

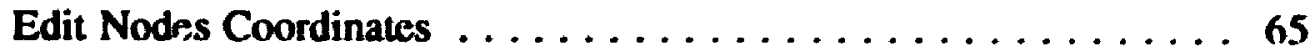

Structure Display Application Menu $\ldots \ldots \ldots \ldots \ldots \ldots \ldots 6$

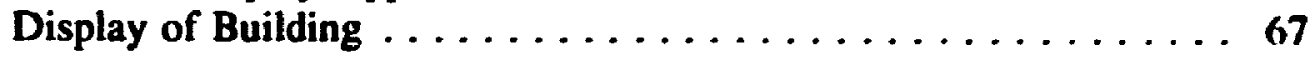

Display Selected Surface ..................68

Object Space and Initial Camera Position . . . . . . . . 70

Display Building - SECTION and SOLID/TOGGLE . . . . . 71

Climatic Data . . . . . . . . . . . . . . . . . 73

Dead Load Structural Sandwich Systems ............ 74

Dead Load Structural Sandwich Systems for Walls ... . . . . . 75

Create/Edit Dead Load Structural Sandwich System ... . . . . 76

Input Element By Keyboard . . . . . . . . . . . . . 77

Live Load Use and Occupancy - Select UDL . . . . . . . 79

Live Load Use and Occupancy - Select Concentrated Load .... . 80

Attribute Loads to Surfaces . . . . . . . . . . . . . . 81

Dead Load - Surface and Load Intensity Identification . . . . . 83

Select Surface with Attributed Dead Load Intensity . . . . . . 84 
Fig. 3.36

Dead Load Intensity Area Information $\ldots \ldots \ldots$. . . . . . 85

Fig. 3.37

List Nodes and Nodes ID Information . . . . . . . . . . 86

Fig. $\mathbf{3 . 3 8}$

Live Load Use and Occupancy Load Intensity List . . . . . . . . 87

Fig. 3.39

Snow Load - Select Roof Conditions . . . . . . . . . . . . . . . . 88

Fig. 3.41)

Fig. 3.41

Select Snow Load Figure From Table . . . . . . . . . . . . . . 88

Fig. 3.42

Mesh Spacing Definition and List of Surfaces

89

Select Adjacent Surfaces that Influence Snow Load

Distributions and Intensities . . . . . . . . . . . . . . 90

Fig. 3.43

Surface Selection for Attibuting Wind Load . . . . . . . . . . . 92

Fig. 3.44

Fig. 3.45

Distribution of Openings for the Caiculation of Wind Loads . . . 93

Fig. 3.46

Snow Load - Clinnatic Data Information ... . . . . . . . . . . 94

Fig. 3.47

Fig. 3.48

Fig. 3.49

Fig. 3.50

Fig. 3.51

Fig. 3.52(a)

Snow Load Example for Gabled Roofs - Figure H-1 . . . . . . . . 95

Example Low-Rise Structure . . . . . . . . . . . . . . . . . 96

Snow Load Example for Valleys - Figure H-3 . . . . . . . . . . 97

Snow Load Example for Lower Roof with Sliding Snow - Fig.H-4

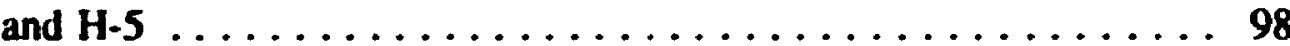

Wind Load - Climatic Data Information . . . . . . . . . . . . . . 99

Structural Characteristics ................... 100

Example Wind Load Distribution for a Wall of a High-Rise

Building ........................ 101

Fig. 3.52(b) Example Wind Load Distribution for a Roof of a High-Rise

Building .......................... 102

Fig. 3.53 Example Low-Rise Building. Application of Figures B-7 to B-10 . 103

Fig. 3.54(a) Wind Load Distribution for a Roof of a Low-Rise Building . . . . 104

Fig. 3.54(b) Wind Load Distribution for a Wall Parallel to the Ridge of a Low-Rise Building ..................... 105

Fig. 3.54(c) Wind Load Distribution for a Wall Perpendicular to the Ridge of a Low-Rise Building . . . . . . . . . . . . . . . . . 106

Fig. 4.1

High-Rise Building Example

108

Fig. 4.2

Fig. 4.3

Fig. 4.4

Fig. 4.5

Fig. 4.6

Fig. 4.7

Fig. 4.8

Fig. 4.9

Fig. 4.10

Fig. 4.11

Fig. 4.12

Fig. 4.13

Fig. 4.14

Floor Surfaces - Dead Load and Live Load due to Use

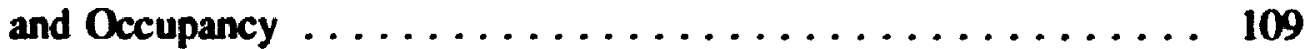

Retail Space . . . . . . . . . . . . . . . . . 110

Office Space . . . . . . . . . . . . . . . . . . 111

Mechanical Room - Floor Plan . . . . . . . . . . . . 112

Dead Load Libraries . . . . . . . . . . . . . . . . . . . . 113

Live Load Use and Occupancy - Library of Areas . . . . . . . . . 113

Dead Load Intensity for "LowRoof_5" . . . . . . . . . . . . . . . 114

Live Load Intensity - Use and Occupancy for "Floor_5" . . . . . 114

Roof Surfaces - Live Load due to Snow and Wind . . . . . . . . . 116

Snow Load Distributions on Selected Roof Surfaces . . . . . . . 117

Wall Surfaces - Live Load due to Wind . . . . . . . . . . . 119

Wind Load Distributions for a High-Rise . . . . . . . . . . . 120

Low-Rise Building Perspective . . . . . . . . . . . . . . 122

Fig. 4.15 Dead Load - Library of Wall Areas . . . . . . . . . . . . . 122 
Fig. 4.16 Dead Load - Structural Roof System . . . . . . . . . . 12.3

Fig. 4.17 Live Load Use and Occupancy - Library of Ancas . . . . . . . 123

Fig. 4.18 Snow Load Distribution on Lower Roof . . . . . . . . . . . 123

Fig. 4.19 Wind Load Distributions $\ldots \ldots \ldots \ldots \ldots \ldots \ldots \ldots \ldots$ 


\title{
List of Symbols
}

\author{
B = Background turhulence factor \\ C $\quad$ Factor for computation of reference pressure, $C=0.00005$ if reference \\ wind speed is in $\mathrm{km} / \mathrm{h}$ \\ C. = Snow accumulation factor \\ $c_{\infty} \quad=$ Cocfricient of snow accumulation factor \\ C. $\quad$ = Basic roof snow load factor \\ C. $=$ Exposure factor for wind load intensity \\ $C_{0}^{*} \quad=$ Exposure factor for wind load intensity increased on the hill or \\ escarpments \\ $C_{\text {etf }} \quad$ Exposure factor for wind load at the top of the building \\ $c_{8} \quad=$ Gust effect factor \\ C $\quad=$ External pressure coefficient \\ $C_{\omega} \quad=$ Internal pressure coefficient \\ C, $\quad=$ Roof slope factor \\ $C_{w} \quad=$ Wind exposure factor for snow load accumulation \\ D = Dead Loads, kN, kN/m, kNm, kIJ per metre square \\ $F \quad=$ Gust energy ratio \\ $H \quad=$ Height of windward face of the building, in metres \\ $\boldsymbol{K}=$ Factor related to the surface roughness coefficient of the terrain \\ $L \quad=$ Live load due to use and occupancy, snow, ice, rain, $k N, k N / m$, \\ $\mathbf{k N m}, \mathbf{k N}$ per metre square
}




\begin{tabular}{|c|c|}
\hline $\boldsymbol{Q}$ & $\begin{array}{l}=\text { Live load due to wind and earthquake, } \mathrm{kN} . \mathrm{kN} / \mathrm{m}, \mathrm{kNm} \text {, } \\
\text { kN per metre square }\end{array}$ \\
\hline $\boldsymbol{s}$ & $=$ Specified load due to snow, $\mathrm{kN}$ per metre square \\
\hline $\boldsymbol{s}_{\mathbf{r}}$ & = Rain load associated with snow load. $\mathrm{kN}$ per metre square \\
\hline$s_{2}$ & $=$ Ground snow load, $\mathrm{kN}$ per metre square \\
\hline $\boldsymbol{T}$ & = Load due to contraction or expansion, $\mathbf{k N}$ \\
\hline$V_{B}$ & $=$ Mean wind speed at top of the structure, $\mathrm{m} / \mathrm{s}$ \\
\hline$\overline{\boldsymbol{V}}$ & $=$ Reference wind speed, $\mathrm{m} / \mathrm{s}, \mathrm{km} / \mathrm{h}$ \\
\hline $\boldsymbol{W}$ & $=$ Width of windward face of the building, $m$ \\
\hline$W_{\text {, }}$ & $=$ Maximum or peak loading effect of wind \\
\hline $\boldsymbol{Z}$ & = Elevation above terrain, $n$ \\
\hline $\boldsymbol{8}_{\boldsymbol{p}}$ & = statistical peak factor for the loading effect \\
\hline $\boldsymbol{h}$ & $\begin{aligned}= & \text { Height of the building for exposure factor by simple procedure } \\
& \text { or height of the adjacent wall above roof for snow accumulation. } m\end{aligned}$ \\
\hline$n_{0}$ & $=$ natural frequency of vibration, $\mathbf{H z}$ \\
\hline $\boldsymbol{p}$ & $=$ Specified external pressure, $\mathbf{k N}$ per metre square \\
\hline 9 & $=$ Reference velocity pressure, $\mathrm{kN}$ per metre square \\
\hline $\boldsymbol{p}_{\boldsymbol{i}}$ & $=$ Specified internal pressure, $\mathbf{k N}$ per metre square \\
\hline$s$ & $=$ Size reduction factor \\
\hline$x_{d}$ & $=$ Length for drift accumulation of snow, $m$ \\
\hline$x_{\text {alopere }}$ & $=$ Length of snow accumulation from snow sliding from upper roof, $m$ \\
\hline $\boldsymbol{\alpha}$ & $=$ Load factors \\
\hline
\end{tabular}




$\begin{array}{ll}\boldsymbol{\beta} & =\text { Critical damping ratio } \\ \boldsymbol{\nu} & =\text { Importance factor } \\ \boldsymbol{\nu} & =\text { mean loading effect } \\ \boldsymbol{\nabla} & =\text { Average fluctuation rate } \\ + & =\text { "root-mean-square" loading effect } \\ & =\text { Load combination factor }\end{array}$




\section{Chapter 1}

\section{Introduction}

\subsection{Building Design Fabrication and Construction Process}

Unlike many manufactured products, building structures tend to be unique. The analysis-design-fabrication-erection process for these structures exhibits great variability and has not been integrated to any significant extent. The process has tended to be sequential and segmented without adequate interaction between the architects, enginecrs and fabricators who are responsible for different parts of the process. The quality of design has also varied greatly.

The development of a system that integrates the process would lead to hetter and more cost effective structures. This would arise from ease of verification, opportunity for increased conceptual development, improved understanding of the loads acting on the structure and the behaviour under those loads, and the unimpeded flow of information th roughout the entire process.

The essential steps for a complete integrated system for the layout, analysis, design, detailing, fabrication and erection of a steel building may be summarized as follows in Table 1.1. 
Table 1.1 Design Fabrication and Construction Process

\begin{tabular}{|c|c|c|}
\hline Step & Designation & Objectives \\
\hline 1 & Preprocessing & $\begin{array}{l}\text { Definition of structure and components, } \\
\text { determination of loads, preliminary sizing of } \\
\text { components }\end{array}$ \\
\hline 2 & Structural analysis & $\begin{array}{l}\text { Determination of displacements and internal } \\
\text { forces, including second-order (non-linear) } \\
\text { geometric effects }\end{array}$ \\
\hline 3 & Component Design & $\begin{array}{l}\text { Selection and verification of suitability of } \\
\text { components }\end{array}$ \\
\hline 4 & Reanalysis and redesign & $\begin{array}{l}\text { Iteration of Steps } 2 \text { and } 3 \text { until all design } \\
\text { requirements are satisfied in a consistent } \\
\text { manner }\end{array}$ \\
\hline 5 & Design of connections & $\begin{array}{l}\text { Selection and verification of suitability of } \\
\text { connections and joints }\end{array}$ \\
\hline 6 & Enection considerations & $\begin{array}{l}\text { Investigation of partial structures under } \\
\text { construction loadings and bracing conditions }\end{array}$ \\
\hline 7 & Description of structure & Preparation of drawings and specifications \\
\hline 8 & Fabrication & $\begin{array}{l}\text { Manufacture of all elements of the structure } \\
\text { for field erection }\end{array}$ \\
\hline 9 & Construction & Erection and completion of finished building \\
\hline
\end{tabular}

In North American practice there are generally a number of different organizations involved in this process. In a typical building project the architect may be responsible for portions of steps 1,7 and 9; the consulting engineer responsible for a portion of 1 , all of 2,3 and 4 and portions of 5,6,7 and 9; steel fabricators responsible for portions of 5. 6. 7, all of 8 and portions of 9 ; and the general contractor responsible for portions of 6 and most of 9. Consequently, communication and coordination are crucial links and a high probability of liigation exists if problems arise.

A complete integrated system would previde a common database for, and the integration of, all the processes involved in all the above steps. Design data would be 
shared by all the participants in the process.

A review of current building design-analysis programs on the market including: S-FRAME (Space Frame); SODA (Structural Optimization Design Analysis); M-STRUDL (Structural Design Language); DAST (Total Structural Analysis Design); STAAD III (Structural Analysis and Design); AMECO-17 (Automated Design in Metals and Concrete), GFD3, HESCO, SCADA/H, STEELCAD III, D.C.A., DESIGN DATA. DESCON, MICROCAD, STEELCON, CONXPRT and others, reveal that the structural engineer is responsible for determining loads; attributing loads to members; geometry and boundary conditions; preliminary sizing of members and for supplying additional information not calculated by but required by the program.

The development of a system for the determination of loads and load combinations acting on the structure is the first step in the overall design process and would fill one of the major gaps in existing software tools.

\subsection{Required Attributes for Determining Loads}

A system for determining loads should be designed to suit the process and must include the following attributes:

1. Common data bases, data base transfer mechanisms, and library functions. Certain databases such as climatic data, masses and weights, use and occupancy live load intensities will remain relatively fixed, while others with respect to geometry. layout, and loads acting on members will be project dependent.

2. Modular system which include the following modules (a) geometric modelling and 
surface definition, (b) determination of loads acting on surfaces, (c) determination of secondary structural systems, (d) definition of primary members, (c) determination of tributary areas, (f) determination of live load reduction factors, (g) attributing loads to members, (h) determination of load combinations.

3. Graphic interfaces for modelling this part of the design process.

4. Comprehensive design notes, structural ir ages, load and load combination summaries.

5. Comprehensive help that should be self explanatory to a structural engineer or architect.

6. Translation functions that generate geometric and load data input for existing structural analysis programs.

\subsection{Components/Mndules Description}

\subsubsection{Geometric Modelling and Surface Definition.}

This module involves three distinct areas and the development of three corresponding sub-modules.

\section{(a) Surface Definition}

Surfaces define the form of the structure and may be classified as floor, wall or roof surfaces. Basic file structures have been created to describe the orientation, size, shape, location and type of surface. These surfaces may be generated from previously defined files or systematically through a series of library functions which identify nodes 
and coordinates and draw the surfaces as they are created. Imegular shaped surfaces within a surface may have to be defined.

\section{(b) Primary Member Definition}

Primary members will have to be defined and a file structure created that will contain the following attributes: member type, orientation, location, shape designation. continuity and end conditions, identification and analysis codes. Features such as bay member generation and column stack drag (relocating column line or position) options should be included to facilitate the member generation prccess and modification process.

\section{(c) Secondary Member Definition and Design}

This will be invoked after the primary members have been defined and will automatically determine the optimum configuration given the primary member layout and the structural floor, wall, or roof system selected within the dead load determination phase. Extensive interaction with industry will be required to develop guidelines and codeable rules for determining these configurations given present construction techniques and costs. The design of these elements would occur at this stage as it does not require any further interaction with other parts of the system. Updated loads will be calculated and stored in the appropriate data base.

\subsubsection{Determination of Loads Acting on Surfaces}

This madule embodies "Part 4 Structural Design" in the NBCC 1990, NRC (1990), 
and the corresponding commentaries and climatic data within the supplement. Data bases, graphic intertaces and library functions which determine the loads described in Clause 4.1.5. Dead Loads, Clause 4.1.6 Live Loads Due to Use and Occupancy, Clause 4.1.7. Live Loads Due to Snow, Ice and Rain, Clause 4.1.8. Live Loads Due to Wind, Ciause 4.1.9. Live Loads Due to Earthquakes and Clause 4.1.10. Other Effects must be developed. This module should be capable of importing wind tunnel and sand flume test data for unique load distributions on irregularly shaped structures.

\subsubsection{Determination of Tributary Areas}

Given the definition of both the primary and secondary members, the surfaces, and the types of structural systems, the determination of tributary areas will be essentially automatic. This will require extensive development of geometric algorithms to determine tributary areas of members arbitrarily oriented within a given surface. Library functions will be included to describe the tributary areas for primary and secondary members of well defined structures like those illustrated in commentary $G$ of the NBCC supplement for (a) flat slabs without beams, (b) two way slabs with beams, (c) two way slabs with joists, beams and girders, (d) one way slabs with girders, (e) one way deck or slabs with joists, beams and girders, and (f) wall systems with girts and sag rods. The structural engineer will be given the option to view these areas graphicelly. The data should be retained as part of member definitions as it would be used subsequently for future load calculations. 


\subsubsection{Live Load Reduction Factors}

Algorithms need to be developed to determine the appropriate live load reduction factors, to modify the live load due to use and occupancy, that reflect the probability of occurrence of a given intensity. These factors are a function of tributary area and the classification of use and occupancy and need to be calculated for cach member independently, slabs or decks, joists, beams, girders, columns and column stacks. Values for the appropriate modification or adjustment of internal forces for any given member and analysis procedure (reflecting the live load reduction factors) should be calculated and stored in the data base for members.

\subsubsection{Attributing Loods to Members}

At this stage the program would automatically calculate the loads acting on the members. A database would be created to give a complete description of the loads (location, magnitude and direction) and the members on which they act. Loads should be displayed graphically on request for verification and the corresponding database should be printed.

File translator functions could be included so that the data may be reformatted into an acceptable format for any given structural analysis program. A special user interface would have to be developed to facilitate this operation.

\subsubsection{Determination of Load Combinations}

This module would automatically determine all the load cases that must be 
considered in the design of the structure. Large and complex structures may have as many as 1000 load cases where medium and low rise structures may have as many as 30 . Provision should be made for the structural engineer, erector or fabricator to introduce special load cases for structures under construction or where structural integrity is being investigated under accidental loads. For example, the Skydome was investigated for the potential of an airplane crash which could take out any portion of the roof $4.5 \mathrm{~m}$ in diameter. Between 200 and 300 load cases were considered for this condition alone, Allen (1988).

\subsection{Objectives and Scope}

The main objective of this work is to develop a computer system for determining loads acting on building surfaces. This includes:

1. the development of databases for climatic data, dead loads, live loads, snow loads, wind loads, and structural geometry, and

2. the development of a geometric modeller to define the surfaces (including subsurfaces) and shape of a structure, and

3. the development of algorithms to determine the corresponding snow and wind loads for the defined structure, and

4. the development of algorithms to auribute the load intensities to the appropriate areas, and

5. the development of user graphic interfaces that will;

(a) facilitate the generation of a geometric model, and 
(b) models the design and load determination process, and

(c) that is easy to use and is self explanatory, making a users manual unnecessary.

Although, the scope of the work is limited to the determination of loads acting on surfaces, the file structure and architecture of the program have been designed to accommodate the remaining components of the complete load determination module as described in section 1.3. The determination of dead loads is tailoned for steel construction.

\subsection{Anticipated Technological and Socio-Economic Impact}

The proposed system for determining loads and load combination acting on steel buildings should have a profound impact on the consulting engineering and fabricating community. It would allow for the systematic, simple and complete determination of loads acting on any building in Canada. The loads acting on a typical structure like salt and sand domes for Departments of Highways, for one part of the country could easily be redetermined by simply redefining its geographic location.

Updating the loads on a structure that result from modifications to the geometry could easily be accommodated. Errors such as the one described in the commissioners inquiry into the failure of the Station Square Development, pertaining to not reevaluated the dead loads as they were deemed to be insignificant when in fact, they contributed to the failure. Through interactive graphics, the loads will be displayed visually, making verification easier. 
Code committee's could with little effort, investigate the influence of changes to the NBCC on the loads, hence the design of the structure and subsequently the cost, prior to introducing the changes in new releases. The impact across the country could be investigated on certain benchmark structures. Note, that recent changes in the 1990 NBCC. NRC (1990), have had a significant effect on building costs since its introduction; i.e. earthquake loads are now a more severe lateral loads than wind in most major centres in Canada with the exception of Saskatoon.

The development of this system will lead to advancements in computer representation of code, the development of user interfaces for structural engineering, and advances in database management and data base transfer mechanisms.

The load determination system in its completed form, with its enhanced graphics and visual displays will help architects, engineers, fabricators and students to visualize the structure and its components. The sophisticated interactive determination of loads acting on the structure will give designers an increased understanding of loads, shapes of structures and their impact on loads and how loads are carried by the structure. This knowledge will enable them to explore new framing systems and concepts. Removing the drudgery of mundane calculations from the process will generate enthusiasm amongst all users and will eliminate the corresponding errors. 


\section{Chapter 2}

\section{Determination of Load Intensities and Mesh Generation}

\subsection{Limit States Design}

Limit states are those limiting states or conditions of a structure (serviceability and fatigue, ultimate) at which it ceases to fulfil its intended function. Limit States Design is that design philosophy in which the designer, recognizing the various limit states, proportions the structure such that these are not exceeded, and in general can be expressed 25

$$
\phi R \geq \alpha S
$$

(factored resistance $>=$ effect of the factored loads)

Where,

$\phi$ and $\alpha$ are resistance and load factors, respectively, and are based on statistical variations of the member resistance and load distributions $\mathbf{R} \quad$ is the member resistance

S is the effect of the loads

The effect of the factored loads is expressed in Part 4 of the National Building Code of 
Canada 1990 (NBCC 1990), NRC (1990) in clause 4.1.4.2.(3) for ultimate limit states (strength and stability) as,

$$
\alpha_{D} D+\gamma \psi\left[\alpha_{L} L+\alpha_{Q} Q+\alpha_{T} T\right]
$$

and in clause 4.1.4.3.(2) for serviceability and fatigue limit states (deflection, vibration, fatigue cracking) as,

$$
D+\Psi[L+Q+T]
$$

where,

$D=$ dead loads

$L=$ live loads due to intended use and occupancy, snow, ice and rain, earth and hydrostatic pressure, horizontal components of static or inertia forces

$Q=$ live load due to wind or earthquake, whichever produces the more unfavourable effect

$T=$ loads due to contraction or expansion, caused by temperature changes, shrinkage, moisture changes, creep in component materials, movement to differential settlement or combination thereof

$\alpha_{D}, \alpha_{L}, \alpha_{Q}, \alpha_{T}=$ are the corresponding load factors for each load type, refer to clatise 4.1.4.2.(4)

$\Psi=\quad$ load combination factor, nefer to clause 4.1.4.2.(5) and (6)

$\gamma=\quad$ importance factor, refer to clause 4.1.4.2.(7)

Establishing the design loads acting on the structure, and hence its members, is essential to the design process and to the design of the building. The computation of the loads 
described in Part 4 of the NBCC 1990, NRC (1990), and assessment of these loads to the appropriate surfaces of the building forms the basis of the program LDFSSBC, "Load Determination For Structural Steel Buildings in Canada", written for this thesis and is described in the following sections.

\subsection{Dead Load}

The specified dead load for a structural member that needs to be considered in design is defined in clause 4.1.5. of Part 4 of the NBCC 1990. NRC (1990) and consists of the self weight of the structural member, floors and floor finishes, ceilings, exterior walls, permanent partitions, electrical and mechanical equipment. Forces due to prestressing are not currently included in any load assessment. The composition of the structural sandwich systems for walls roofs and floors of the finished building are generally well defined, and the corresponding dead loads can be predicted with reasonable accuracy. Variations may occur due to construction practices (tolerances), substitutions or revisions of specified materials and/or construction errors. The loads for a given construction are determined per unit area and subsequently attributed to individual members according to their tributary area and framing scheme.

The program LDFSSBC provides the facility to interactively create and/or edit a list of load intensities (identified by name), from standard libraries of unit weights or standard dead load values, for any structural sandwich system and to attribute these to the appropriate surface or subsurface within the building. 


\subsection{Live Load Due to Use and Occupancy}

The specified live load acting on floor and roof areas is a function of the intended use and occupancy and is defined in clause 4.1.6. of Part 4 of the NBCC 1990, NRC (1990). The minimum specified live load intensities are given in Tables 4.1.6.A. and 4.1.6.B. in Clause 4.1.6. for uniformly distributed and conr atrated loads, respectively.

Live load reduction factors are applied to the specified live load intensity. according to the tributary area of the member and the classification of use and occupancy. to reflect the probability that the entire tributary area, may not be fully loaded simultaneously. Concentrated loads acting over a $750 \mathrm{~mm} \times 750 \mathrm{~mm}$ square area, may be applied anywhere within the corresponding use and occupancy area to produce the worst load effect. Provisions have been made to incorporate these facets of live load determination in the program LDFSSBC.

Currently, the program provides the facility to interactively create and/or edit a list of loads (concentrated) and load intensities (uniformly distributed), identified by name, from reproduced versions of Table 4.1.6.A. and 4.1.6.B., and to attribute them to the appropriate surface or subsurface within the building.

\subsection{Live Load Due to Snow, Ice and Rain}

The specified live load due to snow, ice and rain, acting on roof area, is a function of the locale (climatic conditions snow fall, density), site conditions (exposure to wind) and the roof configuration. The load distributions are defined in Clause 4.1.7. of Part 4 of NBCC 1990. NRC (1990). The basic climatic data required for the determination of 
snow load distributions, given in Chapter 1 "Climatic Information for Building Design in Canada" of the Supplement to the NBCC 1990, NRC (1990), is easily retrievable from a database created for the program LDFSSBC.

Currently, the program provides the facility to calculate and interactively display the snow load distributions for a building having any or all of the roof configurations (gable roof, shed roof, simple arch or curved roofs, valleys, lower level of adjacent roofs, lower roofs with sloping upper roofs and roof projections) given in Commentary $H$ of the Supplement to the NBCC 1990, NRC (1990).

The specified loading, $\mathbf{S}(\mathbf{k P a})$, due to snow accumulation on a roof is given in Claus: 4.1.7.1.(1) as

$$
S=S_{s}\left(C_{b} C_{w} C_{s} C_{a}\right)+S_{r}
$$

where,

$S_{s}=\quad$ is the ground snow load in $\mathrm{kPa}$ with 1 -in-30 annual probability of exceedance. The value, Ss, given in the database for approximately 650 different locales across Canada, is based on measured depths and densities of snow. The unit weight of accumulated snow may vary from 1.0 to $4.5 \mathrm{kN}$ per metre cubed depending upon the locale and time of year. The supplement recommends that a value of $3.0 \mathrm{kN}$ per metre cubed be used for design in lieu of better local data.

$S_{r}=\quad$ the associated rain load in $\mathrm{kPa}$ (rain that fall into the snow cover). The rain load at any location on the roof must be less than the corresponding snow load 


$$
S_{r} \leq S_{s}\left(C_{b} C_{w} C_{s} C_{a}\right)
$$

$C_{b}=\quad$ the basic roof snow load factor represents the fraction of the ground snow load which is expected to occur on the roof. Based on measurements from across Canada the value has been set to $\mathbf{0 . 8 0}$.

$C_{w}=\quad$ the wind exposure factor is defined in Clause 4.1.7.1.(2) and (3) as being $1.0,0.75$ or 0.5 depending on whether the site is considered exposed or exposed and north of the tree line. Values less than one indicate that the site is exposed to wind and a reduction in snow load intensity occurs from snow being blown off or by preventing accumulation use the guidelines given in Clausi 4.1.7.1.(3) to determine whether or not the site is exposed. $C_{s}=\quad$ the slope factor is defined in Clause 4.1.7.1.(4),(5) and (6) and reflects the reduction in accumulation of snow due to creep and sliding on a sloped roof. Roof surfaces are classified either as normal and have a slope factor that decreases linearly from 1.0 at a 30 degree slope to 0.0 at 70 degrees, or as unobstructed slipper (made of glass or metal) where the slope factor decreases linearly from 1.0 at 15 degrees to 0.0 at 60 degrees. Reductions in snow load intensity only apply to sloped roof surfaces where the snow can slide off.

$C_{a}=\quad$ accumulation factor is a function of the roof configuration and describes the snow load distribution of the roof surface for all probable load cases (uniformly distributed, drifts, unbalanced loads). The Supplement to the 
NBCC 1990, NRC (1990), provides a series of snow load distributions (accumulation factors) for typical mof configurations that were derived from the results of model tests and measurements on existing structures. Figures H-1 to H-6 give the accumulation factor for gable, flat and shed roofs; simple arch or curved roofs; valleys; lower levels of adjacent roofs; lower roofs with sloping upper roofs; and roof projections, respectively. Wind tunnel or sand flume tests must be conducted to establish the snow load distributions for buildings that have roof configurations that cannot he adequately described by these figures. Note, the snow load distributions described by Fig H-6, triangular drift loads for roof areas adjacient to significant vertical obstructions, are calculated within the program using the functions for Fig H-4 with the width defined as the width of the obstruction.

Example calculations which illustrate the application of Clause 4.1.7 and Figures H-1, H-3, H-4 and H-5 for the low-rise building described in section 3.7 , located in Ottawa classified as not exposed, and with unobstructed slipper roofs are given below.

Design Data. Summary

Locale: Ottawa, Ontario

$S_{s}: \quad 2.2 \mathrm{kPa}$

$S_{r}: \quad 0.4 \mathrm{kPa}$

Site characteristics: classified as not exposed

Roof characteristics: unobstructed slippery 


\section{Application of Figure H-1:}

Example solutions verified by LDFSSBC (figures on the left hand side) and the corresponding hand calculations for the design snow load cases for the gable roofs are given in Figure 2.1.
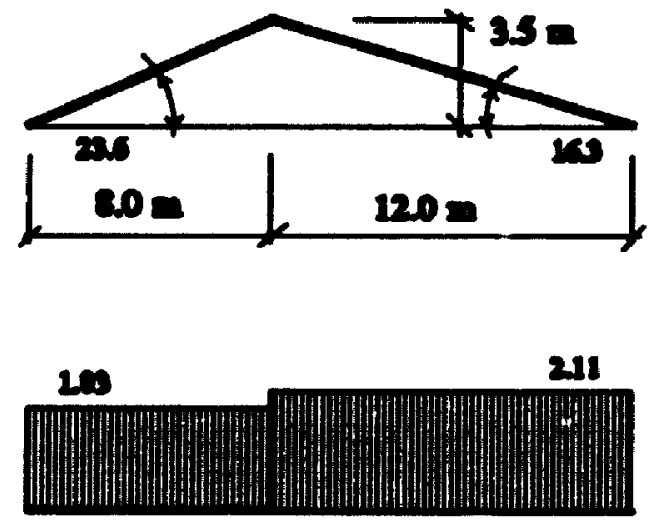

20

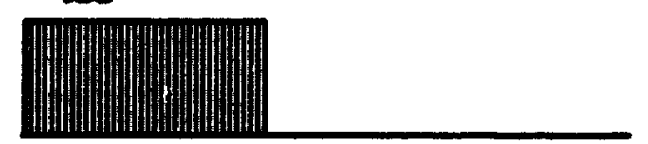

$C_{w}=1.0$

$C_{s}^{L}=\frac{60-23.6}{45}=0.81$

$C_{s}^{R}=\frac{60-16.3}{45}=0.97$

LOAD CASE I :

$C_{e}=1.0$

Li $2.2 \cdot(0.8 \cdot 1.0 \cdot 0.81 \cdot 1.0)=1.43>S$,

IE $2.2 \cdot(0.8 \cdot 1.0 \cdot 0.97 \cdot 1.0)=1.71>S_{r}$

$S^{L}=1.43+0.4=1.83 \mathrm{kPa}$

$S^{2}=1.71+0.4=2.11 \mathrm{kPa}$

LOAD CASE Illa :

$C_{a}^{2}=1.25$

R. $2.2 \cdot(0.8 \cdot 1.0-0.97 \cdot 1.25)=2.13>S$,

$S=2.13+0.4=2.53 \mathrm{kPa}$

LOAD CASE IIb :

$C_{a}^{L}=0.25+\frac{\alpha}{20}=0.25+\frac{16.3}{20}=1.065$

L: $2.2 \cdot(0.8 \cdot 1.0 \cdot 0.81 \cdot 1.065)=1.52>S$,

$S=1.52+0.4=1.92 \mathrm{kPa}$

where $\alpha=$ roof slope in dogrees

Fig. 2.1 Example Calculations; Figure H-1. 
Application of Figure H-3:

Example solutions verified by LDFSSBC (figures on the left hand side) and the corresponding hand calculations for the design snow load cases for the valley areas of roof are given in Figure 2.2.

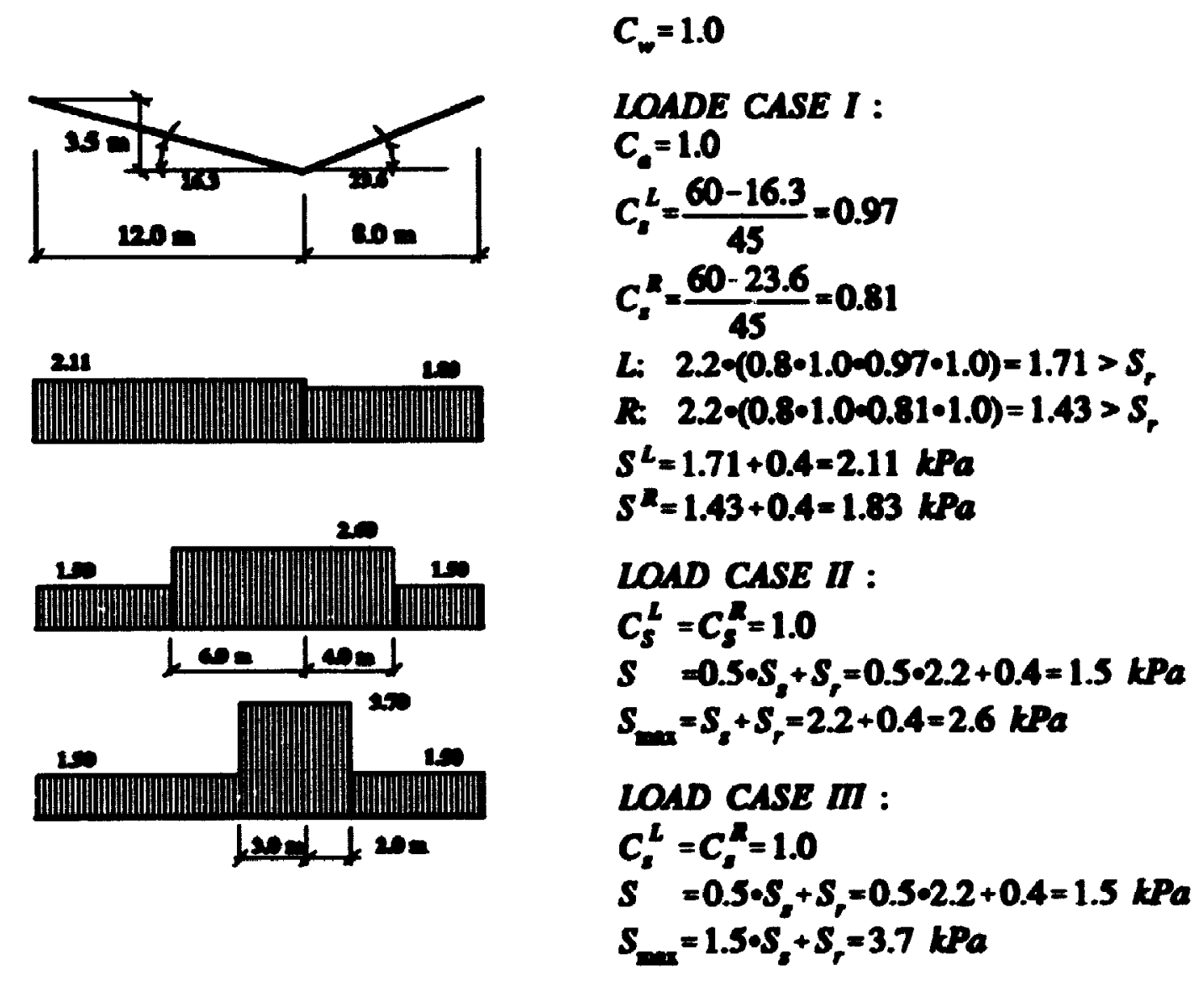

Fig. 2.2 Example Calculations; Figure H-3. 


\section{Application of Figure H-4:}

Example solutions verified by LDFSSBC (figures on the left hand side) and the corresponding hand calculations for the design snow load for lower levels of adjacent roofs are given in Fig. 2.3.

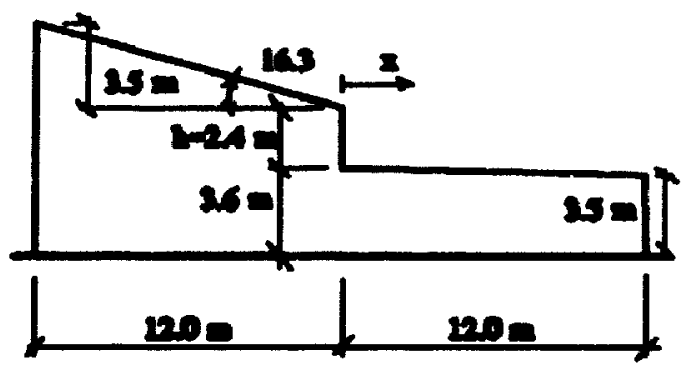

$$
\begin{aligned}
& \text { slope }=4.8^{\circ} \quad C_{s}=1.0 \\
& C_{w}=1.0 \\
& h=2.4 \mathrm{~m} \\
& x_{d}=2 h=4.8 \mathrm{~m} \\
& \text { but } 3 m<x_{d}<9 m \text { or } \\
& C_{\infty}=\frac{r h}{C_{w} S_{s}}=\frac{3.0 \cdot 2.4}{0.8 \cdot 2.2}=4.1 \\
& \text { but if } C_{\infty}>\frac{3}{C_{b}} \text { use } \frac{3}{C_{b}}=3.75 \\
& \text { at } x=0: \\
& S=2.2 \cdot(0.8 \cdot 1.0 \cdot 1.0 \cdot 3.75)+0.4=7.00 \mathrm{kPa} \\
& \text { for } x 2 x_{d} \quad C_{d}=1.0 \\
& S=2.2 \cdot(0.8 \cdot 1.0-1.0 \cdot 1.0)+0.4=2.16 \mathrm{kPa}
\end{aligned}
$$

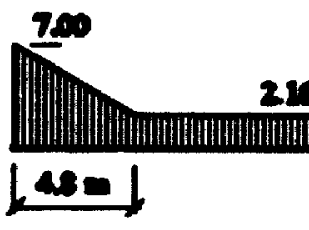

Fig. 2.3 Example Calculations; Figure H-4. 


\section{Application of Figure H-5:}

Example solutions verified by LDFSSBC (figures on the left hand side) and the corresponding hand calculations for the lower adjacent roof which is exposed to the possibility of the combination of snow drift accumulation and sliding snow from sloping upper roof are given in Fig. 2.4. Note, the snow load intensity of $6.71 \mathrm{kPa}$ shown in Fig. 3.49. was computed as the average snow load intensity over a unit area defined by the mesh of points $1000 \times 1000 \mathrm{~mm}$ (for this case this represents the load intensity $500 \mathrm{~mm}$ from the wall), not the snow load intensity at one point (at the foot of the wall).

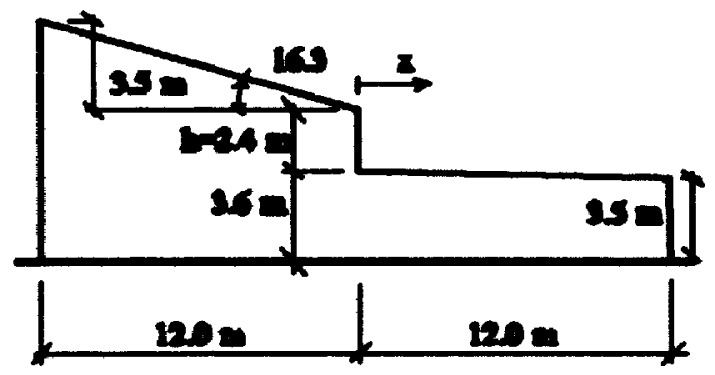

211

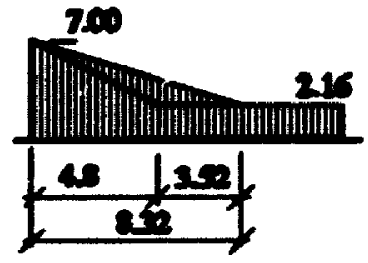

Snow load on upper roof mas computed in Fig. $2.1 \mathrm{H}-1$ for right part as : $S=2.11 \mathrm{kPa}$

Snow dift on lower roof is shown in Fig. 2.3. $\mathrm{H}-4$.

at $x=0.0: S_{x}=7.00 \mathrm{kPa}$

at $x \geq x_{d}: S=2.16 \mathrm{kPa}$

Volume of stiding snow from upper noof is $50 \%$ of CASE I:

$$
\begin{aligned}
& V=\frac{12.0-2.11}{\gamma}+0.50=\frac{12.66}{3.0}=4.22 \mathrm{~m}^{3} \\
& x_{\operatorname{dmg}}=\frac{2 V}{h_{g}}=\frac{2 \cdot 4.22}{2.40}=3.52 \mathrm{~m} \\
& L=x_{d}+x_{\text {mang }}=4.80+3.52=8.32 \mathrm{~m}
\end{aligned}
$$

Fig. 2.4 Example Calculations; Figure H-5. 


\subsection{Live Lood Due to Wind}

The specified live load due to wind acting on external surfaces of a building, is a function of the locale, site conditions and building geometry. The static design pressure distributions, defined in Clause 4.1.8. of Part 4 of the NBCC 1990, NRC (1990), are based on wind tunnel tests for structures classified as low-rise buildings (rectangular in plan, with or without a gable roof) that have widths greater than twice their heights and a reference height less than $10 \mathrm{~m}$; and for medium to high-rise buildings (rectangular shaped, flat roofs) with height to width ratios greater than one and reference heights greater than $20 \mathrm{~m}$. In absence of better data, the static design pressures for low-rise buildings may be used for buildings with geometry that places them between the two catcgories. Note, the static design pressures give the same maximum load effect as the dynamic resonant response to the actual turbulent wind. For all other structural shapes not described and for high-rise buildings where better estimates of design pressures for cladding is required or where the dynamic response is significant (lies outside the limits specified in Clause 4.1.8.2.) wind tunnel tests must be conducted to determine the design pressure.

Currently, the program LDFSSBC provides the facility to interactively determine the wind load intensities (static design pressures) acting on the exterior surfaces of buildings that meet the geometric constraints on the building form stipulated in the NBCC 1990. NRC (1990). The simple and detailed procedure for determining the exposure factor (including variation due to speed-up over hills and escarpments) and the gust factor have been incorporated. Unique building geometries and the corresponding wind tunnel 
test data (describing the wind load distributions) can be imported. Details of wind load calculations are given in the following sections.

\subsubsection{Definition of Static Design Pressures}

The specified external pressure or suction due to wind on part or all of surface of a building, defined in Clause 4.1.8.1.(1), is calculated from Equation (2.5)

$$
p=q \cdot C_{e} \cdot C_{e} \cdot C_{p}
$$

and the specified internal pressure or suction due to wind, defined in Clause 4.1.8.1.(3), is calculated from Equation (2.6.)

$$
p_{i}=q \cdot C_{e} \cdot C_{i} \cdot C_{\mu}
$$

where,

$p=$ the specified external pressure acting statically and in a direction nomal to the surface either as a pressure directed towards the surface or as a suction directed away from the surface

$q=$ the reference velocity pressure

$C_{e}=$ exposure factor evaluated at height of the element for external pressure and evaluated at the building mid height for internal pressure

$C_{8}=$ the gust effect factor

$C_{p}=$ the external pressure coefficient average over the area of the surface considered

$P_{i}=$ the specified internal pressure acting statically and in a direction normal to the surface either as pressure (directed outward) or as a suction (directed 


$$
\begin{gathered}
\text { inwards) } \\
C_{\mu}=\text { the internal pressure coefficient }
\end{gathered}
$$

The net specified wind load for the building as a whole is computed as algebraic difference of wind pressure acting on the windward and suction acting on the leeward surfaces. The net specified wind load intensity on part or all surface of a building is computed as algebraic difference of the external pressure or suction and specified internal pressure or suction on the corresponding surface. Subroutines have been wriven to compute all possible wind load cases for individual external surfaces, only.

\subsubsection{Reference Velocity Pressure}

The reference velocity pressure is determined from reference wind speed by,

$$
q=C \cdot \bar{v}^{2}
$$

where,

$$
\begin{aligned}
& \bar{v}=\text { reference wind speed in } \mathrm{km} / \mathrm{h} \\
& C=\text { an atmospheric condition factor that depends on the atmospheric pressure } \\
& \text { which is primarily a function of elevation above the see and air temperature. } \\
& \text { A nominal value of } 0.00005 \text { is used if } \bar{v} \text { is given in } \mathrm{km} / \mathrm{h}
\end{aligned}
$$

The reference wind speed was determined by extreme value analysis of metcorological observations from 100 locations, during a period of 10 to 22 years. The annual maximum hourly wind speed was analyzed using Gumbel's extreme value method 
to calculate the hourly wind speed with a retum period of 10,30 and 100 years. From this data the hourly wind speed for an additional 500 locations has been estimated and the corresponding reference velocity pressures computed. These are listed in the Table Design Data for Selected Locations in Canada in Chapter 4 of the Supplement to the NBCC 1990, NRC (1990).

Wind load intensities on surfaces for design of cladding and structural members for deflection and vibration are based on reference velocity pressures which have retum period of 10 years and for the design of structural members for strength. 30 years. and for the design of structural members for strength for post-disaster buildings, 10() years.

\subsubsection{Exposure Factor}

The exposure factor reflects the changes in wind speed with respect to height (velocity profile) and is a function of the surrounding terrain and topography over which the wind crosses and the profile develops. Modifications to these profiles may be required to account for local speed increases (speed up) over hills and escarpments. Both the simplified and detailed procedure for calculating of exposure factor, as presented in the NBCC 1990, NRC (1990) have been incorporated into the program LDFSSBC.

\section{a) Simple Procedure}

The exposure factor (wind speed profile) simply expressed as a US power of height, Equation 2.8 , is representative of the wind speed profile in open terrain, where. " $h$ " is the hcight above ground in metres. 


$$
C_{e}=(h / 10)^{1 / 5} \geq 0.9
$$

\section{b) Detailed Procedure}

The detailed procedure explicitly recognizes that the mean wind speed profile varies with the roughness of the terrain over which the wind has been blowing before it reaches the building and classifies the calculation for exposure factor into one of the following three categories.

Exposure A: is suitable for open or standard exposure of open level terrain with only scattered buildings, trees or other obstructions.

$$
C_{e}=\left(\frac{Z}{10}\right)^{.20} \geq 1.0
$$

where, $Z=$ height above ground in metres

Exposure B: suburban and urban areas, wooded terrain or centres of large towns.

$$
c_{e}=0.5\left(\frac{Z}{12.7}\right)^{0.50} \geq 0.5
$$

Exposure C: centres of large cities with heavy concentrations of tall buildings (at least 50 percent of the buildings should exceed 4 storeys)

$$
c_{e}=0.4\left(\frac{z}{30}\right)^{0.72} \geq 0.4
$$

c) Speed-Up over Hills and Escarpments

Wind speed can be significantly amplified near the ground if the building is situated on a hill or on escarpment and this is reflected by an increase in the exposure factor, given by Equation (2.12).

$$
C_{e}^{*}(Z)=C_{e}(Z)\left(1+\Delta S_{\max }\left(1-\frac{\operatorname{Lx} t}{k L}\right) e^{\left(-\alpha^{2} \mathrm{z}\right)}\right)^{2}
$$


where,

$C_{e}(Z)=$ the exposure factor over flat terrain calculated from one of Equations (2.8), (2.9). (2.10), (2.11.)

$\Delta S_{\max }=$ relative speed-up factor expressed as a function of geometry of the hill, refer to Fig. 2.5

$\alpha=$ decay coefficient for the decrease in speed-up with height above ground

$k L=$ distance from the crest of the hill to the building

$L \quad=\quad$ length of the hill as shown in Fig. 2.5

\subsubsection{Dynamic Respome and Gust Efrect Factor}

The dynamic response and gust effect factor reflect the dynamic interaction of the wind and the structure (fluctuating forces induced by the motion of the structure through the wind; fluctuating forces induced by the wake of the structure) and increased forces due to random wind gusts acting for a short duration over all or part of the structure. Cor.sequently, the factor is defined as the ratio of the maximum effect of the loading to the mean effect of the loading. Both the simplified and detailed procedure for calculating of gust effect factor, as presented in the NBCC (1990), have been incorporated into the program LDFSSBC.

\section{a) Simple procedure}

The majority of structures (low-rise) and components are relatively rigid and the gust effect factor can be calculated using the simplified procedure. For extemal pressures 

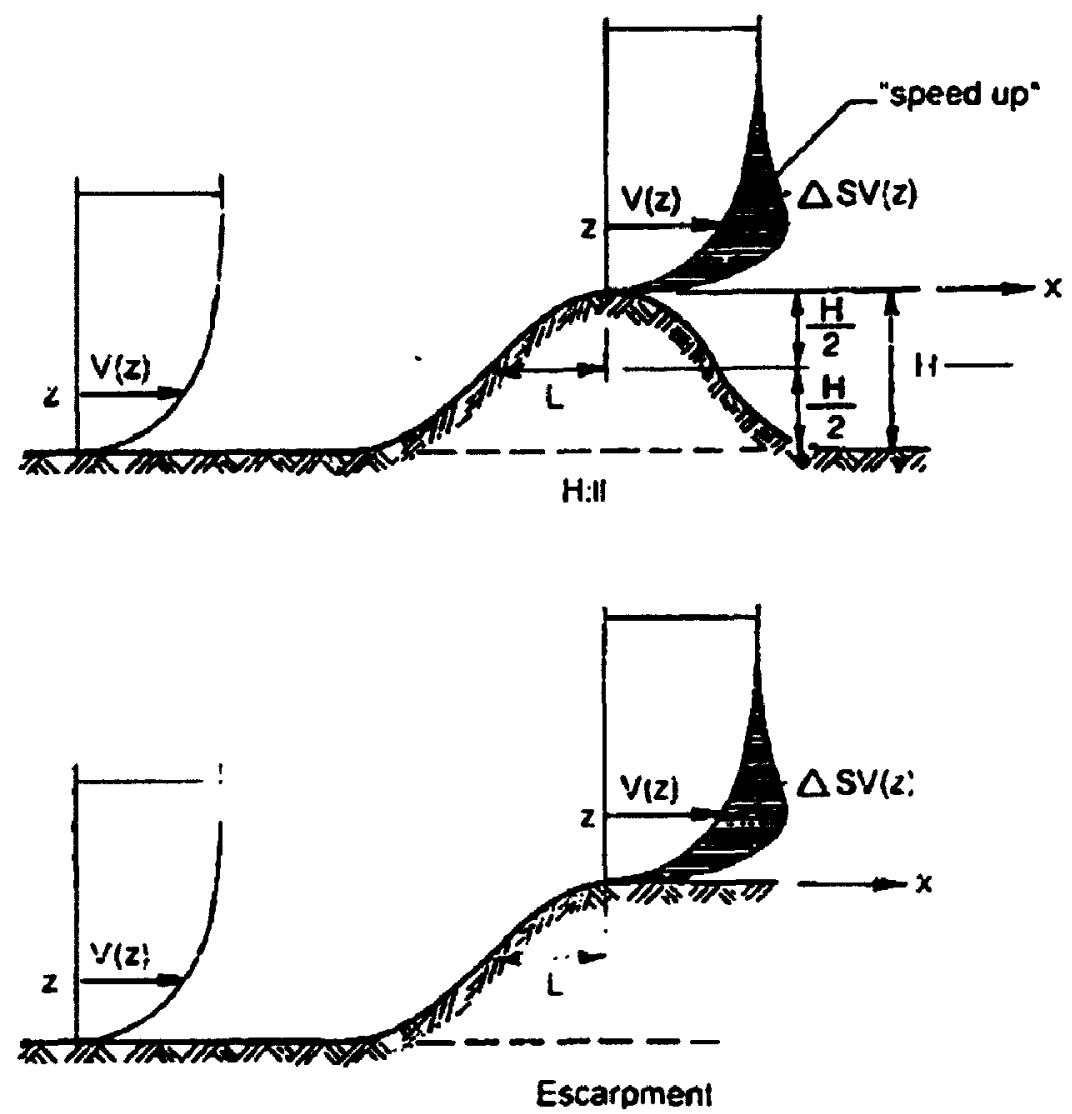

Figure B.2 Delinitions lor wind speed up over hilts and escaprients

Tabo B-1

\begin{tabular}{|c|c|c|c|c|}
\hline \multicolumn{5}{|c|}{ Paremeters tor Maximum Speed-Up Over Low Huls } \\
\hline \multirow[b]{2}{*}{ Holl Shape } & \multirow[b]{2}{*}{$\Delta \mathbf{S}_{r_{11}}{ }^{\prime:}$} & \multirow[b]{2}{*}{$\boldsymbol{\alpha}$} & \multicolumn{2}{|c|}{$\mathbf{k}$} \\
\hline & & & $x<0$ & $x>0$ \\
\hline $\begin{array}{l}\text { 2-dimensiors ribges } \\
\text { (or valioys with H negative) }\end{array}$ & $2.2 \mathrm{HL}$ & $\overline{3}$ & 1.5 & 1.5 \\
\hline 2-dimensionad escapronts & $1.3 \mathrm{Hi}$ & 2.5 & 1.5 & 4 \\
\hline 3-drrensiond axismmetrical hils & $1.6 \mathrm{HLL}$ & 4 & 1.5 & 1.5 \\
\hline Colmnn 1 & 2 & 3 & 4 & $\overline{5}$ \\
\hline
\end{tabular}

Note 10 Tcble 8.1:

$\therefore$ For $H L$ L $>0.5$, assume in the formutae that $H: L=0.5$ and subssitule $2 \mathrm{H}$ lor L ir. Equation (6)

Fig. 2.5 Speed-Up over Hills and Escarpments (reproduced from the Supplement to the NBCC 1990, NRC (1990)) 
calculated from Equation (2.5) the gust factor is 2.0 for the building as a whole and for the main structural members; and 2.5 for secondary members and cladding. For internal pressures, calculated from Equation (2.6.) the gust factor is 1.0 for huilding without large openings (Category 1 and 2), and 2.0 for buildings with large or significant openings (Category 3) or for post-disaster buildings.

\section{b) Detailed Procedure}

The detailed procedure explicitly recognizes the dynamic interaction between the wind and the building and applies to slender, relatively light weight, low frequency, lightly damped structures as specified in Clause 4.1.8.2. of the NBCC 1990, NRC (1990). The gust factor calculation as outlined in Commentary B of the supplement is as follows. The general expression for the maximum or peak loading effect is represented by

$$
W_{p}=\mu+g_{p} \sigma
$$

where,

$$
\begin{aligned}
& \mu=\text { the mean loading effect } \\
& \sigma=\text { the "root-mean-square" loading effect } \\
& \boldsymbol{g}_{p}=\text { a statistical peak factor for the loading effect }
\end{aligned}
$$

The dynamic response and gust factor is equal to the ratio of the peak loading to the mean loading and is expressed as

$$
C_{B}=1+g_{P}\left(\frac{\sigma}{\mu}\right)
$$

The value for (sigma/mu), given in Equation (2.15) is a function of the wind speed at the 
top of the building, and the building geometry and dynamic characteristics

$$
\frac{\sigma}{\mu}=\sqrt{\frac{K}{C_{e H}}\left(B+\frac{s F}{\beta}\right)}
$$

where,

$K=a$ factor related to the surface roughness coefficient of terrain, 0.08 for Exposure A, 0.10 for Exposure B, 0.14 for Exposure C.

$C_{\text {ett }}=$ exposure factor at the top of the building and is calculated from the appropriate equations given is section 2.4 .3

$B=$ background turbulence factor given by Equation (2.16) and expressed as a function of W/H

$$
B=\frac{4}{3} \int_{0}^{\frac{914}{17}}\left(\frac{1}{1+\frac{x H}{457}}\right)\left(\frac{1}{1+\frac{x W}{122}}\right)\left(\frac{x}{\left(1+x^{2}\right)^{4 / 3}}\right) d x
$$

$H=$ height of windward face of the building, for the program LDFSSBC this is taken as total height of the building

$W=$ width of windward face of the building

$s \quad=\quad$ size reduction factor, given by Equation (2.17) and expressed as a function of W/H and reduced frequency

$$
s=\frac{\pi}{3}\left(\frac{1}{1+\frac{8 n_{0} H}{3 V_{H}}}\right)\left(\frac{1}{1+\frac{10 n_{0 w}}{V_{H}}}\right)
$$

$n_{0}=$ natural frequency of vibration, $\mathrm{Hz}$

$V_{H}=\quad$ mean wind speed (mis) at the top of structure

$F=$ gust energy ratio at the natural frequency of the structure, given by Equation 
(2.18) and expressed as a function of wave number

$$
F=\frac{x_{0}^{2}}{\left(1+x_{0}^{2}\right)^{1 / 3}}
$$

where,

$$
x_{0}=\left(1220 \frac{n_{0}}{V_{H}}\right)
$$

$\beta=$ critical damping ratio. Values of 0.01 and 0.02 ane commonly used in the design of building ith steel frames and concrete frames, respectively.

The peak factor for the loading effect, given by Equation (2.20) is a function of average fluctuation rate and is expressed as,

$$
g_{p}=\sqrt{2 \log _{e} v T}+\frac{0.577}{\sqrt{2 \log _{e} v T}}
$$

where, $T=3600$ s.

The average fluctuation rate is computed from,

$$
v=n_{0} \sqrt{\frac{s F}{s F+\beta B}}
$$

The dynamic effects of vortex shedding, generally applicable for slender free standing cylindrical structures such as chimneys or observation towers and to some high-rise building, are not currently included in the program L.DFSSBC. 


\subsubsection{External Pressure Coeficient}

The external pressure coefficients are defined as non-dimensional ratios of windinduced pressures on a building to the dynamic pressure of the wind speed at the reference height. Generally, these coefficients were determined from wind tunnel experiments on small-scale models. Some measurements on full-scale buildings have been incorporated directly. The coefficients are given in series of figures in Commentary B of the supplement for two categories of buildings, low-rise and high-rise.

Low-rise buildings are defined as buildings with widths greater than twice their heights that have a reference height less than $10 \mathrm{~m}$. In the absence of more appropriate data these limits may be extended to buildings with $\mathrm{H} / \mathrm{W}<1$ and a reference height less than $20 \mathrm{~m}$. Buildings with geometry beyond these limits are classified as high-rise. The extemal pressure coefficients for low-rise buildings are given in the supplement as the product $\mathrm{CpCg}$ for primary structural actions (Figure B-7) and for cladding and secondary members in Figures B-8, B-9 and B-10. Recognition of end zones and areas of local maxima on roofs and the determination of the corresponding $\mathrm{CpCg}$ value have not yet been incorporated into the program. The external pressure coefficients for high-rise buildings are given dinectly $(\mathrm{Cp})$ in the supplement for the structure in the direction of the wind in Figure B-11; and for end walls and local suction maxima on the roof in Figure B-12. The latter has not yet been incorporated into the program.

\subsubsection{Internal Pressure Coeficient}

The internal pressure coefficient represents the effect which is produced by wind 
on air pressure inside the building. In some cases, the internal pressure contributes to the total pressure or suction on structural members or on cladding and is important for a proper estimate of the design load intensity acting on these members. Buildings are classified into one of three categories depending on the distribution and size of leakage paths and openings which vent the internal air space to the external wind. A guideline description for categorizing the building and the corresponding range of internal pressure coefficients and gust factors for each category follows.

Category 1 - Includes buildings without large or significant openings, but having small uniformly distributed openings. Most high-rise buildings that ane nominally sealed and ventilated mechanically are included in this category. For these buildings, $C_{p i}$ is taken as zero.

$$
C_{p i}=0.0 \text { to }-0.3 ; C_{g}=1.0
$$

Category 2 - Most low-rise buildings fall into this category, provided, that all elements are designed to be fully wind resistant. This category includes buildings in which significa.st openings can be closed in storms and where the background leakage may not be uniformly distributed.

$$
C_{p i}=0.7 \text { to }-0.7 ; C_{8}=1.0
$$

Category 3 - Includes post-disaster buildings and buildings with large or significant openings through which the gusts are transmitted to the interior.

$$
C_{p i}=0.7 \text { to }-0.7 ; C_{8}=2.0
$$

If the classification of the building or the design value of an internal pressure coefficient 
is unclear, the supplement suggests the use of the following values given in Fig. B-12.

$$
\begin{array}{ll}
C_{p t}=+0.7 & \text { if openings are mainly in windward wall } \\
C_{p t}=-0.5 & \text { if openings are mainly in leeward wall } \\
C_{p t}=-0.7 & \text { if openings are mainly in walls parallel to wind direction } \\
C_{p t}=-0.3 & \text { if openings are uniformly distributed in all } 4 \text { walls }
\end{array}
$$

\subsection{Attributing Loads and Mesh Generation Within any Given Surface}

Loads that are attributed to surfaces of a building can be classified into two groups. The first group includes dead loads and live loads due to use and occupancy. where the load intensity is constant in magnitude and direction (gravity loads) over a defined area. Graphic display of these distributions has little value, hence, a mesh of points is not generated and the data is simply stored in the appropriate file containing only the load intensity and the node coordinates defining the area on which the load acts.

The secord group includes snow loads and wind loads which have varying load distributions and are a function of climatic data and building geometry. For this group of loads a mesh of points is generated interactively along with the corresponding load intensities of tach point to describe the distributions. These can be displayed graphically. The location of the points and the load intensities are stred separately. This eliminates the need to regenerate the mesh should the loads be reevaluated for the same structure at another locale. The structure of the corresponding data files is described in detail in Appendix B - File Architecture. 


\subsubsection{Mesh Generation}

Analytical geometry was used to create an array of mesh points within the surface or area. To simplify the solution, the surface was transformed from general 3 dimensional space to a two dimensional plane, the mesh of points generated and then transformed back to the original three dimensional space. The grid lines are located such that the direction of one set of grid lines is parallel to the maximum slope of the surface. Slope being defined as the dihedral angle between the surface and horizontal projection plane XZ. For surfaces with zero slope the grid lines are set parallel to axis $\mathrm{x}$ and $\mathrm{z}$, for vertical walls the grid lines are set horizontally and vertically. The subroutine functions used to generate the mesh of points, part of the GEOMETRIC-MODELLER module, ane described in order as follows.

create_data_nodes3D()

The array of 3D coordinates for all nodes of a given surface are retrieved from the corresponding surface data file.

compute_plane_EQO

The HOOPS routine Compute_Polygon_Plane() is then executed to compute the equation of plane from array of node coordinates. A plane in three dimensional spact is defined by three non-collinear points. A minimum of four points is necessary to determine all the coefficients for the equation describing that plane (the fourth point can be identical 
with the first one).

compute_unit_vector()

The HOOPS routines Compute_Polygon_Normal() and Compute_Normalized_Vector() is then executed to determine the components of unit vector normal to the plane.

select_plane_for_transformation()

The 3D plane including all nodes is then transformed to one of the principal projection planes horizontal, profile or frontal according to the components of the normalized unit vector. The horizontal projection plane $\mathrm{XZ}$ was used for all slopes other then 90 degrees. For vertical surfaces, if the $x$ component of unit vector was greater than $z$, then $Y X$ projection plane was used, otherwise the projection was made onto XY plane.

transform_nodes3D_to_nodes2D()

The coordinates of all nodes of the surface are then transformed by perpendicular projection to the selected principal projection plane. From this stage on, all computations ane done with respect to the $2 \mathrm{D}$ plane.

compute_MAINLINE_EQ_paralled_to_one_axis 0

MAINLINE is defined as the projection of a line, which is horizontal within original 3D plane (an array of points with constant $y$ coordinates), to the selected projection plane. This routine is executed if the slope of the original plane is equal to 0.0 or 90.0 degrees 
and the MAINLINE is selected as line parallel to axis $X$ in case $X Z$ and $X Y$ principal projection plane or parallel to axis $\mathbf{z}$ in case of $\mathrm{ZY}$ principal projection plane.

compute_MAINLINE_EQ_of_plane_at_point()

For case where the slope of plane is not equal zero, the equation of MAINLINE is computed for the first node of the plane.

\section{line_paralled_through_point()}

The equation of line $m$, parallel to MAINLINE at the reference point, is computed. The coordinates of the reference point $\mathbf{R}$ are selected such that the point lies in the quadrant defined by the planes unit vector components, and is far enough from the tero point to be not part of surface as illustrated in Figure 2.6.

\section{find_point_with_minimum_distance_to_MAINLINE()}

All nodes of the surface are check to determine the surface node closes to line $m$ (minimum distance) and is designed as point $P$, as shown in Figure 2.6. Executing the function line_parallel_through_point(0) at point $\mathbf{P}$ gives the equation of the reference line marked $\mathbf{r}$.

\section{find_points_A_BO}

By inspecting the coordinates of all nodes, the limit points $A$ and $B$ of mesh in one direction are determined. The value representing the range of mesh in the direction 
marked rangeXX is given by the function two_points_distance2D $(A, B)$.

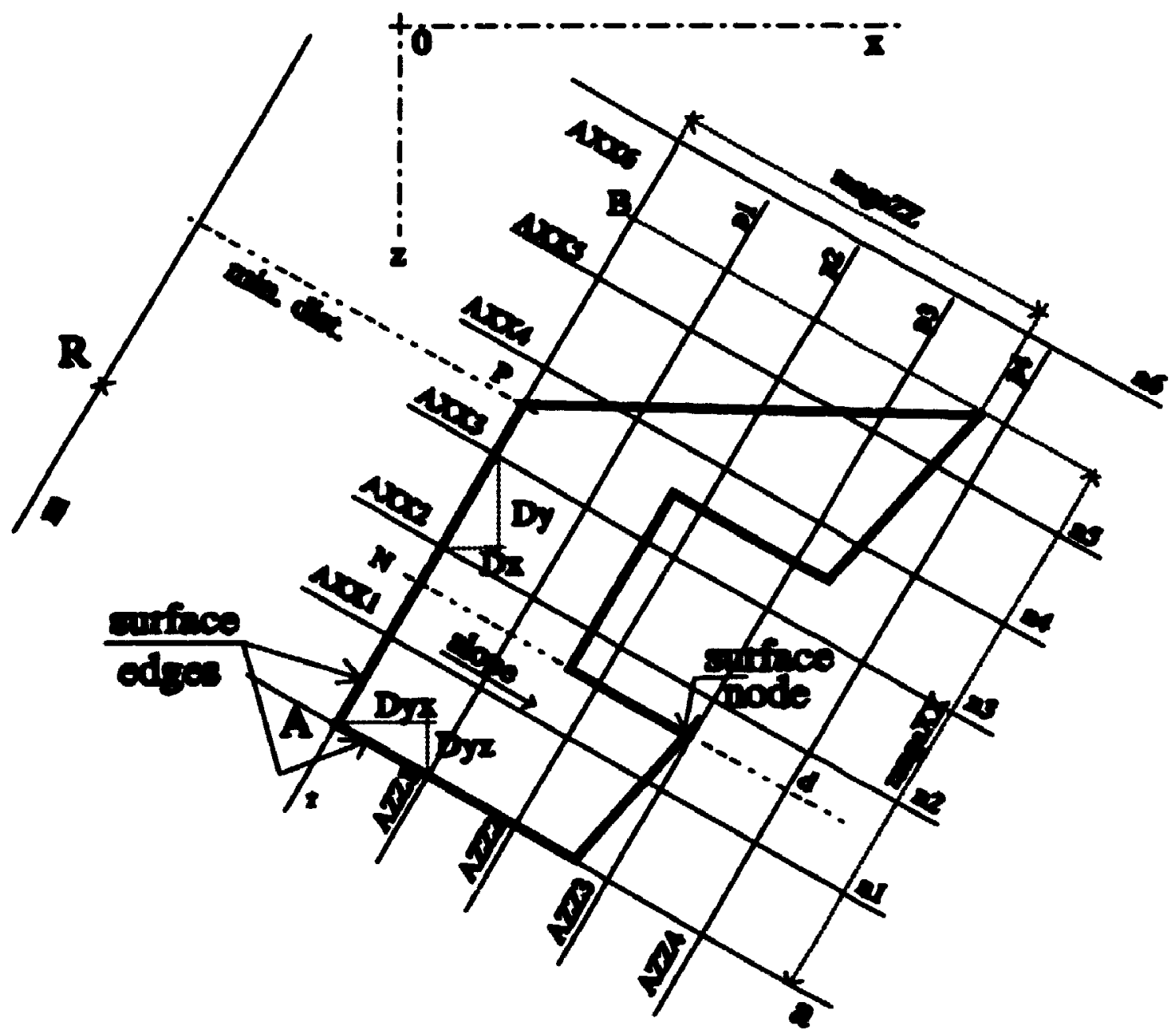

Fig. 2.6 Geometry for Mesh of Points

compute_range_zzo

The range in perpendicular direction, marked rangeZZ, is determined by finding the maximum distance of any node to the refenence line $r$. 
compute_steps_in_mesh()

The differential steps Dx. Dy. Dyx. Dyz in both directions of the mesh are computed from the slope of 3D plane, the selected projection plane. the normalized unit vector of the plane, the equation of plane and from the required mesh spacing.

create_AXX_array() and create_AZZ_array()

An array of coordinates for points along reference line $\mathbf{A} \mathbf{A X X 1 . . .} \mathbf{A X X n}$, over the distance 'rangeXX', is created at a spacing determined by the differential skeps Dy and Dx.

Along line a, perpendicular to reference line $r$ and starting at point $A$, an array of points AZZ1... AZZn over the distance 'rangeZZ', is created at spacing determined by the differential steps.

identify_nodes_ids_EE()

The surface nodes (defined by the intersection of two edges, EE points) are identified and coded by the column and row numbers of the generated mesh. For each node, a line $d$, perpendicular to line $\mathbf{r}$, is created. Point $\mathbf{N}$, shown in Figure 2.6., is the intersection of these two lines. The distance NA and from the node to line $r$ are divided by the corresponding differential steps giving the points coded location on the mesh.

identify_XE_points()

Grid lines, ni, perpendicular to $\mathrm{r}$ are created through each point in the array AXXi. The 
interswction of these lines with each edge of the surface gives a series of XE points that are identified and coded according to their location within the mesh.

\section{identify_EZ_points()}

The method to identify the points with an EZ code is the same as the described for $\mathbf{X E}$ points, except that the grid lines pi are parallel to line $r$ and pass through the AZZi points.

identify_XZ_points ()

"XY" coded points all lie within the surface on the intersection of the pi and ni grid lines. To establish whether or not a point lies with the surface, the number of intersections of the pi line with surface edges for a given mesh point is determined. If the number of intersection is odd then the point lies within the surface, otherwise, it lies outside. Those that lie inside are identified and coded appropriately.

make_proper_order_of_2D_points()

Once all the points have been generated. they are ordered by this function starting from row 1, column 1 to the last column number, to the last row umber.

\section{transform_point2D_to_point_3D()}

Using the equation of the original plane, the set of 2 dimensional mesh point coordinates are then transformed to the original 3-D plane. The identification code and three 
coordinates of each point are then saved in a file as described in Appendix B - File Architecture.

\subsubsection{Identification Code for Points defining the Mesh}

The mesh of points for required surface is formed by intersection of two perpendicular grids in certain distance specified in file "mesh_spacing" or optionally hy intersection of one mesh grid with the surface edge or nodes of the surface located between grid lines. An identification code for the mesh of points generated is nequired to define the relationship of neighbouring points (essential for 3D graphic display of load intensity polygons) and for subsequent work on attributing loads to structural members within a given surface.

An example mesh, points and the corresponding identification code is given in Figure 2.7.

The first four digits of the code represent column number of the mesh in one direction and the last four digits represent the row number, perpendicular to the previous direction. The same number is assigned to the point whether it is located exactly on the grid or it is located between this grid line and the next one. The fifth and sixth characters

f the code are used to distinguish between these two cases.

The fifth character is either a "X" or a "E", where.

"X"indicates that the point is located on grid line ni (with a constant $x$ coordinate)

but, only if this grid line is not coincident with an edge of a surface or area; and

" $E^{\prime \prime}$ indicates that the point is either located at the intersection of two edges of 
surfaces or areas, or the point is located on grid line ni that is coincident with an edge.

The sixth character is either a " $Z$ " or a " $E$ ", where,

" $\mathbf{Z}$ " indicates that the point is located on grid line pi (with a constant $\mathbf{z}$ coordinate) but only, if this grid line is not coincident with an edge of a surface or area; and " $E^{n}$ indicates that the point is either located at the intersection of two edges of surfaces or areas, or the point is located on grid line pi that is coincident with an edge. 


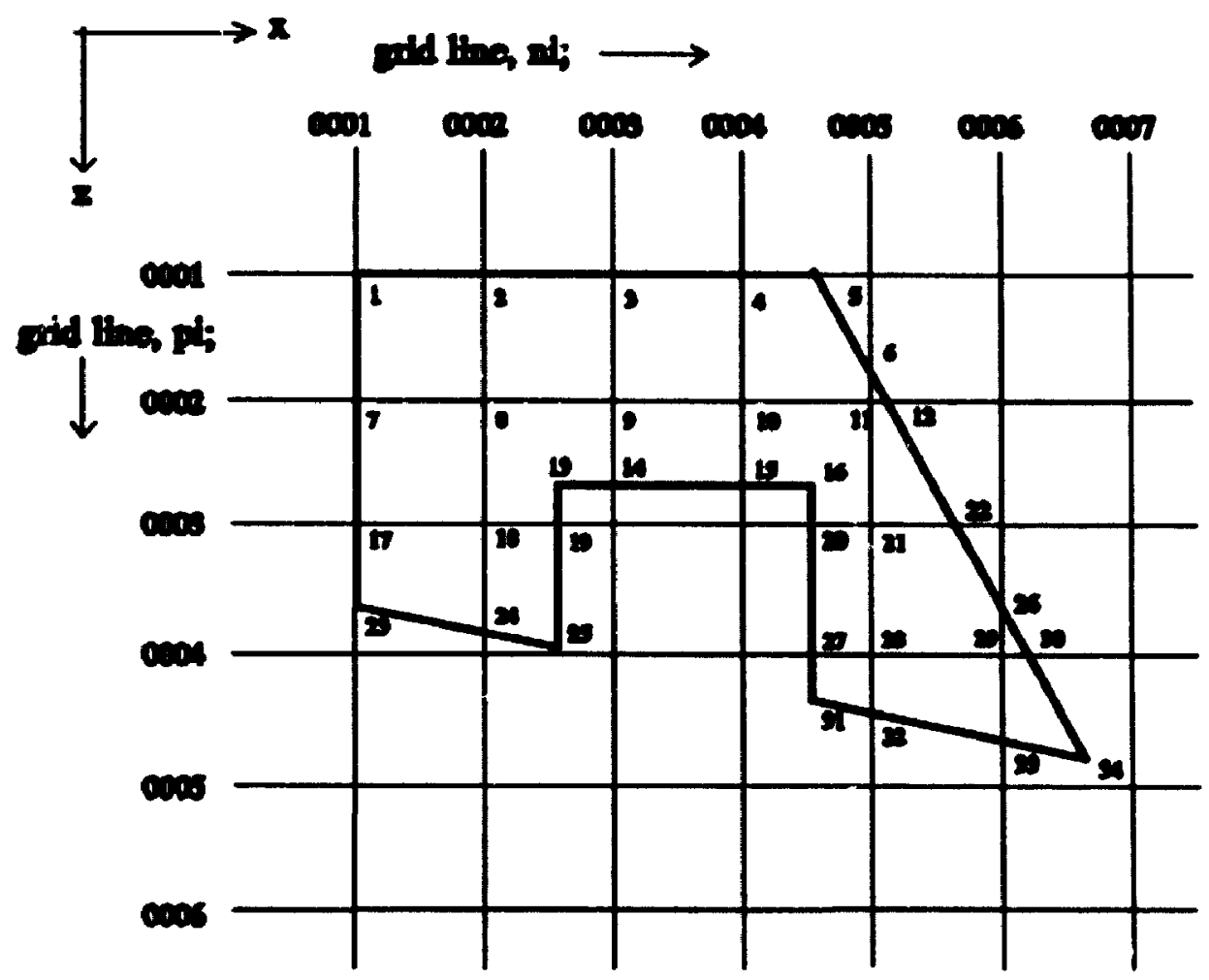

Fig. 2.7 Identification Code for Points of Mesh

Point ID Code

No.

1 - 0001EE0001

2 - 0002XE0001

3 - 0003XE0001

4 - 0004XE0001

5 - 0004EE0001

6 - 0005XE0001

7 - 0001EZ0002

8 - $0002 \times Z 0002$

9 - $0003 \times Z 4002$

10 - $0004 \times Z 0002$

11 - $0005 \times Z 0002$

12 - 0005EZ0002
Point ID Code

No.

13 - O002EE0002

14 - 0003XE0002

15 - 0004XE0002

16 - 0004EE0002

17 - 0001EZOO03

18 - $0002 \times Z 0003$

19 - OCOO2EZOOOO3

20 - 0004EZOOOO3

21 - 0005XZ0003

22 - OOO5EZOO03

23 - OOO1EE0003

24. O002XE0003
Point ID Code No.

25 - OOO2EEOCO3

26 - OOO6XE(O003

27 - OOOAEZOOO4

28 - O0005XZ10004

29 - 0006XZ0004

30 - O006EZOOO4

31 - ODO4EEOOO4

32 - OOO5XEOOOO4

33 - OCO6XXE(0)(1)4

34 - (O006EEOON)4 


\section{Chapter 3}

\section{Program Description}

\subsection{General Description of the Main Menu and Screen Configuration}

The program LDFSSBC, "Load Determination For Structural Steel Buildings in Canada", has been designed to model the load determination phase of the design process. The program provides the capacity for the structural engineer to input the geographic location of the structure and the corresponding clumatic data (including local characteristics that effect snow and winds loads); to define the surfaces (floors, walls and roofs) of a building; to define the composition of the surfaces for the purpose of estimating dead loads; to define the use and occupancy loads for any area; to determine the snow and wind loads acting on the structure according to the NBCC 1990, NRC (1990); and to attribute those loads to the appropriate surfaces. All relevant data files, library functions, geometric algorithms, user interface screens and graphic images have been developed. Structured data files containing the geographic location, climatic data and the corresponding load data are provided for further computations. Graphic representations of the structure and loads are easily obtained from postscript files created by the engineer using the program.

The program was written in " $\mathrm{C}$ " programming language in conjunction with Hoops graphic system to ensure flexibility and ease of portability to other environments. The 
program has been developed on SPARC station running Sun OS 4.0.3.

Once all the requirements on the hardware, operating system and environmental variables, as described in Appendix A, are set up. then the program is ready to be used. To execute the program type LDFSSBC ("Load Determination For Structural Steel Buildings in Canada") on the keyboard, and enter RETURN. The first window with the title and main menu buttons will appear on the screen as shown in Fig. 3.1. The main menu buttons are continuously displayed on the screen during all operations of this program. All the buttons are selectable from the main frame window. On colour monitors

\begin{tabular}{|c|c|c|c|c|}
\hline CLMATIC DATA & 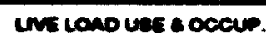 & WND LOAD & QEOMETRAC MODELLEA & OUIT PROQRMA \\
\hline DEAD LOAD & ENOW ICE \& RAN & EAATHOUAKE & PAINT OCAEEN & 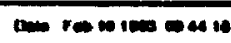 \\
\hline \multicolumn{5}{|c|}{$\begin{array}{l}\text { LOAD DETERMINATION FOR STRUCTURAL } \\
\text { STEEL BUILDINGS IN CANADA } \\
\text { VENEN 1. }\end{array}$} \\
\hline \multicolumn{5}{|c|}{ 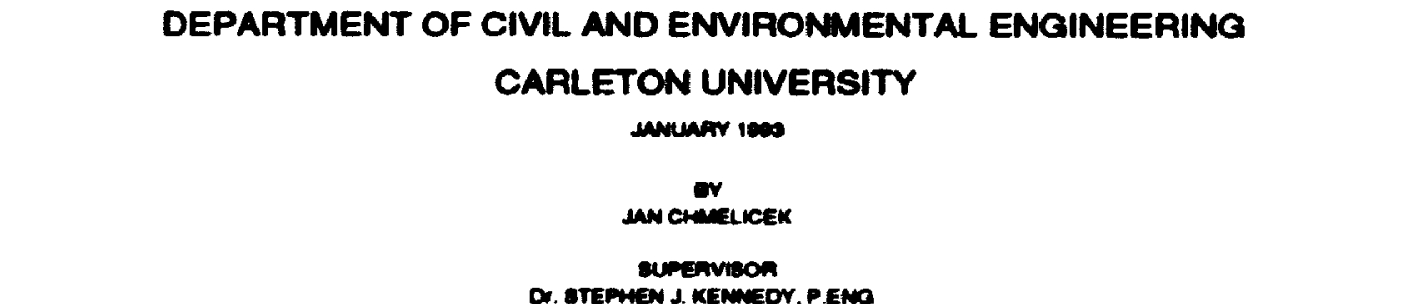 } \\
\hline
\end{tabular}

Fig. 3.1 Title Screen and Main Menu

these buttons have the light blue colour ("periwinkle") and are slightly shaded for black \& white monitors. This colour or pattem of shading represents selectable buttons for all 
windows, in the program -i.e. the appropriate action will be pe-formed if the button is activated. For the purpose of this thesis, the shaded pattern of the buttons was removed to make the text on the hardcopies readable. A brief description of the function of each main menu button follows.

\section{Climatic DATA}

The climatic data button is selected to define the geographic location of the building and the corresponding climatic data required for the determination of loads. Chapter 1 of the Supplement to the National Building Code of Canada 1990, NRC (1990) forms the data base.

\section{DEAD LOAD}

The dead load button is used to build structural sandwich systems for roofs, floors and walls, from libraries of masses and mass densities for different building materials for the purpose of determining the dead load of a building. A list of area names and load intensities can be created. Activating this button within the geometric modeller allows the engineer to attribute load intensities to specified areas.

\section{LIVE LOAD USE \& OCCUPANCY}

The live load use and occupancy button is used to establish a list of area names and load intensities (both uniformly distributed and concentrated loads) for the use and occupancy of the structure under consideration. Tables 4.1.6.A and 4.1.6.B from the 
NBCC 1990, NRC (1990) have been incorporated to form the basic live load use and occupancy load intensity data bases. Activating this button within the geometric modeller allows the engineer to attribute load intensities to specified areas.

\section{SNOW, ICE \& RAIN}

The snow, ice and rain button is used to calculate snow loads acting on surfaces defined as roofs. It is activated within the geometric modeller to set up the geometry of the roof and surrounding surfaces which might influence the snow load intensities; to generate the mesh for each surface to attach snow load library functions for Figure H-1 to H-6 of the NBCC Supplement, NRC (1990) to the appropriate surfacis; and activated from the main window to compute and display the snow loads for each surface. Working menus and instructions with specialty subwindows guide the engineer through the process.

\section{WIND LOAD}

The wind load button is used to calculate wind loads acting on surfaces defined as roofs and walls. Required geometry definitions are made by activating this button within the geometric modeller window, while the load intensities are calculated and displayed by activating this button from within the main window.

\section{EARTHQUAKE}

Not currently active. Activation of the earthquake button will compute the base shear of the structure about each principle axis and will attribute the storey shears 
appropriately. Overturning moments and centre of mass at eâ. : rel will be calculated. Distribution of the shears to the lateral load resisting elements within each stcrey level and the calculation of the torsional moments is considered to be part of the analysis module.

\section{GEOMETRIC MODELLER}

The geometric mudeller button is used to define the building surfaces and to attribute loads to them.

\section{PRINT SCREEN}

Print screen will provide the user with a hard copy of any portion of the screen display in the form of a postscript file.

\section{QUIT PROGRAM}

This button terminates the program session.

The screen is configured into 4 basic windows, as shown in Figure 3.2 , simplifying the appearance, making the program easier to learn and use. The largest window is generally reserved for a three dimensional graphic display of the structure or in the case of snow and wind loads for the load intensities acting on specified surfaces. The left window is used to display either three two dimensional views of the structure or load intensity graphs or additional data definitions required for determining loads or structural

geometry data. The last window contains menu commands, status and other relevant 
information that are specific to the main menu button selection.

\begin{tabular}{|c|c|}
\hline \multicolumn{2}{|r|}{ MAIN MENU } \\
\hline $\begin{array}{l}\text { - three } 2 D \\
\text { views of the } \\
\text { structure } \\
\text { - load intensity } \\
\text { graphs } \\
\text { - additional data } \\
\text { definitions for } \\
\text { determining loads } \\
\text { - structural geometry } \\
\text { data }\end{array}$ & 3-D graphic display \\
\hline & $\begin{array}{l}\text { - command menu specific to the main menu button } \\
\text { - current status or other relevant information }\end{array}$ \\
\hline
\end{tabular}

Fig. 3.2 Screen Configuration

The following sections describe the process of creating or editing a geometric model of a structure and the determination of loads acting or the surfaces.

\subsection{GEOMETRIC MODELLER - Display, Edit or Create Surfaces}

The program is capable of simultaneous creating or editing as many projects as the capacity of the data storage device allows. Each project is stored in separate subdirectory and switching between project is handled within GEOMETRIC MODELLER. Each time the program is started, the last edited or created project becomes the current active project. 
To display or edit the currently active project, or to create a new project select the GEOMETRIC MODELLER button. The curresponding window shown in Figure 3.3 will be displayed. The main command menu buttons of Geometric Modeller invoke following actions.

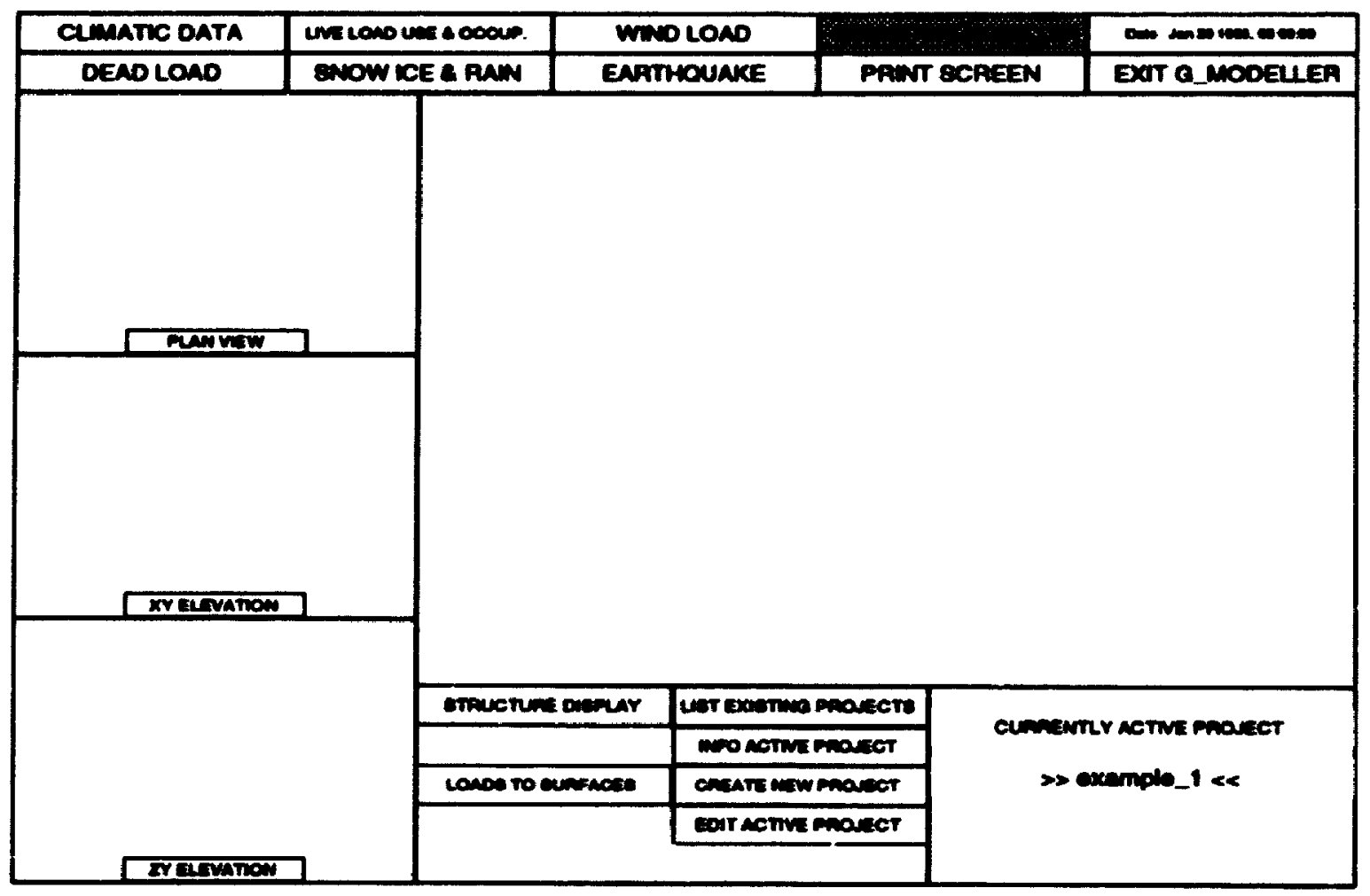

Fig. 3.3 Geometric Modeller - Main Window

\subsubsection{LIST EXISTING PROJECTS}

The selection of this button activates a display of a list of existing projects in the right portion of the command menu window as shown in Fig. 3.4. Any project can be selected and made active by mouse selection. Scroll devices allow the engineer to browse through the list of existing projects. 


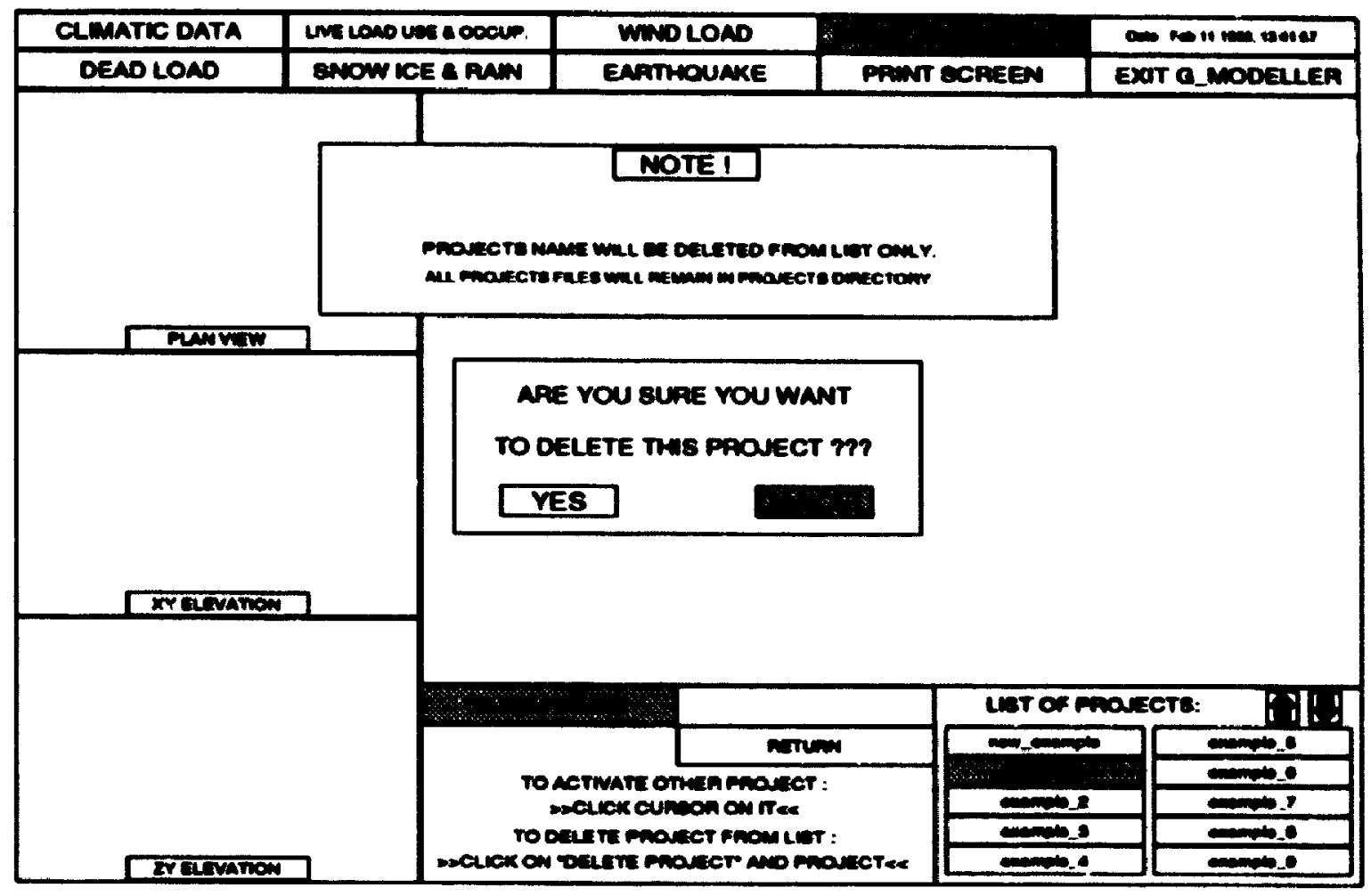

Fig. 3.4 Geometric Modeller - Activate Existing or Delete Project

\subsubsection{DELETE PROJECT}

Deletion of any project name from list is possible by activating the button DELETE PROJECT and selecting the project to be deleted. As shown in Fig. 3.4 . a window asking for confirmation of the action is displayed, to avoid accidental deistion. As a precaution only the name is erased from the project list only. The files are retained in the projects subdirectory and can only be deleted by using the appropriate operation system commands. After deletion, the first project name from the list becomes the 'currently active project'. 


\section{2. $\% .2$ RETURN}

Selection of the retum button retums the process one step back within the program.

\section{2 .2 INFO ACTIVE PROJECT}

By selecting this button the name of the currently active project is displayed in the bottom command menu window as shown in Fig. 3.3.

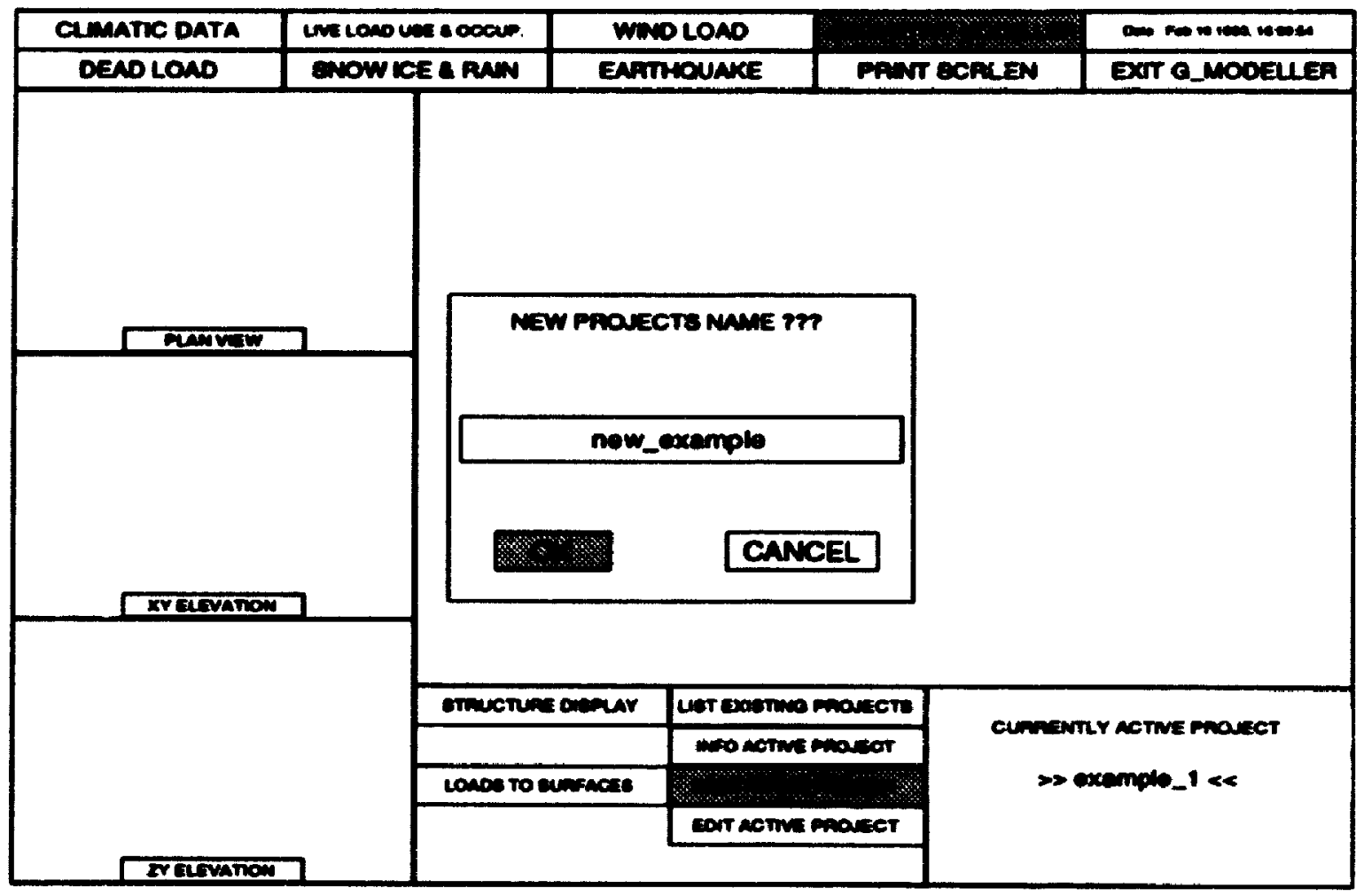

Fig. 3.5 Create New Project

\subsubsection{CREATE NEW PROJPCT}

Selection of this button, shown in Fig. 3.3 starts the process of creating a new project i.e. a geometric model of a building composed of a series of surfaces. First, the engineer inputs the name for the project as shown in Fig. 3.5. After confirmation that the 
name selected is OK, the programs checks if all characters of this name are permitted by system as a name for a subdirectory. All unacceptable characters ane substituted by an underscore '- character. The next window, shown in Fig. 3.6 , requires the enginuer to

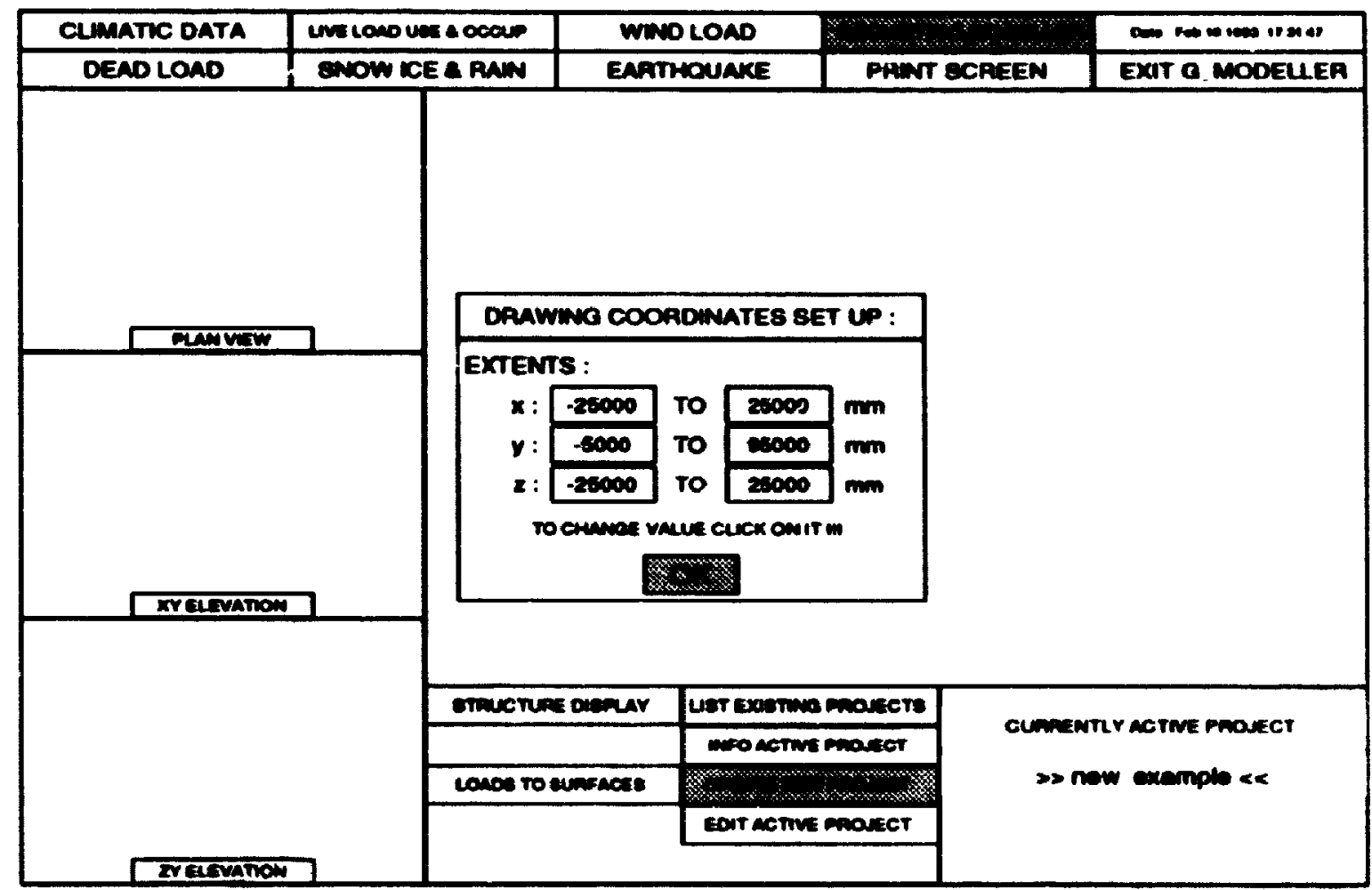

Fig. 3.6 Drawing Coordinate Set Up

confirm or to adjust the approximate range of coordinates that will be used to deseribe the struc 'ure. The values are adjusted by mouse selection and keyboard input. This provides the program with a definition of size so that the entire structure can be drawn within the 3D graphic display window during the first stage of the designing process (creation of new surfaces). Confirmation of the range of coordinates initiates the set up of a subdinuctory for the project and all subsubdirectories for snow and wind loads required by system. Subsequently, the button menu for creating new surface will be displayed and is shown in Fig. 3.7. 
If an existing structure is selected, made the currently active project, then the scale and the coordinates transform?tion are computed automatically.

\begin{tabular}{|c|c|c|}
\hline CAEATE FLOOR & SUAFACE ID ONOFF & \\
\hline CAEATE DOOF & NOOE DONOFF & 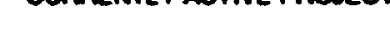 \\
\hline CAEATE WALS & EOUT MOOE COOOROMUTES & $\gg$ new_example << \\
\hline DELETE SUPFACE ONUUFF & COOADMUTES SETUP & \\
\hline SAVE CHWOES & CANCE-CAEATE MEW & \\
\hline
\end{tabular}

Fig. 3.7 Creatc New Surface Button Menu

\subsubsection{CREATE FLOOR}

The creation of a new floor surface is started by the selection of this button. The three basic ways of creating a floor system, node number and coordinate definition, duplication of existing surfaces, or by drawing the surface directly on the screen with the

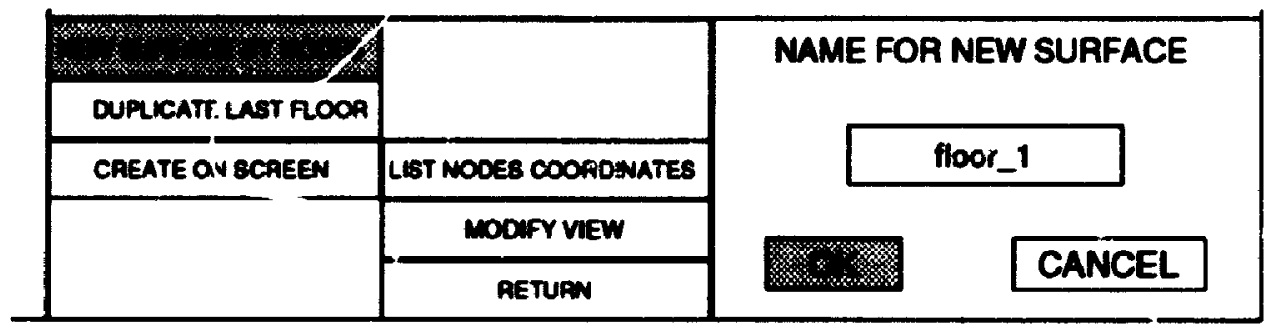

(a) Name Input

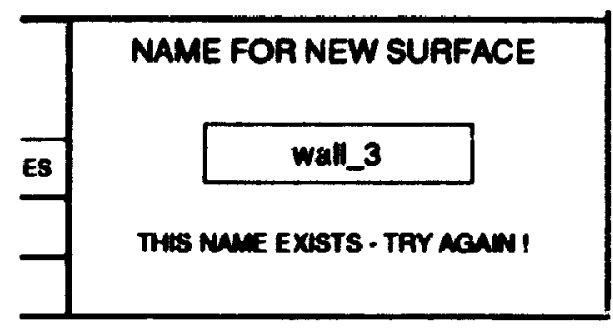

(b) Correction

Fig. 3.8 New Surface Definition

mouse make the system flexible and simple to use. Regardless of the method used, the 
engineer is fi:st prompted for a surface name. The program then checks for name duplication and if necessary will prompt for a new name. Refer to Fig. 3.8(a) and (b).

\subsection{NEW SURFACE BY NODES}

There are two ways of defining nodes as shown in Fig. 3.9. Either the value for each of three coordinates has to be inputted or an existing node ID is selected.

\begin{tabular}{|c|c|c|c|}
\hline 2 & & CAEATMU MODES FOR: & noot_1 \\
\hline \multicolumn{4}{|l|}{ DUPUCATE LAST ROOOR } \\
\hline \multirow[t]{3}{*}{ CREATE ON SCAEEN } & LLET MODES COORDINATES & eracose $D$ & CAMCEL \\
\hline & MODIFY VIEW & & \\
\hline & RETUFW & & \\
\hline
\end{tabular}

Fig. 3.9 Create New Surface By Nodes

\subsection{BY COORDINATES}

Keyboard input of $x, y, z$ coordinates of node in milimetres is required and the node ID is automatically generated. Editing of any coordinate within the window is possible by mouse selection and input of new coordinate values as shown in Fig. 3.10(a). After the confirmation of coordinates for any given node the application menu shown in Fig. 3.10(b) is displayed and the list of nodes ID belonging to the new surface are shown in the bottom portion of the window. To create another node within the surface, select the NEXT NODE: button and the process will repeat itself, starting with the menu shown in Fig. 3.9. Selection of the SURFACE FINISHED button terminates the definition of surface, and the building (including the newly defined surface) is displayed in four typical views as shown in Fig. 3.11. 


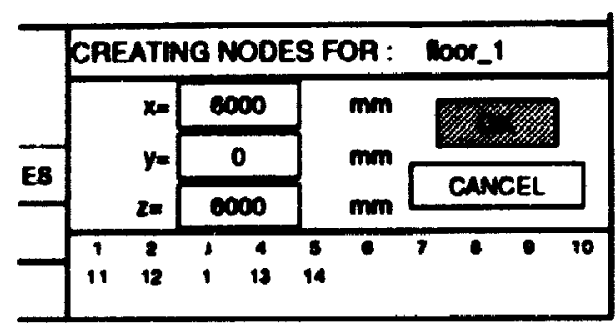

(a) $X, Y, Z$ coordinates

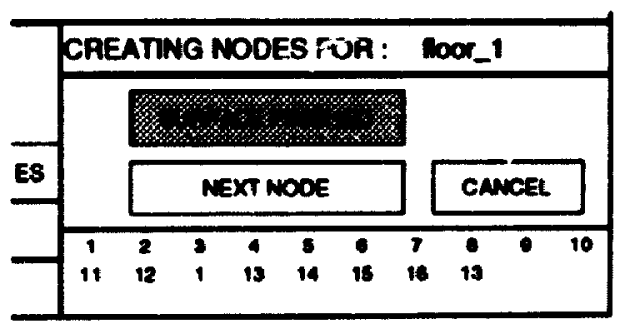

(b) Application Menu

Fig. 3.10 Surface Definition By Coordinates

As shown by the active application rnenu in Fig. 3.11 , additional surface can be created (if required), or edited or saved if the definition of the structure is complete.

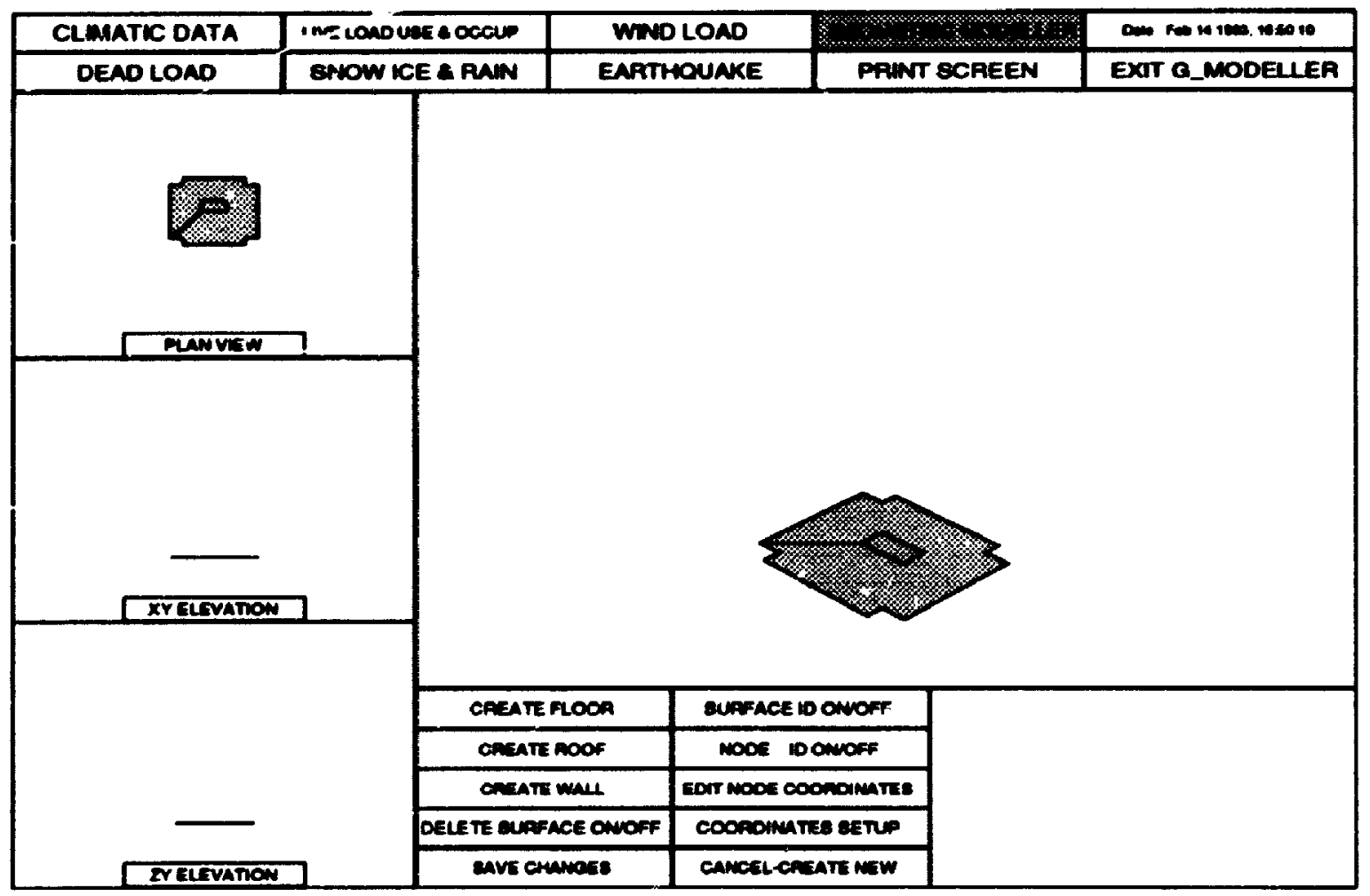

Fig. 3.11 Finished Surface Displayed

\subsection{BY NODE ID}

Selection of this button allows an engineer to add an existing node to a new surface 
avoiding duplication of nodes. The corresponding application menu, shown in Fig. 3.12 . indicates that there are three ways of selecting existing nodes, by keyboard, from the screen or from a list of nodes.

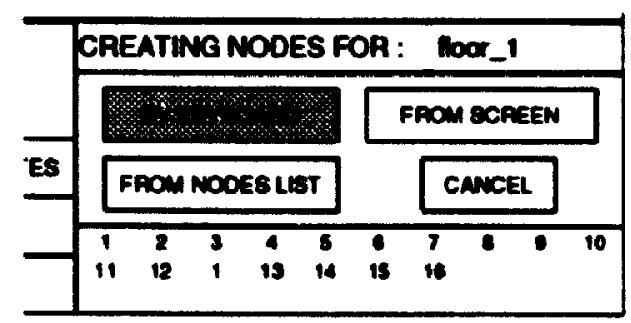

(a) By Keyboard Entry

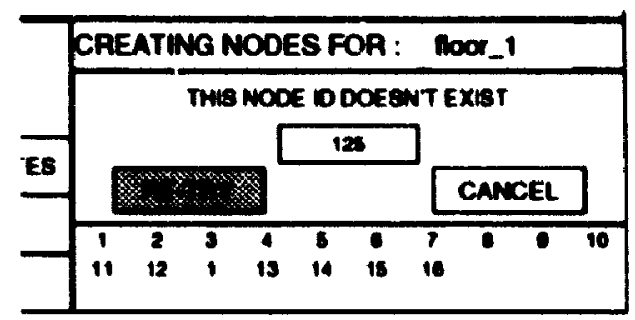

(b) Error Message

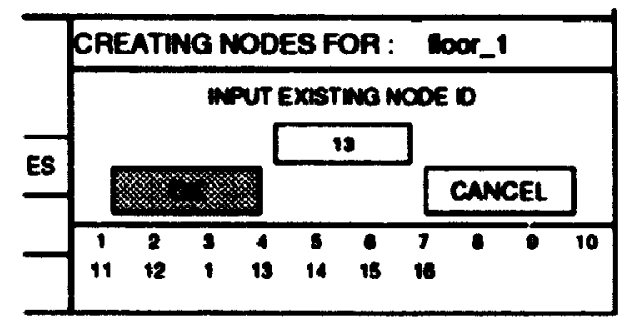

(c) Verification

Fig. 3.12 Input Node ID

Keyboard input of existing node ID numbers can be made by activating the appropriate button shown in Fig. 3.12(a). The input values are compared with list of existing nodes and discrepancies are reported to the engineer within window as indicated by the error message shown in Fig. 3.12(b). Successful node ID number inputs are accepted and verification is called for, retum to Fig. 3.12(c).

Selection of nodes from the screen is very fast and most useful for creating walls (generally walls are created atter the floor and roof surfaces). The existing nodes are 
represented in 3 dimensional display as small squares, as shown in Fig. 3.13, and are selected with the mouse. The selected node ID number will appear in the lower right hand window. If a mistake has been made, simply delete the series of nodes that define the

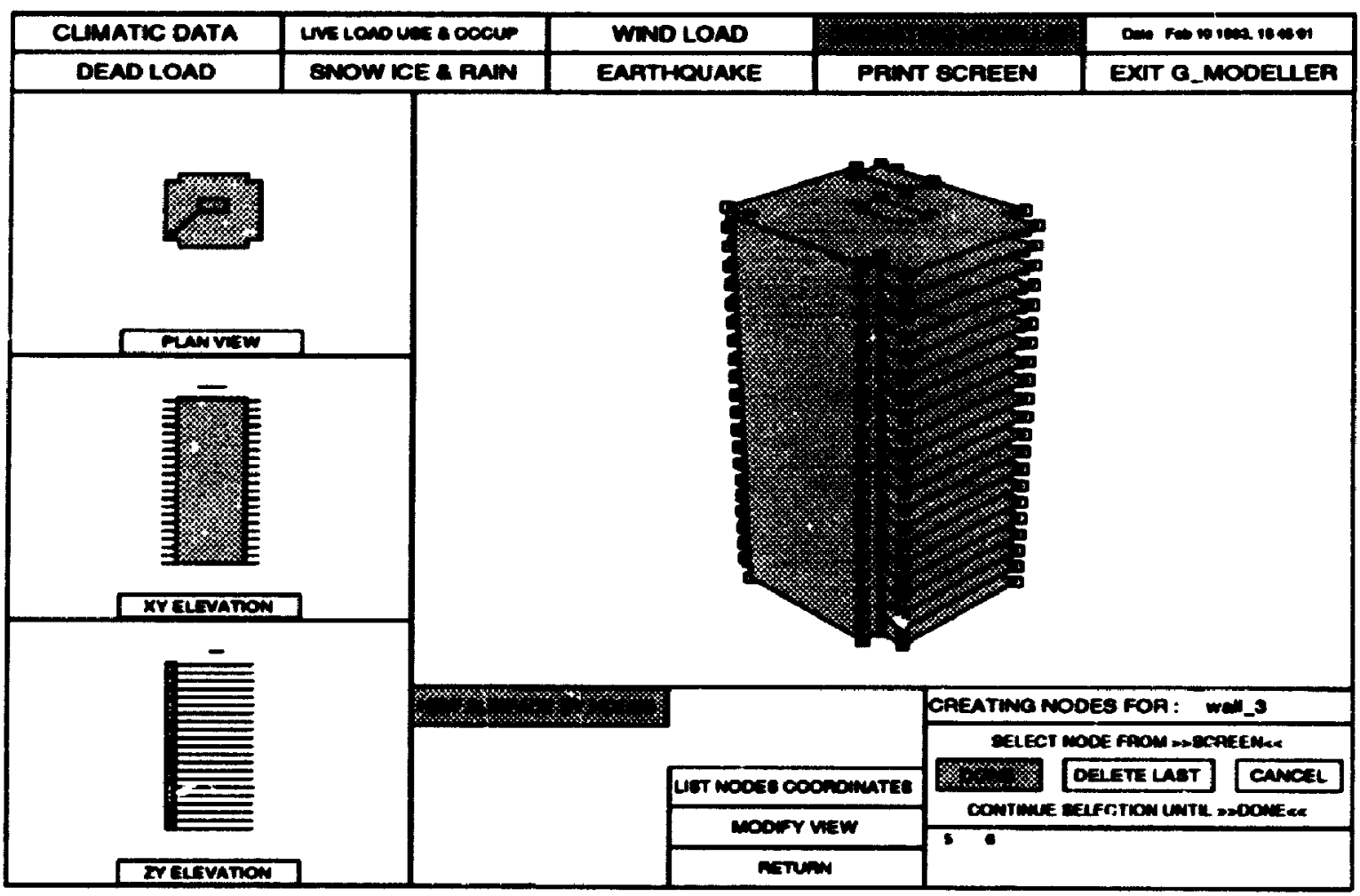

Fig. 3.13 Select Node ID from Screen

surface back to the incorrect entry with the DELETE LAST button. To end the selection from the screen select DONE and menu will return to the application menu for surface definition shown in Fig. 3.10(b). At this point the surface definition may be complete and the process terminated by activating SURFACE FINISHED or additional nodes may be defined by activating NEXT NODE.

Creating a surface from a list of nodes function like the selection of nodes from the screen except. the nodes are selected from a list shown in the left hand wirdow of 
Fig. 3.14.

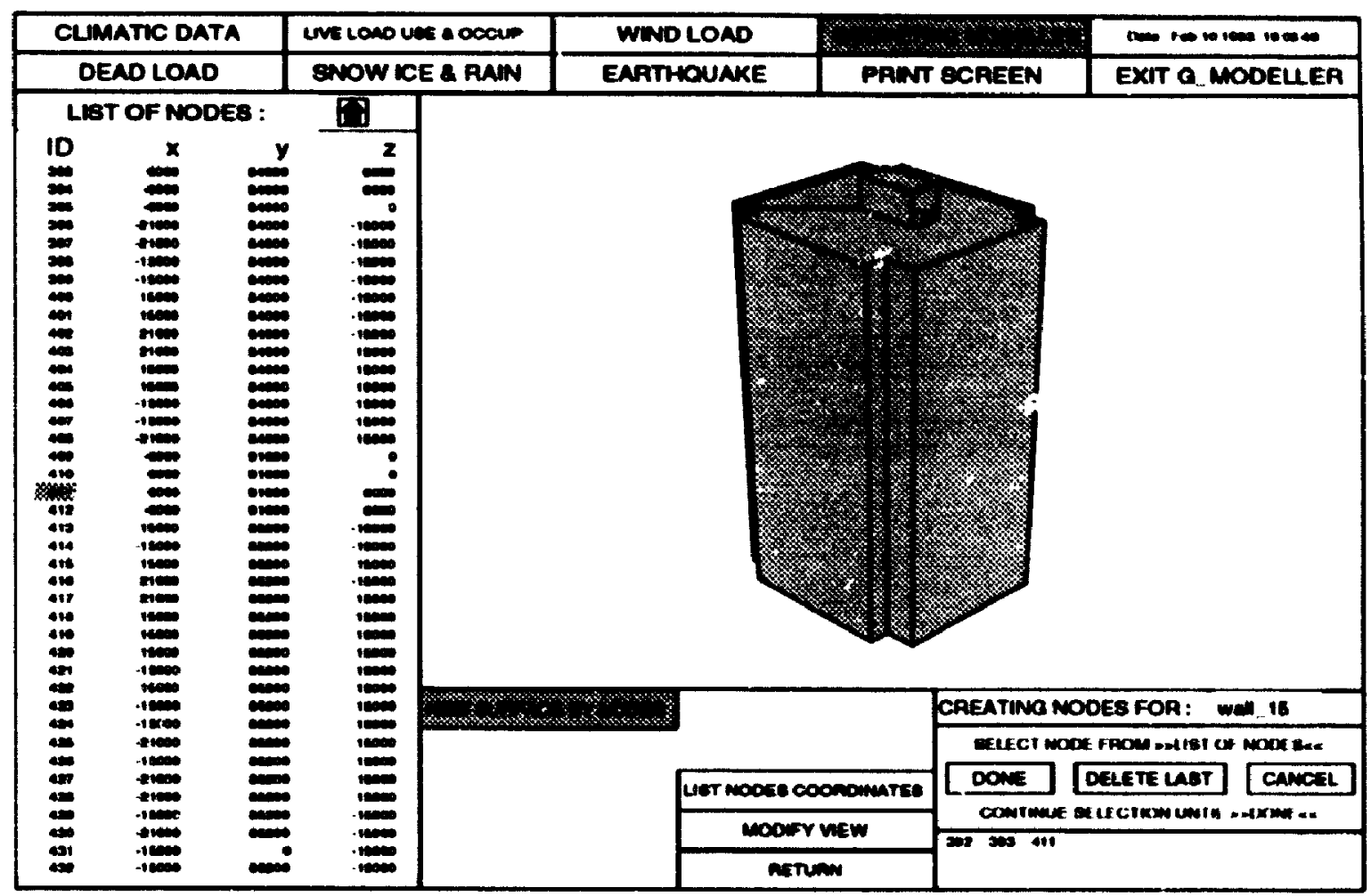

Fig. 3.14 Select Node ID from List of Nodes

\subsection{DUPLICATE LAST FLOOR}

Activating this button gives the option to create floors or roofs by duplicating the shape of the last floor created. Simply input the new surface name as requined, refer to Fig. 3.8, and input the appropriate elevation of the new surface as shown in Fig. 3.15. Only horizontal surfaces can be created by activating button.

\subsection{CREATE ON SCREEN}

Horizontal surfaces can be created on the screen by mouse scrolling and button selection. Activating the CREATE ON SCREEN button will prompt the engineer to input 


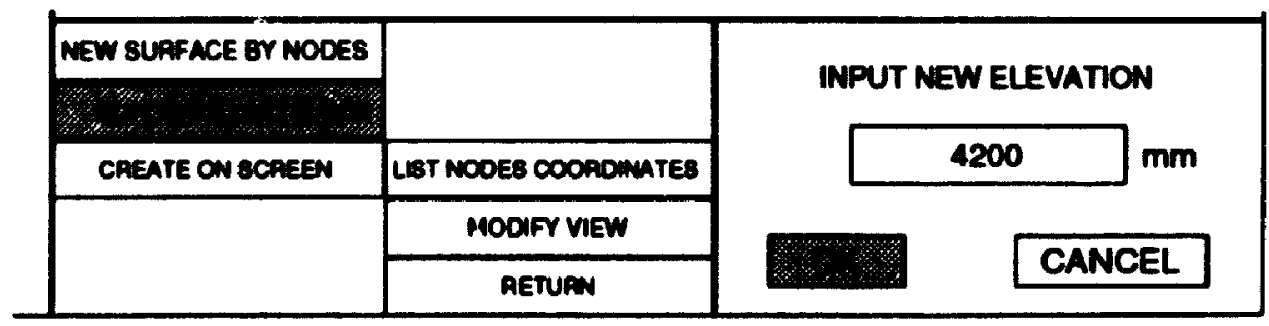

Fig. 3.15 Create Surface by Duplicating the Last Floor

the name of the new surface and the corresponding elevation as described previously, and subsequently, display the information and application buttons shown in the bottom right hand window shown in Fig. 3.16. Activating the left hand button of the mouse within the main window will give the ' $x$ ' and ' $z$ ' coordinates of the current cursor position. These

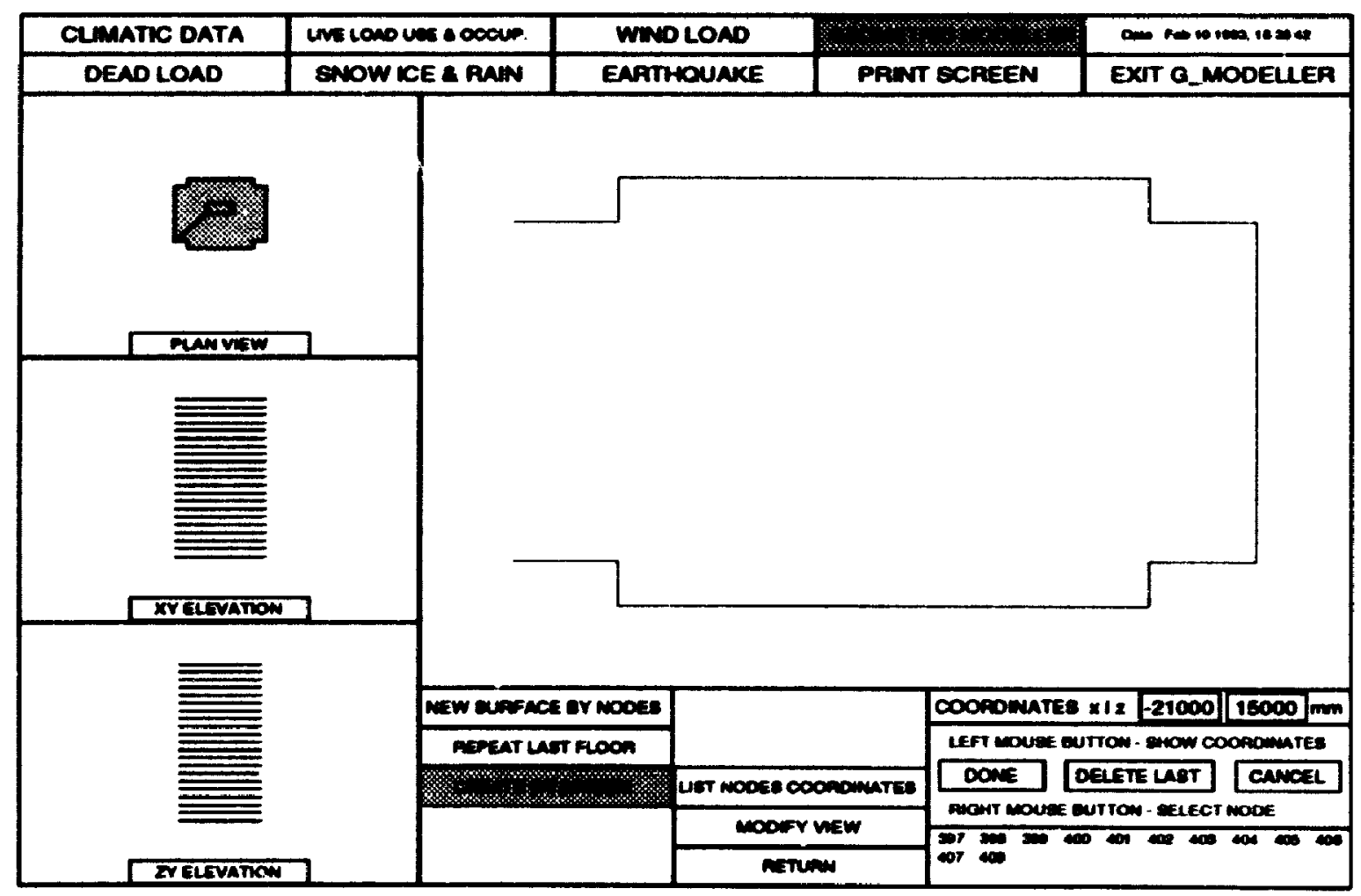

Fig. 3.16 Create Surface by Mouse Selection on Screen

will be constantly updated while scrolling the mouse if the button is held dow'n. To select 
any position as a node release the button and activate the right hand button. The selected coordinates are displayed in appropriate windows and the corresponding node ID is added in the bottom display. To edit use the DELETE LAST node option and recreate the remaining surface required. Because the sensitivity of physical motion of the mouse is limited, the coordinates displayed are rounded to the nearest $100 \mathrm{~mm}$. Note, the sensitivity of the mouse increases as the range of coordinates (nefer to section 3.2.3.9) or scale of the main window increases. To terminate creation of the surface select the DONE button and four views of the building, including the new surface, will be displayed.

\subsubsection{CREATE ROOF}

The process to create a new roof surface is similar to that for a new floor surface. The CREATE ON SCREEN option currently applicable to horizontal surfaces only, can be used for creating sloped roof surfaces by simply editing the ' $y$ ' coordinates of appropriate nodes as described in section 3.2.3.4 with the button EDIT NODE COORDINATES.

\subsubsection{CREATE WALL}

Again, the process to create a new wall surface is similar to that for new floor surfaces, except that the options REPEAT LAST FLOOR and CREATE (ON SCREEN are not applicable. This is not seen as a shortcoming as floors and roofs are created before walls in the design process. Walls then can be created very quickly by the selection of existing nodes on the screen or from the list of nodes which are common with floors and 
roofs.

\subsubsection{Other Editing and Viewing Buttons.}

DELETE SURFACE ON/OFF Selection of this button allows the deletion of any existing surface. Select the surface type (roofs, floors or walls) and the corresponding list of surfaces will be displayed in the lower right hand window as shown in Fig. 3.17. Locate and delete the required surface by mouse selection.

\begin{tabular}{|c|c|c|c|c|}
\hline \multirow{2}{*}{$\frac{\text { CAEATE FLOOR }}{\text { CAEATE ROOF }}$} & SURFACE IO ONOFF & \multicolumn{2}{|c|}{ LIST OF SURFACES : } & \\
\hline & NOOE DOMNOFF & POOFS & FLOORS & \\
\hline CAEATE WALL & EOT NCOE COOODOMATES & $=1$ & mallo & $\frac{m-11}{10}$ \\
\hline & COOPONUTES SETUP & & metco & mallis \\
\hline & & mat & manco & $=14$ \\
\hline BAVE CHAMBes & CAMCEL-CFEATE NEW & $=-5$ & mell_10 & III 15 \\
\hline
\end{tabular}

Fig. 3.17 Delete Surface from List of Surfaces.

SAVE CHANGES Activating this button saves the data for created or edited surfaces and terminates the current creating or edising process session.

SURFACE ID ON/OFF Selection of the SURFACE JD ON/OFF button will activate or deactivate the surface identification routine. While activated, mouse selection of any surface within any of the four display windows will display the corresponding surface identification information in the bottom right window as shown in Fig. 3.18. The surface name and node numbers defining the surface are shown. 


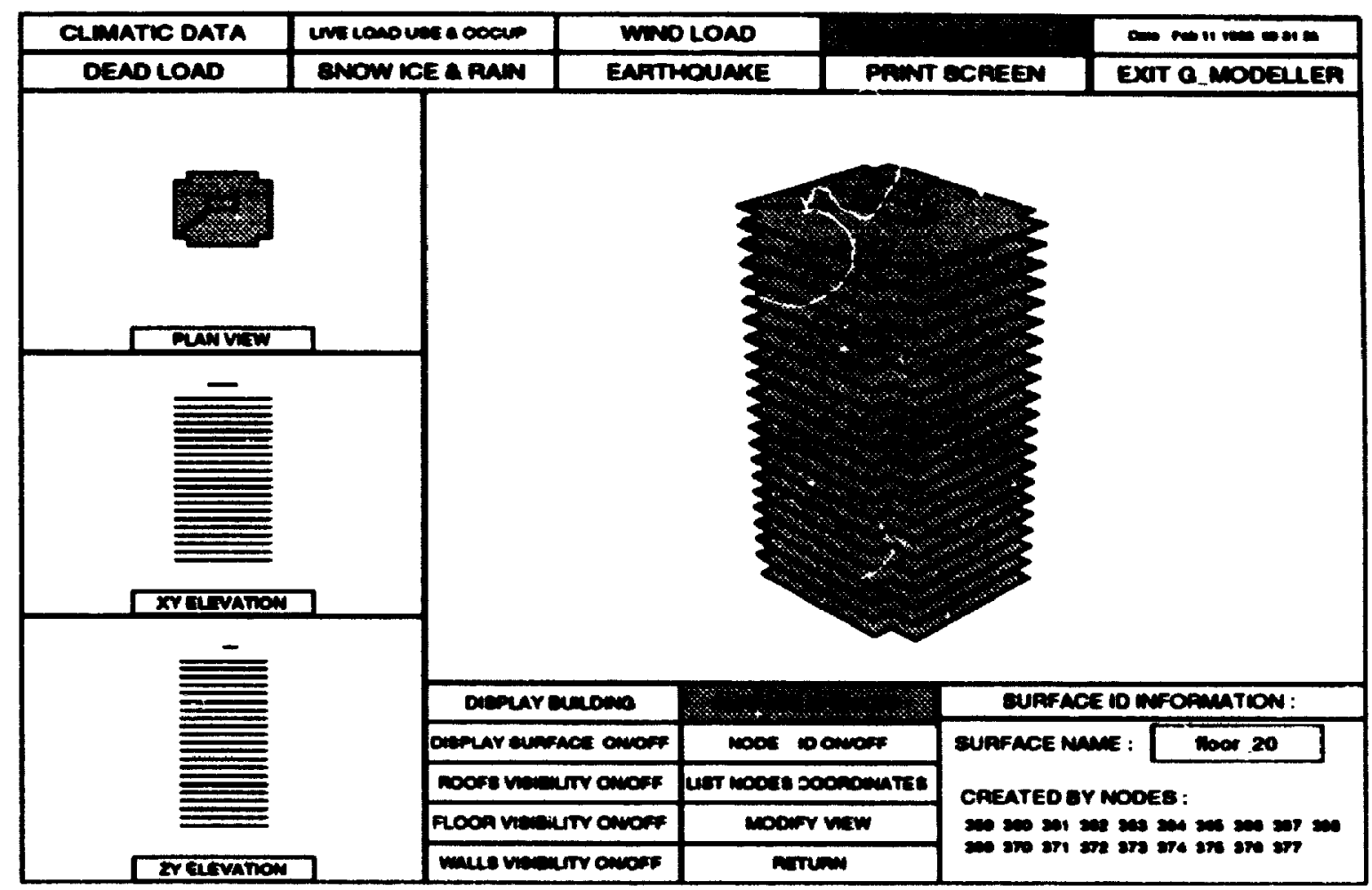

Fig. 3.18 Surface ID Information.

NODE ID ON/OFF Selection of the NODE ID ON/OFF button will activate or deactivate the node identification routine. All nodes are displayed in 3D view as small squares. While activated, mouse selection of any node gives the node identification number and its coordinates in bottom right window as shown in Fig. 3.19.

EDIT NODE COORDINATES To correct errors in existing node data or to creake sloped surfaces for roofs activate the EDIT NODE COORDINATES button. Select the appropriate node number from the list of nodes displayed in the left hand window shown in Fig. 3.20. The corresponding node number and coordinates will then be displayed in the lower right hand window. Select the coordinate to be edited and key in the new value. Confirm and save the changes. To determine the process select the 


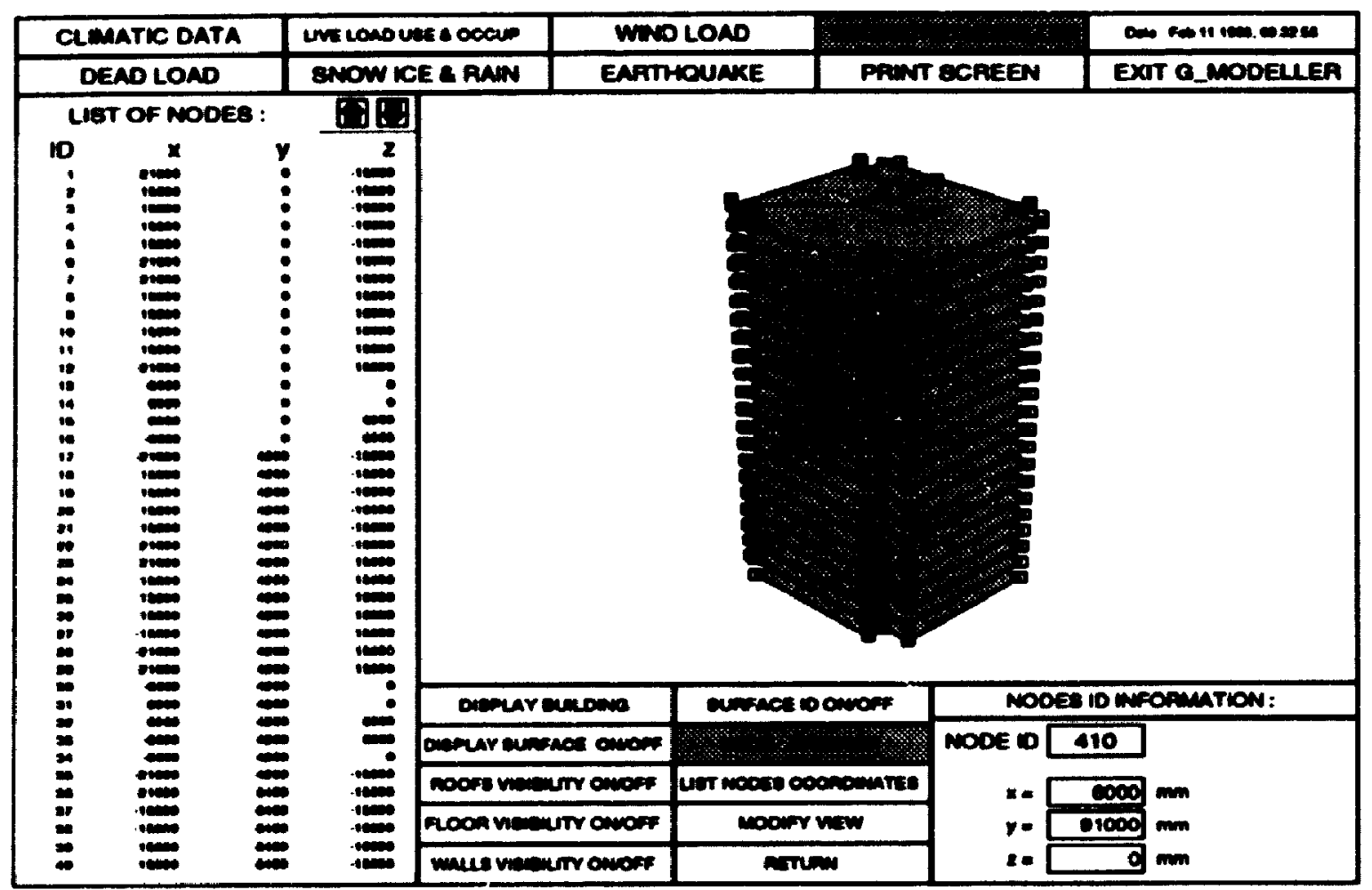

Fig. 3.19 Nodes ID Information.

EDIT NODE COORDINATES button.

COORDINATES SETUP Activate this button if the initial coordinates setup (defines the scale within the windows; need to be changed. The function is similar to th: described in selection 3.2.3 CREATE NEW PROJECT.

CANCEL CREATE NEW By activating this button, the changes made from the last saving of data (initiated by SAVE CHANGES) ane deleted and the deleted data cannot be restored. 


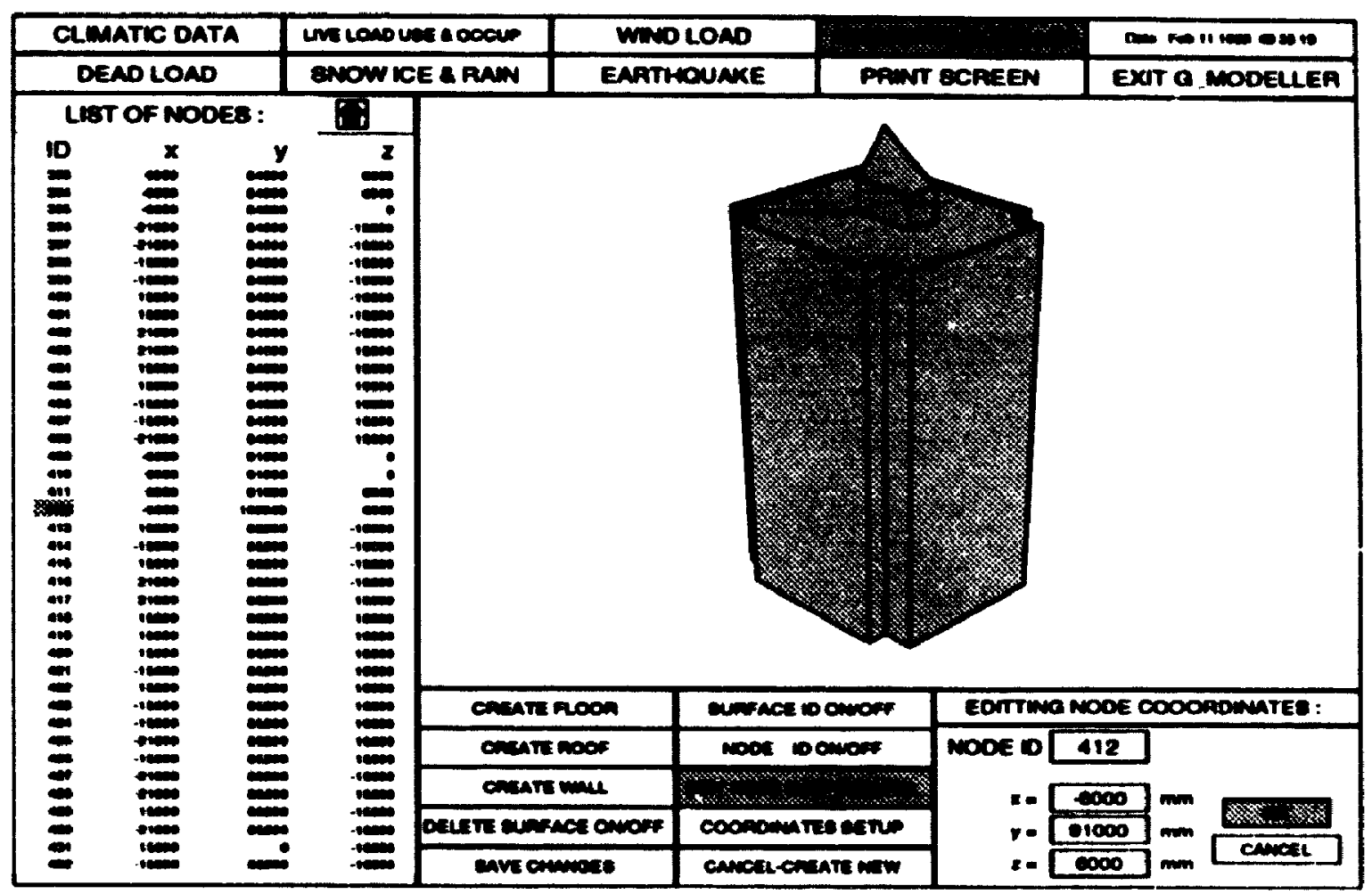

Fig. 3.20 Edit Node Coordinates.

\subsubsection{EDIT ACTIVE PROJECT}

The process of editing the geometry of the surfaces of a building is similar to that described in section 3.2.3 CREATE NEW PROJECT, with the exception that the new name definition and coordinates setup steps are bypassed.

\subsubsection{STRUCTURE DISPLAY}

To view the structure or different parts of the structure (used to verify that the structural geometry form is currect) the engineer would activate the STRUCTURE DISPLAY button found in the geometric modeller main window shown in Fig. 3.3. The corresponding application menu is shown in Fig. 3.21. Functions that have been provided to facilitate the process include: display of one surface type or a given surface, surface and 
node identification, and routines for modifying the view (scaling, panning and rotating). These are described below.

\begin{tabular}{|c|c|c|}
\hline Daglar bullomo & SUAFACE DO OWOFF & \multirow{5}{*}{ 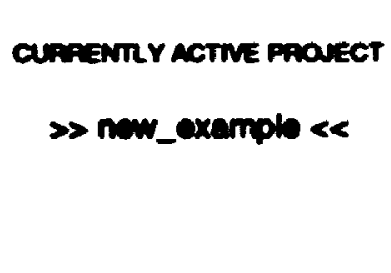 } \\
\hline omplay euaface onoff & Moos Donioff & \\
\hline noore vinumponorf & LET MOOES COOAOWUTES & \\
\hline 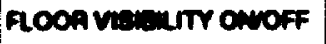 & Moowr vin & \\
\hline muls waturtr oncoff & Aetring & \\
\hline
\end{tabular}

Fis. 3.21 Structure Display Application Menu.

DISPLAY BUILDING By activating this button, the image of the currently active project is displayed in plan, elevation (two views) and in the 3 dimensions, as shown in Fig. 3.22. The position and scale of the stucture shown in each window on the screen (centred and within the window provided) has been computed from the nodal coordinate data.

DISPLAY SURFACE ON/OFF After the selection of this button, the engineer is asked to select the surface name to be displayed from the List of Surfaces in the bottom right hand window shown in Fig. 3.23. The corresponding plan view of the surface will be displayed in main window. Currently, only horizontal surfaces (floors and roofs) are displayed properly. Transformation or rotation of planes have not yet been implemented i.e. vertical walls are displayed as a line. To obtain more information about displayed surface activate the SURFACE ID ONOFF button. 


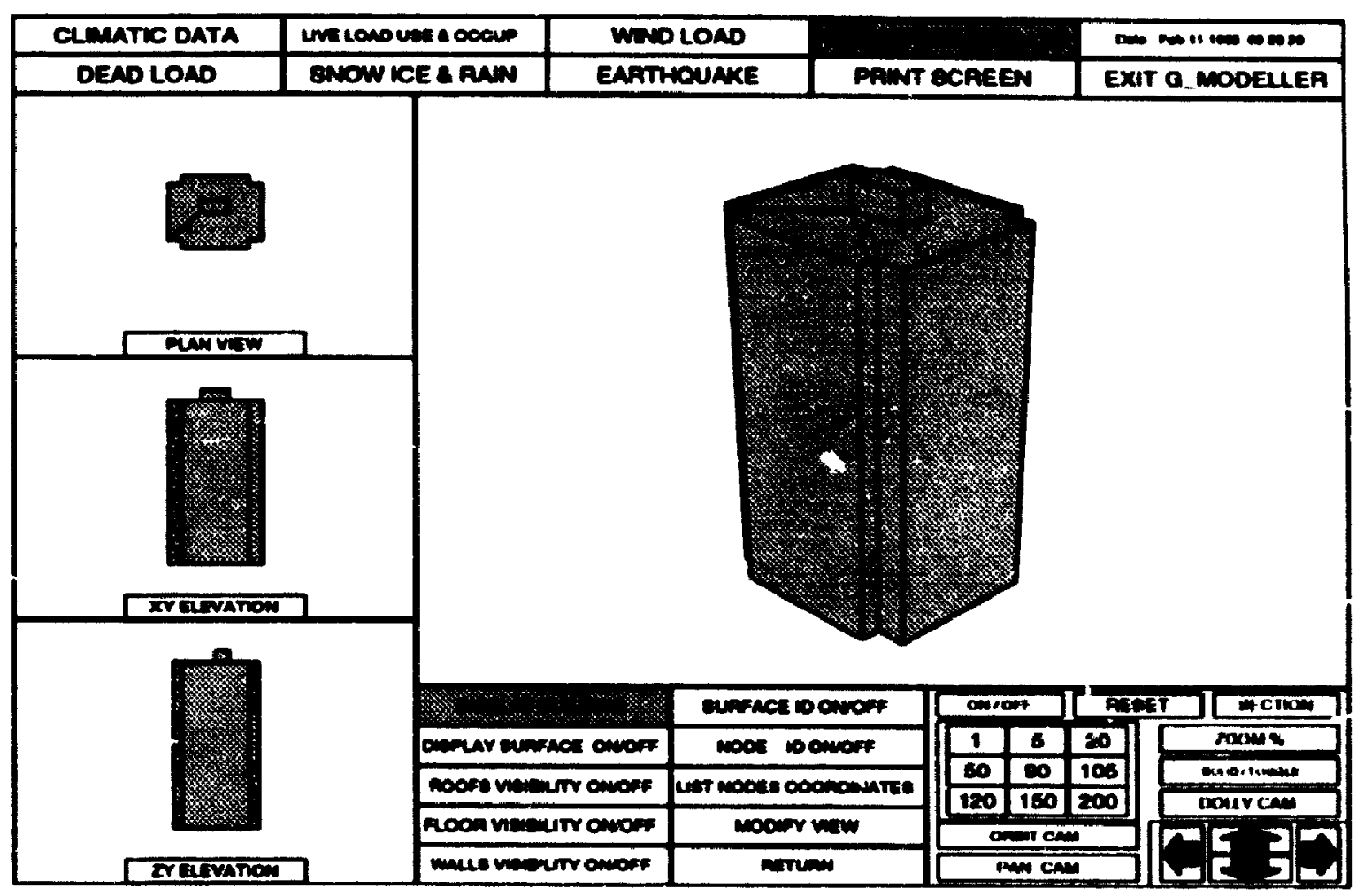

Fig. 3.22 Display of Building.

ROOFS - FLOORS - WALLS VISIBILITY ON/OFF Identification and viewing of one surface type is possible by setting the visibility of the other surfaces to OFF. As illustrated in Fig. 3.18 . where only the roof and floor surfaces are shown (wall visibility is set to OFF) the display is consistent in all four windows.

\section{LIST NODE COORDNATES A list of nodes and the corresponding coordinaces will} be displayed in the left hand window by selecting this button, refer to Fig. 3.19. Editing the coordinates for each node is only possible by activating EDIT NODE COORDINATES button. 


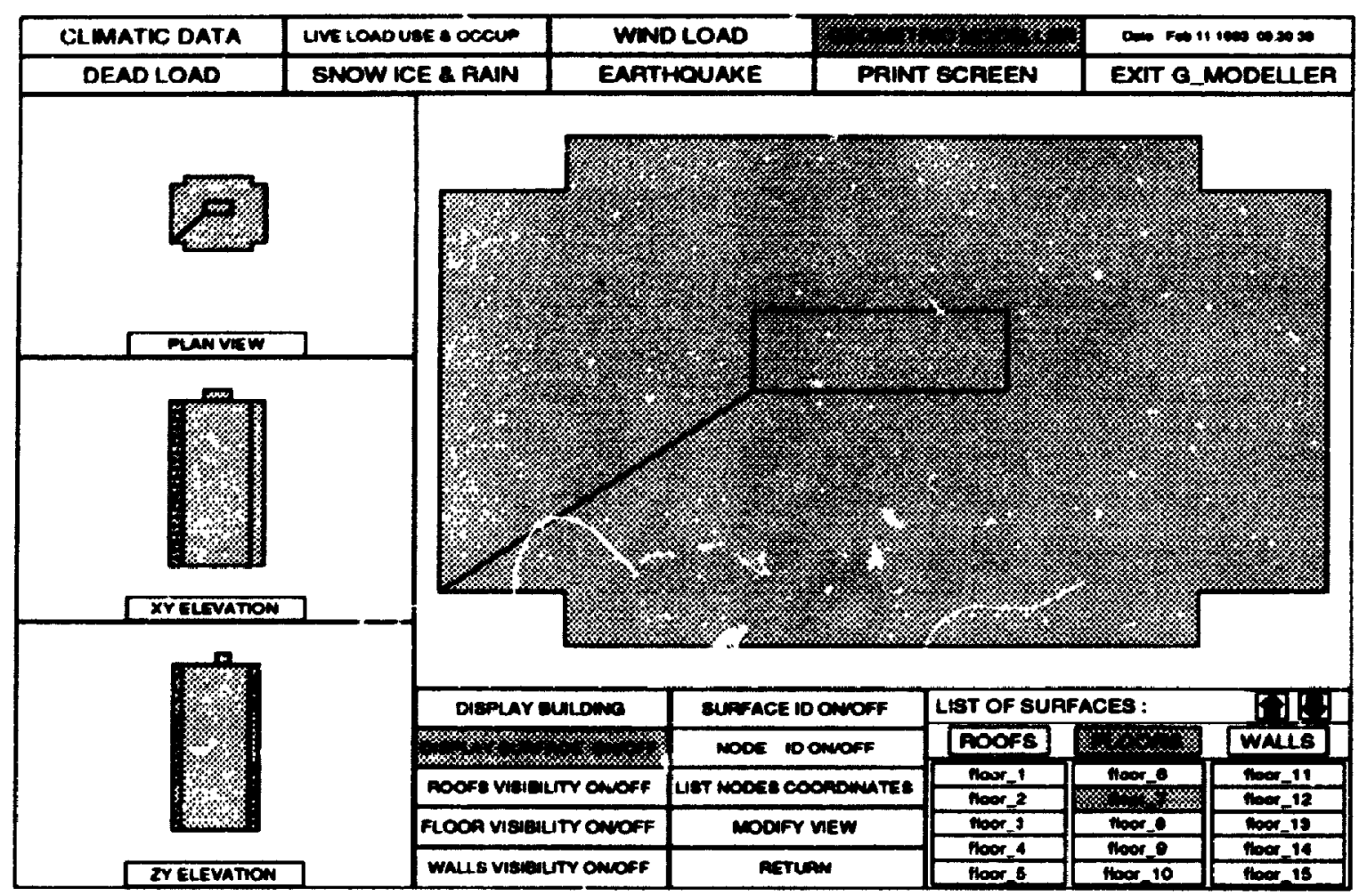

Fig. 3.23 Display Selected Surface.

MODIFY VIEW To modify the 3 dimensional image of the building activate the MODIFY VIEW button. The corresponding application menu will be displayed in the bottom right hand window as shown in Fig. 3.22. Selection of the ON/OFF button (-i.e. 'ON' position) allows the values of displayed graphic attributes to be modified. Graphic attributes in Hoops are the details that determine how the picture is displayed rather than what the picture consists of. The buttons particular to this application menu are described below.

a) ON/OFF - Switches (toggles) the option to modify view ON and OFF.

b) RESET - The initial setting of the graphic attributes (default values) for the 3 dimensional image of the structure was selected to a view that clearly illustrates the structural form. The size of the scene, in terms of object space coordinates 
around the 'target' shown in the relevant screen window, is dependent on what the virtual viewing device-like TV camera can see from a defined position (orbit). The initial default setting of the camera field and camera position. defined by Hoops (internally) are as follows:

- object space (camera field)

The coordinate system defined by Hoops graphics is shown in Fig. 3.24. The object has been scaled to fit within the camera field defined by Hoops. The limits along the $x$-axis and $y$-axis are set to vary from -1.0 to 1.0 in both directions.

- orbit of camera (camera position;

The initial viewing direction is aloug the z-axis. The default camcra position is set counterclockwise in the $x-z$ plane and rotated above that plane by 45 degrees and 30 degrees, respectively. The RESET button sets the graptic: attributes to the default setting giving the original view.

c) SECTION Sets the view to give an $\mathrm{XY}$ elevation of the structure.

d) NUMBERS 1-200 Numbers representing degrees of rotation or percent of magnification when modifying the view of the structure, while using the ORBIT CAM and ZOOM \% button, respectively.

e) ZOOM \% Narrows or enlarges the viewing field of the camera. A value of 2(0) will zoom the picture in, until the viewing filed is half as wide, while a value of 50 will zoom the picture out the same amount.

f) SOLID/TOGGLE Visibility of the faces of surfaces in the 3 dimensional display 
are toggle on and off by activating the SOLID/TOGGLE button. The corresponding image appears either as a solid or a wire framework showing the edges of the surfaces, as shown in Fig. 3.25.

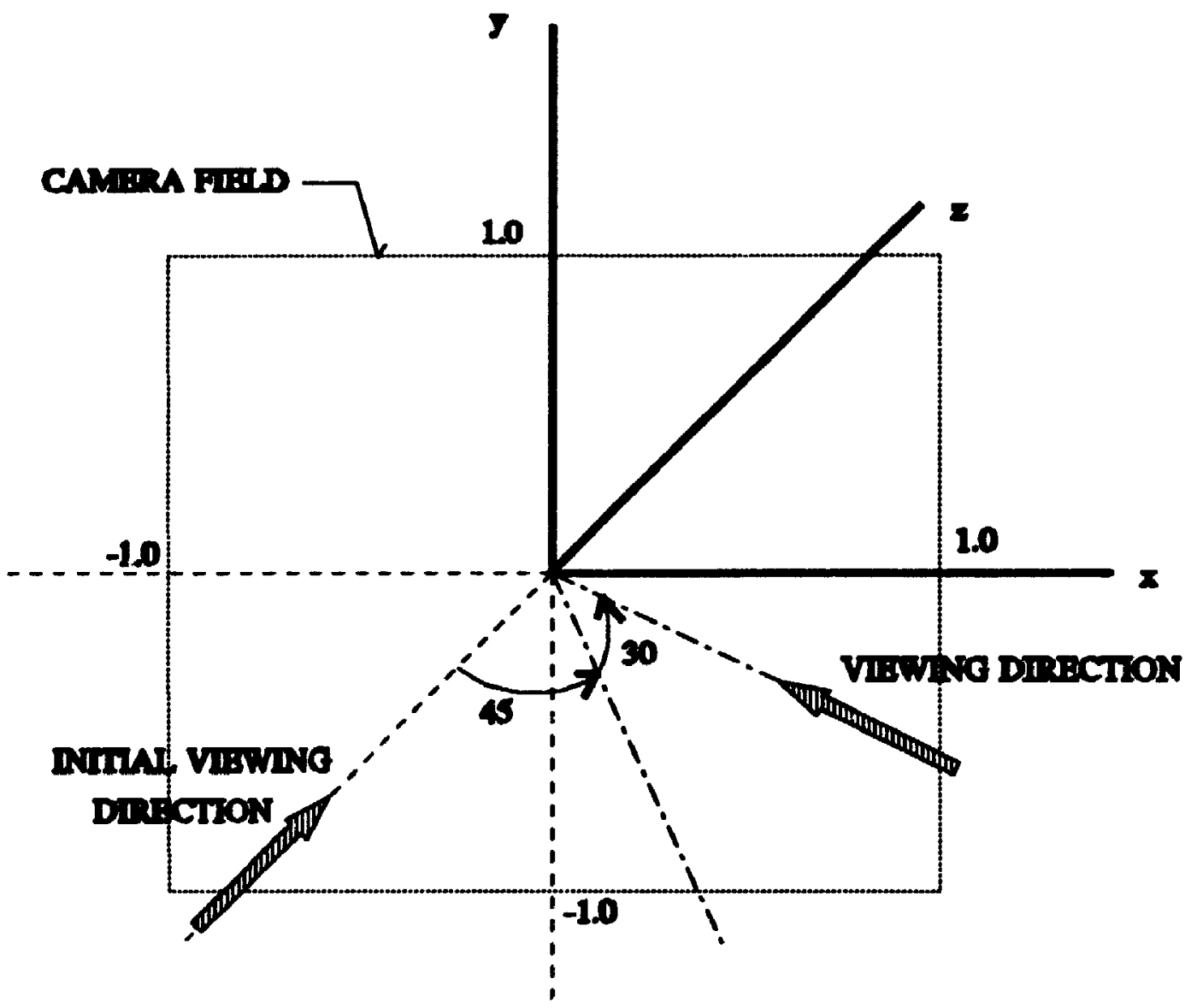

Fig. 3.24 Object Space and Initial Camera Position.

g) DOLLY CAM Dolly Camera moves the camera left and right, up and down (Iranslates) along the target so that the field-of-view remains unchanged. The direction of movement is determined by selecting one of arrows with required 
direction.

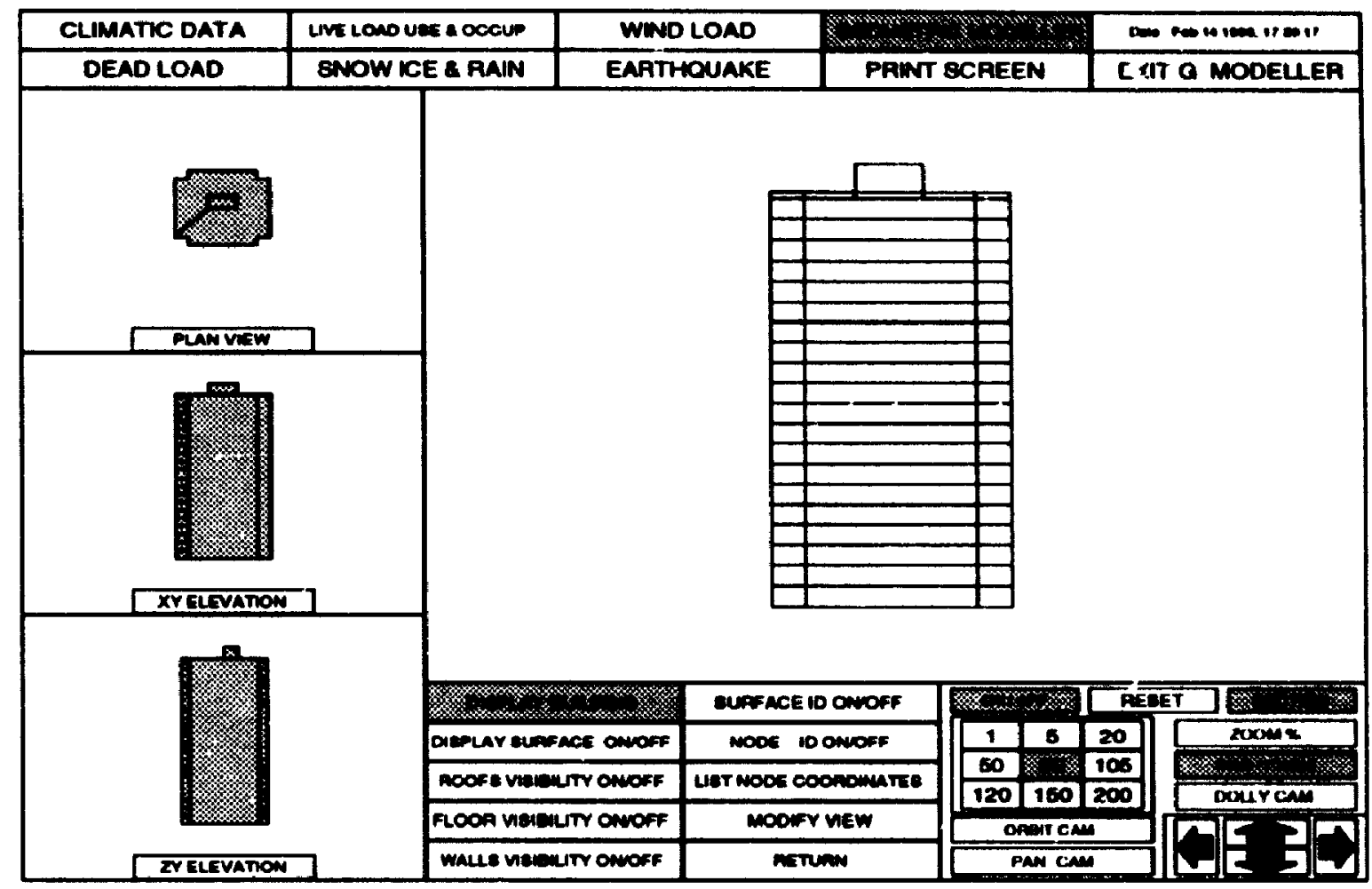

Fig. 3.25 Display Building - SECTION and SOLID/TOGGLE.

h) ORBIT CAM Walks the point of view around the object being looked at. By selecting one of horizontal arrows the camera will "walk around" the target to the right or to the left. By selecting one of vertical arrows the camera will float up or down over the target.

i) PAN CAM Sweeps the camera (pirets) across its current scene in the direction of selected arrow.

\subsubsection{LOADS TO SURFACES}

This button is located in the application menu for the geometric modeller - main 
window shown in Fig. 3.3. Within the sequence of tasks for determining loads acting on building, attributing load intensities to surfaces follows the definition of dead and live loads (use and occupancy) and the specification of climatic data. The description of the functions performed by activating this button is given in the same sequence in section 3.6.

\subsection{Climatic dATA}

The climatic information for building design in Canada given in the Supplement to the National Building Code of Canada 1990 and all subsequent revisions, NRC (1990), is accessible by activating the CLIMATIC DATA button in the main menu. To retrieve the data for snow, wind and earthquake load calculations;

1) Select the appropriate province or territory from the list in the left hand window (the province of British Columbia appears as the défault) and the list of locations for that province or territory will be displayed in the middle window entitled "LOCATION" ("100 Mile House" appears as the default for British Columbia), refer to Fig. 3.26. The first 20 locations will be displayed.

2) Use the arrows in the top and bottom of the scroll bar meter to browse through the locations for that province or territory. The scroll bar meter indicates the current position within the list. Select the required location and the climatic data will be retrieved and displayed in the right hand window entitled, "CLIMATIC DATA".

3) These values can either be save to a text file, "location_climatic_data" located in the subdirectory for the currently active project, by activating the SAVE LOCATION button, or the values changed by mouse selection and keyboard entry, 


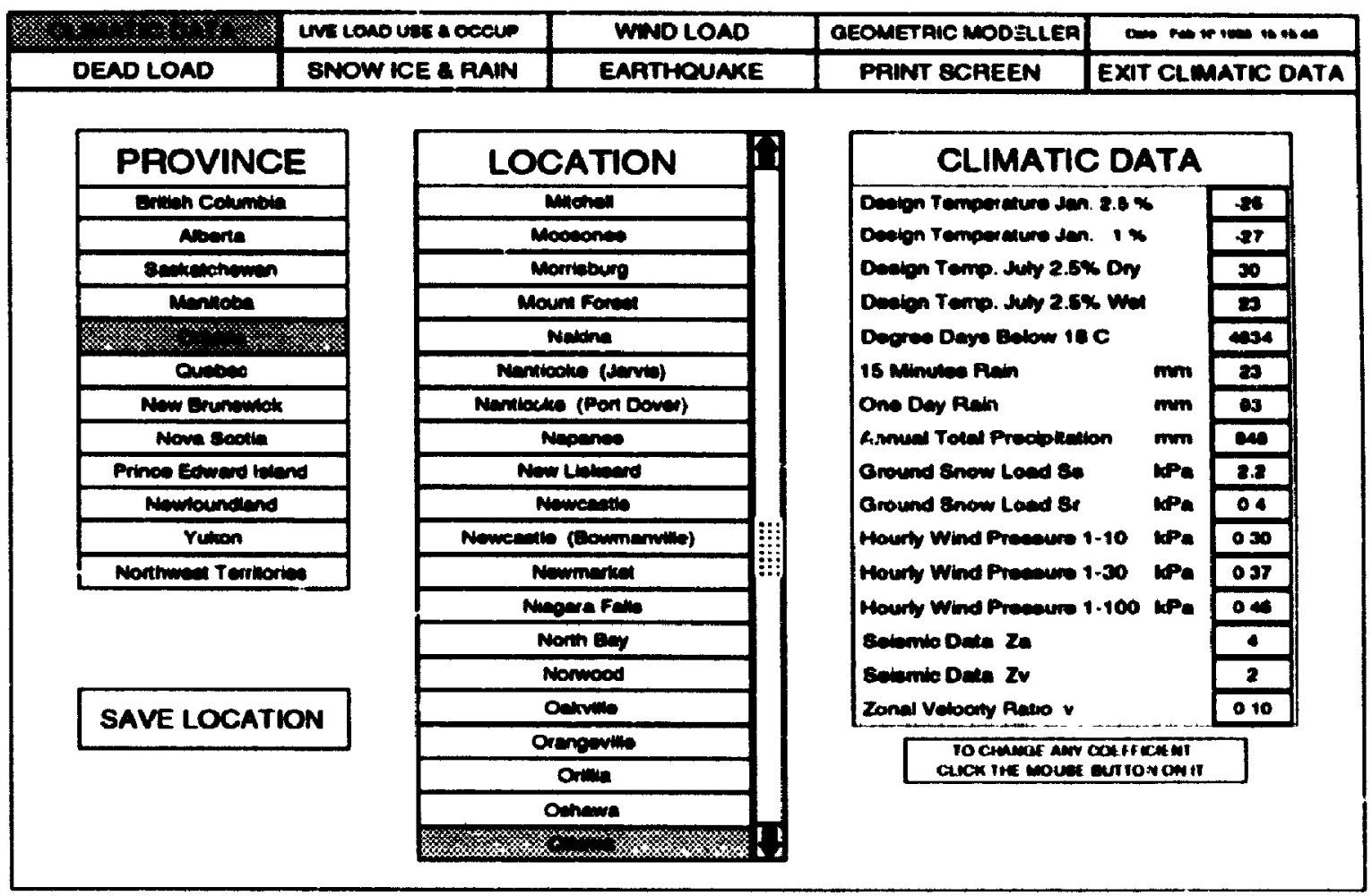

Fig. 3.26 Climatic Data.

and then saved. This feature is useful for building lo:duions where the climatic data is different from that listed, -i.e. snow load values change radically from one valley to another in the mountains in British Columbia. Altered climatic data is particular to the project. The original library cannot be ovs...ritten.

\subsection{DEAD LOADS}

The DEAD LOAD determination module is used to create list(s) of structural sandwich systems (identified by name) and the corresponding dead load intensities in $\mathbf{k P a}$ for floors, roofs and walls in the building being designed. These can be created and edited graphically from libraries of standard dead load intensities used in design for typical elements that make up these structural sandwich systems, such as, roofing materials, 
insulation, vapour barriers, concrete slabs, steel deck, composite slabs, beams, OWSJ's, ceilings, floor finishes and other loads. As these building systems are created, the list of elements are compiled, the total dead load intensity is calculated and the corresponding system is illustrated (to scale - a representative $3 \mathrm{~m} \times 3 \mathrm{~m}$ section) as shown in Fig. 3.27. Newly defined structural sandwich systems and the corresponding load intensities are added to the existing list stored in the appropriate files, "DL_roofs_defaults", "DL_floor_defaults", and "DL_walls_defaults". Subsequently, these loads will be attributed to specified surfaces selected in the geometric modeller.

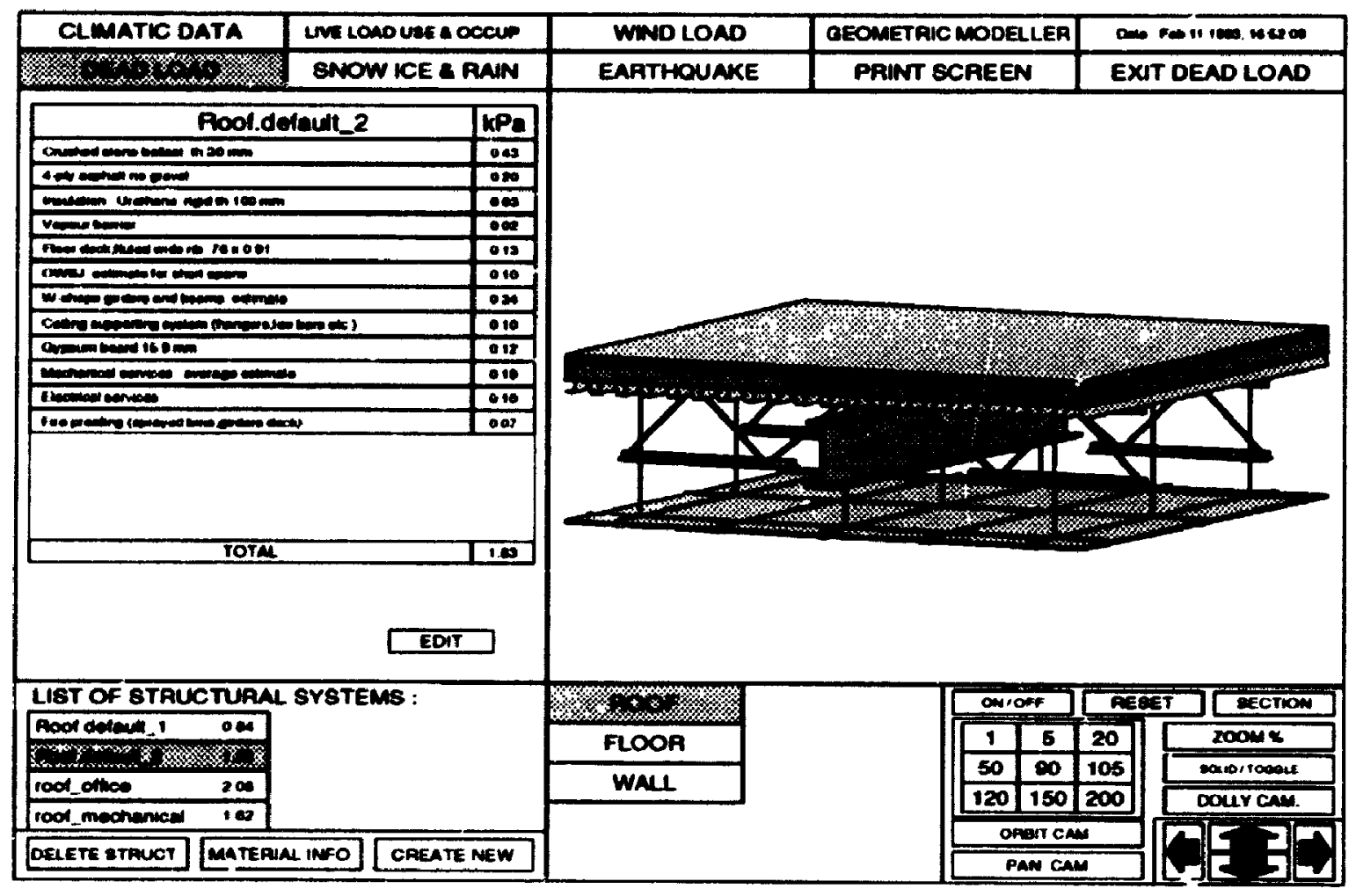

Fig. 3.27 Dead Load Structural Sandwich Systems.

Activating the DEAD LOAD button from the main menu generates the display given in Fig. 3.27. The buttons FI OOR, ROOF and WALL, shown in the application menu window, are selected in turn to create, edit or display the structural sandwich systems 
required for the project. Specific button and the corresponding functions used in this module are described in detail below.

\begin{tabular}{|c|c|c|c|c|c|c|}
\hline CLIMATIC DATA & \multicolumn{2}{|c|}{ Line LOAD UAE A OCCUN } & WWD LOAD & OEOMETRIC MOOELLEF & \multicolumn{2}{|c|}{ 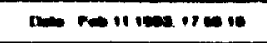 } \\
\hline 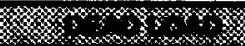 & \multicolumn{2}{|c|}{ SNOW ICE \& RAN } & EARTHOUAKE & PAWT SCREEN & \multicolumn{2}{|c|}{ EXIT DEAD LOAD } \\
\hline \multicolumn{7}{|c|}{ Wall.delauk_1 } \\
\hline \multicolumn{7}{|c|}{ 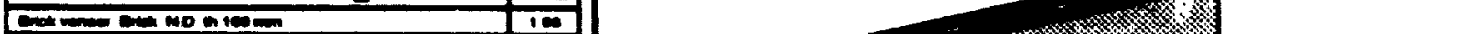 } \\
\hline \multirow{2}{*}{\multicolumn{7}{|c|}{ 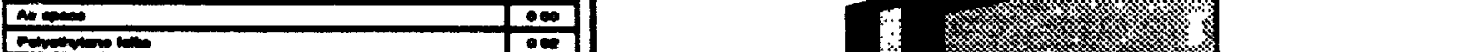 }} \\
\hline & & & & & & \\
\hline \multicolumn{7}{|l|}{ 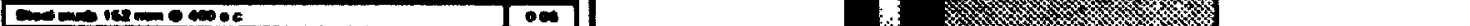 } \\
\hline \multicolumn{7}{|c|}{ 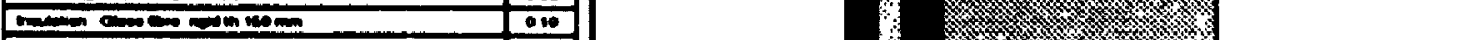 } \\
\hline \multirow{2}{*}{\multicolumn{7}{|c|}{ 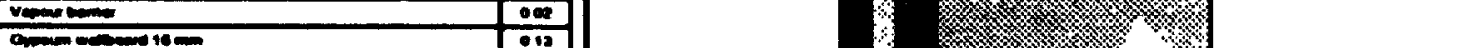 }} \\
\hline & & & \multicolumn{4}{|c|}{ 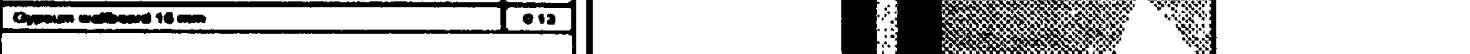 } \\
\hline \multicolumn{7}{|c|}{ Tothe } \\
\hline \multicolumn{7}{|c|}{ EO:T } \\
\hline \multicolumn{3}{|c|}{ LIST OF STRUCTUAML SYSTEMS } & DAMCK VEMEEA & onicent & $\overline{A I}$ & 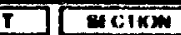 \\
\hline \multicolumn{3}{|c|}{ 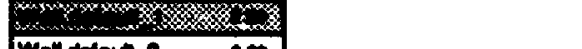 } & CONCATTE ELOCK & 1 & 20 & $\operatorname{sxcme}$ \\
\hline \multirow{2}{*}{\multicolumn{3}{|c|}{ 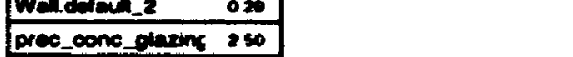 }} & PaAtriom & 60 & 106 & moricmant \\
\hline & & & anoome & 1201 & 200 & oonircan \\
\hline \multicolumn{3}{|l|}{ mexelarren_mo 120} & meluation & onen & & $<$ \\
\hline DELLTE ETAUCT & L info & CAEATE MEW & 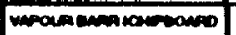 & AETuan & & 2 \\
\hline
\end{tabular}

Fig. 3.28 Dead Load Structural Sandwich Systems for Walls.

ROOF, FLOOR, WALL To display the list of existing structural sandwich systems and to initiate the process for creating new systems or to edit existing systems for a given surface type, activate the appropriate button. An example for walls is illustrated in Fig. 3.28.

DELETE STRUCT. To delete a structural sandwich system from the list. select the DELETE STRUCT button and the system name. Confirmation is required. 
MATERIAL INFO Select this button and the appropriate element type, -i.e. roofing, to review the library of matcrials and load intensities. An example for roofing materials is showr in Fig. 3.29.

CREATE NEW Activate this button to create a new structural sandwich system. First. enter the system identification name into the appropriate window and then use the editing buttons shown in the left hand window in Fig. 3.29, to build the structural sandwich system from the libraries provided.

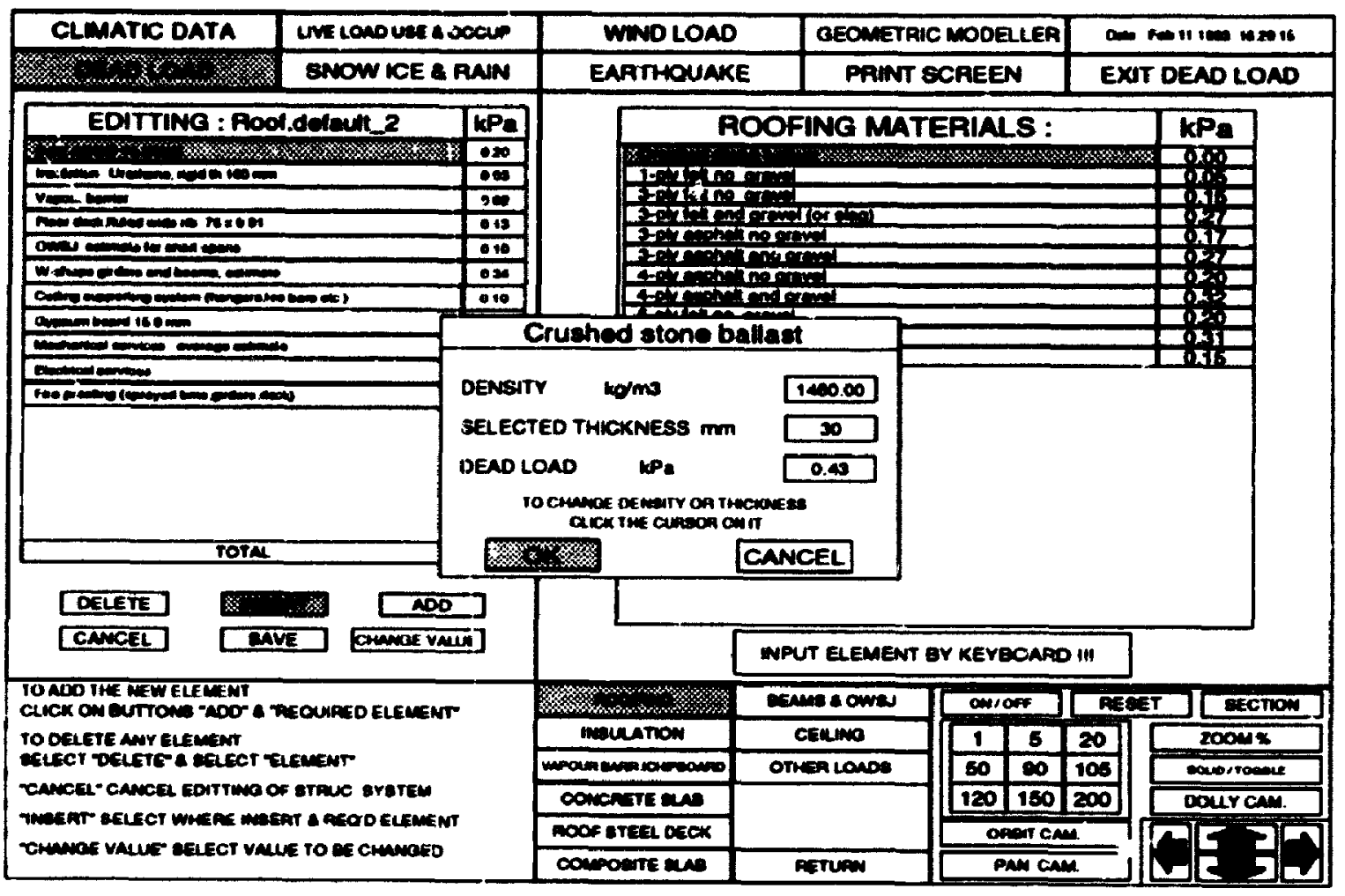

Fig. 3.29 Create/Edit Dead Load Structural Sandwich Systems.

EDIT Activates the editing mode. Through the use of the editing buttons elements can be delewed. added or inserted from the list shown or the load intensities can be changed to 
reflect better estimates.

a) ADD New elements can be added either by mouse selection from the serren libraries, as shown in Fig. 3.29, or by keyboard input as shown in Fig. 3.30.

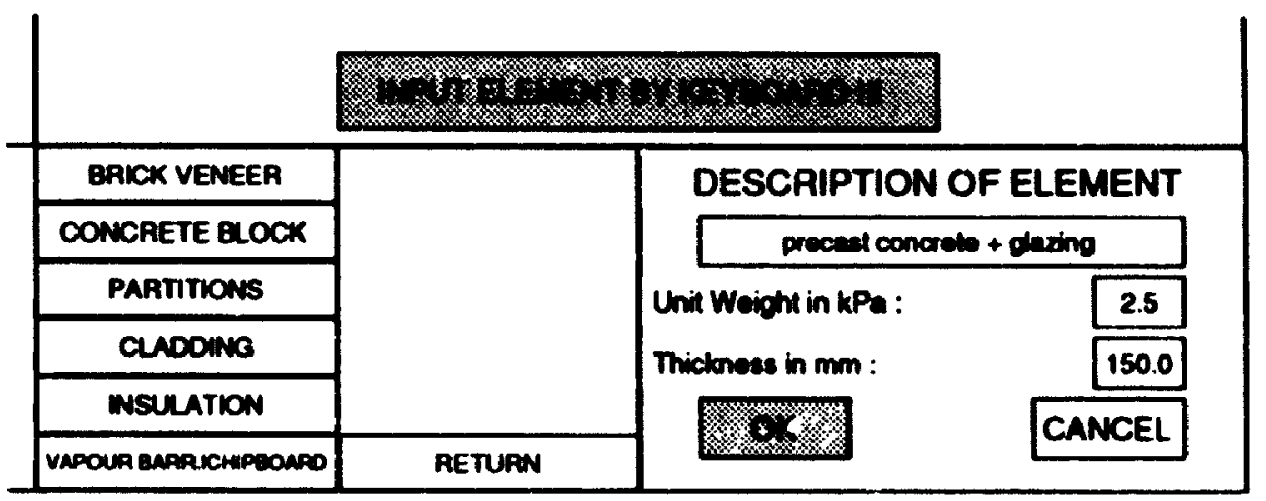

Fig. 3.30 Input Element by Keyboard.

The libraries are organized in groups of the materials that ane found in structural sandwich systems. The list of materials for any group is displayed by activating the corresponding button located in the lower right hand window. To add an element from library to the list for the system, select button ADD followed by required element. For elements with variable thickness (crushed stone ballast, insulation, concrete slab etc.) the engincer is required to input the thickness in $\mathrm{mm}$. The load intensity in $\mathrm{kPa}$ is calculated and displayed. Note, the density may be redefined. The element is added to the end of the list once the data is confirmed. New elements, not existing in the current library listings, can be added through keyboard input. The corresponding window is shown in Fig. 3.30).

b) INSERT INSERT places an element between two existing elements within list. 
Activate the INSERT button, select the element in the list just prior to the location where the element is to be inserted, and then select the element from the appropriate library list.

c) DELETE Activate the DELETE button and select the required elements to be deleted.

d) CHANGE VALUE The load intensity in $\mathrm{kPa}$ of any element in the list for the structural sandwich system, can be changed by activating the CHANGE VALUE button. selecting the required value to be changed and keyboard input of new value. The total load intensity of edited or newly crealed structural sandwich systems will be updated after each modification.

e) SAVE Activating the SAVE button will save edit or newly created structural sandwich systems in an output file, as described in Appendix B - File Architecture.

n CANCEL All modifications are cancelled

\subsection{LIVE LOADS DUE TO USE AND OCCUPANCY}

The LIVE LOADS DUE TO USE AND OCCUPANCY module is used to create a list of areas (identified by a user specified name) and the corresponding uniformly

distributed and concentrated loads due to the specified use and occupancy. Subsequently, these loads will be attributed to specified surfaces selected in the geometric modeller. 
Activating the LIVE LOAD USE AND OCCUPANCY button from the main menu gives the display shown in Fig. 3.31. The list of loads shown in the left hand window is interactively generated from the screen by the selection of series of buttons that can retrieve and edit the load intensities and loads given in LDFSSBC (neproduced from Table

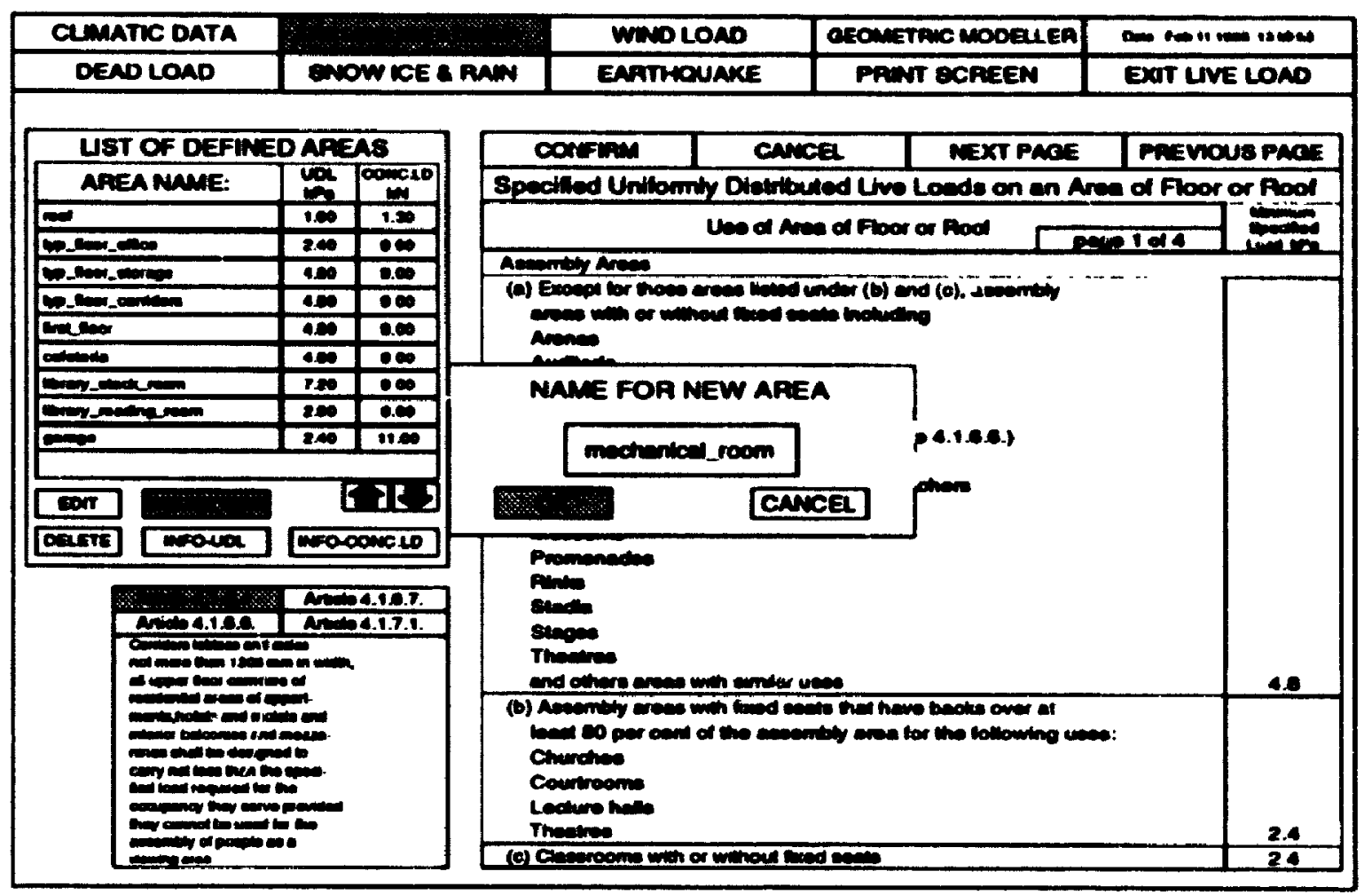

Fig. 3.31 Live Load Use and Occupancy - Select UDL.

4.1.6.A and 4.1.6.B in section 4.1.6. in the National Building Code of Canada 1990, NRC (1990). Refer to Fig. 3.31. Specific buttons and the corresponding functions used in this module are described in detail below.

INFO-UDL Selection of this button activates a window, displaying Table 4.1.6.A Specified Uniformly Distributed Live Loads on an Area of Floor or Roof from NBCC 1990, NRC (1990), as shown in Fig. 3.31. The buttons NEW PAGE or PREVIOUS PAGE 
are used to browse through the pages. To view the related articles, select the appropriate button in the bottom left hand window.

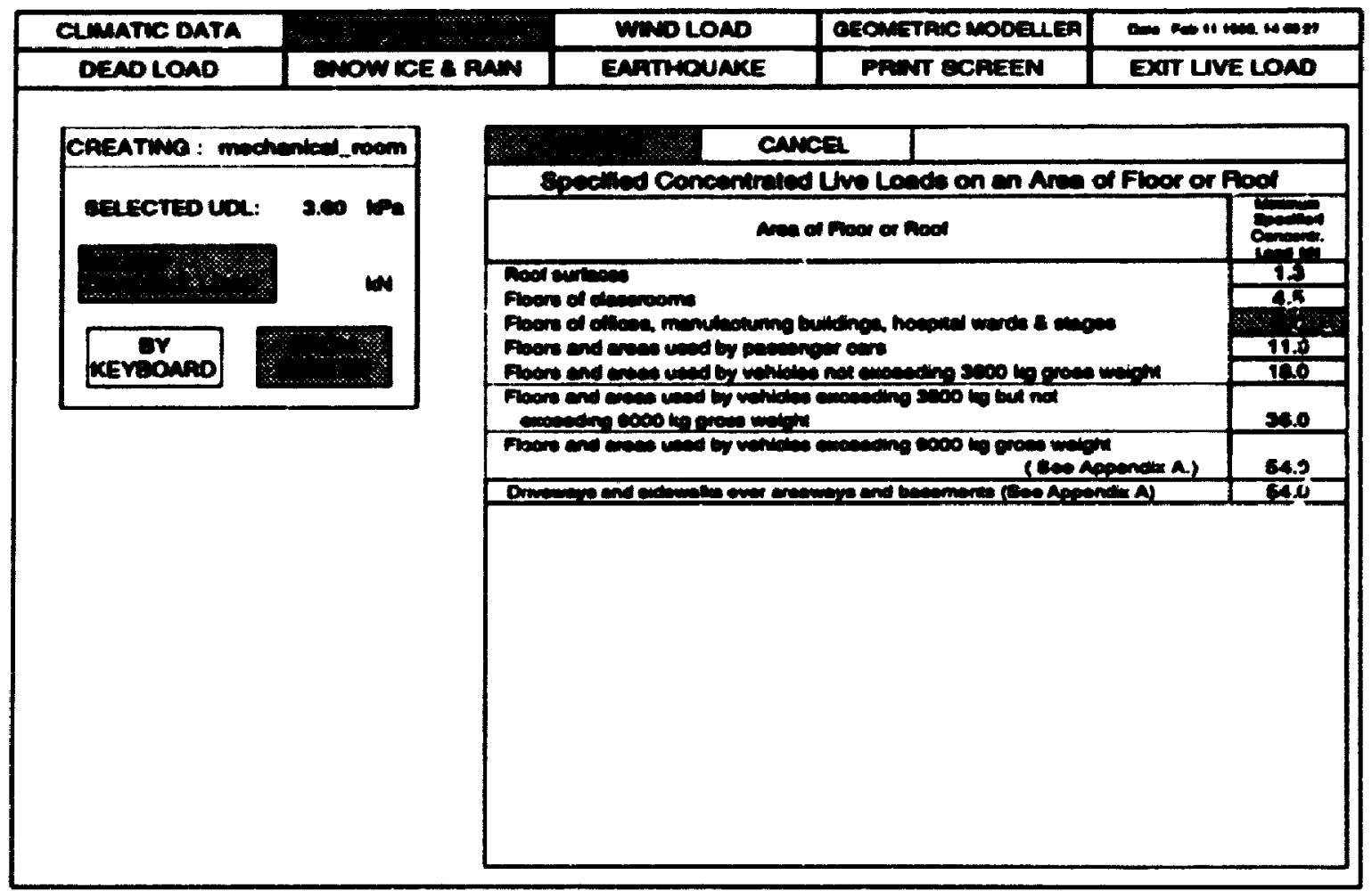

Fig. 3.32 Live Load Use and Occupancy - Select Concentrated Load.

INFO-CONCR.L. Selection of this button displays Table 4.1.6.B. Specified Concentrated Live Loads on an Area of Floor or Roof from NBCC 1990, NRC (1990), as shown in Fig. 3.32.

CREATE NEW To create a new listing, activate the CREATE NEW button, input of new area name and select the uniformly distributed load value from table (the selection must be confirmed) or input the value from the keyboard, as shown in Fig. 3.32. The same procedure is followed for the selection of the concentrated load value. 
EDIT To edit a value from the lish, activate the EDIT button. select the uniformly distributed load or concentrated load value from the list of defined areas to be changed and use the keyboard to input the new value.

DELETE To delete any defined are, select DELETE button, followed by the area to be deleted. Confirmation is not required.

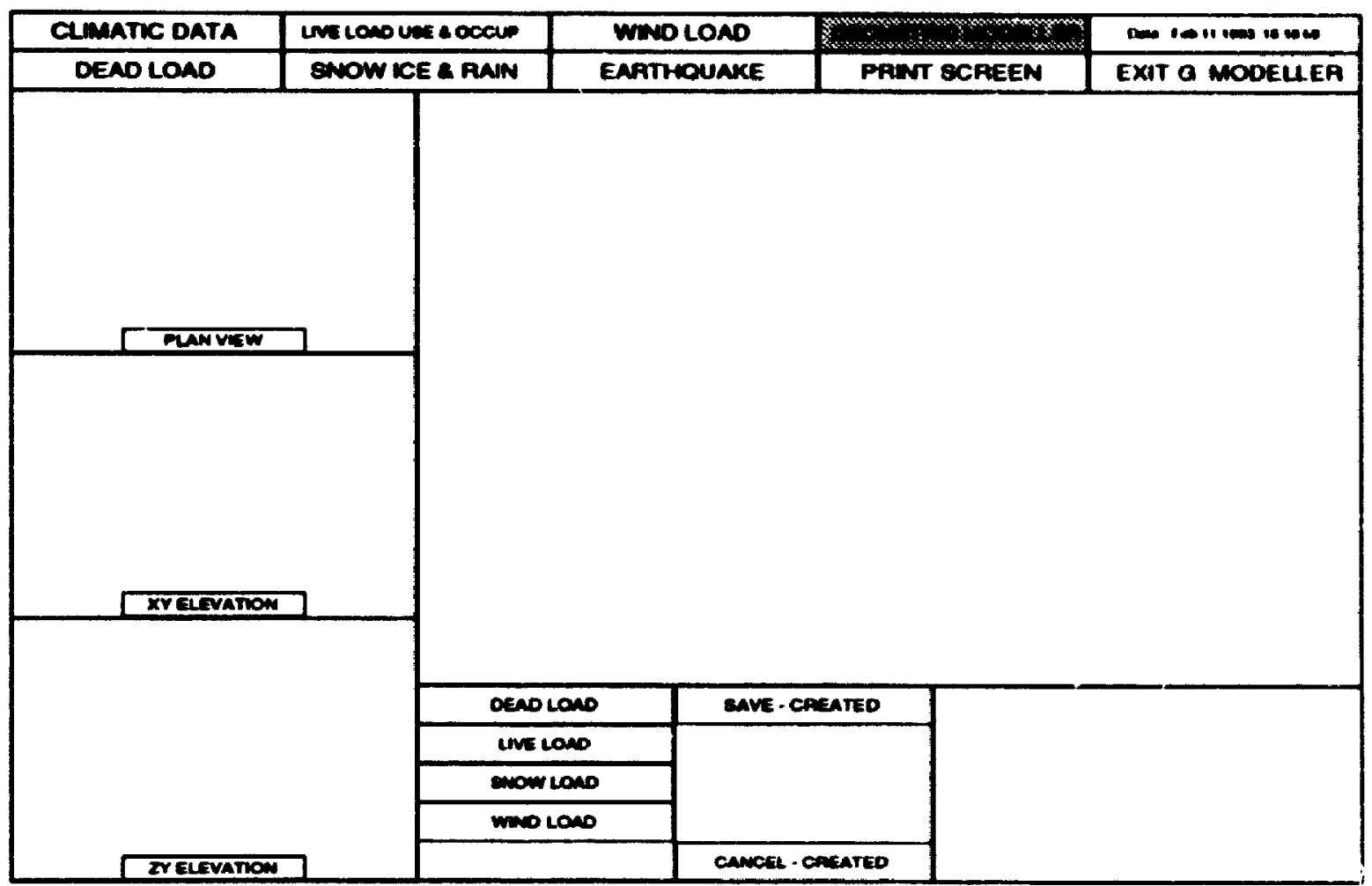

Fig. 3.33 Attribute Loads to Surfaces.

\subsection{Attributing Loads Within the Geometric Modeller}

Once the structur $!$ geometry has been defiıted and the dead and live load intensities specified, then the process of attributing the loads to the appropriate surfaces can start by 

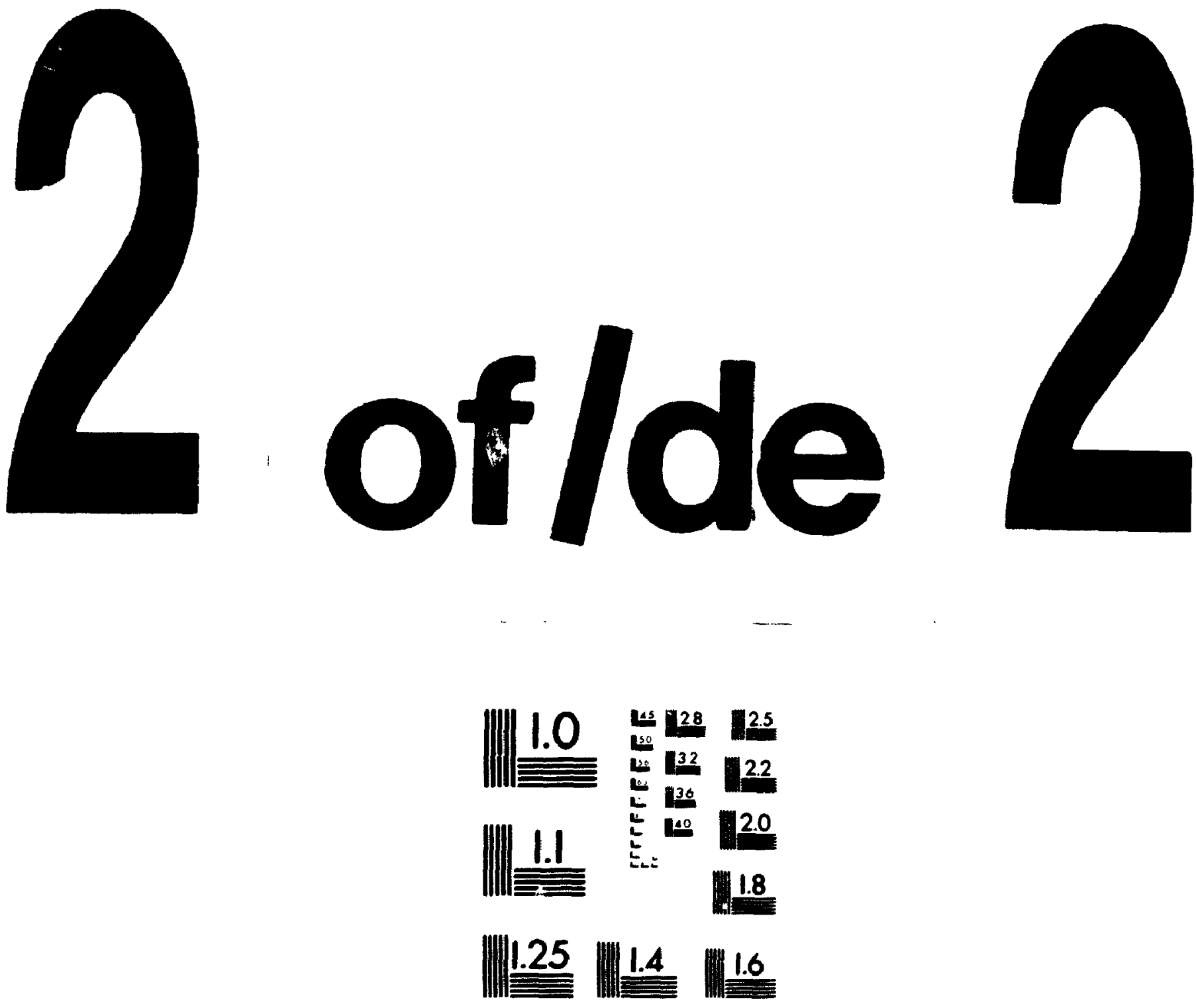

MICROCOPY RESOLUTION TEST CHART

NATIONAL BUPEAU OF STANDARDS

STANDARD REFERENCE MATERIAL 1010

(ANSI and ISO TEST CHART NO 2) 
selecting the LOAD TO SURFACES button from the geometric modeller main window. To attribute any given load type (DEAD. LIVE (used and occur...cy). SNoW and WIND) activate the corresponding button shown in the applications menu in Fig. 3..3.3.

\subsubsection{DEAD LOAD}

Selection of this button initiates the process for attributing dead loads to surfaces. uttlizing specific menus as shown in Fig. 3.34 (a) (b) and functions similar to those for creating a new surface. The process follows the following steps.

STEP 1 Select the required surfaces from the LIST OF SURFACES shown in Fig. 3.34 (a), to which the load will be attributed. The list of existing surfaces for a given type is displayed when the corresponding surface type button, ROOFS. FLOORS or WALLS is activated.

STEP 2 Select the dead load intensity from the list shown in Fig. 3.34 (b) (a list of structural sandwich systems previously created) to be attributed; after which a plan vicw of the surfaces selected in STEP 1 will be displayed in the main window. Refer to Fig. 3.35. Areas in which dead loads have already been atuributed are distinguished by dashed lines and a different shade pattern or colour for grey scale and colour monitors. respectively.

STEPS 3 Also shown in the application menu window in Fig.3.35 are buttons similar to those for creating a new surface. These are used to attribute the specified dead luad intensity to any given area(s) shown by LOAD AREA BY NODES or 
LOAD AREA ON SCREEN. The function of all button are described below

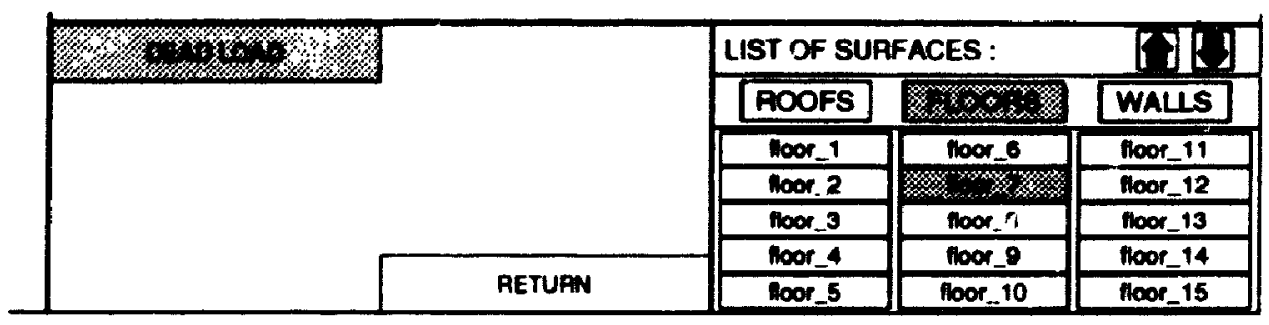

(a) Select Surface

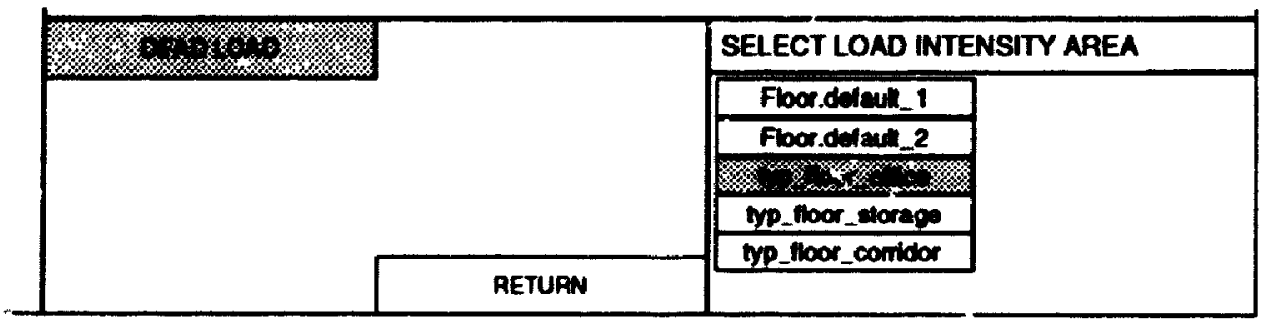

(b) Select Corresponding Structural Sandwich System

Fig. 3.34 DEAD LOAD - Surface and Load Intensity Identification

LOAD AREA BY NODES The load intensity is attached to an area by defining that area. The nodes defining the area are established by (a) keyboard input of three coordinates for each node (tedious) or (b) by selection of existing nodes from the list of nodes or (c) by keyboard input of node ID or (d) by node identification and selection on the screen.

LOAD AREA ON SCREEN The area is defined in the some manner as that where surfaces were creaied with the CREATE ON SCREEN option (described in section 3.2.3.1.3) by mouse scrolling and button selection. This option is extremely useful for defining subareas where nodes have not been previously defined. 


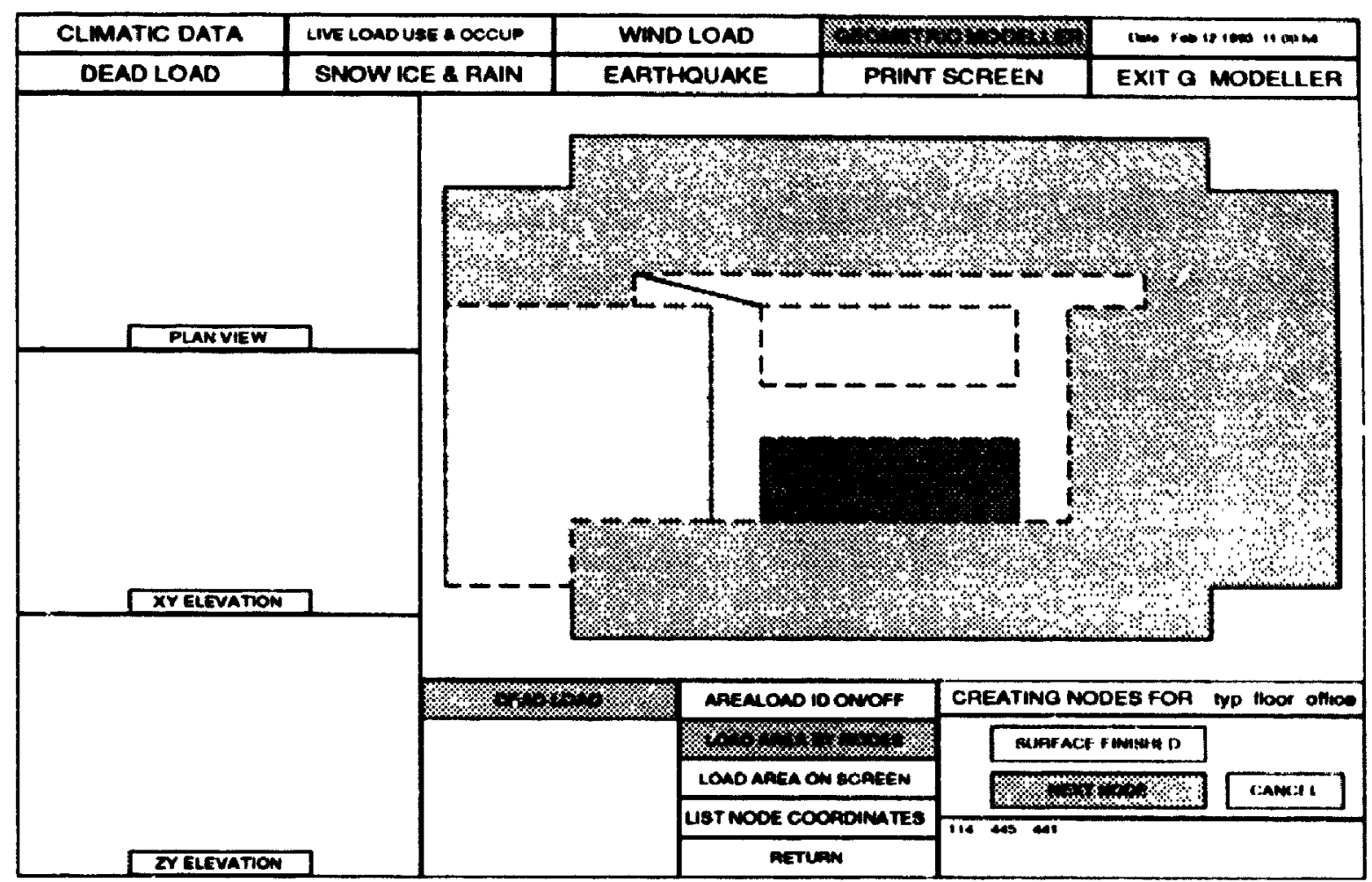

Fig. 3.35 Select Strface with Attributed Dead Load Intensity.

AREA LOAD ID ON/OFF The selection of this button followed by the selection of any area identified on the screen will display the structural sandwich system name and the corresponding load intensity ( $\mathrm{kPa}$ ) in the lower right hand window as shown in Fig. 3.36.

LIST NODE COORDINATES Activating this button displays the list of all existing nodes and their coordinates in the left hand window as shown in Fig. 3.37.

NODE ID ON/OFF Selection of this button followed by the mouse selection of any node on the screen (identified by the square symbol) will display the node ID and the corresponding coordinates in the lower right hand window shown on Fig. 3.37. 


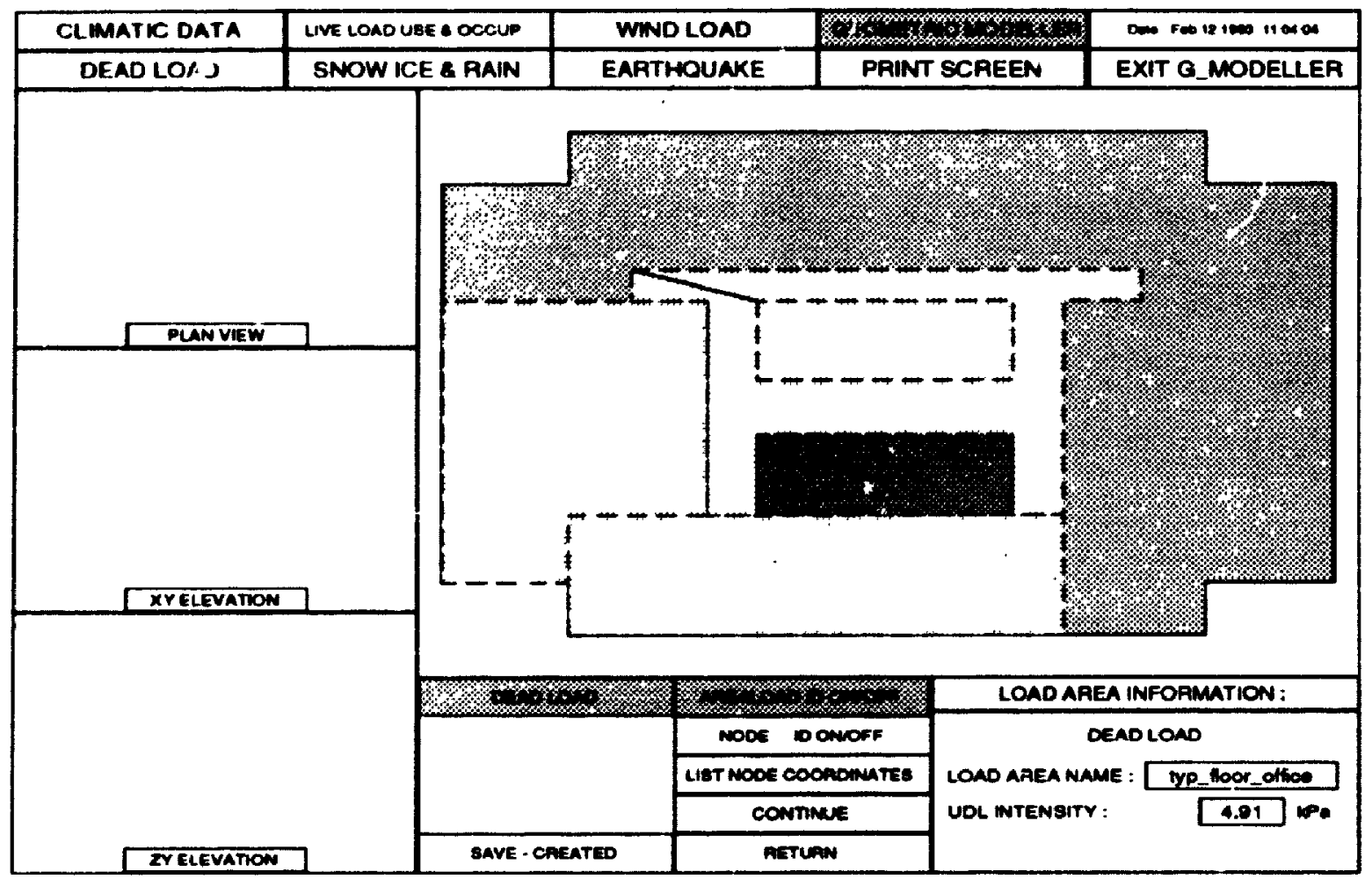

Fig. 3.36 Dead Load Intensity Area 'nformation.

CONTINUE To attribute other load intensities, on the same surface, select the CONTINUE button and the appropriate dead load intensity from the list, shown in Fig. 3.34 (b). Attribute the load as per STEP 3.

S. VE-CREATED The SAVE-CREATED button saves the data, terminates the process for the specified surface and returns the program to the main menu, shown in Fig. 3.3.

RETURN RETURN button terminates the process for a given load type and returns the program to the load type selection menu, shown in Fig. 3.33. 


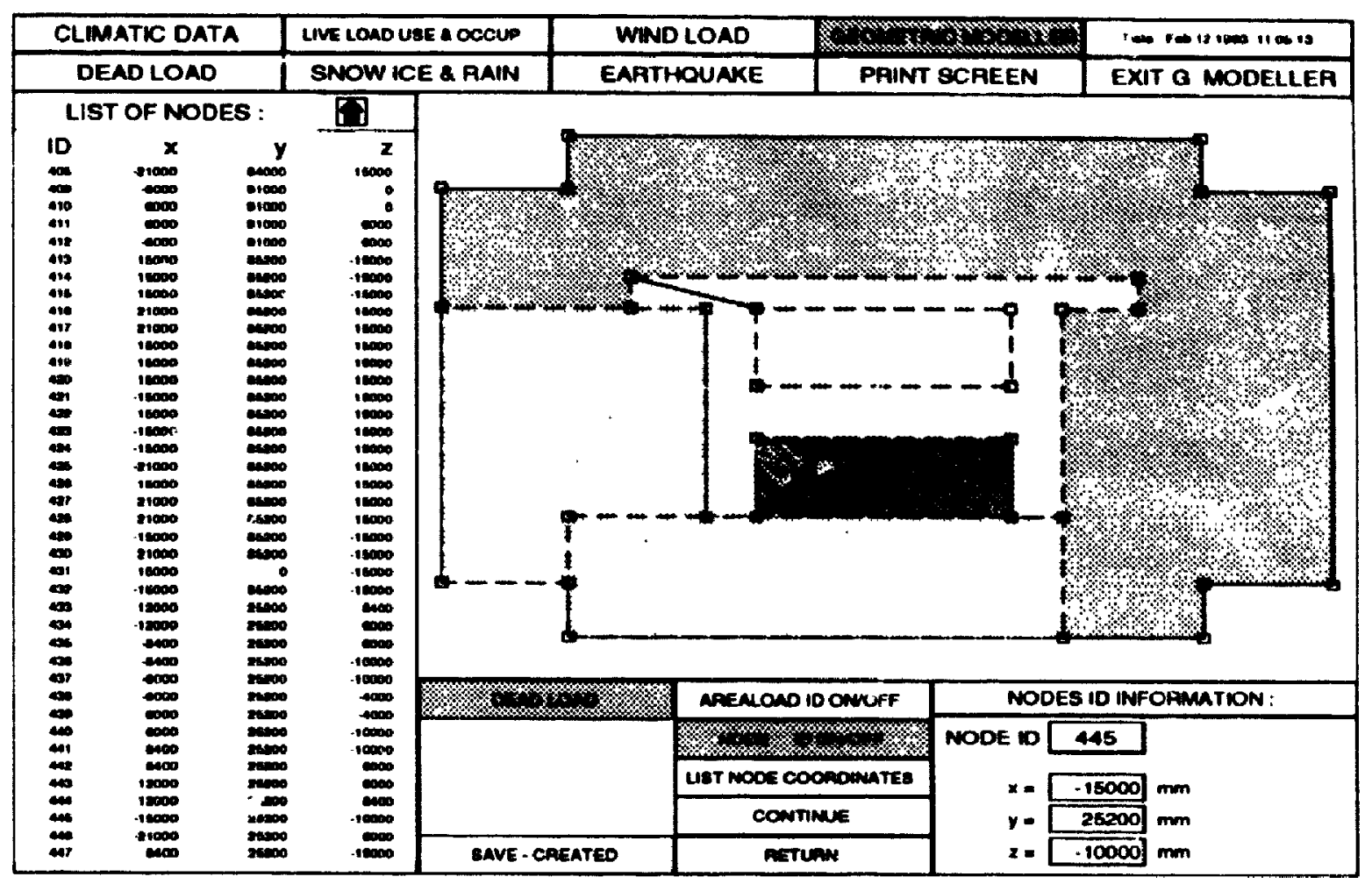

Fig. 3.37 List of Nodes and Nodes ID Information.

\subsubsection{LIVE LOAD}

The procedure for attributing Live Load Use and Occupancy load intensities , surfaces is the same as that described for dead loads. The live load intensity name is selected from the corresponding list (compiled through the process described in section 3.5.), shown in the bottom right hand window in Fig. 3.38.

\subsubsection{Snow Loads - Roof Geometry and Snow Load Distributions}

The type of snow load distributions (function of the roof surface) and the geometry of each roof surface and the corresponding surrounding surfaces that influence snow load distributions and intensities are defined within the geometric modeller module by selecting 


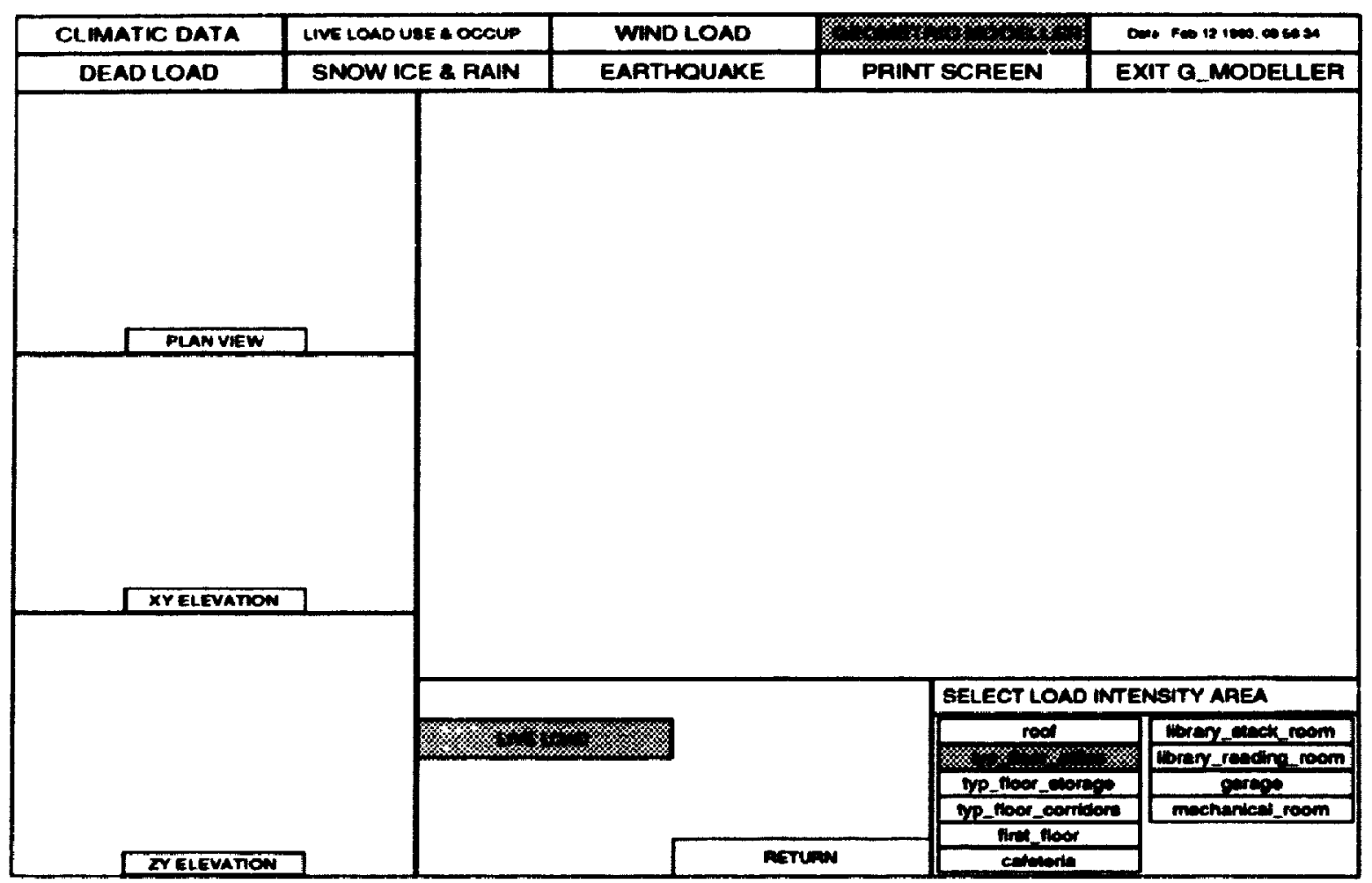

Fig. 3.38 Live Load Use and Occupancy Load Intensity List.

the SNOW LOAD BUTTON. Note, the intensities for a given geographic location are calculated within the snow load module. After the SNOW LOAD button is activated within the geometric modeller menu, the process for each roof surface is as follows.

\section{STEP 1. Select Roof Conditions}

Select the appropriate roof surface condition regular or unobstructed slippery, from the lower right hand window shown in Fig. 3.39.

STEP 2. Select the Appropriate Snow Load Figure

Select the appropriate snow load distribution figure $\mathrm{H}-1$ to $\mathrm{H}-6$, as given in the Supplement to the National Building Code of Canada 1990, NRC 1990, to be applied to 


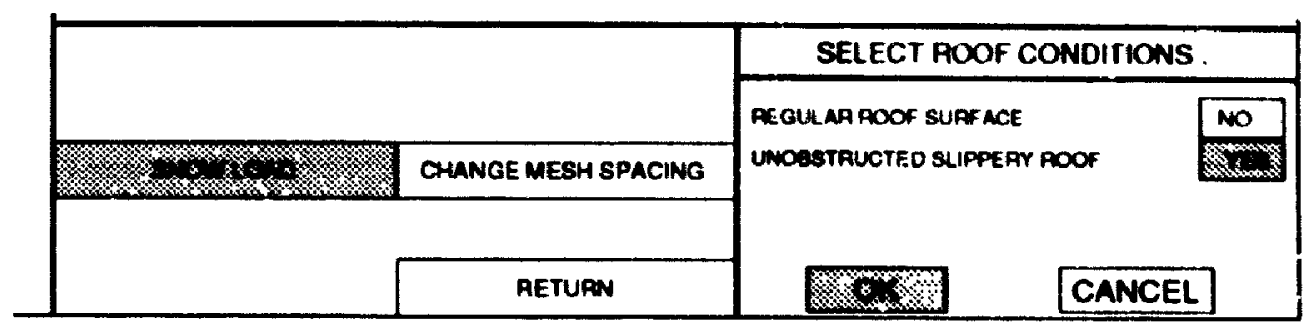

Fig. 3.39 Snow Load - Select Roof Conditions.

the specified roof surface. Refer to Fig. 3.40. These do not apply to special roof surfaces that have unique load distributions. Sand flume and wind tunnel tests that determined these distributions must be conducted. This data can be imported within the snow load module.

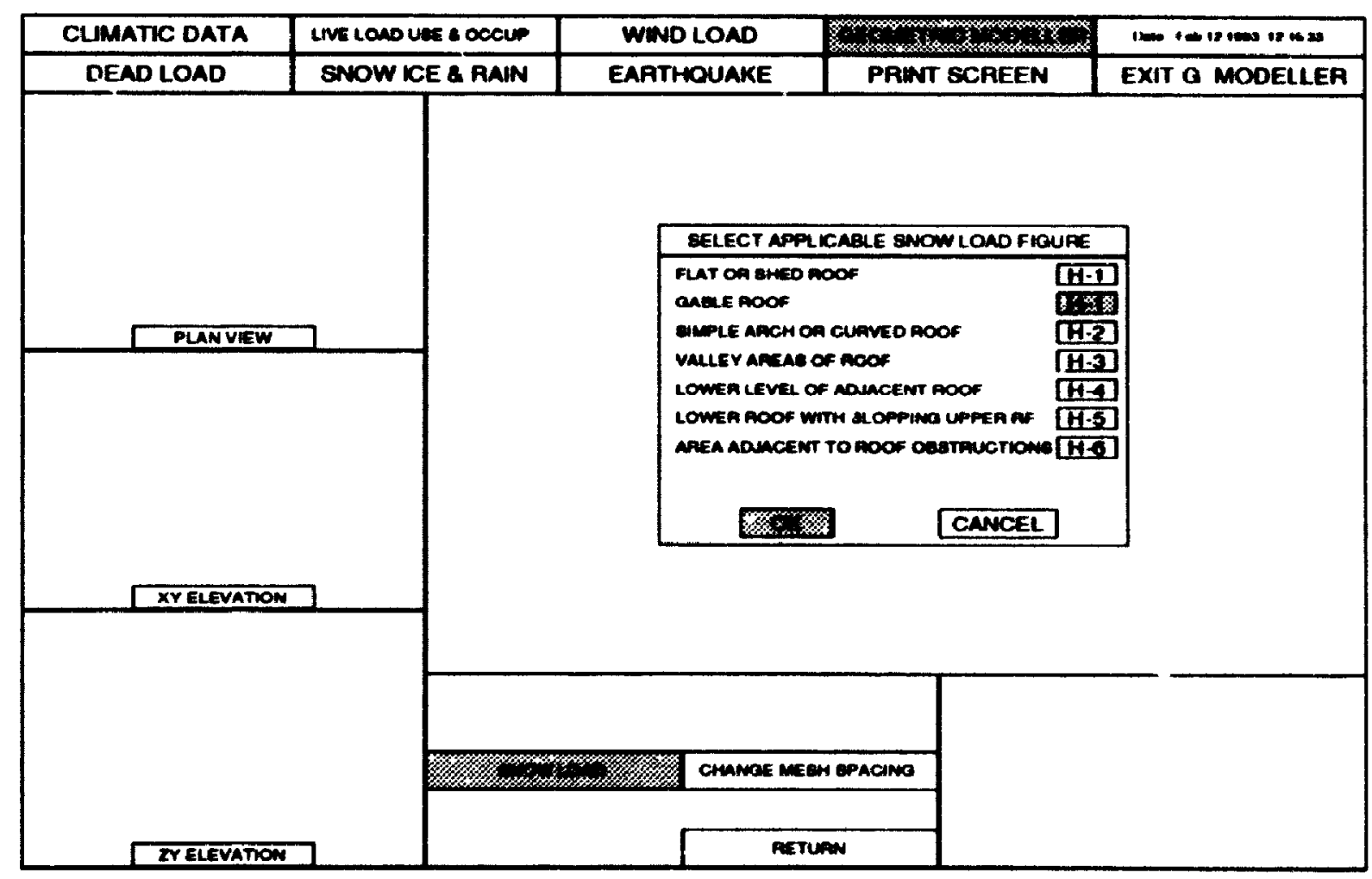

Fig. 3.40 Select Snow Load Figure from Table.

STEP 3. Select the Appropriate Mesh Spacing

The surface is discretized into a rectangular mesh and the load intensity wili be 
calculated at each point. The default mesh spacing is set at $1000 \mathrm{~mm}$. The engineer can alter this spacing for each roof surface to give a more accurate representation of the surface. Refer to Fig. 3.41. For distributions with significant gradient changes, reduce the mesh spacing and for flat surfaces, increase the mesh spacing. Note, flat surfaces need only four points to describe the distribution accurately.

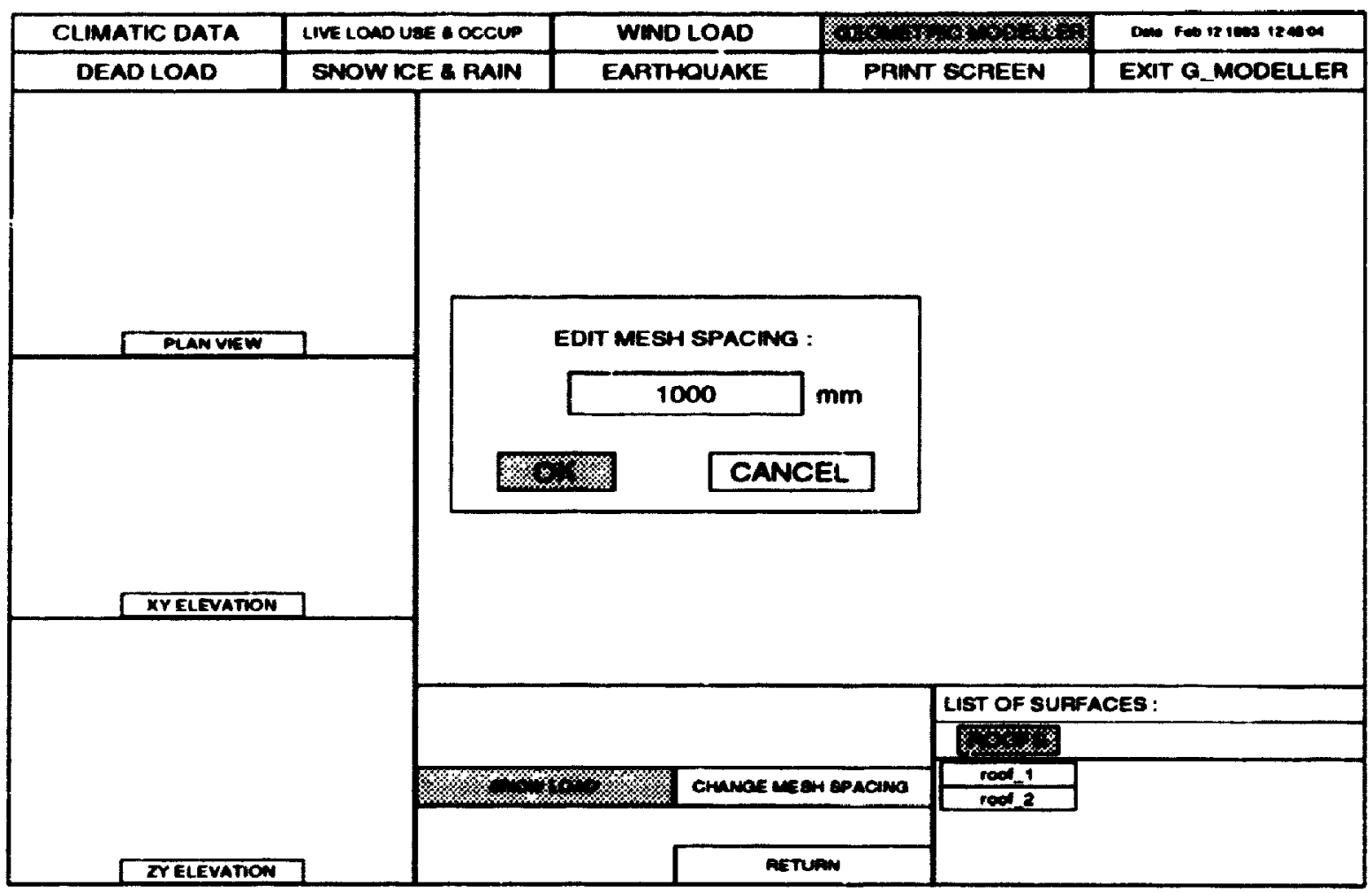

Fig. 3.41 Mesh Spacing Definition and List of Surfaces.

\section{STEP 4. Select a Roof Surface}

Select the roof surface from the list of surfaces, shown in Fig. 3.41, to which the load distribution will be applied and the mesh created.

STEP 5. Identify Adjacent Roofs, Walls or Projections

The program will prompt the engineer to identify adjacent roofs, walls or 


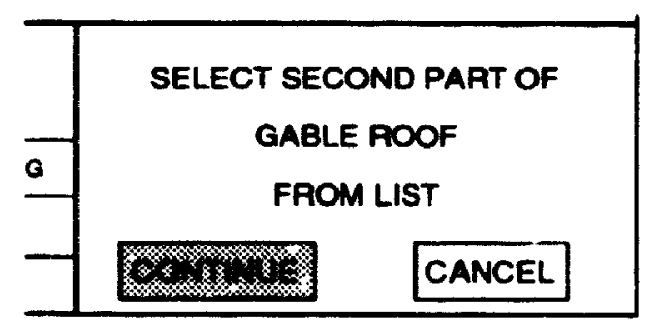

(a) Gable Roofs - Figure H-1

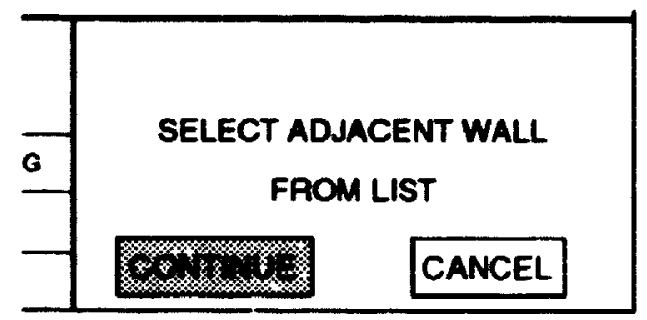

(c) Roofs with Obstructing Walls

- Figure H-4

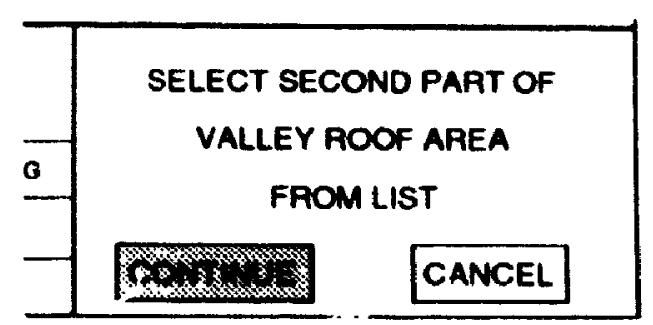

(b) Valleys - Figure H-3

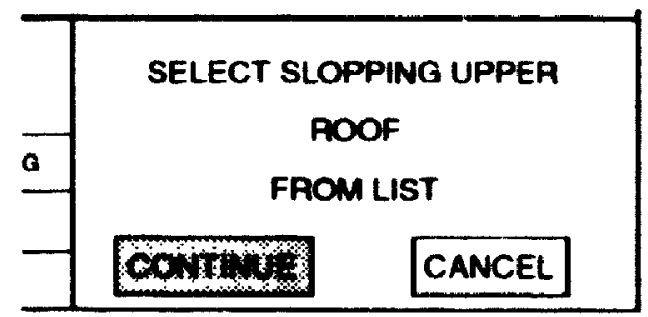

(d) Roofs with Sliding Snow Load - Figure H-5

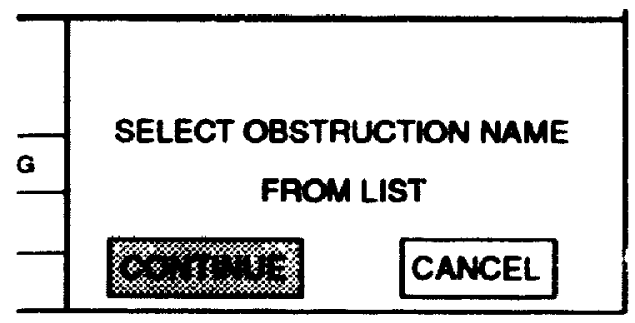

(e) Roof Obstructions - Fig. H-6

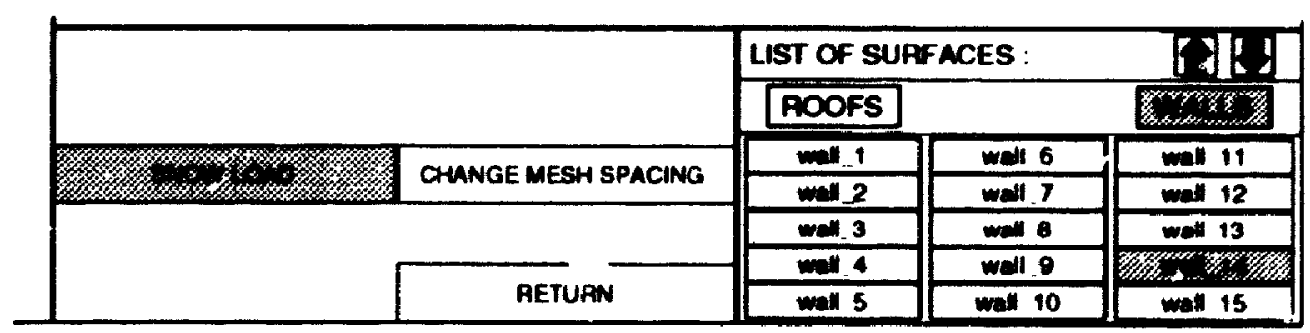

(f) List of Adjacent Walls

Fig. 3.42 Select Adjacent Surfaces that Influence Snow Load Distributions and Intensities. 
projections to the specified roof surface that will influence the snow load distribution. The prompt is automatic and is a function of the snow load figure selected in STEP 2. As shown in Fig. 3.42 (a), (b) and (d) for gable, valley and sloping roofs respectively, the engineer is prompted to select the adjacent roof from the list of roofs. A similar prompt is made for adjacent walls for lower roofs, Fig. 3.42 (d) and for roof obstructions, Fig. 3.42 (e). The corresponding list of walls for the building is shown in Fig. 3.42 (f). A file with the appropriate geometric data for the snow load calculations for this roof surface is generated at the end of this step.

STEP 6. Repeat STEPS 1 to 5 for each roof surface.

The RETURN button returns the program to the attribute loads to surfaces menu shown in Fig. 3.33.

\subsubsection{WIND LOADS}

The main functions of this part of the program are to attach building envelop characteristics to different surfaces subjected to wind pressure (the distribution of openings influence the internal pressure) and to define the appropriate size of mesh at which the load intensities will be calculated. The intensities for a given geographic location are calculated within the wind load module. Afte- the WIND LOAD button is activated within the geometric modeller menu, the process for each exterior surface is as follows.

\section{STEP 1. Select a Roof or Wall Surface}

Select a roof or wall surface from the lists of surfaces shown in Fig. 3.43 for 
which the distribution of openings in the walls and mesh size will be detined.

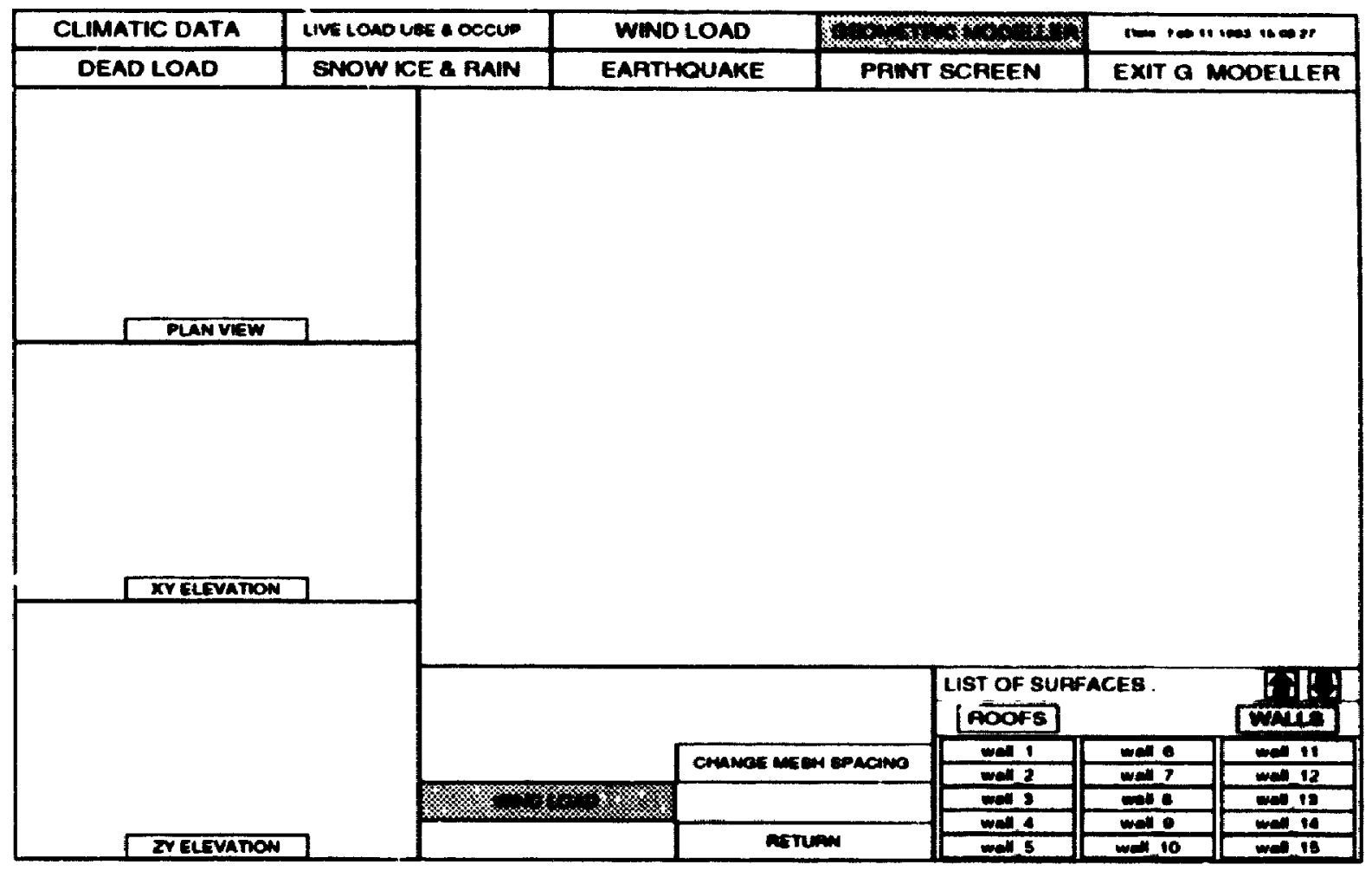

Fig. 3.43 Surface Selection for Auributing Wind Load

STEP 2. Define the Distribution of Openings in the Walls

Select the appropriate classification for the distribution of opxenings in the walls from the menus shown in Fig. 3.44 (a) and (b) for roof surfaces and walls, respectively. Note, the distribution of openings in exterior surfaces influences the internal pressures and hence the net specified pressure or suction on the surface. For example, the largest nct specified pressure for a roof surface is generated when the openings are located in one wall and the wind direction is perpendicular to it. A file with the appropriate data is generated at the end of this step. 


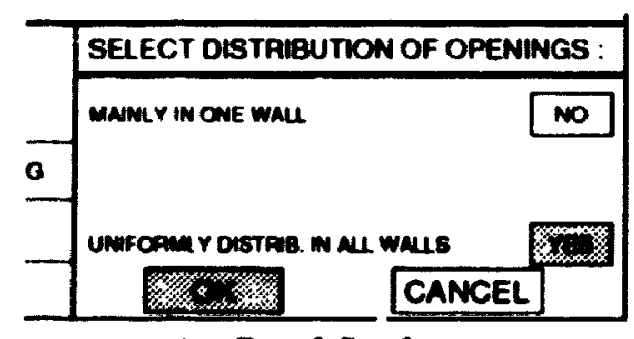

(a) Roof Surfaces

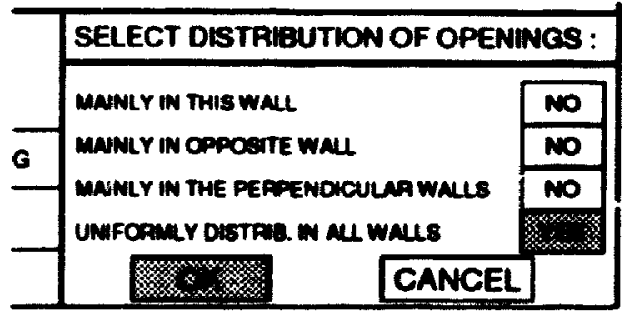

(b) Walls

Fig. 3.44 Distribution of Openings for the Calculation of Wind Loads.

Step 3. Repeat STEPS 1 to 2 for each exterior surface

As with the snow load, the mesh spacing can be redefined using the CHANGE MESH SPACING button, otherwise the default value of $1000 \mathrm{~mm}$ will be used. Execute the RETURN button to exit this section of the program.

\subsection{Calculation OF SNOW loAdS}

The calculation of snow load intensities acting on roof surfaces of the structure is only possible once the climatic data and the geometry have been defined. The selection of the SNOW LOAD button from top main menu activates the screen display as shown in Fig. 3.45 with an applications menu containing the buttons LIST ROOF AREAS, CLIMA IIC DATA INFO, SAND FLUME DATA and WIND TUNNEL DATA. The process for calculating snow loads is as follows:

STEP 1. Verify and Edit Climatic and Building Site Data

The climatic and building site data for the specified location must be verified before 


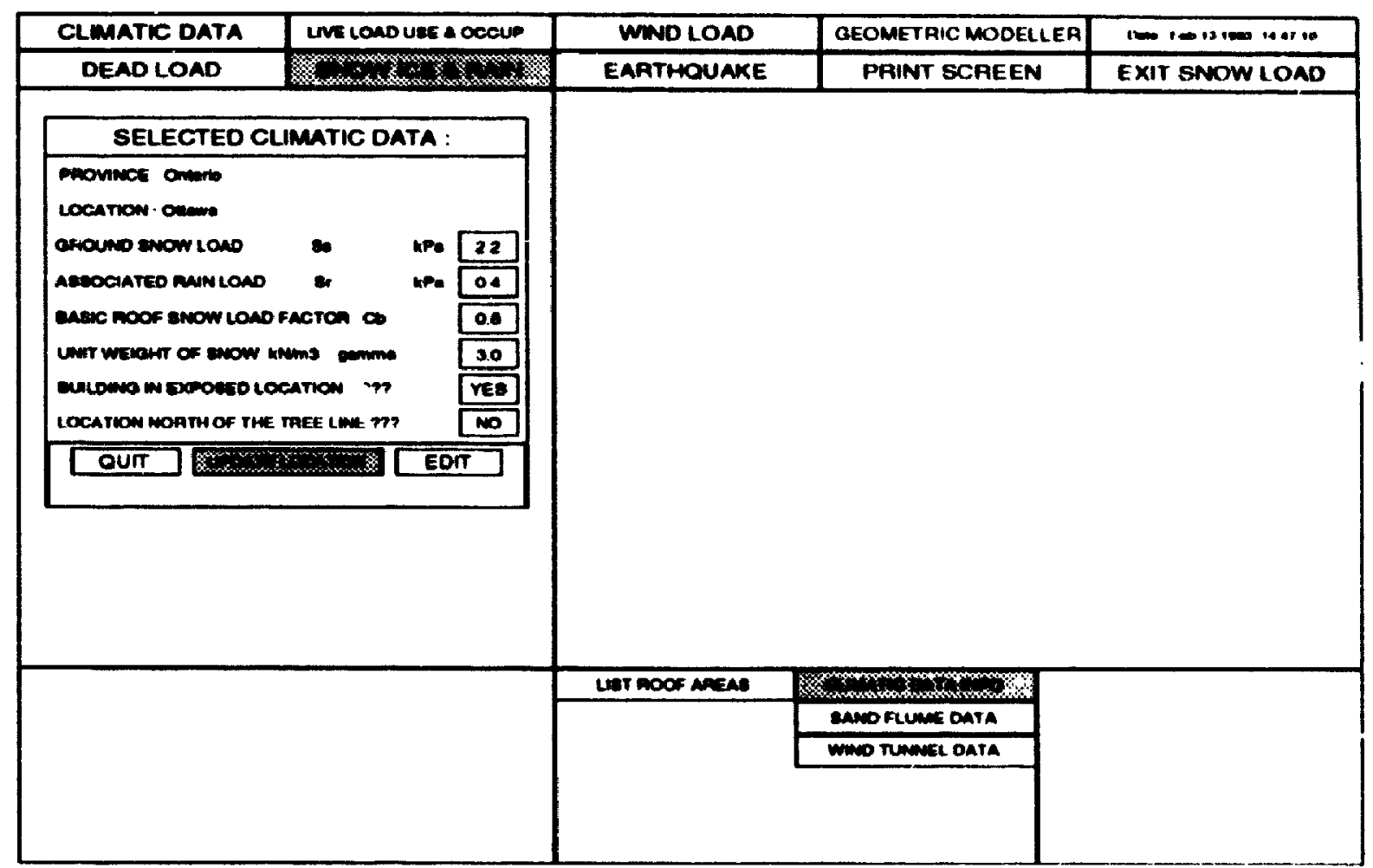

Fig. 3.45 Snow Load - Climatic Data Information.

the snow load intensity can be calculated. Selection of the CLIMATIC DATA INF() button gives the option of viewing and editing the climatic data shown in the left hand window in Fig. 3.45. Information about the building site, exposure and whether or not the location is north of the tree line must be verified to obtain the comect value for the wind exposure factor. To modify the data select the EDIT button and then the data value or building site information to be changed and enter the new value from the keyhoard. YES NO values toggle when selected. This is particularly useful for mountainous artas where the ground snow load changes radically from one valley to the next or for the Maritime Provinces where the unit snow load may be greater than $3.0 \mathrm{kN}$ per metre cubed. Select the UPDATE LOCATION button to save the revised climatic data for this project. To terminate the editing process select the QUIT button and the window displaying the 


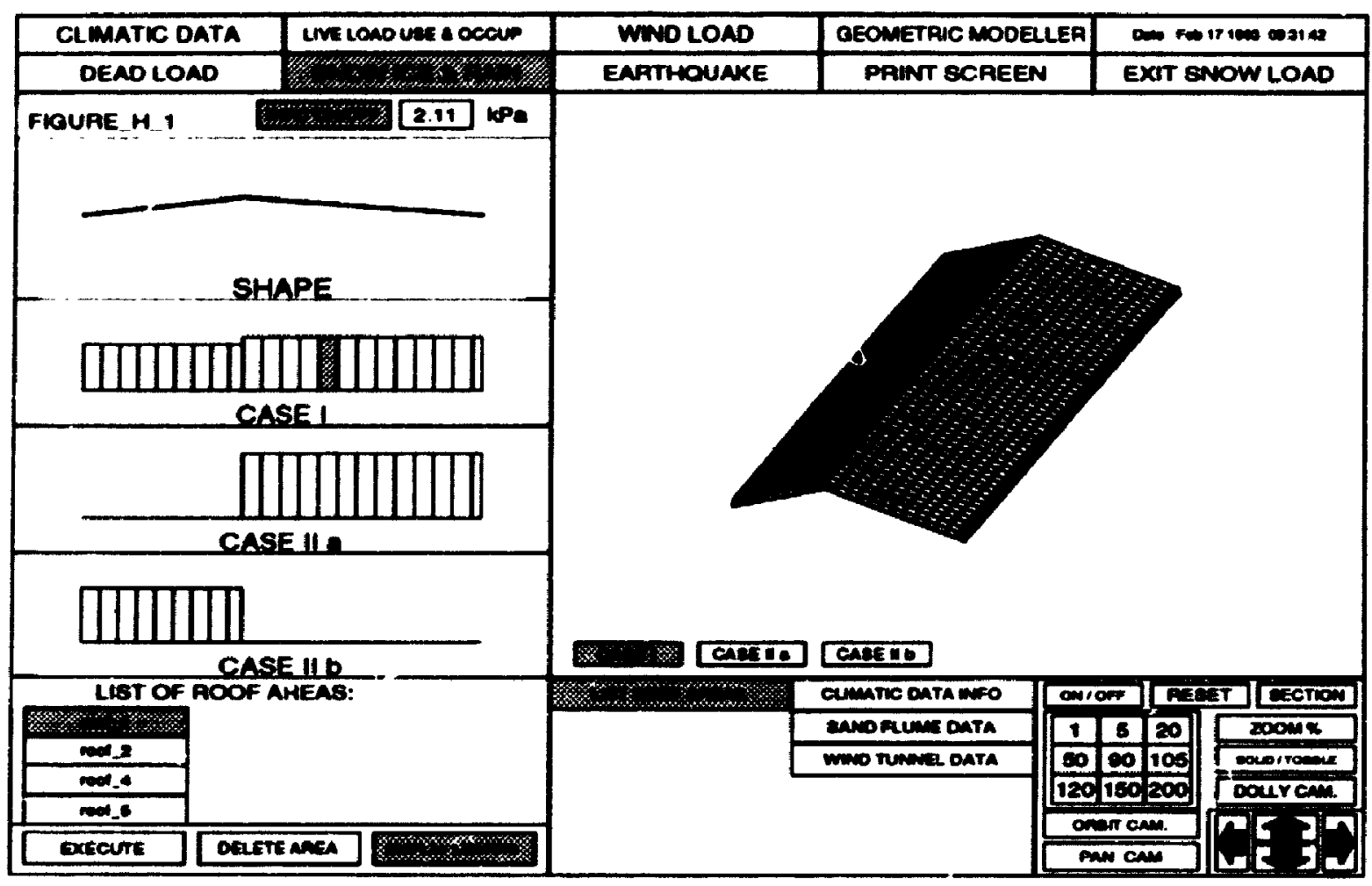

Fig. 3.46 Snow Load Example for Gabled Roofs - Figure H-1.

climatic and building site data disappears.

STEP 2. Select Roof Area and Execute Calculation Procedure

Selection of the LIST ROOF AREAS button lists the roof surfaces defined by the process described in section 3.6.3. in the bottom left hand window in Fig. 3.46. Select the EXECUTE hutton and the surface to calculate the snow load intensity for all possible load cases at each point on the prescribed mesh. The data is stored in the appropriate output file described in Appendix B - File Architecture. Currently, the loads on each surface must be calculated individually. By selecting the DISPLAY LOADING button, followed immediately by surface name button, all the applicable snow load cases for the appropriate snow load figure, as applied to the specified roof, including a cross section of the roof, are 


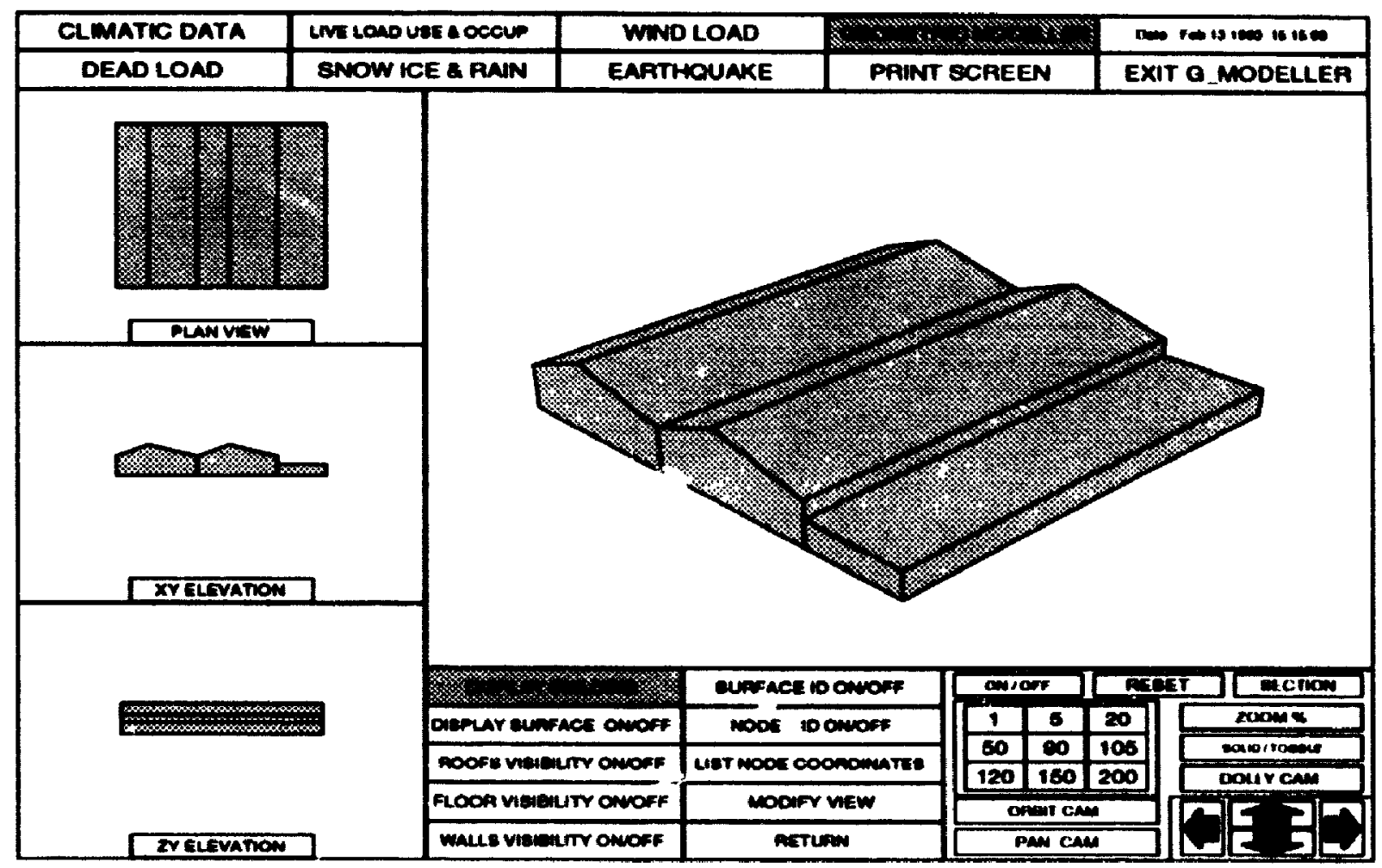

Fig. 3.47 Example Low-Rise Structure

displayed in the left hand window with the roof displayed in $\mathbf{3}$ dimensions in the main window as shown in Fig. 3.46. A 3 dimensional view of each snow load distribution is activated by the load case buttons, CASE I, CASE II (a) AND CASE II (b), shown in the main window. The depth of the displayed snow accumulation on the roof is based on average unit weight of snow of $3.0 \mathrm{kN}$ per metre cubed as recommended in the NBCC 1990, NRC (1990). Figure 3.46 is an illustration of the snow load distributions for the gahled shape portions of the roof of the low ris industrial building shown in Fig. 3.47. Figure 3.48 and 3.49 illustrate the snow load distributions for the valley section and for the lower roof with the upper sloping roof respectively. The INFO ON/OFF button located in the header of the left hand window activates the option which will display the load intensity at any location on the snow load graphs or at any location within the 3 


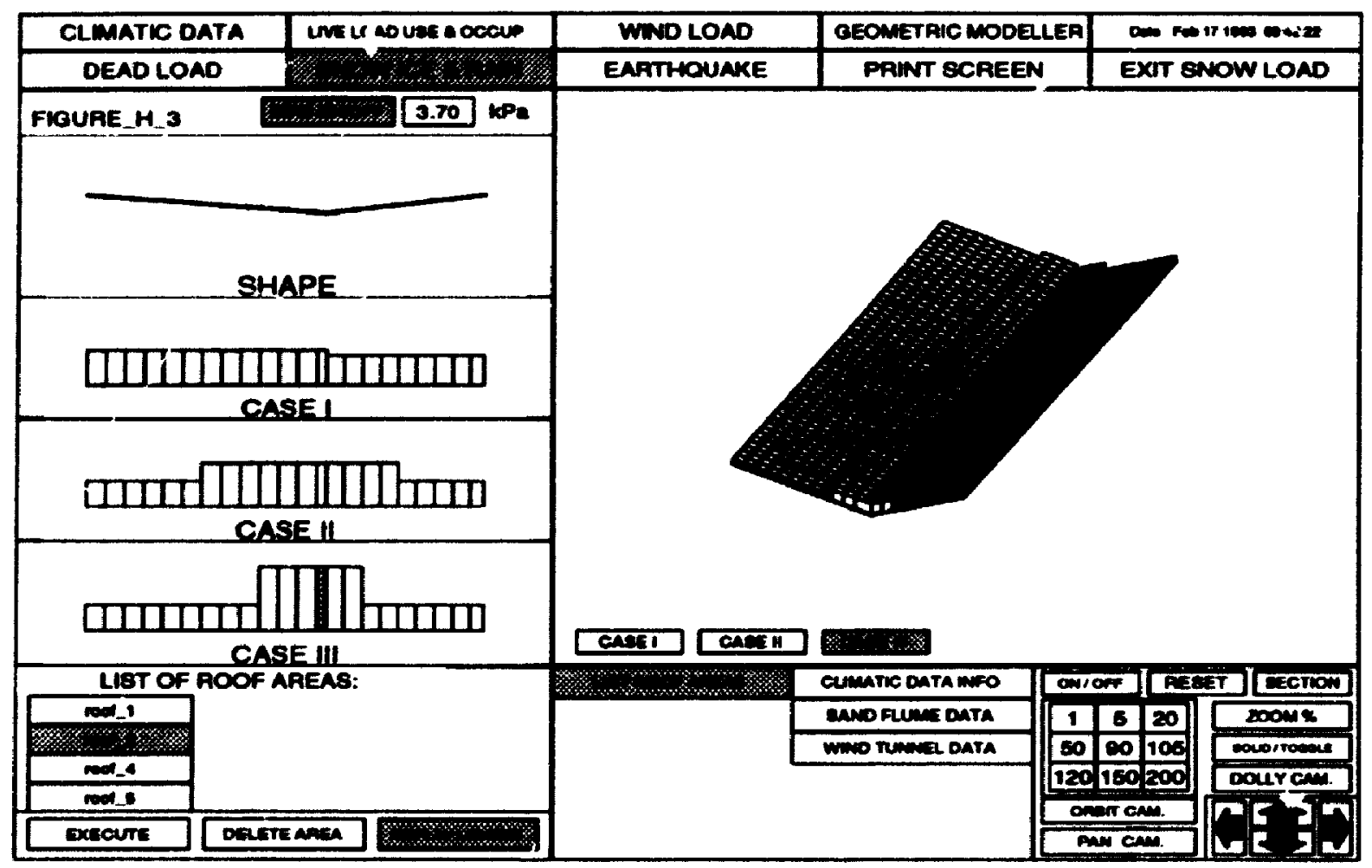

Fig. 3.48 Snow Load Example tor Valleys - Figure H-3.

dimensional view by mouse selection at that location. The load intensity displayed is the average snow load intensity over area surrounded by neighbouring points of mesh. To modify the view of the 3 dimensional image activate the ON/OFF button in the lower right hand application window. All other buttons function as described in sectic $: 3.2 .5$. Any surface can be deleted from the list of roof areas by selecting the DELETE AREA button and then the name of the surface from the list. Confirmation is required. The SAND FLUME DATA and WIND TUNNEL DATA buttons are reserved for future versions of the program where the snow load distributions for complex surfaces (cannot be determined from the standard library functions given in Fig. H-1 to H-6 of the NBCC Supplement. NRC 1990) obtained by model tests can be imported and displayed directly on the corresponding geometric model. 


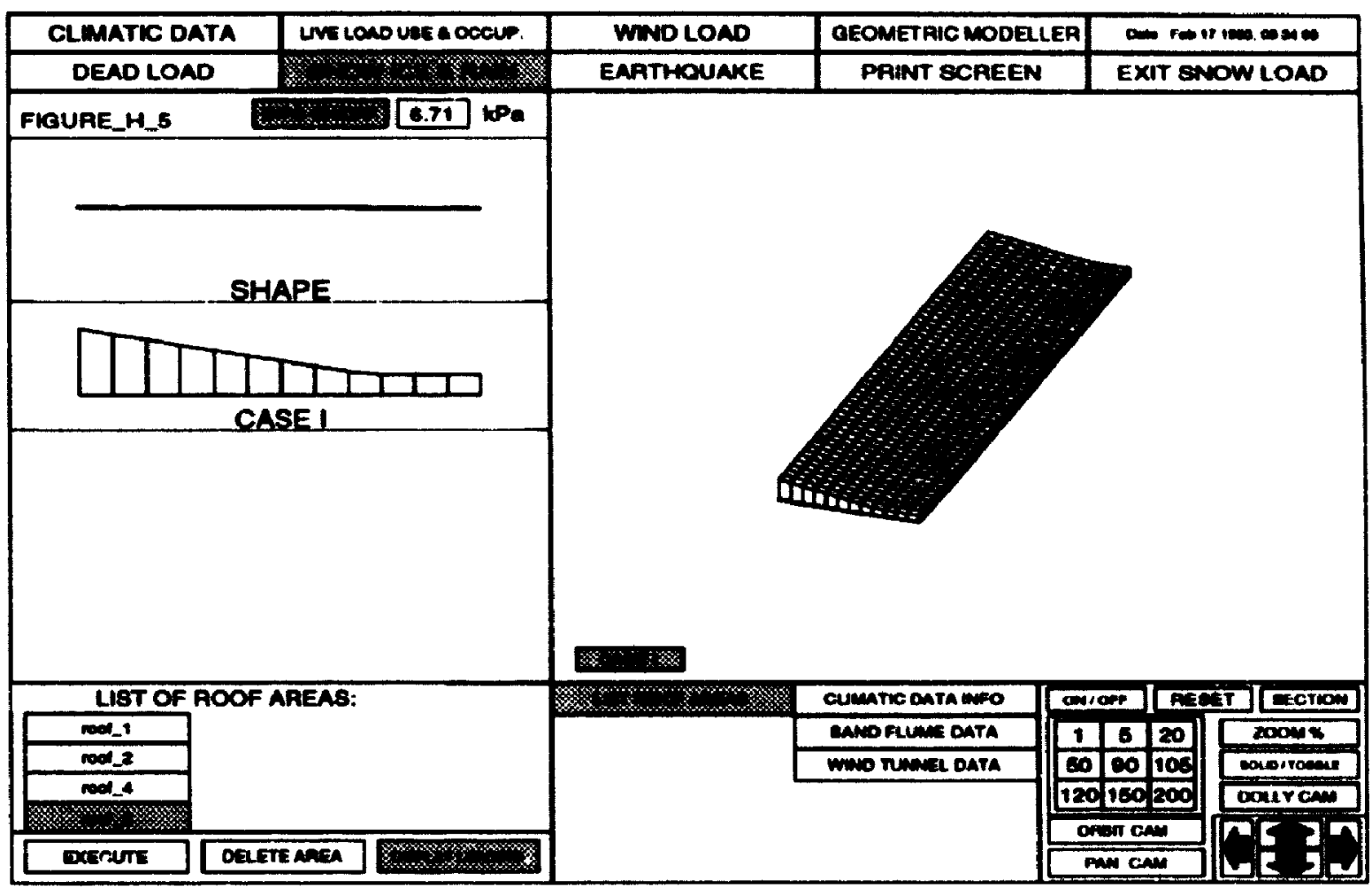

Fig. 3.49 Snow Load Example for Lower Roof with Sliding Snow - Figure H-4 and H-5.

\subsection{CALCULATION OF WIND LOADS}

The calculation of wind load intensities acting on exterior surfaces of the structure is only possible once the climatic data and the geometry have been defined. The selection of the WIND LOAD button from top main menu activates the screen display as shown in Fig. 3.50 with an application menu containing the buttons LIST EXTERIOR SURFACES, LOCATION INFO, and STRUCTURE SET UP DATA. The process for calculating wind loads is as follows: The climatic and building site data for the specified location must be verified before the wind load intensity can be calculated.

STEP 1. Verify and Edit Climatic and Building Site Data

Selection of the LOCATION INFO button gives the option of viewing and editing 


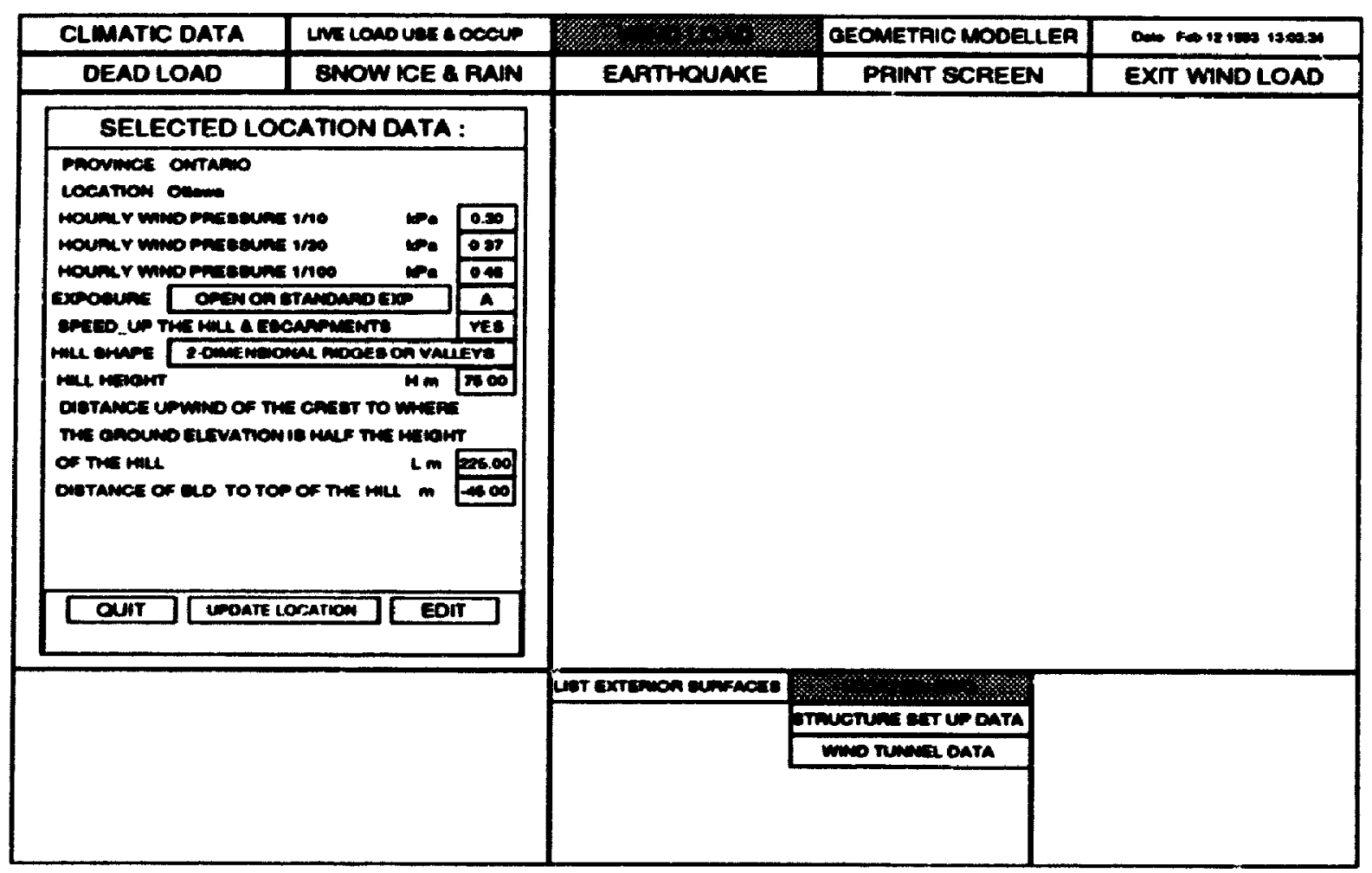

Fig. 3.50 Wind Load - Climatic Data Information.

the climatic and building site data (exposure factor and parameters for speed up calculations), shown in the left hand window in Fig. 3.50. To modify the data select the EDIT button and then the data value or building site information to be changed and enter the new value from the keyboard. Non-numeric inputs tither toggle or scroll through the available options when selected.

Select the UPDATE LOCATION button save the revised data for this project. To terminate the editing process select the QUIT button and the window displaying the climatic and building site data disappears. 


\begin{tabular}{|c|c|c|c|c|}
\hline CLMATIC DATA & LMT LOAD UAE A OCOUP & $1 \times-1$ & GEOMETAIC MODELLER & 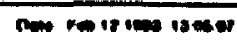 \\
\hline DEAD LOAD & SNOW ICE \& RAIN & EAPTHOUAKE & PAINT SCREEN & EXIT WIND LOAD \\
\hline \multicolumn{2}{|c|}{ STRUCTURE SET UP DATA : } & & & \\
\hline \multicolumn{2}{|c|}{ 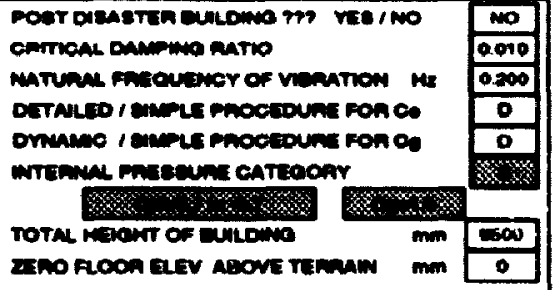 } & & & \\
\hline $\begin{array}{l}\text { To cromate } \\
\text { CANCEL }\end{array}$ & aracomit me & & & \\
\hline & & LAT EXTEMTOM DONFACES & Location ins:o & \\
\hline & & & miso ruman oata & \\
\hline
\end{tabular}

Fig. 3.51 Structural Characteristics.

STEP 2. Define Structural Characteristics and the Procedure for Calculating the Wind Loads

Selection of the STRUCTURE SET UP DATA button gives the option of defining dynamic properties of the building (critical damping ration, natural frequency of vibration) and the procedure for calculating the wind loads as shown in left hand window in Fig. 3.51. To modify the data select the EDIT button and then the data value or set up parameter to be changed and enter the new value from the keyboard. Non-numeric inputs either toggle or scroll through the available options when selected. Select the SAVE CHANGES to save the data for this project. To terminate the process select the QUIT button and the window displaying the structure set up data disappears. Note, if the height of the building is not specified, then it is set to the largest ' $y$ ' coordinate value. 


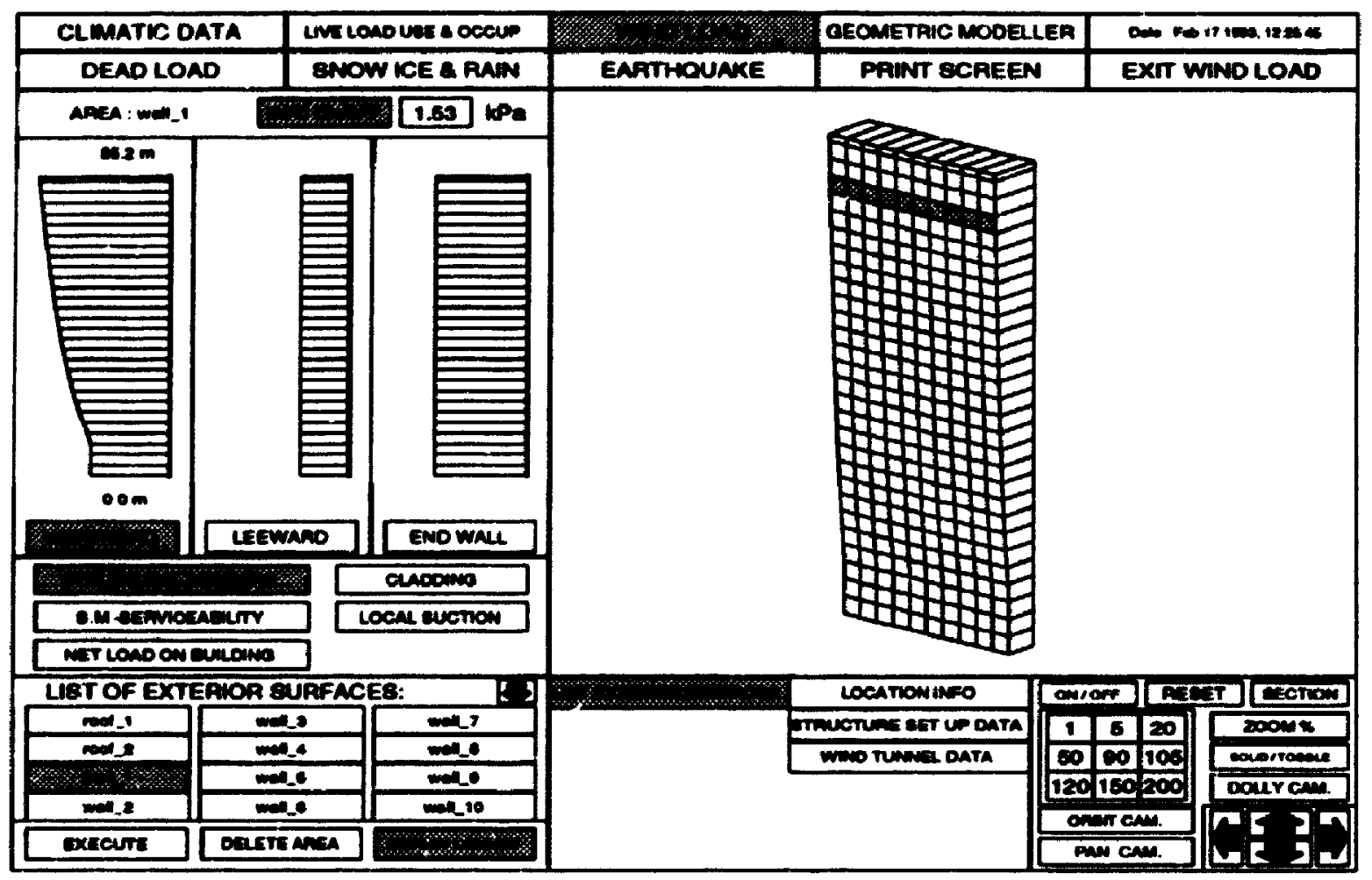

Fig. 3.52 (a) Example Wind Load Distribution for a Wall of a High-Rise Building.

STEP 3. Select Exterior Surface and Execute Calculation Procedure

Selection of the LIST EXTERIOR SURFACES button lists the exterior surfaces of the building defined by the process described in section 3.6 .4 in the bottom left hand window in Fig. 3.52 (a). Select the EXECUTE button and the surface to calculate the wind load intensities, for all possible load cases (refer to section 2.5 ), at each point on the prescribed mesh. The data is stored in the appropriate output file described Appendix B File Architecture. Currently, the loads on each surface must be calculated individually. By selecting the DISPLAY LOADING button, followed immediately by surface name button, all the applicable wind load cases for the specified surface are displayed in the left hand window with the surface displayed in 3 dimensions in the main window as 


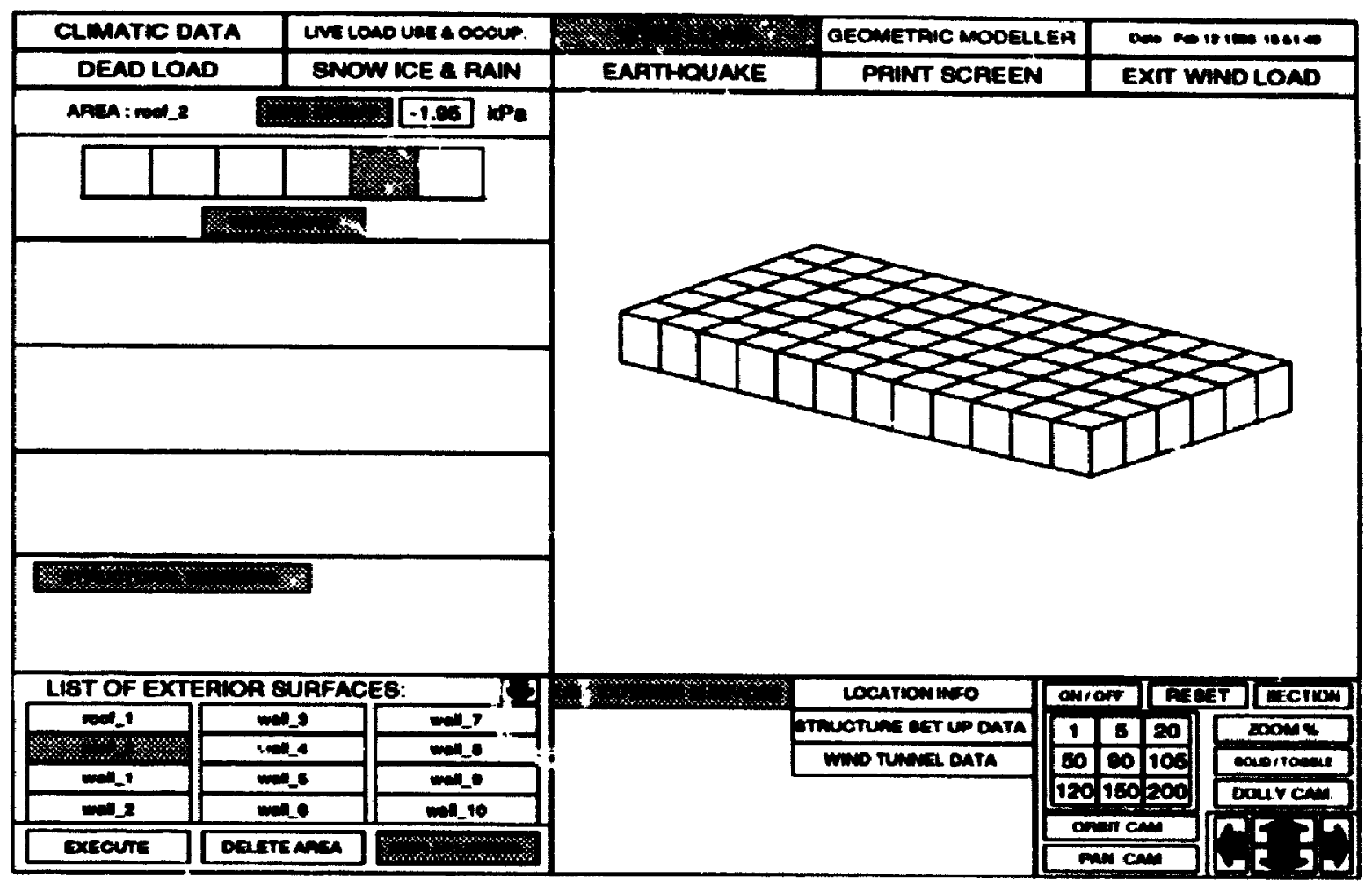

Fig. 3.52 (b) Example Wind Load Distribution for a Roof of a High-Rise Building.

shown in Fig. 3.52 (a). A 3 dimensional view of each wind load distribution is activated by selecting the corresponding button name, ie. WINDWARD, LEEWARD or END WALL. Figures 3.52 (a) and b) show the wind load distributions for the high-rise building example created in section 3.2. for a typical wall and roof, respectively. A typical low-rise building, shown in Fig. 3.53 (meets all the geometric requirements of a low-rise structure given in Chapter 4, Commentary B of the NBCC Supplement 1990, NRC (1990), was created to illustrate the application of Figures B-7 to B-10 of the commentary. Illustrated in Fig. 3.54 (a), (b) and (c) are wind load distributions for one roof surface, a wall parallel to the ridge and a wall perpendicular to the ridge, respectively. 


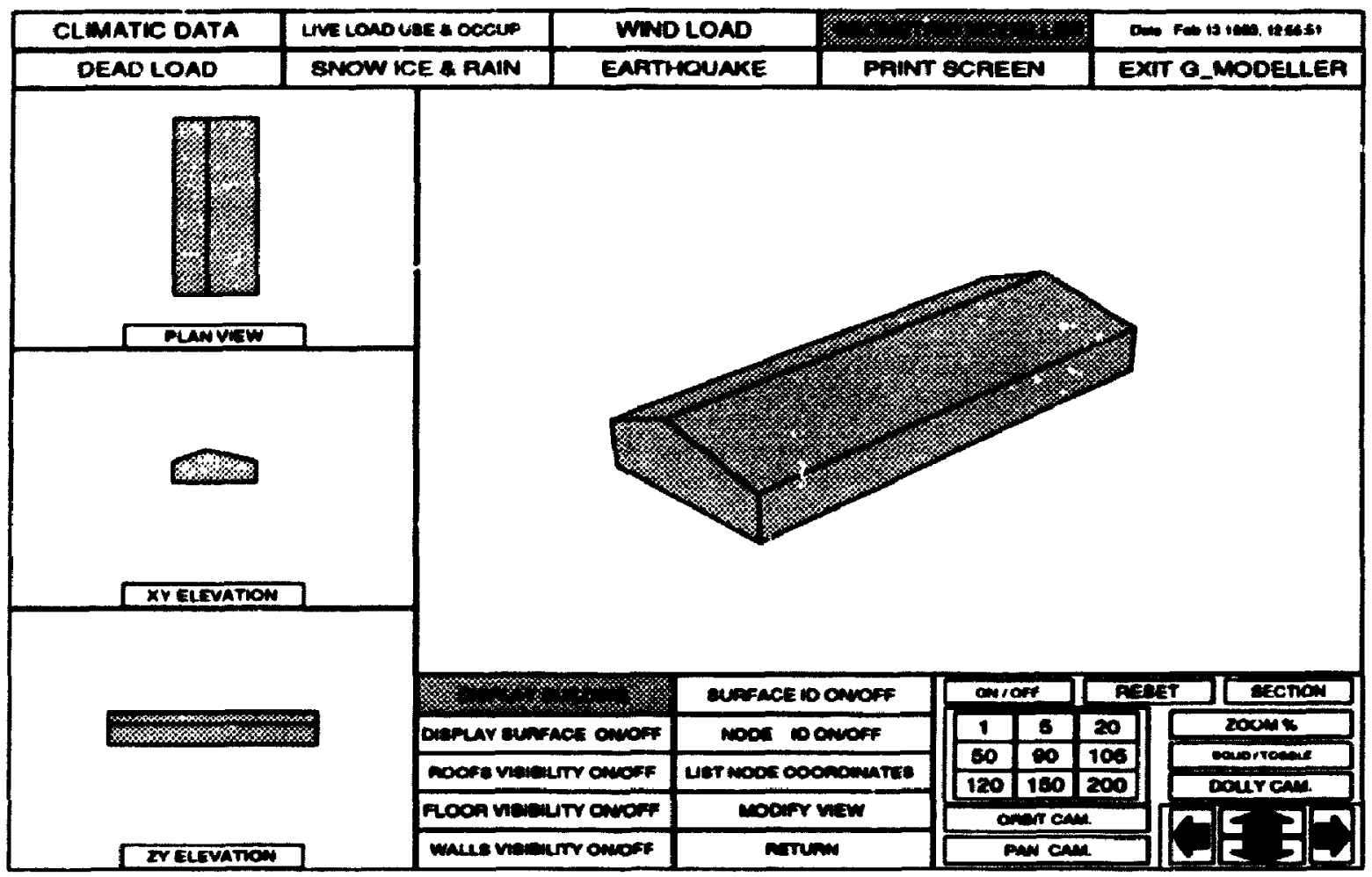

Fig. 3.53 Example Low-Rise Building. Application of Figure B-7 to B-10.

As shown in the left hand window, the wind load distributions for structural members (Fig. B-7) and for secondary structural members and cladding (Fig. B-8, B-9 and B-10) are displayed independently by activating the corresponding button. The wind load profiles are shown for either the midjle section or in the end zone depending upon which button is currently active. Note, for the high-rise example in Fig. 3.52 (a), additional button applicable to the type of building (CLADDING, LOCAL SUCTION, S.M.SERVICEABILITY and NET LOAD ON BUILDING) serve similar functions. Although a limited number of load cases can be viewed at one time on the screen, all are calculated and stored in the appropriate output files. 


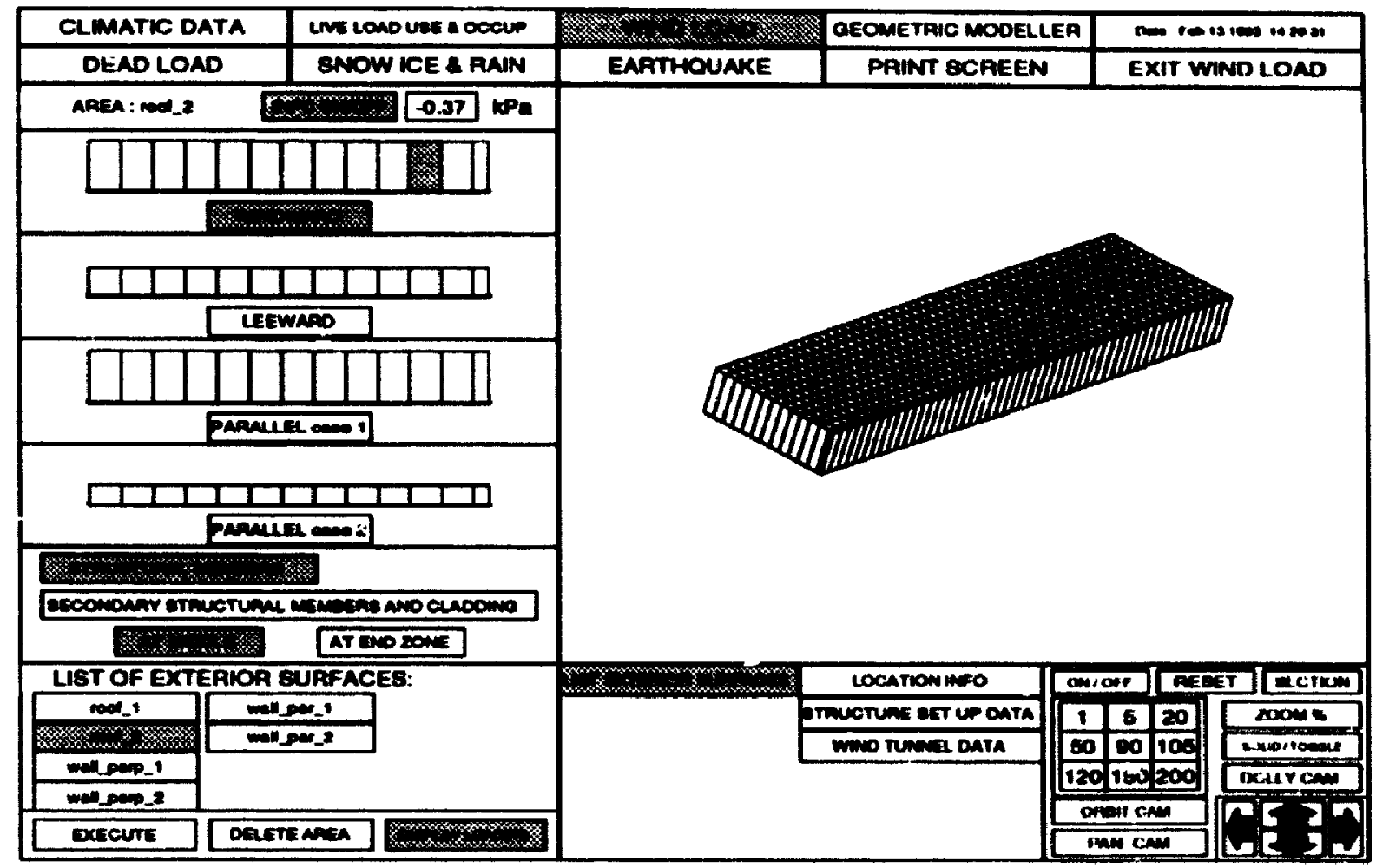

Fig. 3.54 (a) Wind Load Distribution for a Roof of a Low-Rise Building.

The INFO ON/OFF button and the ON/OFF button serve the same function as that described for snow loads. Any exterior surface can be deleted from the list by selecting the DELETE AREA button and then the name of the surface from the list. Confirmation is required. As before, the WIND TUNNEL DATA button is reserved for future versions of the program where the wind load distributions for complex or unique buildings obtained from model tests can be imported and displayed directly on the corresponding geometric model. 


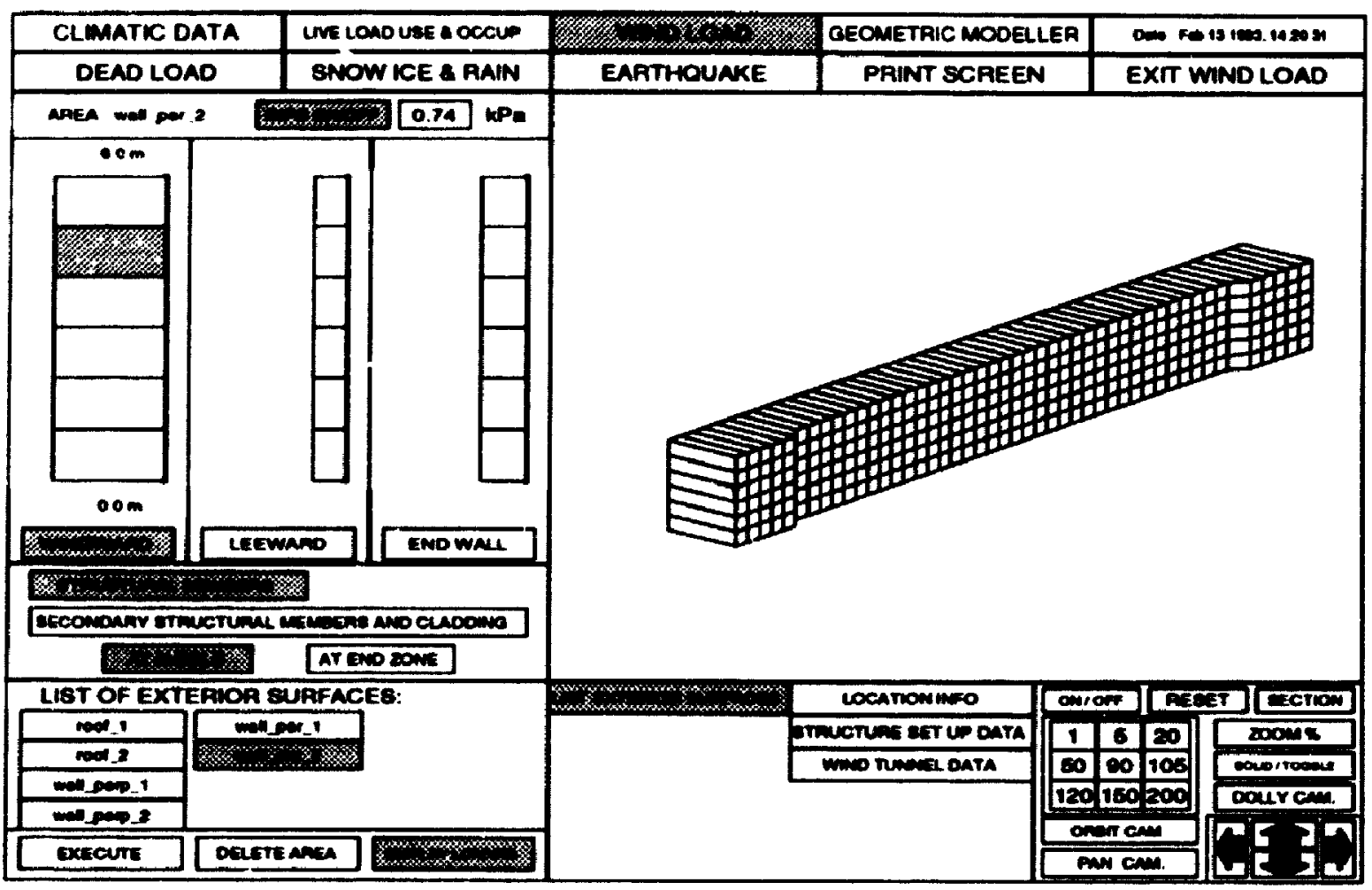

Fig. 3.54 (b) Wind Load Distribution for a Wall Parallel to the Ridge of a Low-Rise Building. 


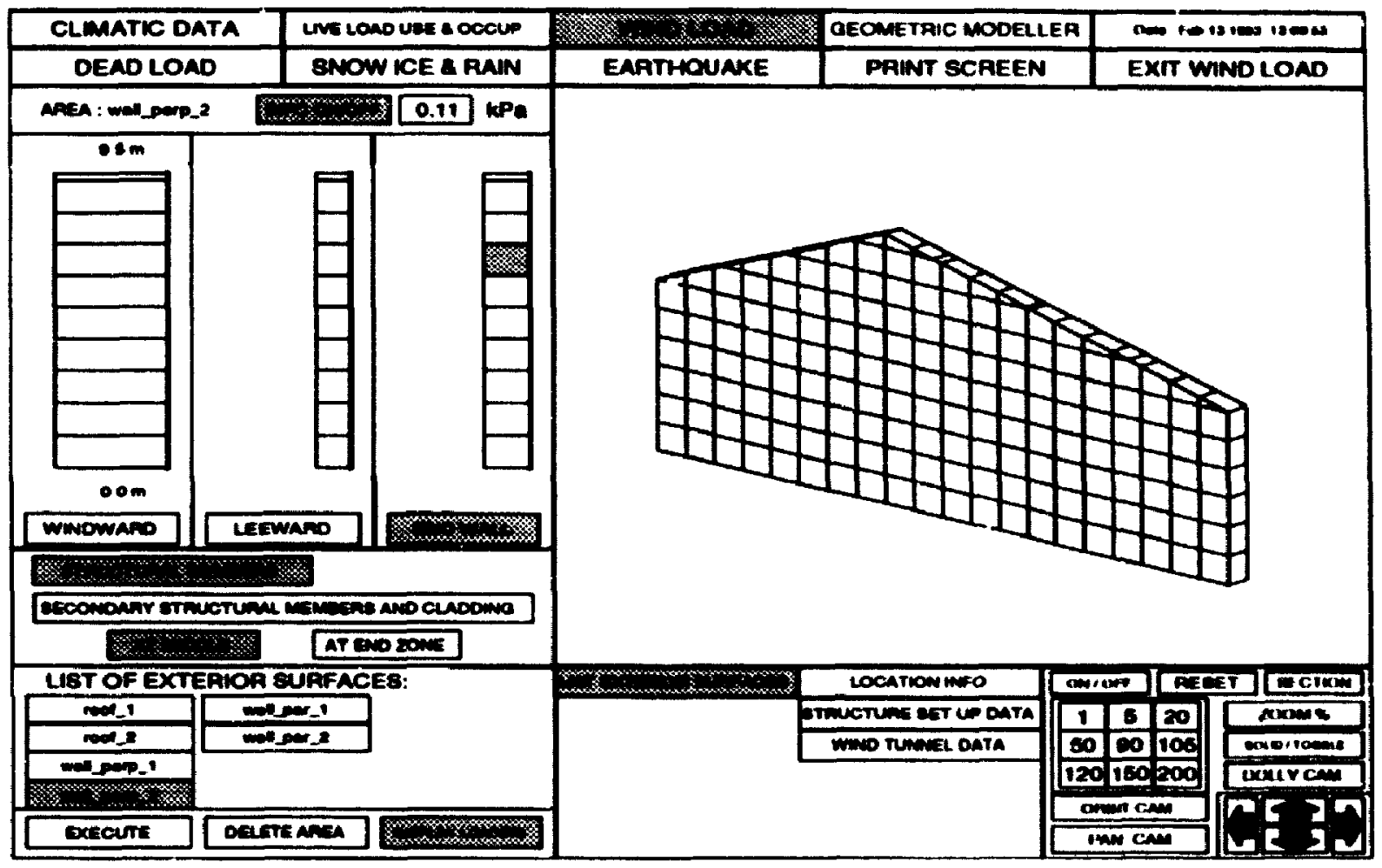

Fig. 3.54 (c) Wind Load Distribution for a Wall Perpendicular to the Ridge of a LowRise Building. 


\section{Chapter 4}

\section{Examples}

To demonstrate the capabilities of program LDFSSBC, the loads were determined and attributed to the surfaces of two buildings, a typical high-rise and low-rise building.

\subsection{High-Rise Building}

The building given in the Multi-Stoney Stcel Building Design Aid, Canadian Institute of Stcel Construction (1987) was selected, as the high-rise building example. Detailed load calculations given in the design aid serve in verify those generated by LDFSSBC.

The structure is an office/retail building complex which includes a 20 storey office tower and two adjacent retail sections with 2 and 3 floors. South and east elevations of the building are shown in Figures 4.1. The lower 3 floors of 20 storey office tower are used as retail space. Mechanical equipment is housed in and on the penthouse. The structure is a steel framed building with composite floor systems. For this example, the building is located in North Vancouver, British Columbia, and is considered to be in an exposed location.

The isolated views of the floor, roof and wall surfaces of the building, to which 


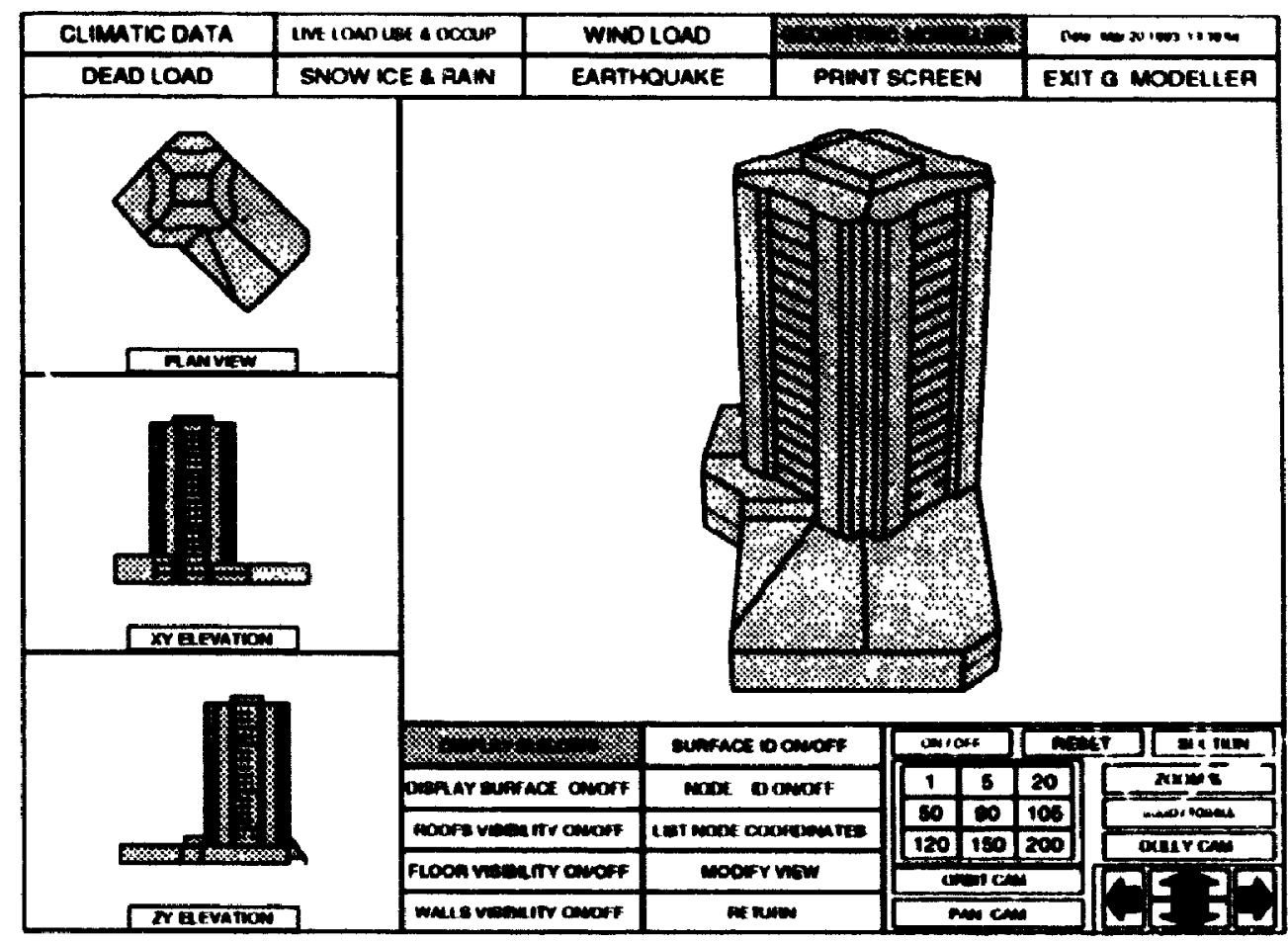

(a) South Elevation

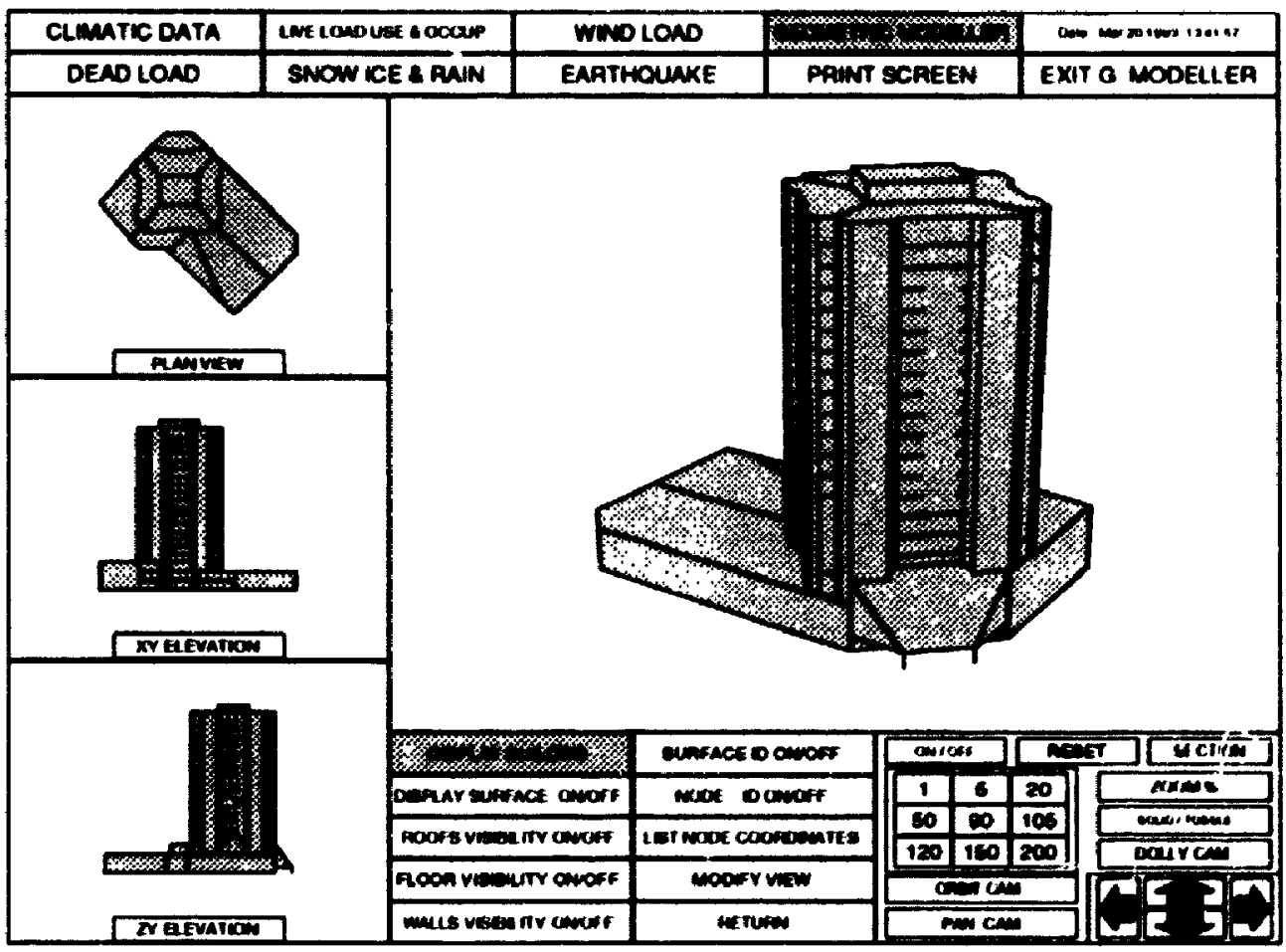

(b) East Elevation

Fig. 4.1 High-rise Building Example 
dead and live loads will be attributed are shown in Figures 4.2, 4.10 and 4.12, respectively. The floor plans for the retail space (floors 2 and 3), the office space (floors 4 to 19 , inclusive) and the mechanical room on the 20th floor are shown in Figures 4.3, 4.4 and 4.5, respectively. The rectangular areas within the floor plan are elevator and mechanical shafts. The lines connecting these with the perimeter are part of the polygon used to draw the floor plan within HOOPS. These will be deleted from view in the next version of the program.

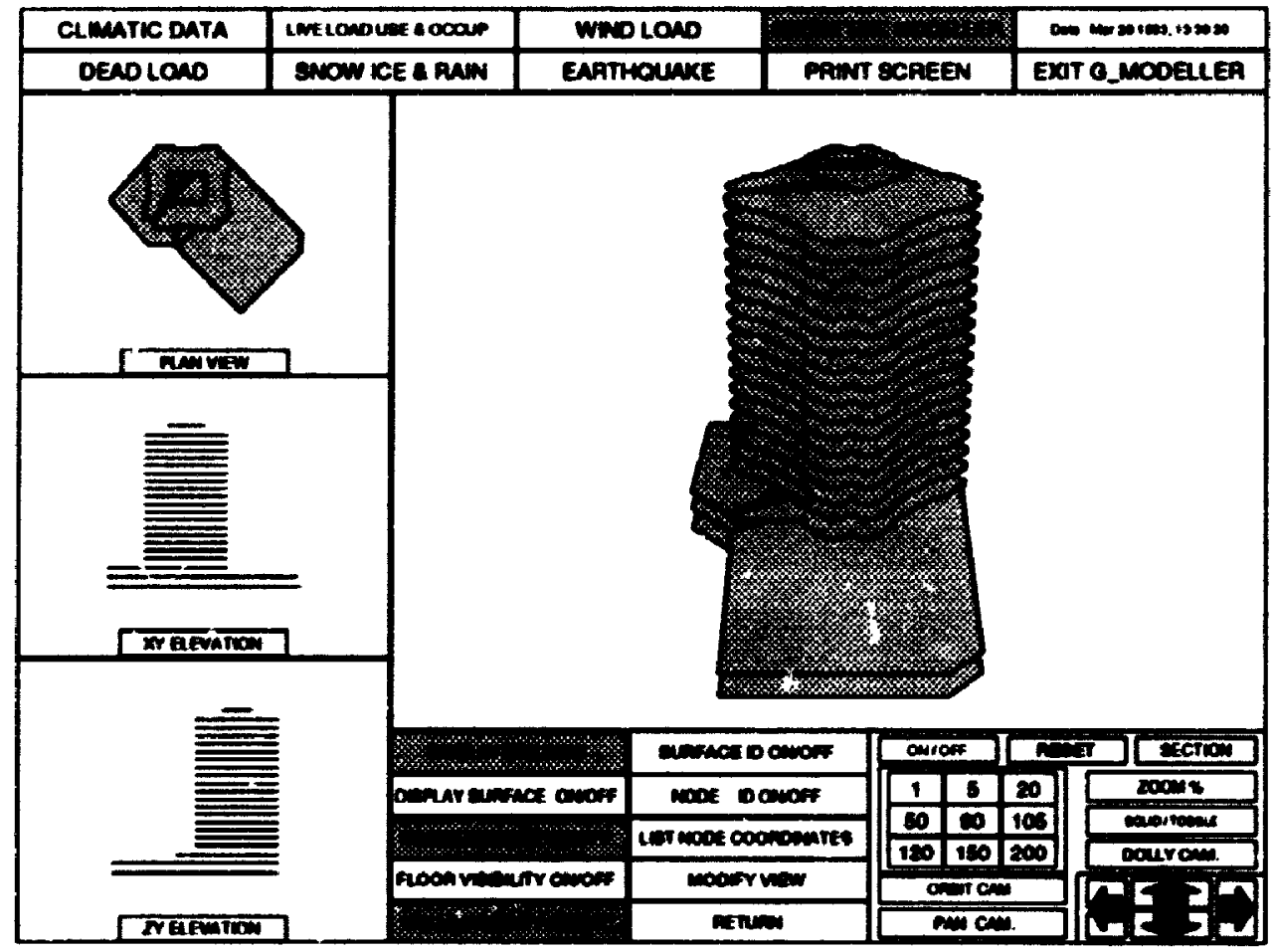

Fig. 4.2 Floor Surfaces - Dead Load and Live Load due to Use and Occupancy

Libraries of areas with the typical dead load and live load due to use and occupancy intensities were created for the building, as detailed in the design aid, and are listed in Figures 4.6 and 4.7, respectively. A typical sandwich system for a stub-girder system is shown in Figure 4.6 (a). Atuributing dead load to floor, roof or wall surfaces is trivial 


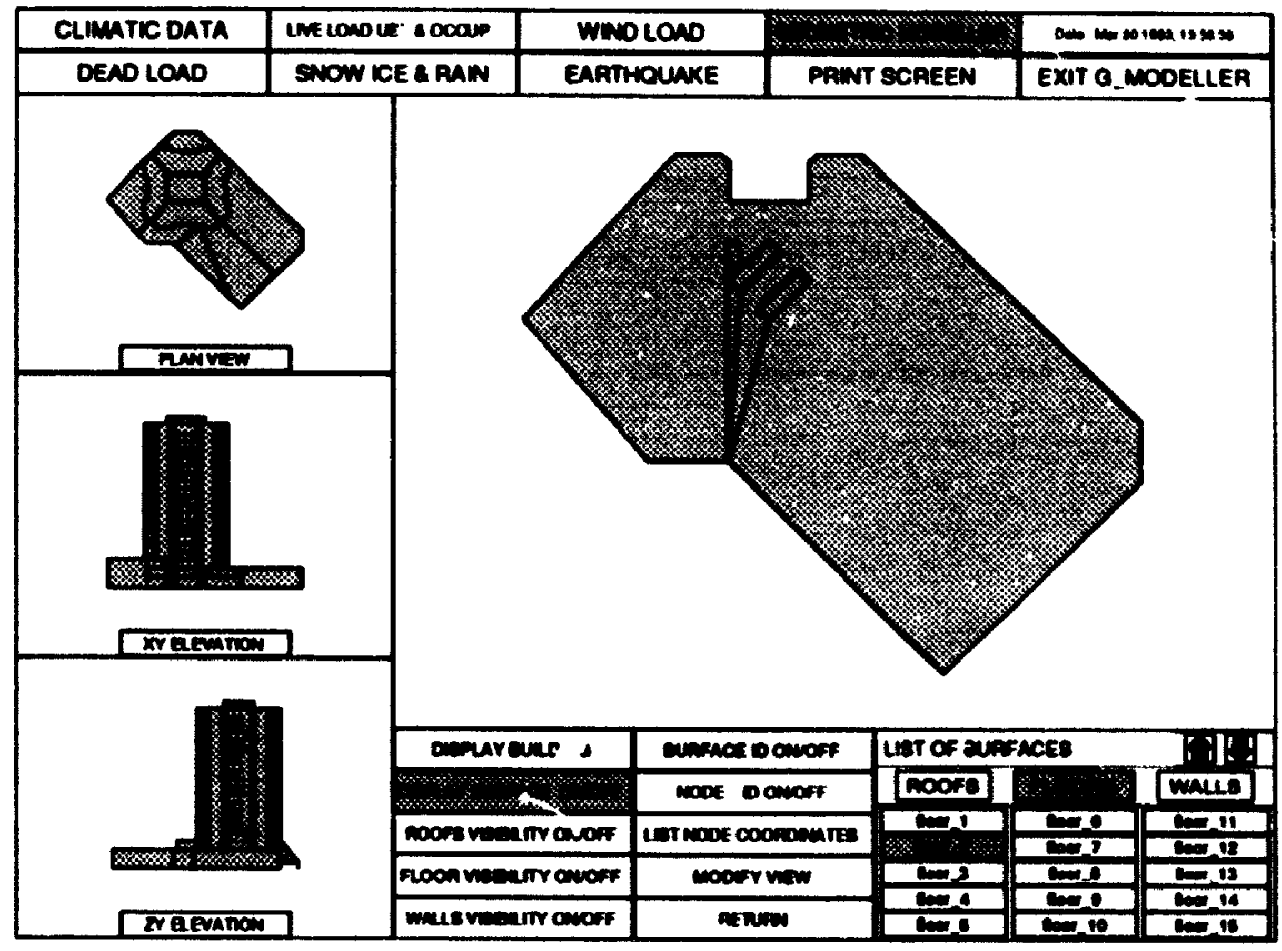

(a) 2nd Floor Plan

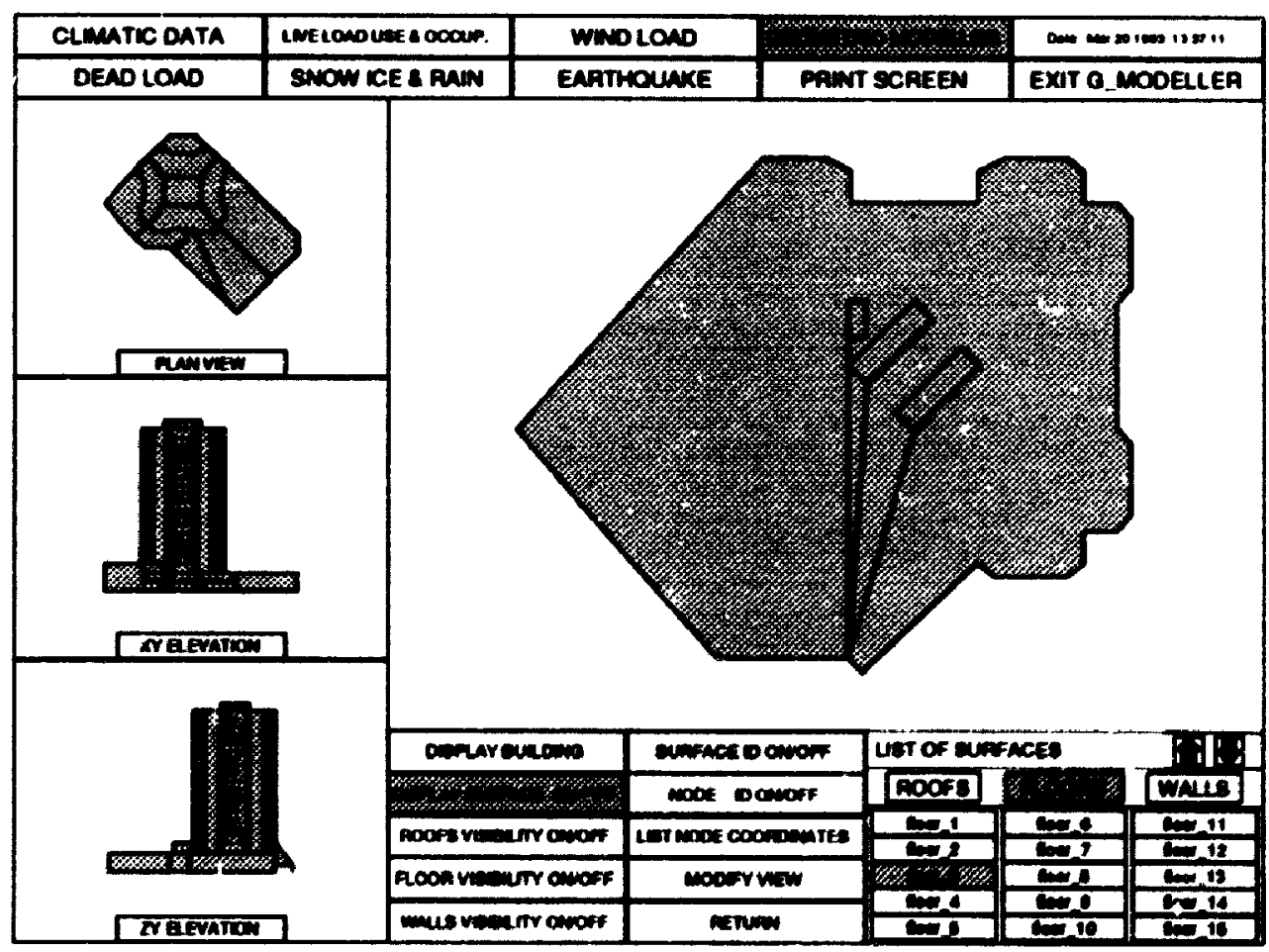

(b) 3rd Floor Plan

Fig. 4.3 Retail Space 


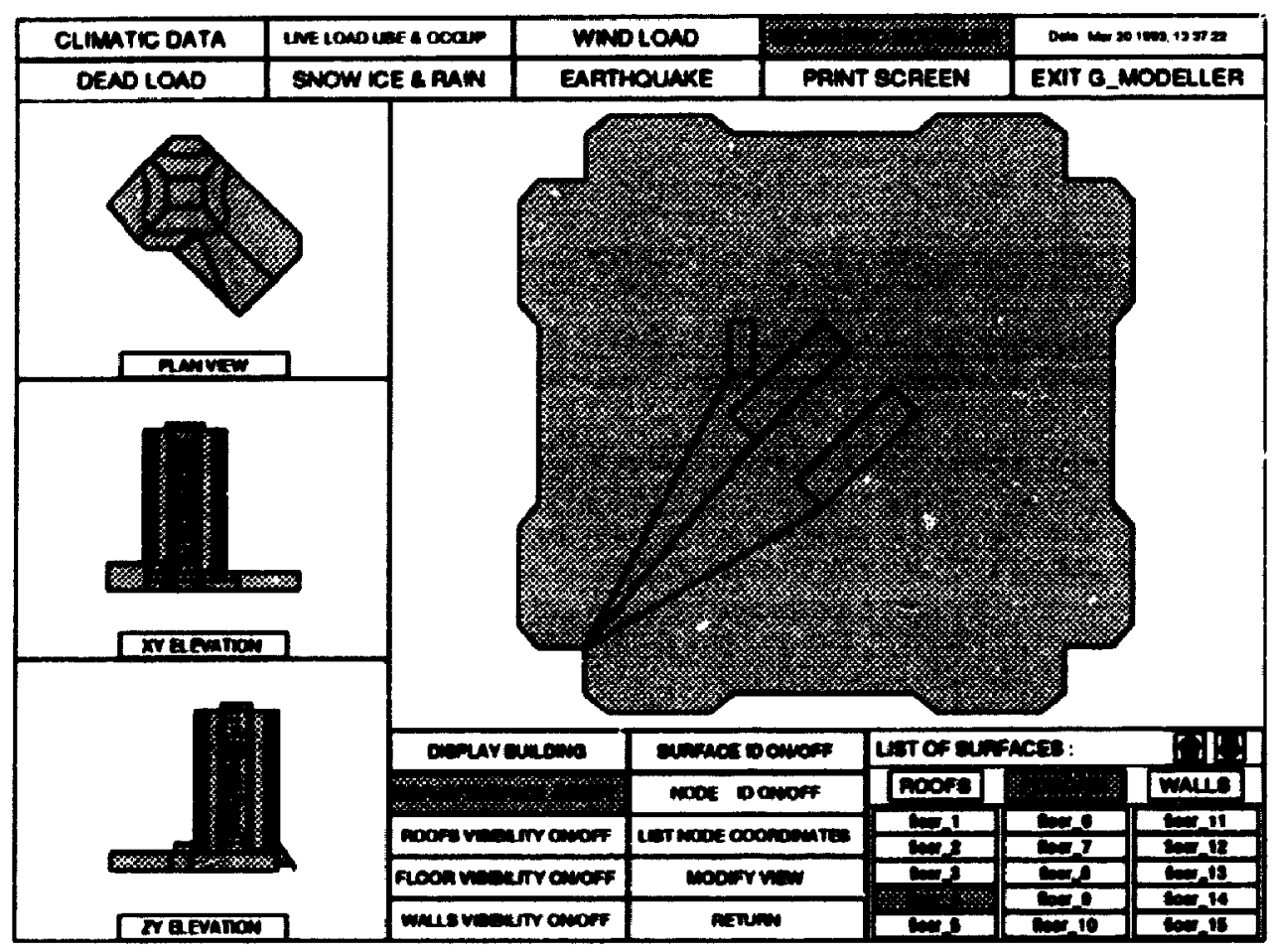

(a) 4-12th Floor Plan

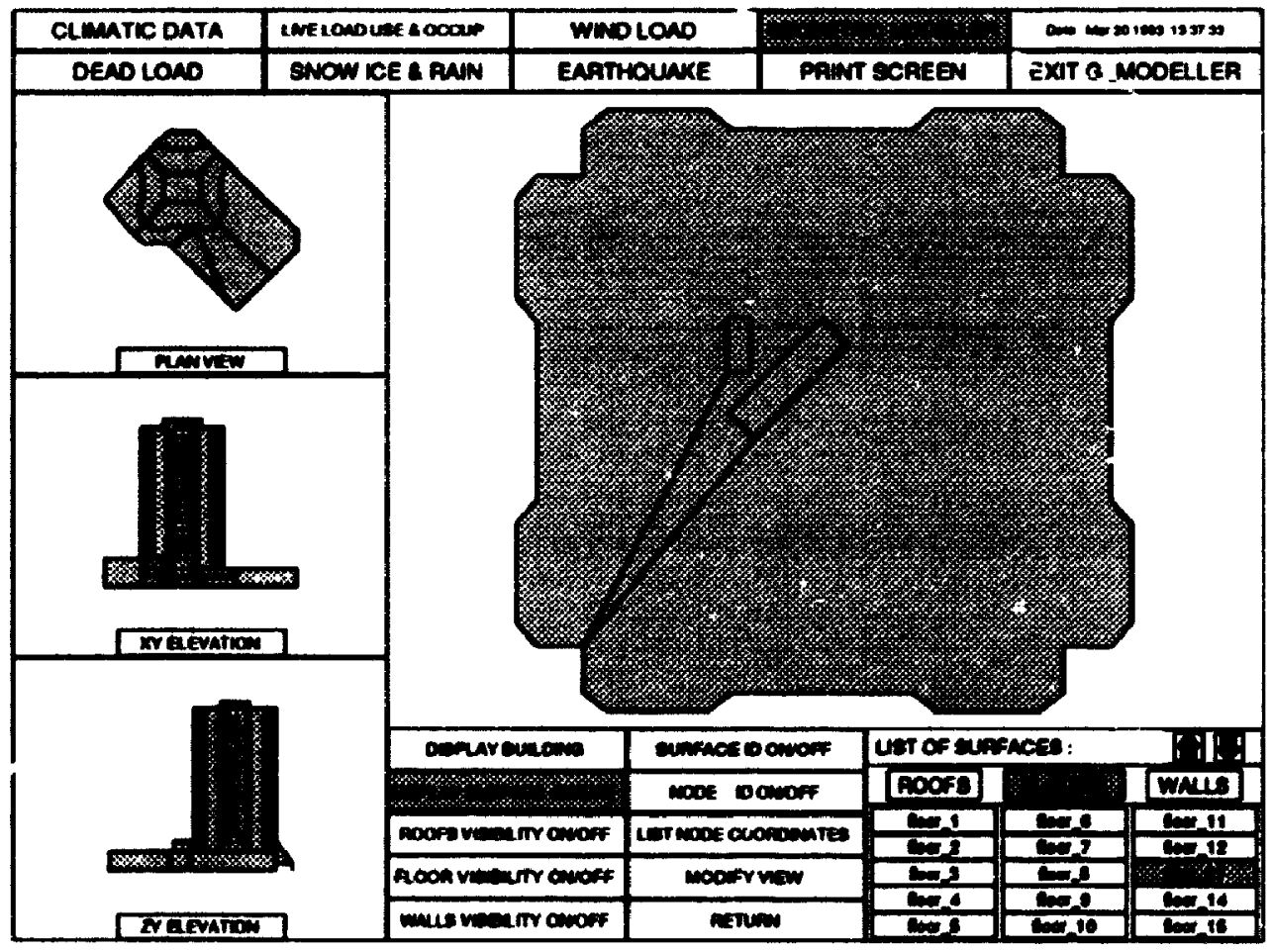

(b) 13-19th Floor Plan

Fig. 4.4 Office Space 


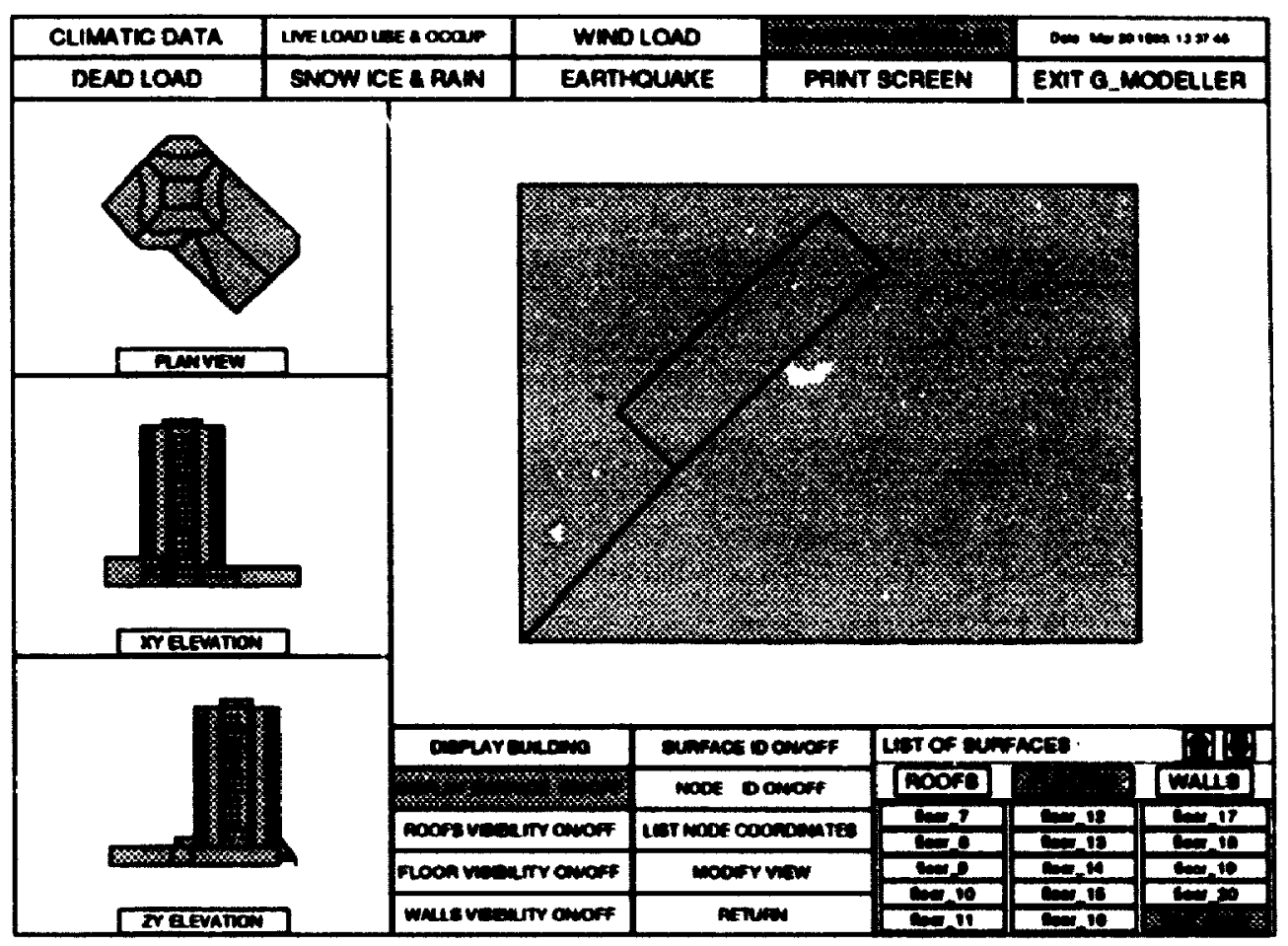

Fig. 4.5 Mechanical Room - Floor Plan

since each surface consists of one structural system with constant dead load intensity. For example, a dead load intensity of $4.28 \mathrm{kPa}$ has been attributed to the surface defined as "lowRoof_5", as shown in Figure 4.8.

Figure 4.9 shows the live loads due to use and occupancy distribution on 5th floor where two intensity types are imposed, core floor areas with a udl intensity of $4.8 \mathrm{kPa}$, and office areas with a udl of $2.4 \mathrm{kPa}$. Detailed architectural drawings were not available, therefore, the core floor area was taken to be the area within the dashed line. Both areas must also be designed for $9.0 \mathrm{kN}$ of concentrated load, acting anywhere over a $750 \mathrm{~mm}$ $x 750 \mathrm{~mm}$ area to produce the maximum load effects. 


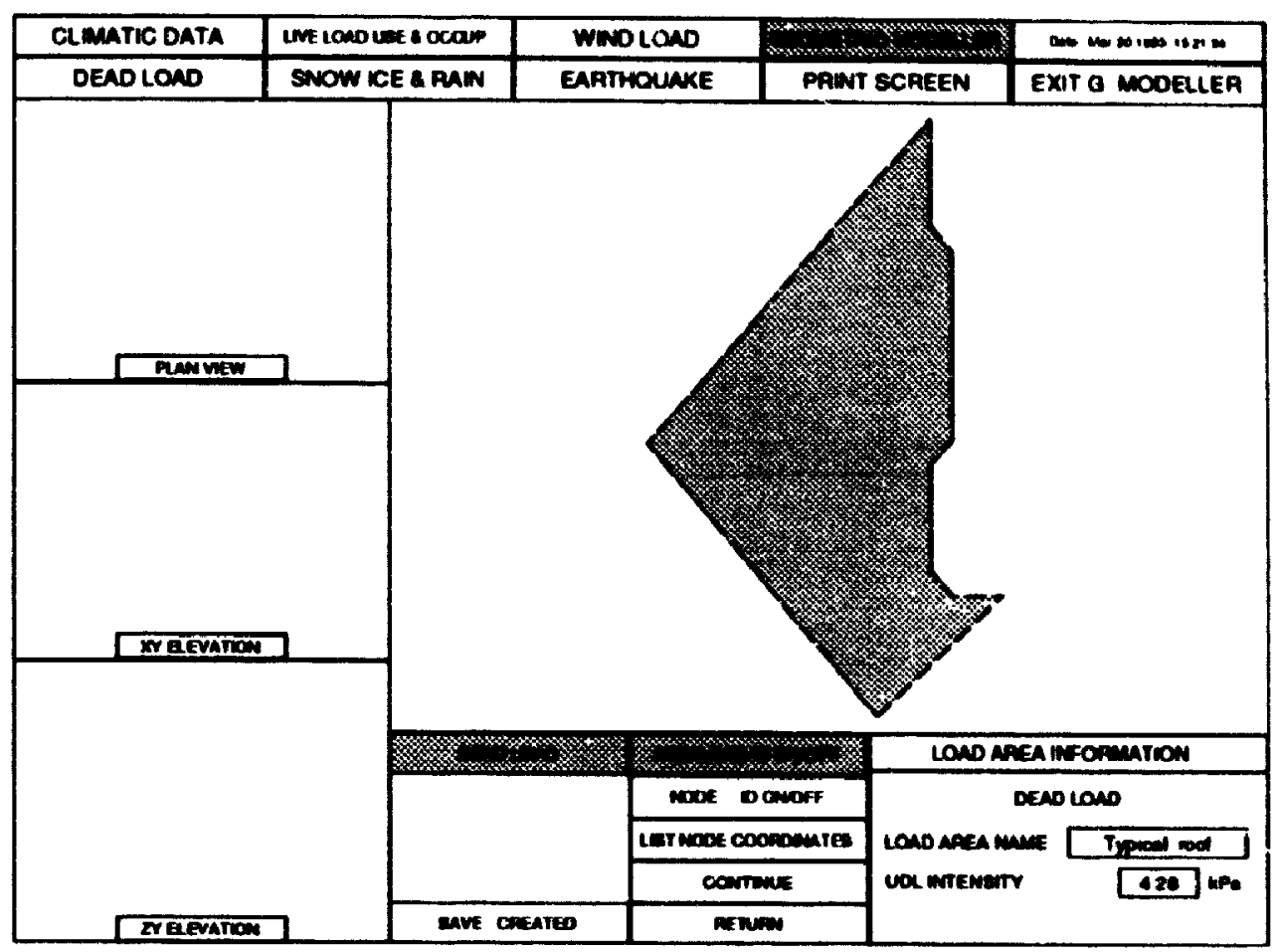

Fig. 4.8 Dead Load Intensity for "LowRoof_5"

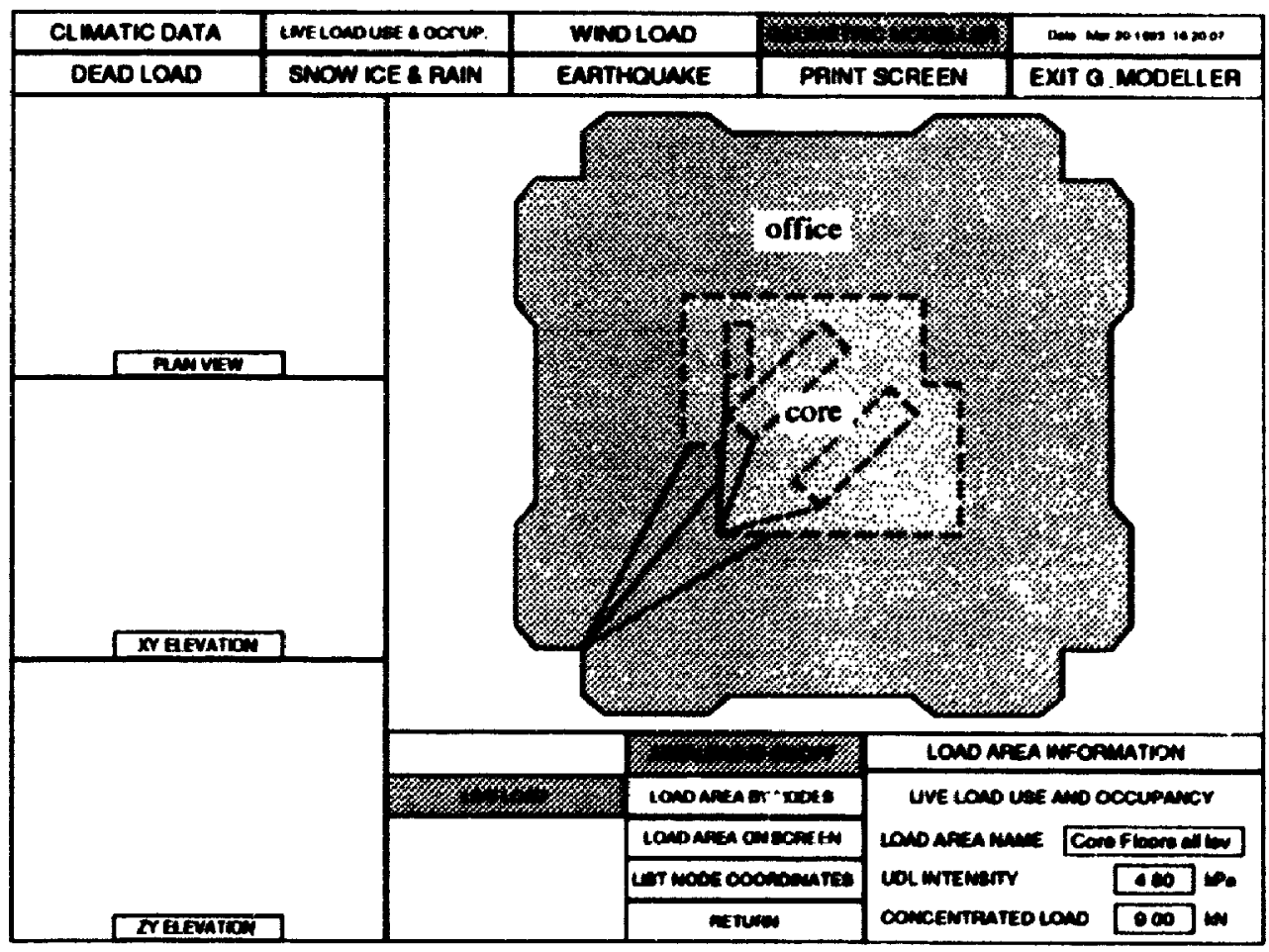

Fig. 4.9 Live Load Intensity - Use and Occupancy, for "Floor__5" 
Roof areas are subdivided into sections, interactively defined by the structural engineer, to give typical roof types that the snow load accumulation factor figures in commentary $H$ of the supplement can be applied. Good engineering judgement is required. For this particular case the snow load accumulation factor for the majority of roof sections (the only exception is the penthouse. Figure $\mathrm{H}-1$ ) are best described by Figure $\mathrm{H}-4$ for lower levels of adjacent roofs. The roof sections illustrated in Figure 4.10. are defined by lines extending 45 degrees from the corners of the building with upper roof sections to the edge of the roof and further subdivided according to height differences of adjacent upper roef sections.

The upper roof of the office tower is simply divided into four equal parts (due to symmetry). The corresponding snow load distribution for each section is given in Figure 4.11(a). The roof area over the two storey retail space is subdivided into 3 sections with the accumulation factor, $\mathrm{Ca}$, calculated using the height difference between the $3 \mathrm{rd}$ and 2 nd floor for section 1; and the 20th ind 2 nd floor for sections 2 and 3. The line defining section 1 and 2 was extended at 30 degree from the corner indicating a slight dominance of the taller wall on the snow load distribution. The irregular shape of the wall for section 2 and 3 prevents a uniform definition of ' $x$ ', the distance from the wall to any given point on the roof perpendicular to the wall for that section. The controlling walls for section 2 and 3 are the bay window and the wall between bay windows, respectively. The corresponding snow load distributions are shown in Figure 4.11 (b), (c) and (d).

Both wall height differences and wall irregularities will lead to small discontinuities in snow load intensities along common boundaries. For example, the magnitudes as shown 
in Figures 4.11 (c) and (d) at neighbouring points (highlighted on the figure) differ by a maximum of 11 percent. It should be noted that the distributions are approximations (snow load models) of the actual distributions and may contain discontinuities.

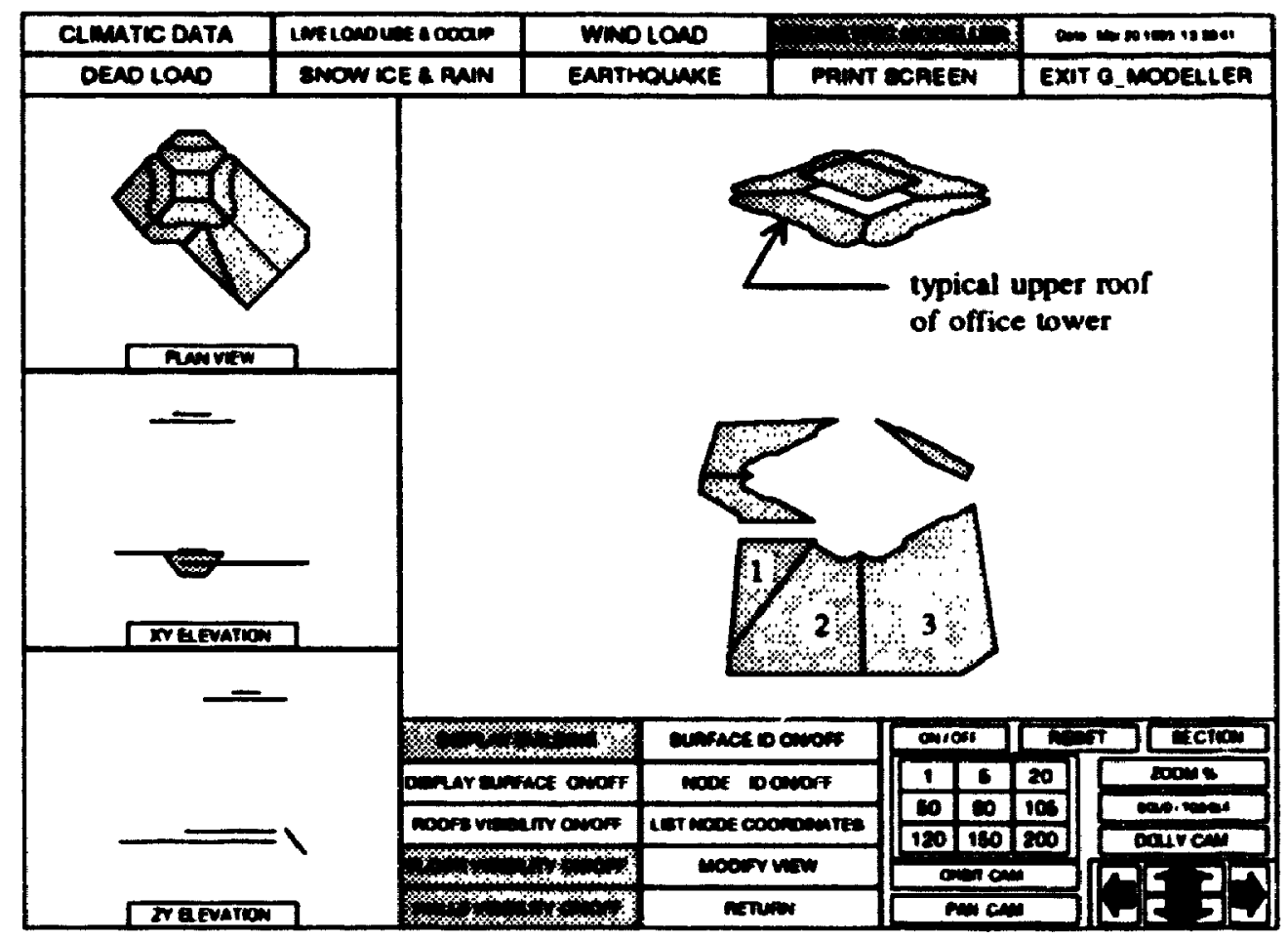

Fig. 4.10 Roof Surfaces - Live Load due to Snow and Wind 


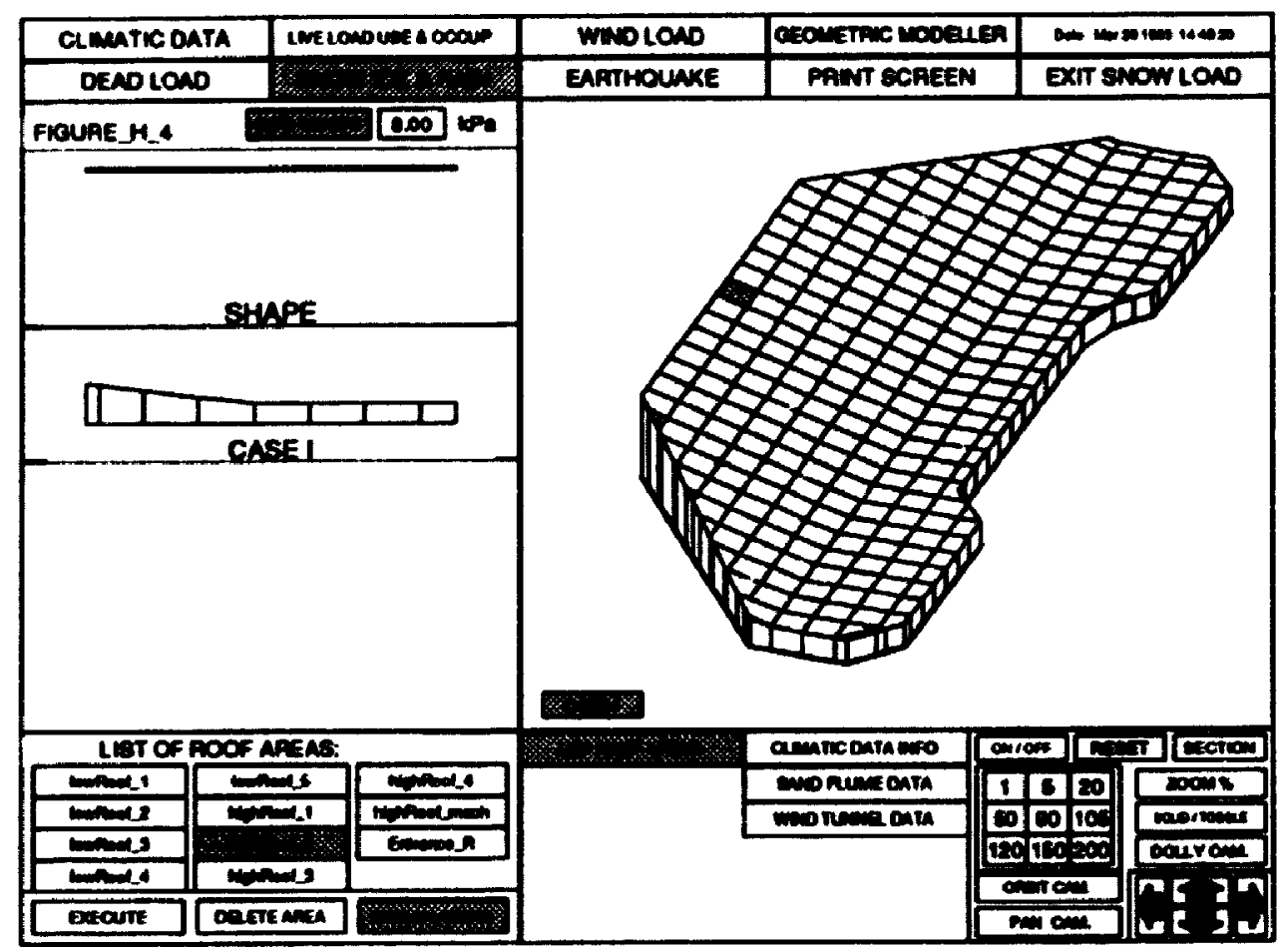

(a) Typical Upper Roof of Office Tower

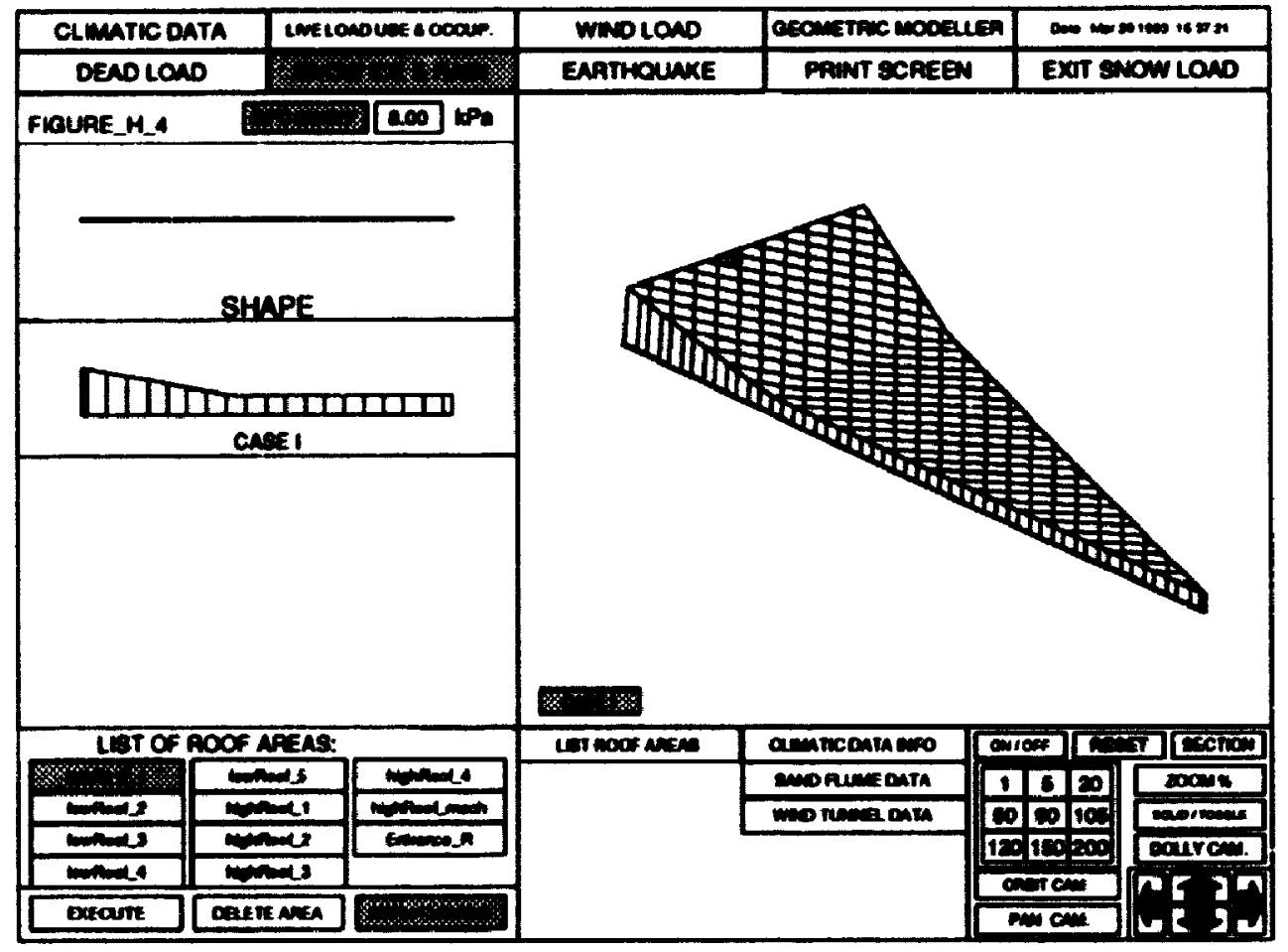

(b) Section 1 of the Lower Roof for the two storey retail space 


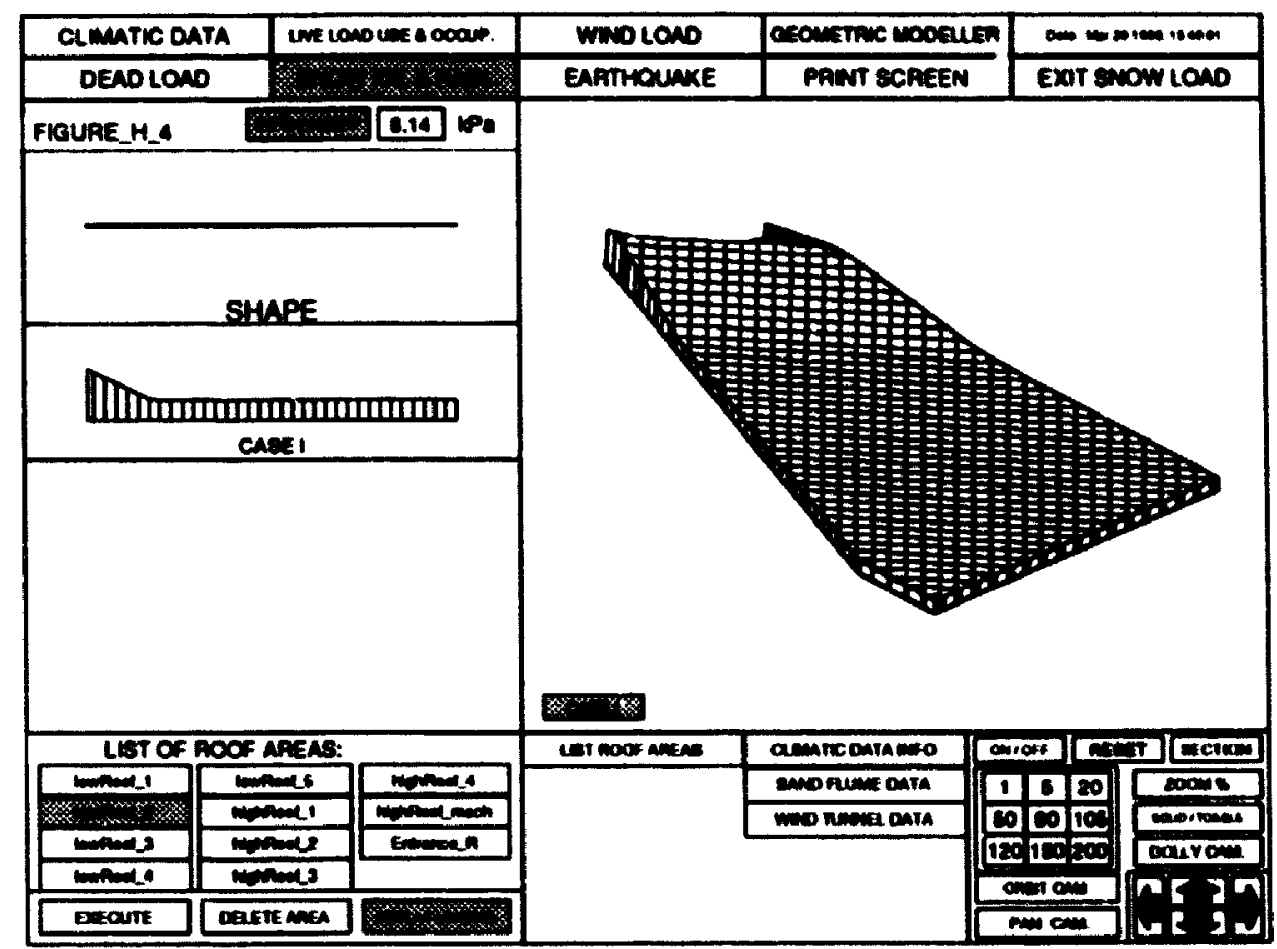

(c) Section 2 of the Lower Roof for the two storey retail space

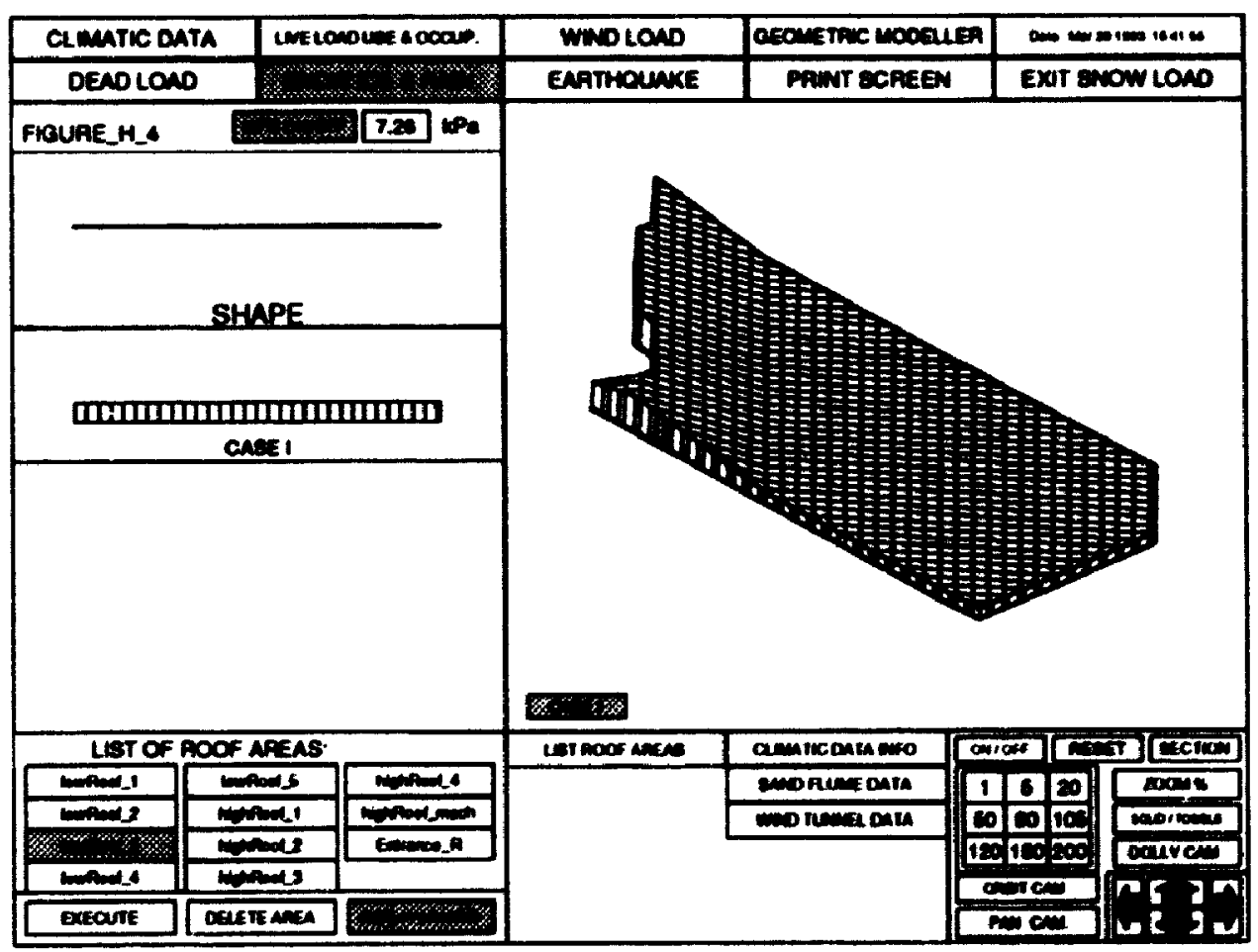

(d) Section 3 of the Lower Roof for the two storey retail space

Fig. 4.11 Snow Load Distributions on Selected Roof Surfaces 
The exterior surfaces of the building used for the determination of wind loads are shown for roofs and walls in Figures 4.10 and 4.12, respectively. The wind loads acting on the office tower were calculated using the simplified procedure, Figure B-11 of Commentary B of the supplement, NRC (1990), and an internal pressure coefficient for a building with a uniform distribution of openings on all walls. Example wind load distributions for a typical roof and wall section are illustrated in Figures 4.13 (a) and (b), respectively. The load distributions determined by LDFSSBC compared directly with those calculated by CISC (1987).

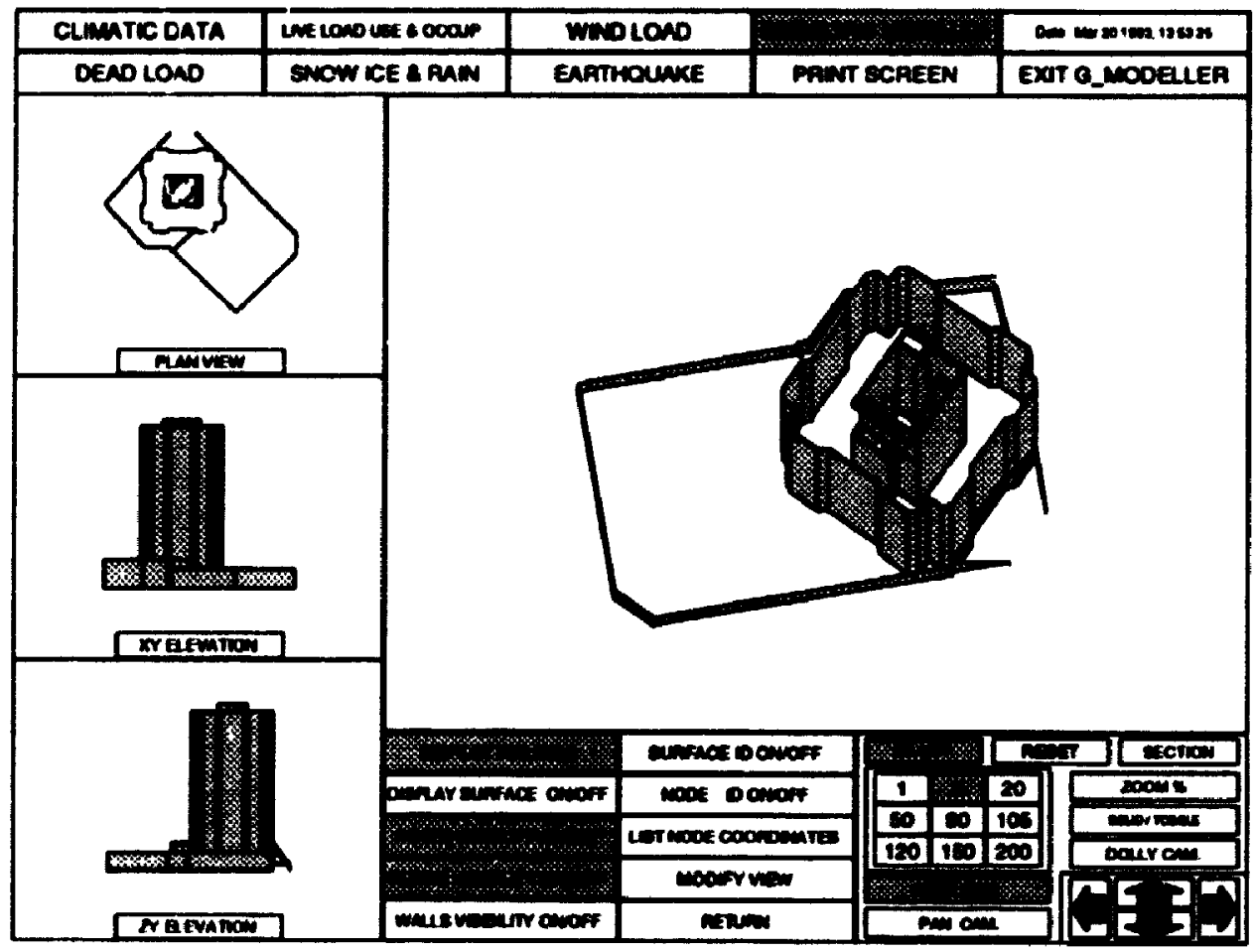

Fig. 4.12 Wall Surfaces - Live Load due to Wind 


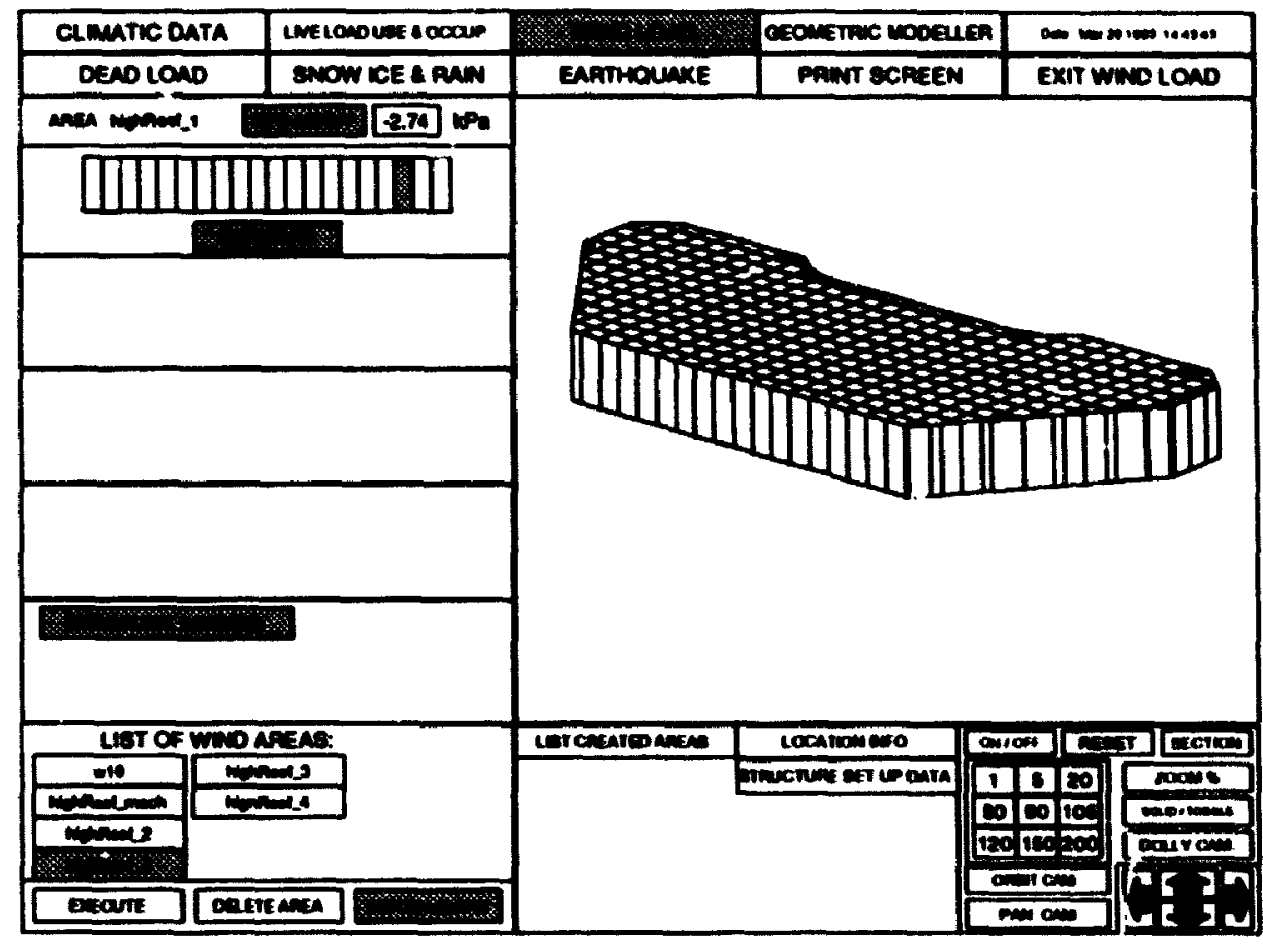

(a) Typical Upper Roof of Office Tower

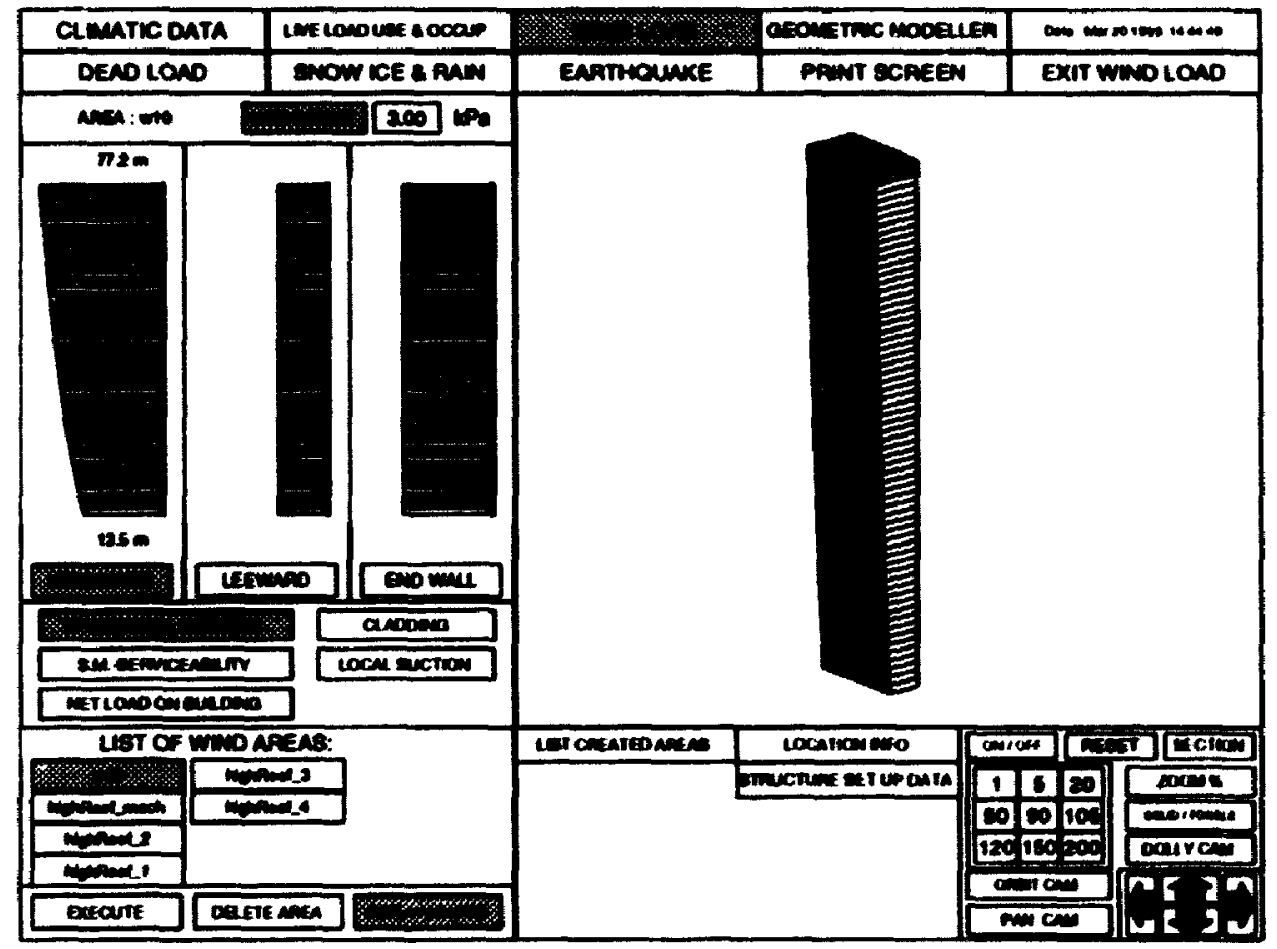

(b) Wall No. 10

Fig. 4.13 Wind Load Distributions for a High-rise 


\subsection{Low-Rise Building}

A typical low-rise building constructed in Ottawa and designed by a local consulting engineering firm, Oliver, Mangione and McCalla (1992), was primarily used to illustrate the wind load calculations for low-rise buildings as prescribed in the NBCC 1990 , NRC (1990), and to verify the loads generated by LDFSSBC.

The one storey building consists of two rectangular sections with the same ground nloor elevation and $600 \mathrm{~mm}$ step in the roof. The exterior walls consist of reinforced load bearing hollow concrete blocks. Large door openings are situated along the south wall of the lower section and around on the south-east comer of higher section. The parapet above the doors is $1600 \mathrm{~mm}$ high and $300 \mathrm{~mm}$ high on the rest of the buildings perimeter. W-shape steel girders are seated on the perimeter walls and frame onto HSS columns inside the building. In turn these support a series of $600 \mathrm{~mm}$ deep open web steel joists. The roof is composed of a $38 \mathrm{~mm}$ deep steel deck, $150 \mathrm{~mm}$ of rigid insulation, 3-ply roofing felt and $\mathbf{4 0} \mathrm{mm}$ of ballast. All the surfaces of the building were created according to dimensions given on the drawings and are shown in Figure 4.14.

The dead load values for the roof and walls for all the surfaces of the building are given in Figures 4.15 and 4.16.

The uniformly distributed and concentrated live loads due to use and occupancy for roof ane $1^{n} \mathrm{kPa}$ and $1.3 \mathrm{kN}$, respectively. The corresponding library is shown in Figure 4.17. 


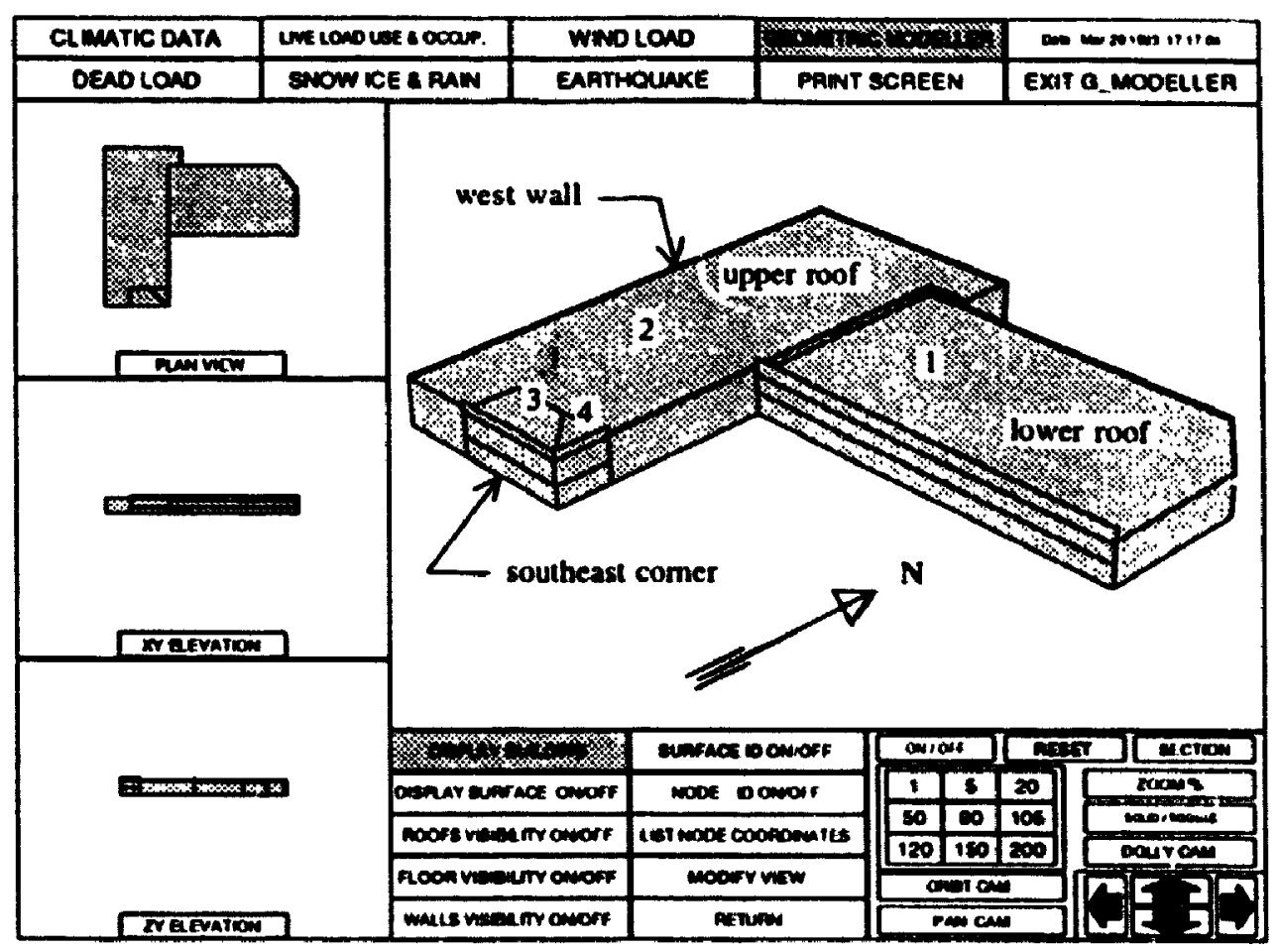

Fig. 4.14 Low Rise Building Perspective

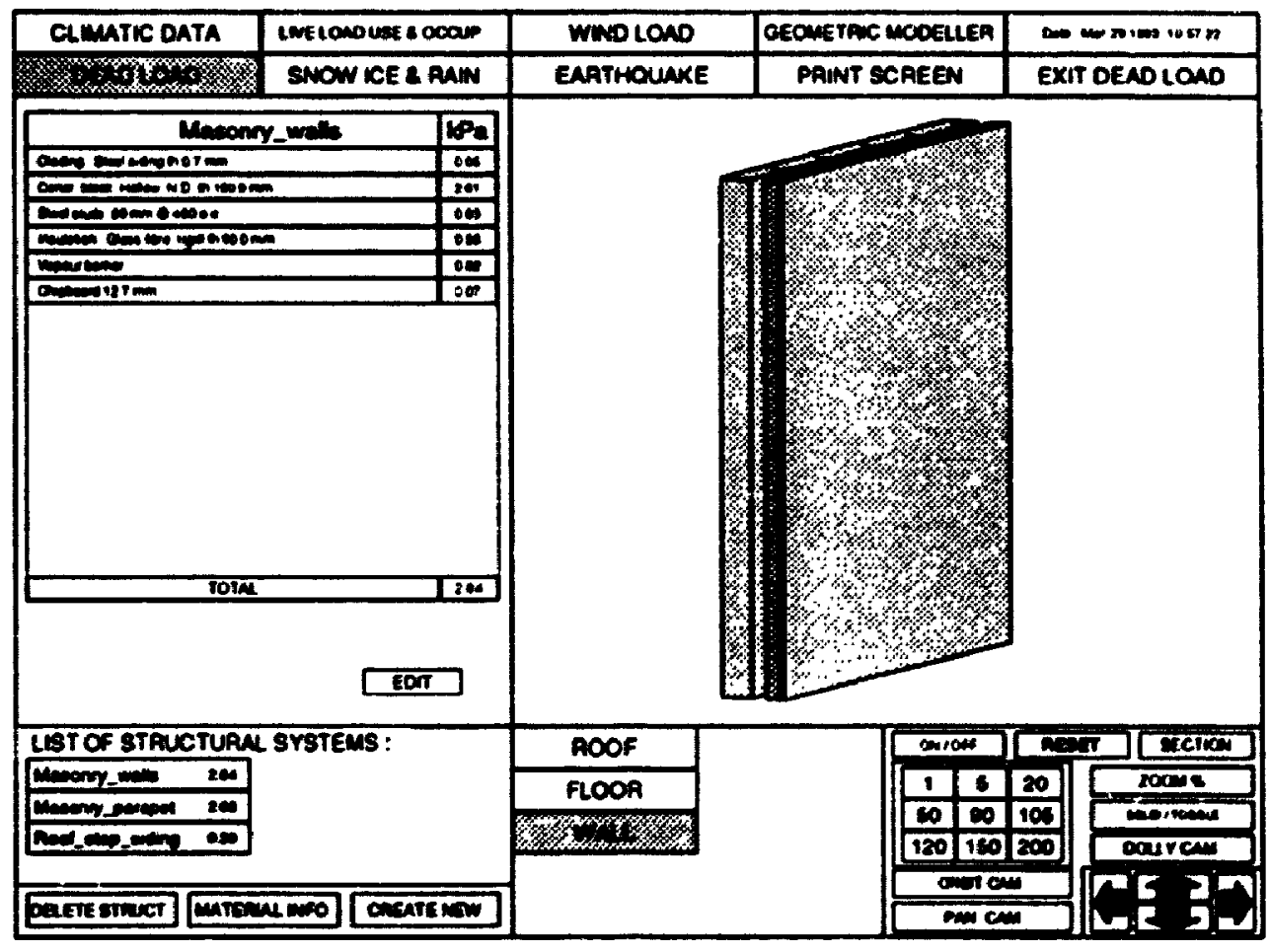

Fig. 4.15 Dead Load - Library of Wall Areas 


\begin{tabular}{|c|c|}
\hline Typical_roof & kPa \\
\hline Conehed trome bellent th.40 mm & 0.80 \\
\hline 3ply eppheil no orevel & 0.16 \\
\hline Inacuetion : Orme 10m, digd th. $150.0 \mathrm{~mm}$ & 0.10 \\
\hline Vepourberiser & 0.08 \\
\hline Crivboud $12 \% \mathrm{~mm}$ & 0.07 \\
\hline Plool decte $34 \mathrm{~mm} \times 0.78 \mathrm{~mm}$ & 0.10 \\
\hline Ourst; cellm in lor long pere & 0.20 \\
\hline 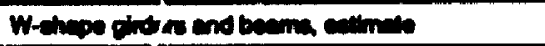 & 0.30 \\
\hline 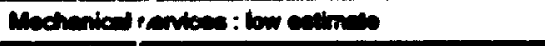 & 0.10 \\
\hline Elocution esmions & 0.10 \\
\hline 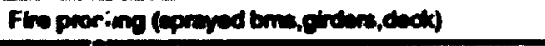 & 0.07 \\
\hline 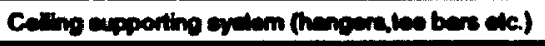 & 0.10 \\
\hline Acountionl onting torls & 0.10 \\
\hline TOTAL & 2.05 \\
\hline
\end{tabular}

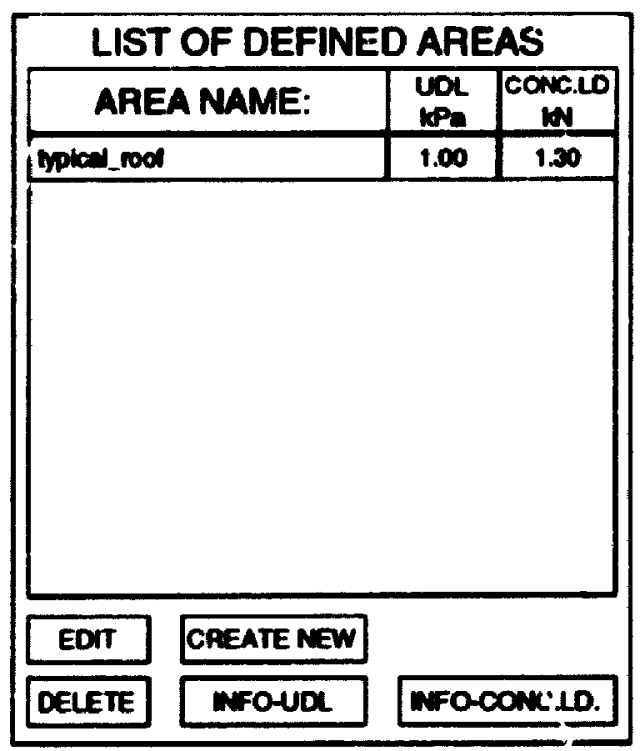

Fig. 4.17 Live Load Use and

Occupancy - Library of Areas

Fig. 4.16 Dead Load - Structural Roof System

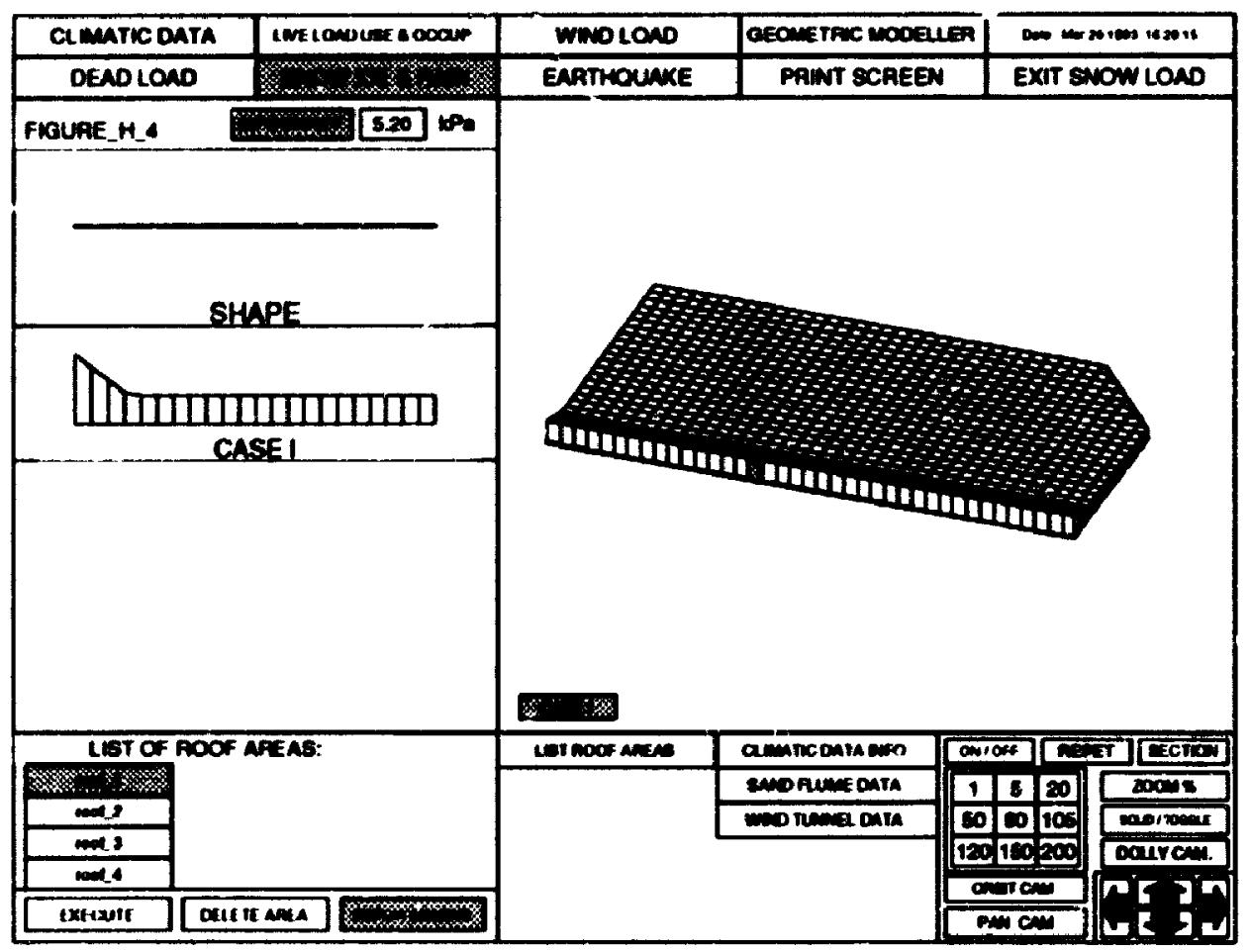

Fig. 4.18 Snow Load Distribution on Lower Roof 
The computation of snow load intensities are based on climatic coefficients for Ottawa and a wind exposure factor at location that is not exposed. The default value 1000 $\mathrm{mm}$ for the mesh spacing was used. The distribution of snow on lower roof due to the accumulation of snow along the $1600 \mathrm{~mm}$ high parapet is shown in Figure 4.18. The maximum value of $5.2 \mathrm{kPa}$ occurs adjacent to the parapet. Similar snow load distributions occur on roof sections 3 and 4 of the upper roof as a result of the 1600 parapet on the south east corner. The $600 \mathrm{~mm}$ roof step and the $300 \mathrm{~mm}$ high parapet are insufficiently high to cause a drift to form.

Wind load intensity values were evaluated for exposure B terrain category (subir tban and urban areas) and for Category 2 buildings for the internal pressure coefficient (buildings with significant openings - shipping doors). The simple procedure was used for computation of the exposure factor and the external peak pressure coefficients, $\mathrm{CpCg}$, were determined appropriately from Figures B-7 to B-10 of the supplement. Typical wind load distributions on the lower roof are shown in Figure 4.19 (a). The roof is horizontal (zero slope). Four graplss marked WINDWARD, LEEWARD, PARALLEL c.1, PARALLEL c.2 indicate varying load intensity for the roof which is caused by a change in a internal pressure that accurse due to a change in wind direction. This variation must be considered when the openings are mainly in one wall. The wind directions are marked on Figure 4.19(a). The wind load intensities for any given point (highlighted) are shown in the upper left hand window of the figure. Figure 4.19(b) shows the wind load distributions on one typical external wall (west wall of the higher section). Note, the increase intensity within wall end zone areas. 


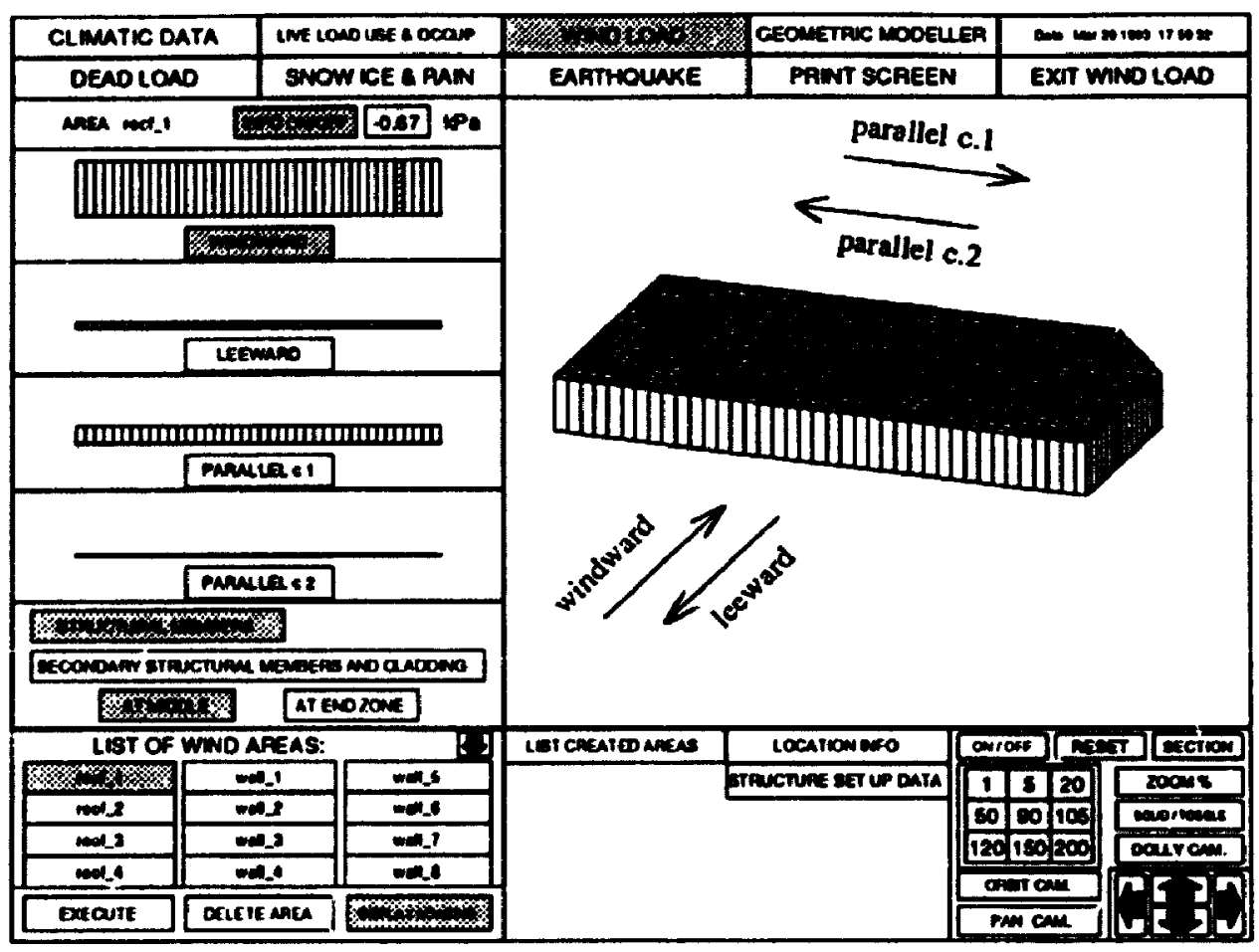

(a) Lower Roof

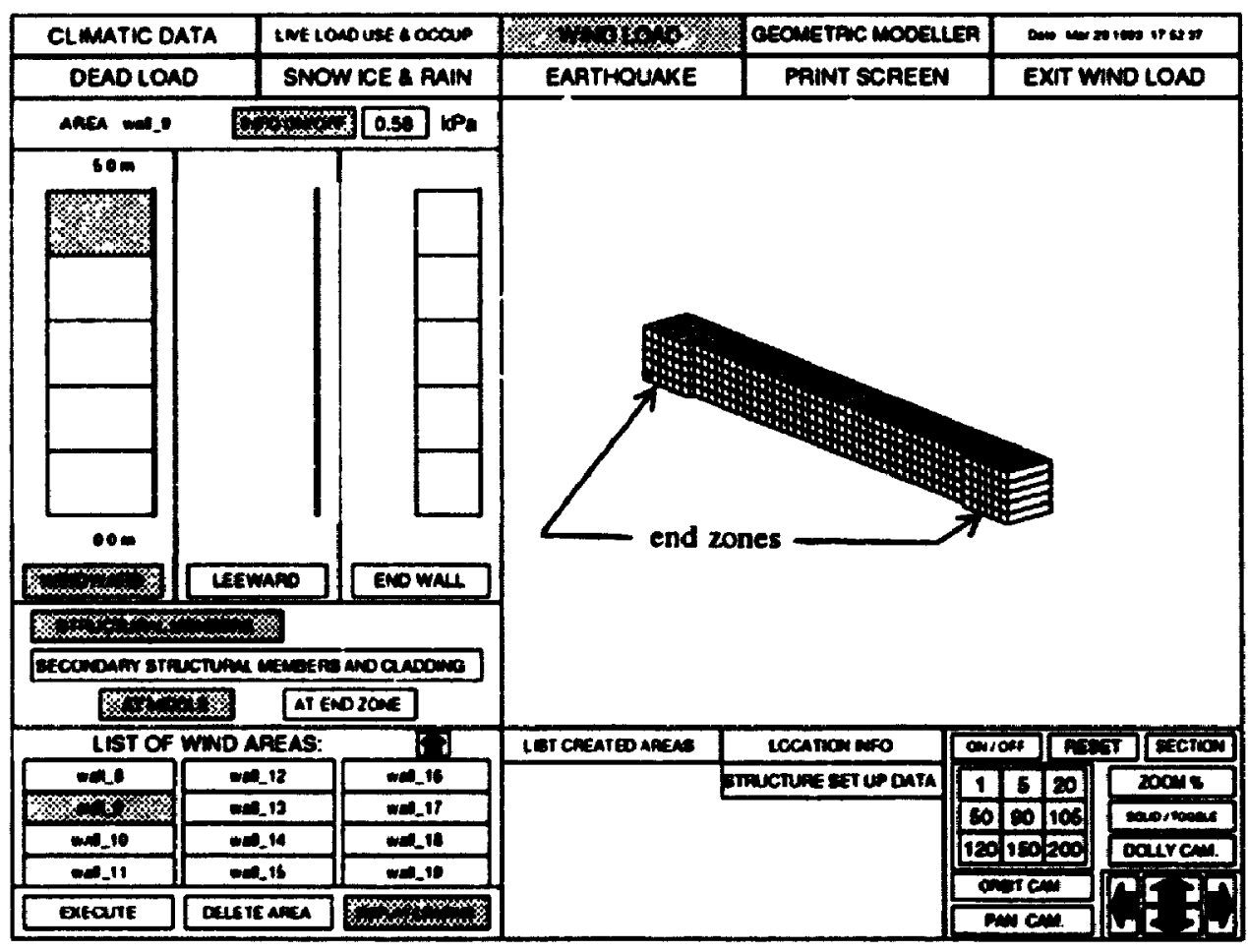

(b) West Wall

Fig. 4.19 Wind Load Distributions 


\section{Chapter 5}

\section{Conclusions, Recommendations, and Future Work}

\subsection{Conclusions}

Interactive graphics based computer software was developed for the geumetric modelling of the surfaces of steel buildings and for the automatic determination of loads acting on those surfaces. The loads were determined in accordance with Part 4-Structural Design, from NBCC 1990, NRC (1990) and the corresponding commentaries in the Supplement. Currently the program is restricted to defining the building form. floors. roofs, and walls from flat surfaces (may he sloped) and generates files that contain surface geometry and the dead loads, live loads due to use and occupancy, snow, ice and rain and wind, acting on those surfaces. Live loads due to earthquake and loads from other effects are not included in this version. Snow load distributions are limited to those geometric configuration of the roof surfaces described in Figures H-1 through H-6 of the Supplement to NBCC 1990 Part 4, Commentary H, NRC (1990). A detailed description of the completed work is given below:

1. the development of a geometric modeller for the definition of building form and surface geometry including shape, orientation, location and type of surface (roof. wall, floor), and 
2. the creation of a climatic design data database (reproduced from Chapter 1 of the Supplement) arranged according to province and location

3. the creation of the databases for masses, weights of typical construction materials and the development of 3-D graphical representations of structural sandwich systems for walls, roofs and floors

4. the development of a module that creates a database that specifies surfaces, surface areas and the corresponding dead load and live load (use and occupancy) intensities acting on those areas

5. the creation of a database for live load due to use and occupancy intensities (reproduced from Table 4.1.6.A and Table 4.1.6.B of Part it of the NBCC, NRC (1990))

6. a mesh generator for arbitrarily shaped polygons that calculates the coordinates of points on a flat surface arbitrarily located in space

7. the development of modules for the computation of snow and wind load intensities at each point on the mesh that takes into account the geometrical configuration of related surfaces and their effect on snow and wind load distributions. These modules also create database that contain all the relevant load determination information, the loads (may be more than one distribution for a given area) and the corresponding surface area geometry

8. The development of the interactive graphics design for the process of determining loads acting on buildings 
The loads generated by the program LDFSSBC have been compared to many hand calculations and examples provided by others and are identical. All aspects and options have been thoroughly tested.

\subsection{Recommendations and Future Work}

The work completed in this thesis represents the first step for a fully interactive program ft determining loads and load combinations acting on structural members. The remaining tasks that need to be completed are outlined in section 1.2. and 1.3. include:

1. inclusion of curved surfaces in geometric modeller

2. automatic self recognition of geometrical configuration of all sur faces bearing influence on selectability of applicable snow load figures on the roof or specific areas of the roof

3. development of earthquake load determination and other load effects module

4. development of algorithms for defining primary structural members including; member type , location, orientation, numbers representing structural analysis code, node and member numbering

5. development of algorithms for determining secondary member structural systems

6. development of algorithms for determining tributary areas for both secondary and jrimary structural members

7. development of algorithms for determining live load reduction factors

8. development of algorithms for determining load combinations and the 
corresponding data bases with loads attributed to members

9. development of routine to accept unique data from wind tunnel tests for snow and wind load distributions 


\section{References}

Allen. C.M.. Duchensene. D. and Humar, J.L.. 1988. Application of computer aided design in the Ontario Domed Stadium. Canadian Journal of Civil Engincering. Vol. 15. No. 1, February. p. 14-23.

Chen, E., 1987. Multi-storey Steel Building Design Aid. Canadian Institude of Stexl Construction, Willowdale, Ontario.

Closkey, D.J., 1988. Report of the Commissioner Inquiry Station Square Development. Bumaby, British Columbia, Province of British Columbia.

Duce, D.A., Gomes, M.R., Hopgood, F.R.A., Lee. J.R., 1991. User interface management and design. Proceedings of the workshop on user interface management systems and environments, Lisbon, Portugal, June 4-6, 1990. New York, Springer-Verlag.

Encarnacao, J., Krause F.L., 1982. File Structures and Data Bases for CAD. Working Conference on File Structures and Data Bases for CAD. Secheim, Gurmany. North-Holland Publishing Company.

Galitz, W.O., 1993. User-interface screen design. Boston, QED Publishing Group.

Gillet, P., 1984. Calcu!us and Analytic Geometry. Lexington, Heath and Company.

Hagen. H., Rnll:, D., 1981. Geometric Modeling-Methods und Applications. New York, Spring-Verlag.

Holtz, N.M., 1991. Advanced Methods in Computer-Aided Design, Lecture notes from course 82.562W, Carleton University, Ottawa.

HOOPS Graphics System, Release Notes Version 3.0. 1991, Ithaca Software, Alameda. California.

Kennedy, S.J., 1991. Introduction to Structural Design. Leclure Notes from course 82.324F. Carleton University, Ottawa.

Kemighan, B.W., 1978. The C Programming Language. Englewood Cliffs, Prentice-Hall.

Koffman, E.B., 1990. Problem Solving and Structured Programming in Fortran 77. Addison-Wesley Publishing Company. 
Mantyla, M., 1988. An Introduction to Solid Modeling. Computer Science press.

Mortenson, M.E., 1985. Geometric Modeling. New York, John Wiley \& Sons.

National Research Council of Canada 1990a. National Building Code of Canada 1990. National Research Council of Canada, Ottawa.

National Reseanch Council of Canada 1990b. Supplement to the National Building Code of Canada 1990. National Research Council of Canada, Ottawa.

Pare, E.G., 1971. Descriptive Geometry. New York. The Macmillan Company.

Peter, B.G.W., Dalgliesh, W.A. and Schriver, W.R. Variation of Snow Loads on Roofs. Division of Building Research, National Research Council, Ottawa, Canada.

Preparata, F.P., Shamos, M.I., 1985. Computational geometry; an introduction. New York, Springer-Verlag.

Sachs, P., 1978. Wind Forces in Engineering. Pergamon Press, Toronto, Canada.

Sack, J.R., 1984. Rectilinear computational geometry. Technical report SCS-TR-54, School of Computer Science, Carleton University, Ottawa, Canada.

Schirmer, C., 1987. Programming in C for UNIX. Chichester, England, Horwood.

Silvester, P.P., 1984. The UNIX System Gridebook. New York, Springer-Verlag.

Simiu, E., Scanlan, R.H., 1986. Wind Effects on Structure. New York, John Wiley \& Sons.

Software for detailers and fabricaters. Joumal-Modem Steel Construction, American Institude of Steel Construction, Chicago, May-June 1990, pp. 56-64.

Taylor, D.A.. 1992. Snow on Two-level Flat Roofs - Measured vs. 1990 NBCC loads. Canadian Journal of Civil Engineering, Volume 19, Number 1, June. pp. 59-67 .

Toussaint, G.T., 1985. Computational Geometry. New York, Elsevier Science Publishing, Inc.

Waite, M.. Prata, S., 1990. C: Step-by-Step. Howard W.Sams \& Company, Carmel, Indiana. USA.

Walker, A.N., 1984. The UNIX Environment. Chichester, John Wiley \& Sons. 


\section{APPENDIX A}

\section{Programming Languages and Graphic Tools}

\section{A.1 Computer Programming Language Selection}

Over the last couple of decades a number of programming languages have been developed by various computer companies, universities and private groups. Or these the most popular are Basic, Cobol, Algol, Pascal, Fortran and C. More recent, advanced and powerful languages like object oriented $\mathrm{C}++$, Smalltalk, rules based systems Clips, are being used by thousand of research laboratories, corporations, systems development companies in government and private companies.

The selection of the most appropriate programming language for the purpose of this thesis was influenced by the previous decision to use HOOPS Graphic Systems for the interface of the Integrated Analysis, design and fabrication of steel buildings of which this

thesis is one part. HOOPS Graphic System is supported by Fortran, $\mathrm{C}$ and C+t. Although HOOPS is system dependant, versions exist for most platforms, making the interface code relatively portable.

\section{A.1.1 Fortran Programming Language}

Fortran was developed in 1957 and was the first high-level programming language. 
It was originally used primarily for scientific computation but has evolved over the years into a general purpose programming language. Fortran is still he highly favoured language for numerical work among the scientists and engineers, and has the large library of available applications.

\section{A.1.2 "C" Programming Language}

During the last decade, $\mathrm{C}$ has become one of the most popular and important programming languages. C was created in 1972 in Bell Laboratories by Denise Ritchie and Ken Thompson as they worked on designing the Unix operation system, Waite, M., Prata. S. (1990).

The programming language $\mathbf{C}$ was selected for this thesis because of its attributes and potential, some of which are listed below:

1. Increase programming power, as $C$ is designed to work with the hardware and gives access to manipulate individual bits in memory.

2. A program written in $\mathbf{C}$ can be broken down into short independent functions making it simpler for the programmer to document the program and easier for testing and debugging of each function.

3. Portability. Programs written on one system can be made to run on another system with little or no modification. Often, the changes can be made just in the header files.

4. C has a large library of useful functions that are generally available on most C implementations. 


\section{A.2 Hardware and Operating System Requirements}

Program has been developed and tested on SUN SPARCstation I with a colour monitor and SUN SPARCstation 2 with a black and white monitor. Both workstations are running Sun OS 4.1.1. HOOPS will run on all Sun 4 (SPARC archilecture) workstations running Sun 4.0.3 or higher.

\section{A.3 Hoops Graphic Systems}

Version 2.20 of Hoops Graphic Systems was used for the graphics interface. The Hoops Graphics System must be supported by GX Sun hardware graphics accelerator. The Hoops XGL, X11 and SunView Drivers all support this accelerator. The appropriate environment variables must be defined to successfully run the program.

\section{A.3.1 Set Up of HOOPS Environment Variables}

The environment variables were defined in terms of C shell "csh" and seting variables for Boume shell were not tested. Run-time environment variables is an option that alters Hoops program execution. At start-up, the Hoops program reads the environment for variables beginning with "HOOPS_" and uses these to alter the default settings, given in the Hoops Manual, Ithaca Software (1991). The environment variables described in sections A.3.1.1, A.3.1.2 and A.3.2 were placed as the csh-style definition in ".cshrc" file following the command 'setenv'. The program runs under both Open Window version 2.0 and SunView for Unix OS. 


\section{A.3.1.1 Open Windows Driver}

To run Hoops under Open Windows, the environment was set up, so that the X11 Driver was the default Hoops driver. The following line was inserted to .cshrc file: setenv HOOPS_PICTURE "X11/unix:0.0"

\section{A.3.1.2 SunView Driver}

To run Hoops under SunView with the appropriate environment variables set up the following line was inserted to .cshre file:

\section{setenv HOOPS_PICTURE "sunview/wind0"}

The program was run successfully under Open Window Driver on either the Black \& White monitor or on the Colour monitor of the Sun SPARCstations when the environmental variables were set as described above. Note, under the SunView driver, the paletue of colours were slightly modified on the Sun SPARCstation 1 with a colour monitor, and the black and white colours were reversed giving a black background with white lines and boxes (windows and buttons) on the Sun SPARCstation 2. The black background preiented the user from seeing highlighted buttons, hence the running of the program was a litule confusing.

OpenWindow Driver handles the colours on the black and white monitor as different shaded patterns. The colours, are set up automatically at the beginning by the program. when it inspects whether the system is using a black \& white or colour monitor. Different colours are set up for black \& white monitor or colour monitor to make the text within black \& white shaded areas more clearer. 
For the hardcopies of the screen in this document all the colours except highlighted (selected) buttons were set to white, otherwise the picture when scaled down would make the text within shaded areas unreadable.

\section{A.3.2 PostSeript Driver}

The PostScript Driver was used to obtain a hardcopy of the screen. To set the PostScript driver as the default Hoops driver, the environment variable was defined in .cshre file by adding the following two lines:

$$
\begin{aligned}
& \text { setenv HOOPS_HARDCOPY "postscripthoops.ps" } \\
& \text { setenv HOOPS_HARDCOPY "force black-and-white" }
\end{aligned}
$$

Hardcopies of similar quality were made with the laiser printers listed below:

1. QMS PS 810 with 2"B RAM

2. Personal Apple LaserWriter NTR with $16 \mathrm{MHz}$ CPU and $3 \mathrm{MB}$ of RAM. 


\section{APPENDIX B}

\section{File Architecture}

\section{B.1 Source Code Files}

Complete source code is formed by separate modules, each developed for the specific task, and are described in sections B.1.1 to B.1.7. Each module can be run independently with minor modifications.

\section{B.1.1 File LDFSSBC.c}

This module acts as a suppon frame which creates the first window image, shown in Figure 3.1 where the button in the menu shown along the top of the window represent all the other modules. This source code module contains following headers:

Idfssbch - the functions, that create segments and modify the geometric attributes in HOOPs, that are common for all source files, are defined within this thader.

c_hoops.h this header defines all 'C' and HOOPS library headers, functions defined as macros and short aliases for HOOPS subroutines utilized by LDFSSBC.

C_hoops_var.h - global variables for colour definition (initialized by inspecting the 
type of running monitor device) and sizes of frequently used string variables are declared within this header.

The headers c_hoops.h and c_hoop_var.h are included in all source files.

\section{B.1.2 File SELECT_LOCATION.C}

This module retrieves the climatic data coefficients for a selected location in Canada from file "CLIMATIC_DATA_CND" and saves them in the file "location_cimte_data" in the appropriate directory of the currently active project.

\section{B.1.3 File DEAD_LOAD.c}

This module is used to create typical structural sandwich systems, including the computation of the corresponding dead load intensities for a given project. This source code includes the following headers:

dl_variables.h - includes definition of colours for display of specific materials and default values for the camera position for 3D display.

dl_materials.h - is a library of typical building materials including their description. unit weight in $\mathrm{kPa}$ and thickness in $\mathrm{mm}$ (or density in kilonewtons per meter cubed if the unit weight is not specified).

dl_graph_def.h - defines the 3D graphic display of typical struc'"ıral members, roof layers, floor and wall sandwiches. 


\section{B.1.4 File LL_USE_OCCUPANCY.c}

Within this module, a list of selected areas is created for intended occupancy use according to Section 4.1.6 n! the NBCC 1990, NRC (1990). Articles referred to in Table 4.1.6.A are reproduced and defined for display. The source code includes the following header:

II_var.h - defines the description of areas for intended use and occupancy with the related load intensities per meter square and definition of required design concentrated load according Tables 4.1.6.A and 4.1.6.B, respectively.

\section{B.1.5 File SNOW_LOAD.c}

This module contains library functions which calculate snow load intensities at nodes of a mesh (defined in the GEOMETRIC_MODELLER module) according to the climatic data coefficients for the selected location, site condition, and the geometric configuration of the roof. The source code includes the following header:

snow_var.h - defines the structure data templates, macros for the length of character strings and default settings for the camera position for the 3D display.

\section{B.1.6 File WIND_LOAD.c}

This module contains library functions which calculate wind load intensities at nodes of a mesh (defined in the GEOMETRIC_MODELLER) according to the climatic data coefficients for the selected location, site conditions, building characteristics and geometric configuration. The source code includes the following header: 
wind_var.h - defines the structure data templates, macros for the length of character strings, and default setting for the camera position for the 3D display.

\section{B.1.7 File GEOMETRIC_MODELLER.C}

This module contains library functions to define surfaces of a building (roofs, noors and walls, -i.e. structural form), to determine the coordinates for a mesh of points on any specified surface and to retrieve information relating the geometry of adjacent surfaces. The source code includes the following header:

gm_var.h - defines the structure data templates, macros defining constants and default settings for the camera position for the 3D display.

\section{B.2 The Executable File "LDFSSBC" and the Corresponding Defaults}

The name of executable file is LDFSSBC and the following list of files must be present in the working directory for its proper exccution:

CLIMATIC_DATA_CND table of design data (climatic data) for selected locations in Canada reproduced from Chapter 1 of the Supplement to the NBCC 1990, NRC (1990)).

MESH_SPACING_default - default spacing for grid lines that define the location of a mesh of points within a given surface.

ERAWING_SETUP_default - default values specified at the start of a new projeit and is used in set-up coordinate ranges for the 
computation of scale factors and coordinate transformation factors to maintain the display of the structure within the windows view.

DL_Hoor_defaults, DL_roof_default and DL_wall_defaults - default files, each with two typical structural sandwich systems including a description of the clements and their load intensity, and total dead load intensity.

SNOW_defaults - default values for the basic roof snow load factor, the unit weight of snow and those related to site conditions.

WIND_defaults - default values for building characteristics, site conditions and values for the exposure and gust effect factors that are specific to the procedure (simple or detailed) required to determine the wind loads.

\section{B.3 Output Files}

The working dinectory (containing the executable file LDFSSBC, common headers and default files) also houses a file "jobs_list" which contains a list of existing projects a simple text file containing one project name per line.

Output files created for each project are housed within a subdirectory of the same name as project. The data files related to the definition of structure geometry, climatic data for the selected location and data commun for all types of load, are placed within the project subdirectory. Two additional sub-subdirectories /snow and /wind are created for the data files with snow and wind loads intensities. 
The following data and output files within the project subdirectory are described in detail.

drawing_setup - stores the specific minimum and maximum values of $x, y$ and $z$ coordinates for the building space, as descritzed in section 3.2.3 CREATE NEW PROJECT, and has the following file form:

$\begin{array}{rr}-60000 & 25000 \\ 0 & 90000 \\ -50000 & 60000\end{array}$

location_clmte_data - stores the selected location (province or territory, lexation) with the cornesponding climatic data in the same sequence given in the Supplement as shown in following example:

BRITISH COLUMBIA

North Vancouver

$\begin{array}{lllllllllllllllllll}-7.0 & -9.0 & 26.0 & 19.0 & 2978.0 & 10.0 & 100.0 & 1889.0 & 2.7 & 0.3 & 0.44 & 0.5 \% & 0 & 0.4 & 4.11 & 4.11 & 11 & .0\end{array}$

nodes_list - identification number and $x, y$, and $z$ coordinates for each node that defines a surface or area for the given building are stored in a lext file as follows:

$\begin{array}{rrrr}1 & -6000 & 0 & -27250 \\ 2 & 25500 & 0 & -59854 \\ . & \cdot & . & . \\ 1106 & -8800 & 77200 & -2000 \\ 1107 & -6500 & 77200 & 2000\end{array}$

floors_dead_load - a series of structural sandwich systems specified for the floors of the given building and corresponding uniformly distributed dead load intensity are stored in this file as a $\mathrm{C}$ data structure block in binary form.

roofs_dead_load - as described above, but for roofs walls_dead_load - as described above, but for walls 
LL_areas_list - text file containing a list of names of live load use and occupancy areas for the given building and the corresponding values for their uniformly distributed and concentrated loads as shown:

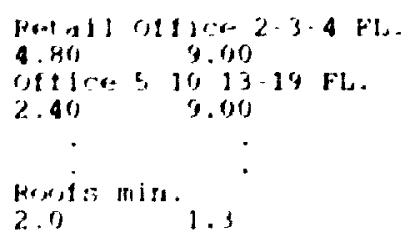

noor_surfaces - a simple text file which lists floor by floor the surface name, the number of nodes and list of node IDs defining the surface. An example file is illustrated below. The format of this file makes it possible to combine it with files that define primary and secondary structures that lie within the surface.

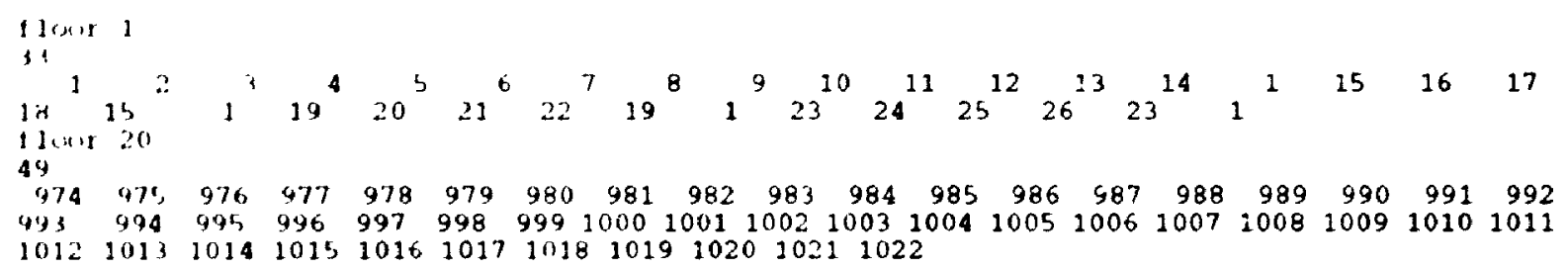

This file is utilized by the program in this form until the loads are attributed to the appropriate surface. Subsequently the data is copied to a C data structure block and stored in binary form in a file called noor_loads

roof_surfaces - as described above, but for roofs wall_surfaces - as described above, but for walls noor_loods - contains data that defines the floor surfaces of the given building and the corresponding dead loads and live loads due to use and 
occupancy

roof_loads -

as described above, hut for roofs

wall_loads -

as described above. but for walls

The sub-subdirectory /snow houses the following files:

mesh_spacing - $\quad$ spacing in millimetres of the grid lines for the gencrated mesh of points are stored in this file

snow_areas_list - contains a list areas (surface names), one per line, for which the snow load intensity cases are calculated.

snow_load_defined - includes basic climatic data and site condition information that is utilized for the calculation of snow load on the building. An example file with explanation is illustrated below.
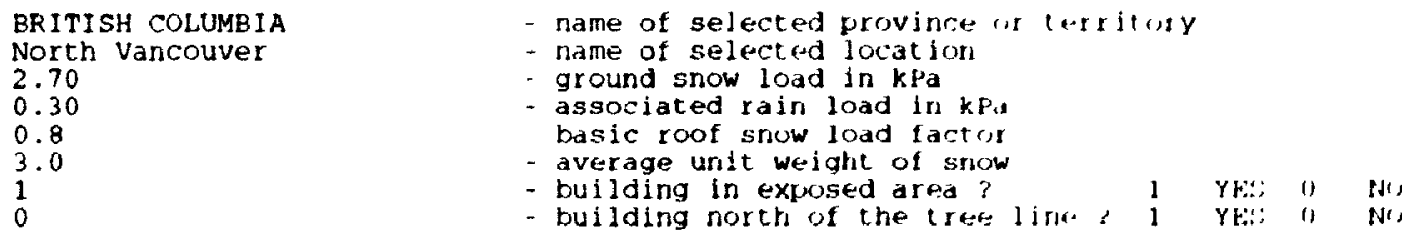

Four files are created for each surface that the snow load distributions are calculated. The name of the files are created by joining the name of the surface with one of the following suffixes, nodes, coord, config and .mg, to give for example roof_2.nodes.

.nodes - the number of nodes, node ID number and the $x, y$ and $z$ coordinates of all nodes defining the surface are listed as shown and are used by the graphics 
portion of the program $\omega$ ay the surface shape in $3 D$ in the main window.

$\begin{array}{rrrr}4017 & 8800 & 50700 & -6800 \\ 1074 & 8800 & 80700 & -6800 \\ 1079 & 8800 & 80700 & 6800 \\ 1040 & -8800 & 80700 & 6800\end{array}$

.coord - the identification code and $x, y$ and $z$ coordinates for each node (point) on the generated mesh for the surface are listed as shown

$\begin{array}{crrr}0001 \mathrm{EEO} 001 & 8000 & 9500 & 0 \\ 0002 \times E 0001 & 8000 & 9500 & 1000 \\ \cdot & . & . & . \\ 0035 \times E 0009 & 28000 & 9500 & 34000 \\ 0036 \mathrm{EEO009} & 28000 & 9500 & 35000\end{array}$

.config - for geometric data required for the calculation of snow load intensity at cach node, including data about adjacent roof surfaces that will influence the snow load distributions are stored in this file in the following form.

\begin{tabular}{|c|c|c|c|c|c|c|c|}
\hline $\begin{array}{l}\text { FIGURE } \\
\underset{866}{1} 0\end{array}$ & 0.0 & 0.0 & 0.0 & 12000.0 & 8000.0 & 163.7 & 23.6 \\
\hline $\begin{array}{c}\text { O001 EE0001 } \\
0002 \times E 0001 \\
\text {. }\end{array}$ & $\begin{array}{l}163.7353973 \\
163.7353973\end{array}$ & $\begin{array}{c}0.0 \\
0.0 \\
.\end{array}$ & $\begin{array}{c}0.0 \\
0.0 \\
.\end{array}$ & $\begin{array}{c}0.0 \\
0.0 \\
.\end{array}$ & $\begin{array}{l}0.0 \\
0.0\end{array}$ & $\begin{array}{l}12000.0 \\
12000.0\end{array}$ & $\begin{array}{l}0.0 \\
0.0\end{array}$ \\
\hline $\begin{array}{l}0035 \times E 0009 \\
0036 E F .0009\end{array}$ & $\begin{array}{l}23.6353760 \\
23.6353760\end{array}$ & $\begin{array}{l}0.0 \\
0.0\end{array}$ & $\begin{array}{l}0.0 \\
0.0\end{array}$ & $\begin{array}{l}0.0 \\
0.0\end{array}$ & $\begin{array}{l}0.0 \\
0.0\end{array}$ & $\begin{array}{l}8000.0 \\
8000.0\end{array}$ & $\begin{array}{l}0.0 \\
0.0\end{array}$ \\
\hline
\end{tabular}

Each data entry is defined below by line number, then by entry number, followed by a brief description. For example. 3.7 height of the external adjacent wall above the roof (" $h$ " in Figure $H-4)$, indicates line 3, entry 7 and the numerical value is ' $h$ '. 


\begin{tabular}{|l|l|}
\hline ENTRY & \multicolumn{1}{|c|}{ DESCRIPTION } \\
\hline 1.1 & surface name \\
\hline 2.1 & applicable snow load figure H-1 through H-6 \\
\hline 3.1 & type of the roof O - regular I - unobstructed slippery roof \\
\hline 3.2 & information if the roof is circular O -NO I - YES \\
\hline 3.3 & curved roof - distance from the top of roof to point where the slope is equal to \\
\hline 3.4 & curved roof - total span ("b" in Figure H-2) \\
\hline 3.5 & curved roof - total height of the curved portion of roof ("h" in Figure H-2) \\
\hline 3.6 & distance from edge cf roof to external adjacent wall ("a" in Figure H-4) \\
\hline 3.7 & height of the external adjacent wall above the roof (" $h$ " in Figure H-4) \\
\hline 3.8 & total length of the first part of valley roof (left "b/2" in Figure H-3) \\
\hline 3.9 & total length of the second part of valley roof (right "b/2" in Figure H-3) \\
\hline 3.10 & roof slope of the first part of valley roof (alpha_1 in Figure H-3) \\
\hline 3.11 & roof slope of the second part of valley roof (alpha_2 in Figure H-3) \\
\hline 4.1 & number of points in file \\
\hline 5.1 & point identification code \\
\hline 5.2 & slope of roof at this point \\
\hline 5.3 & distance of the point to the adjacent wall \\
\hline 5.4 & height of the adjacent wall above the point elevation \\
\hline 5.5 & curved roof - distance of the point to the top of roof ("x" in Figure H-2) \\
\hline 5.6 & $\begin{array}{l}\text { curved roof - difference of elevation of point and top of roof ("hx" in Figure } \\
\text { H-2) }\end{array}$ \\
\hline 5.7 & distance of the point to the bottom of valley roof for case of Figure H-3 \\
\hline 5.8 & width of the roof obstruction ("b" in Figure H-6) \\
\hline
\end{tabular}


.mg - lists the load intensity, for all possible snow load accumulation cases on the roof, for cach node on the surface in the following form:

CAEE: 'SF ENWW L'AAD IITTENSITIES

nigheser.1

FIGUFE..H 4

WOnE

CASE_ 1

OOU1EEOOO1

$0002 \times E 0001$

0036EZ0009

\subsection{7}

1.87

1.87
CASE_2

0.00

0.00

0.00
CASE_3

0.00

0.00
CASE_4

0.00

0.00

0.00
CASE_5

0.00
0.00

0.00

The sub-subdirectory /wind houses the following files:

mesh_spacing spacing in millimetres of the grid lines for the generated mesh of points are stored in this filc. This spacing may be different than that for snow load and should be selected to give an accurate representation of the load distribution. Distributions with varying gradients will require a smaller spacing.

wind_areas_list - contains a list of areas (surface names), one per line, for which the wind load intensity cases are calculated.

wind_load_defined includes climatic data, building characteristics (dynamic properties simple building geometry, classification of openings) conditions and information on the surrounding terrain that is utilized for the calculation of wind load on the building. An example file with explanation is illustrated below:

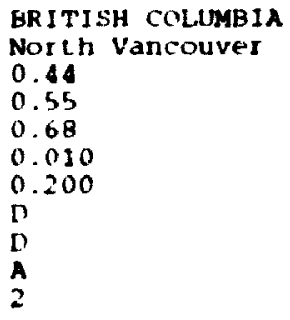

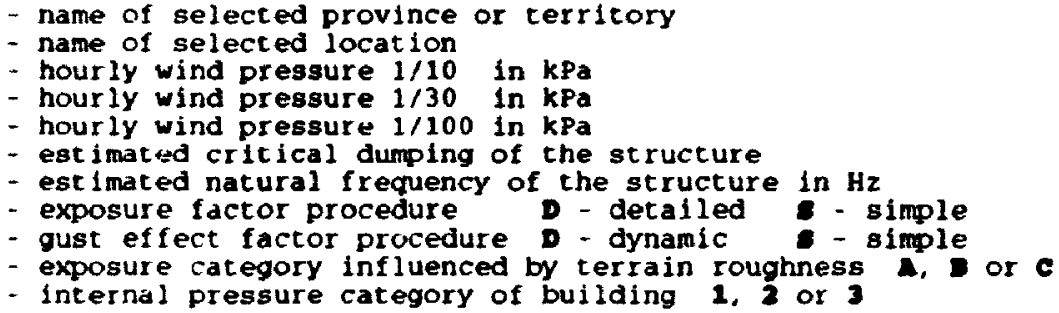




NO
NO
2DR
0.00
0.00
0.00
2.50
2.00
77200.00
0.00

- is bujlding design for post-dlsaster purpose It or wo

- speed-up over hills and escarments in or

- hill shape 20 - 2D ridges. 20. - 20 escarpment s. 30. 3n axisymetrical hills

- nill helght in metres

- distance 1 upwind of the crest to where the atcund elevation is hals the height of the hill

- distance of the buliding to the crest of the hill

- gust effect factor for cladding by simple procedure

- gust effect factor for atructural members by simele procedule

- elevation of the roof of the building in millimetres

- helght above the terrain of the huilding zero elevation

Three files are created for each surface that the wind load distributions are calculated. The file names and structure are similar to those for snow. The config file is not applicable, therefore, not created.

.nodes - the file structure is identical to that described for the sub-subdirectory Isnow.

.coord - additional data required for the calculation of wind load intensity on each surface and the identification code and $x, y$ and $z$ coordinates for each node on that surface are stored in this file in the following form.

\begin{tabular}{|c|c|c|c|}
\hline .0000000 & $\begin{array}{l}\text { HIGHR ISE } \\
0.0000000 \\
77204 \quad 1150\end{array}$ & 0.0000 & $\begin{array}{l}000 \\
90.0000\end{array}$ \\
\hline $\begin{array}{l}001 E E 0001 \\
002 \times E 0001 \\
0003 \times E 0001 \\
0012 \times E 0064 \\
012 E E 0064\end{array}$ & $\begin{array}{l}-18250 \\
-18250 \\
-18250 \\
-18250 \\
-18250\end{array}$ & $\begin{array}{l}13500 \\
13500 \\
13500 \\
77204 \\
77204\end{array}$ & $\begin{array}{r}-5750 \\
-4750 \\
-3750 \\
5250 \\
5750\end{array}$ \\
\hline
\end{tabular}

Each data entry is defined below by line number, then by entry number, followed by a brief description. 


\begin{tabular}{|c|c|}
\hline ENTRY & DESCRIPTION \\
\hline 1.1 & surface name \\
\hline 2.1 & surface type designation WALL or ROOF \\
\hline 2.2 & type of building HIGHRISE or LOWRISE \\
\hline 2.3 & $\begin{array}{l}\text { applicable for low rise buildings only and describes the wall position with } \\
\text { respect to the ridge of the roof is being PARALLEL or PERPENDICULAR }\end{array}$ \\
\hline 3.1-3.3 & components of unit vector normal to this surface \\
\hline 4.1 & $\begin{array}{l}\text { defines the distribution of openings in the walls and is used for the } \\
\text { computation of internal pressures. The symbols have following meaning: } \\
1 \text { - openings mainly in this wall } \\
2 \text { - openings mainly in opposite wall } \\
3 \text { - openings mainly in perpendicular walls } \\
4 \text { - openings uniformly distributed in all walls }\end{array}$ \\
\hline $4.2-4.3$ & $\begin{array}{l}\text { height and width of the surface. These values are utilized for low rise } \\
\text { buildings only, to determine the end zone width. }\end{array}$ \\
\hline 4.4 & slope of the surface in degrzes \\
\hline
\end{tabular}

.mg - files with this suffix contain the calculated values of wind lowd intensities for each applicable loading case, a function of the type of surface and the surface orientation 
to the wind, for each point of the mesh. The header of each file gives the explanation of the stored values.

Four possible cases, for walls and roofs, of a high-rise building and for walls and roofs of a low-rise building are shown in example files bellow.

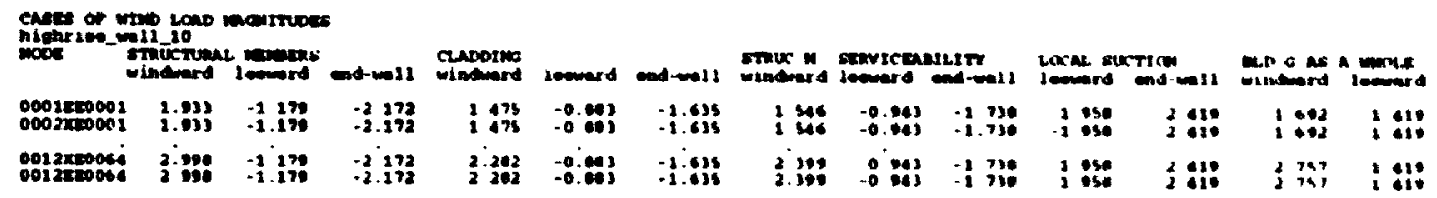

CASES OF WIND LOAD MAGNITUDES

highrise_roof_l

NODE SUCTION

$0002 \times E 0001-2.736$

0002 EE0001 -2.736

$0025 \times 100013-2.736$

$0025 E E 0013-2.736$

CASES OF WIND LOAD MAGNTUDES

lowr ise_wall 9

NODE

PRIMARY STRUCTURAL ACTION

CLADDING \& SEC. STRUC. MEMB.

windward leeward perpend

windward leeward

$0001 E 50001$

$0002 \times E 0001$

0.666

$-0.067$

0.650

0.650

$-0.348$

$0051 \dot{X} \mathrm{E} 0005$

0.666

-0.366
-0.366

0.650

$-0.348$

$0051 E E 0005$

$\begin{array}{lll}0.666 & -0.067 & -0.366\end{array}$

0.650
0.650

$-0.348$

$-0.348$

CASES OF WIND LOAD MAGNITUDES

lowrise_roof_l

NODE

PRIMARY STRUCTURAL ACTION

windward leeward perp_1

perp_2

CLADUIHG \& CEC. SIHUI: MtMk.

$0001 E E 0001$

$0002 \times E 0001$

$\begin{array}{lll}-0.666 & -0.067 & -0.200\end{array}$

$\begin{array}{lll}-0.666 & -0.067 & -0.200\end{array}$

0.000

windwayd leeward

$0034 \dot{X E} 0023$

$-0.666 \quad-0.067 \quad-0.200$

0.000

$0.2 \% 0$

0.000

$-0.108$

$0.2 \%$

0034 EE0023

$-0.666$

.0 .067

$-0.200$

0.000

$-0.10 \mathrm{~s}$

$0.2 \% 0$

$-0.1060 .270$ 


\section{APPENDIX C}

\section{Program Installation and Maintenance}

Source code files, connected libraries and hens.rs are structured to allow easy and flexible updating, and modification of the program.

\section{C.1 Installing the Software}

The executable file, files with default settings and all files of source code, can be stored on one 3 1/2" high density floppy. Two tar files, executable.tar.Z and source_code.tar.Z ane stoned on the floppy in compressed version along with two installations files, install_exe and install_source. To install the executable file and files with default settings;

1. insert the floppy into the disk drive,

2. create a suitable new directory where this program is to be installed (cd new_directory)

3. execute the following command, tar xf /dev/rfd0a install_exe (assuming, for example, that the floppy disk drive is /dev/rfd0a)

4. type install_exe. and all files necessary for program running will be atitomatically installed. To retrieve the source code files follow the some procedure for 
install_source instead of install_cxe. Before running the program check to ensure that the proper libraries and environment variables for the Hoops Graphic System are set up.

\section{C.2 Updating of Climatic Data Library}

Design Data for selected location in Canada are stored in a text file "CLIMATIC_DATA_CND". This file is created in the same order as Table "Design Data for Selected Locations in Canada from Chapter 1 of the Supplement to the NBCC 1990. NRC (1990) (each one location with appropriate sixteen climatic coefficients per line). Updating oi the Design Data for Selected Location in Canada is required each time revisions are made to this section and can be accomplished without recompiling, by editing the data file. Editing of existing coefficients in the file "CLINiATIC_DATA_CND" can be done with any text editor. To add or delete any location within any province or territory is also possible. To add a new location, insert the location name and all sixtexen climatic data coefficients in the data file, at any position between the name of appropriate province or territory and the terminator 'END_OF_PROVINCE'. All of the sixteen coefficients have to be specified, if not with a value, then by ' $0 .(1)$ '. There is no limitation for the maximum number of locations within any province. Data in the current file have been updated according to: Revision 1 January 1991, Revision 2 January 1992, Revision 3 January 1993. 


\section{C.3 Updating Dead Load Libraries and Tools}

The library of typical building materials consists of material description, unit weight per meter square and thickness, or mass per meter cube, as applicable and is stored in header file "dl_materials.h" as a structure data form defined by the $\mathrm{C}$ language. The list of matcrials currently stored in this library were taken from the following references:

1. Handioock of Steel Construction, Fifth Edition 1991 section Mass and Forces for Materials.

2. Conciete Design Handbook, First Edition, Second Printing December 1989, Table 1.11. Dead Loads for Floors, Ceilings, Roofs and Walls and Table 1.12. Minimum Design Load, for Materials.

Space in data structure was left free, after each group of material, for adding new materials or updating existing materials. Editing of library can be done with any text editor. To add or delete any material the variables for example MINROOFING 0 and MAXROOFING 11 (specify the start and end of a list of materials) in a file "dl_variables.h" must be redefined accordingly. Only the owner of the source code can edit these files. The program must be compiled and linked after a change has been made. The data defining the three dimensional graphic display of created structural sandwich systems is given in a "dl_graph_def.h" file. Default member sizes include: W-shape girders, W410x67;

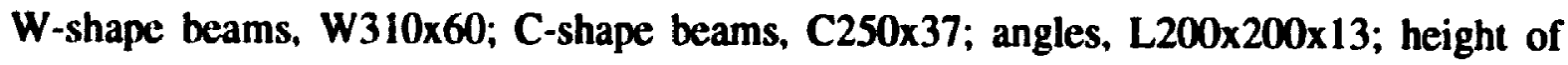
OWSJ of $500 \mathrm{~mm}$; top and bottom chord of OWSJ; two back to back angles L50x50x8; joist shoc height of $100 \mathrm{~mm}$ created by two back-to-back angles $L 75 \times 75 \times 10$. To change these defaults, edit the function 'DL_display_picture_of_selected_structure()' in the source 
code DEAD_LOAD.c, and then recompile and link the program.

\section{C.4 Updating Live Loads Due to Use and Occupancy Libraries}

The macros which define the text to be displayed in the tables or articles are found in the file "ll_var.h". Editing of the text can be done with any text editor. To change any load intensity value in the tables, edit the source code file "LIVE_LOAD.c" within functions 'LL_display_udl_table_page 1()$^{\prime}$...page2() e.t.c. Erasing or adding of any text or values requires new configuration of tables graphic image in the functions mentioned above. Recompile and link if modification are made to "LIVE_LOAD.c" and "LL.h".

\section{C.5 Updating Live Loads Due to Snow, Ice and Rain Defaults}

The default values as defined in the NBCC 1990, NRC (1990), for the basic roof snow load factor, $\mathrm{Cb}=0.8$, and averaze unit weight of snow on roofs, gamma $=3.0 \mathrm{kN}$ per metre cubed are stored in the file "SNOW_defaults". The default location is set to he not in an exposed area and not north of the tree line. Permanent changes in the default values can be done within the file "SNOW_defaults" by any text editor. The adjustment of default values for any particular job can be done during execution of the program within the screen window shown in Figure 3.45 by mouse selection and keyboard input.

\section{C.6 Updating Live Loads Due to Wind Defaults}

The default data utilized by the program are stored in the file "WIND_dicfaults" and are as follows: 
- The building is not design for post disaster purpose.

- Gust effect factor, $\mathrm{Cg}$, for the building as a whole and main structural members evaluated by simple procedure is $\mathbf{2 . 0}$.

- Gust effect factor, $\mathrm{Cg}$, for the small elements including cladding evaluated by simple procedure is $\mathbf{2 . 5}$.

- Critical damping ratio, beta, is 0.010 .

- Natural frequency of vibration, $n_{\infty}$ is $0.200 \mathrm{~Hz}$

- Exposure factor is computed by the detailed procedure.

- Gust effect factor is computed by the detailed procedure (dynarnic approach).

- Exposure of building according to surrounding terrain and topography: Exposure $\mathbf{A}$

- Internal pressure category: Category 2

- No speed up over hills and escarpments.

- If speed up over hills and escarpments exist, the default for hill shape is 2 Dimensional Ridges.

Permanent changes of default values can be done within file "WIND_defaults" by any text editor. The adjustment of default values for any particular job can be done during execution of the program within the screen windows, shown in Figures 3.50 and 3.51, by mouse selection and if applicable by keyboard input. 

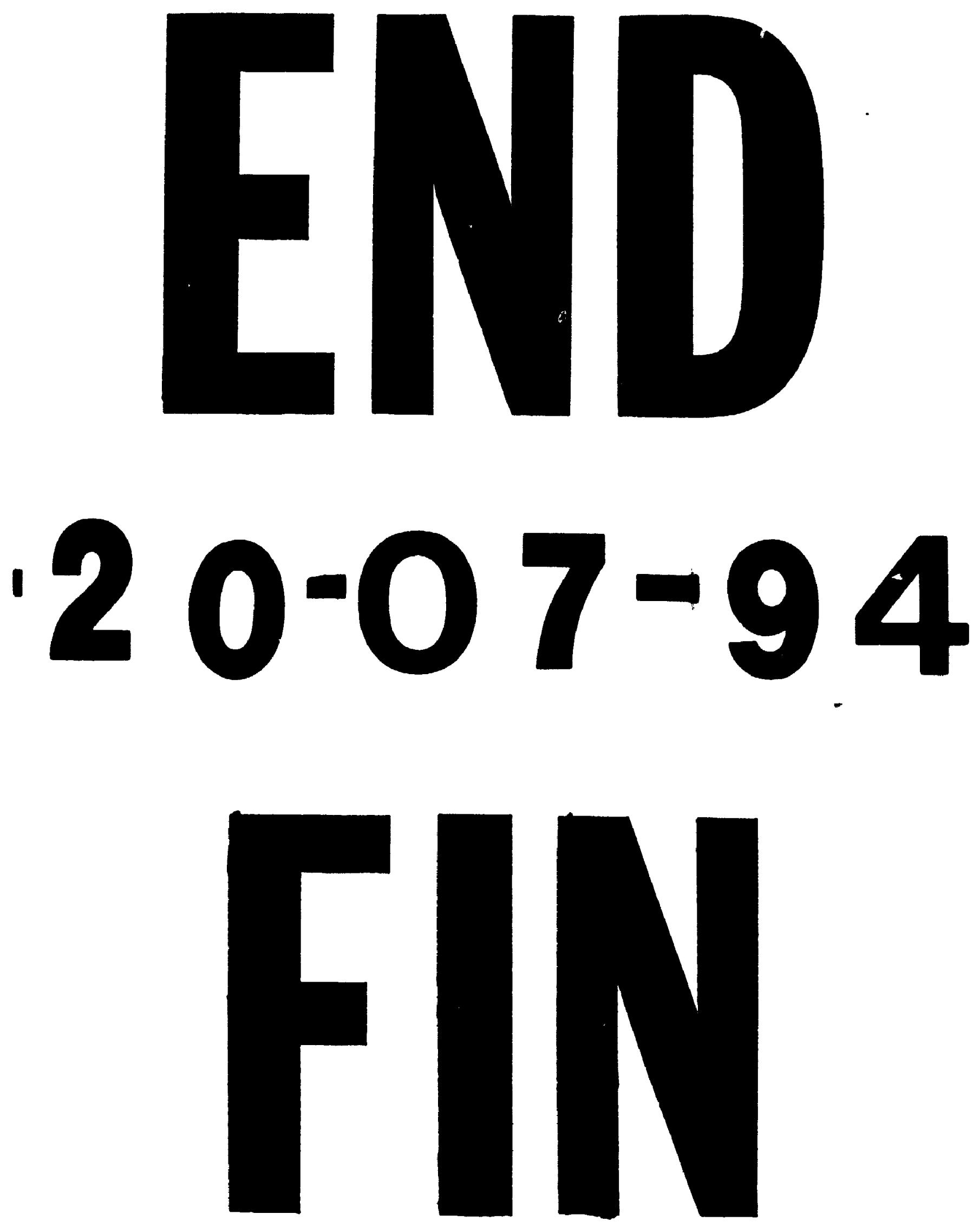